\title{
Preliminary Failure Modes and Effects Analysis of the US DCLL Test Blanket Module
}

Lee C. Cadwallader

August 2007

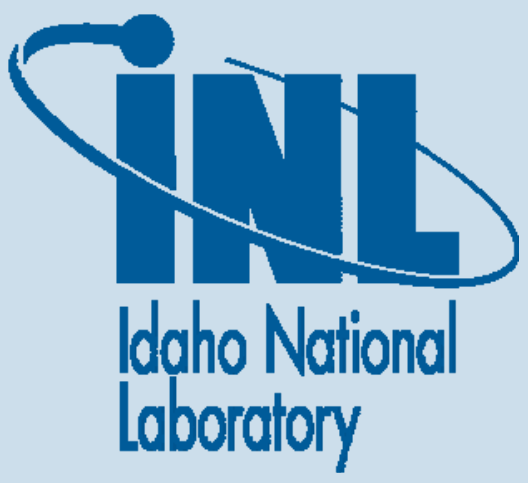

The INL is a U.S. Department of Energy National Laboratory operated by Battelle Energy Alliance 


\title{
Preliminary Failure Modes and Effects Analysis of the US DCLL Test Blanket Module
}

\author{
Lee C. Cadwallader
}

August 2007

\begin{abstract}
Idaho National Laboratory
Advanced Nuclear Energy Systems Department

Idaho Falls, Idaho 83415
\end{abstract}

Prepared for the

U.S. Department of Energy

Office of Fusion Energy Sciences

Under DOE Idaho Operations Office

Contract DE-AC07-05ID14517 



\begin{abstract}
This report presents the results of a preliminary failure modes and effects analysis (FMEA) of a small tritium-breeding test blanket module design for the International Thermonuclear Experimental Reactor. The FMEA was quantified with "generic" component failure rate data, and the failure events are binned into postulated initiating event families and frequency categories for safety assessment. An appendix to this report contains repair time data to support an occupational radiation exposure assessment for test blanket module maintenance.
\end{abstract}




\section{CONTENTS}

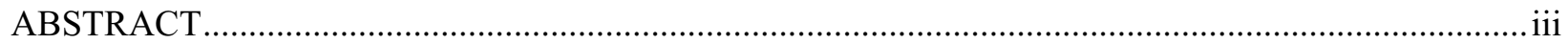

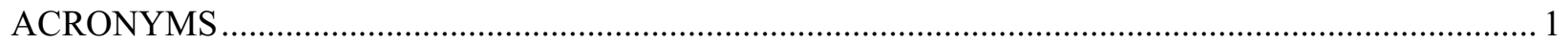

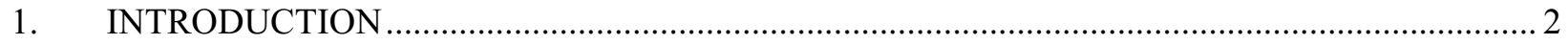

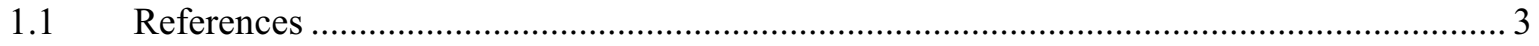

2. PRELIMINARY FMEA ON U.S. DCLL TBM PB-17LI FLOW LOOP .................................... 4

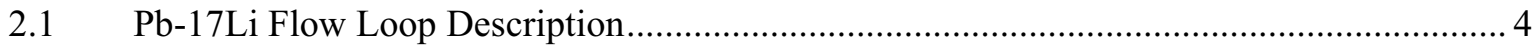

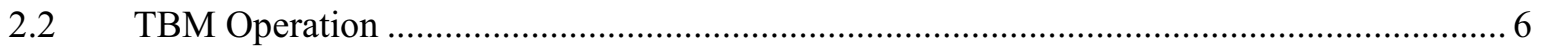

2.3 Current Design Information on Pb-alloy Fission Reactors.............................................. 7

2.4 Related Operating Experiences Supporting the FMEA ................................................. 9

2.4.1 Sodium Liquid Metal Experiences .......................................................... 14

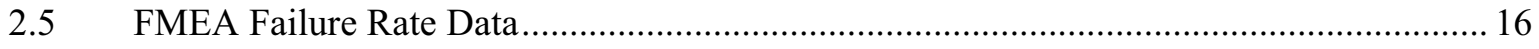

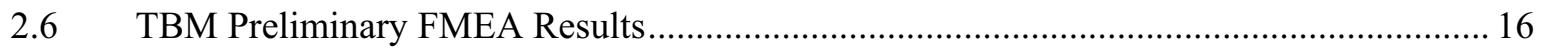

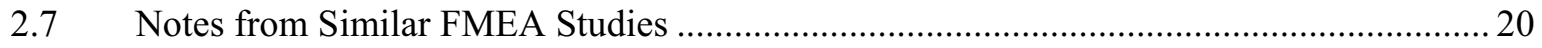

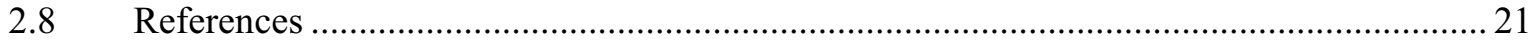

3. PRELIMINARY FMEA ON U.S. DCLL TBM HELIUM COOLANT LOOP …..........................25

3.1 TBM Helium Coolant System Description ............................................................... 25

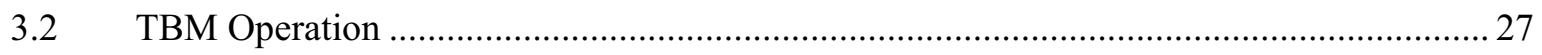

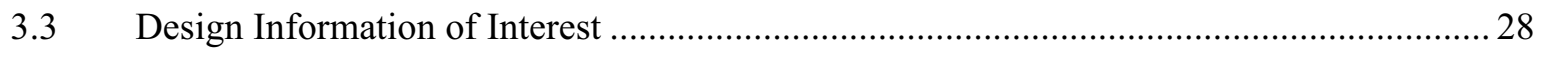

3.4 Related Operating Experiences Supporting the FMEA ................................................ 29

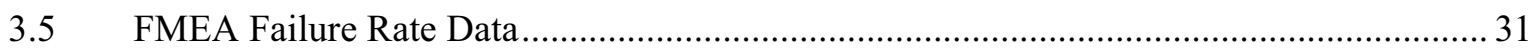

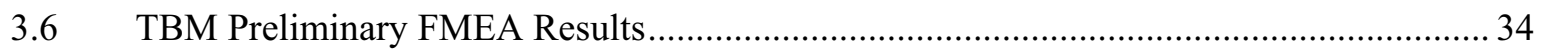

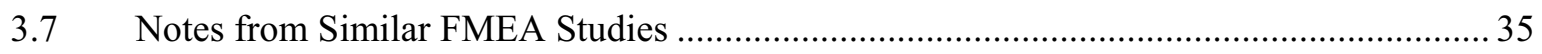

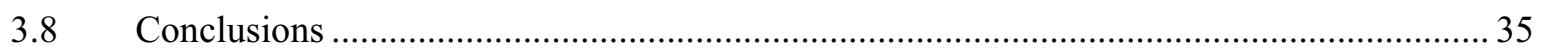

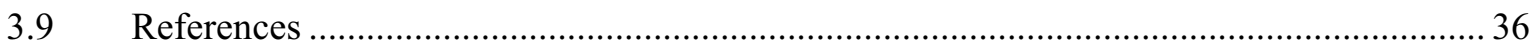


4. PRELIMINARY FMEA ON U.S. DCLL TBM MODULE BOX

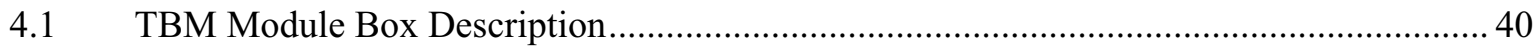

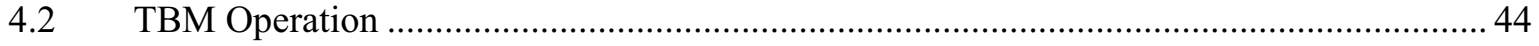

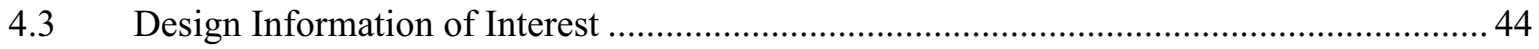

$4.4 \quad$ Related Operating Experiences Supporting the FMEA ................................................... 46

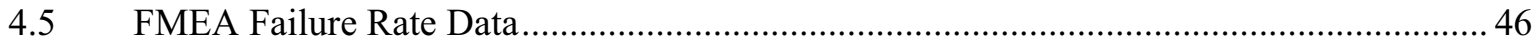

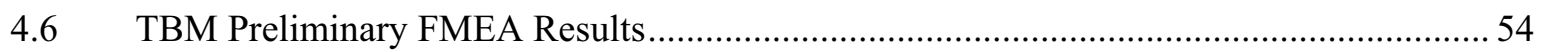

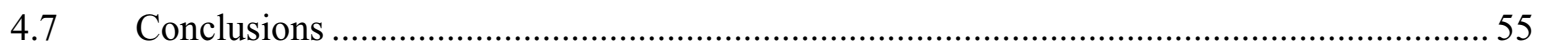

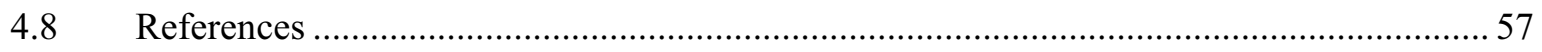

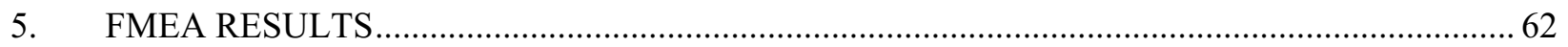

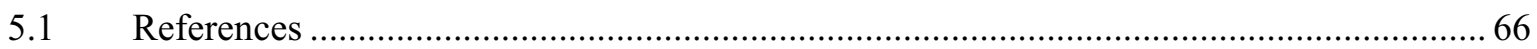

Appendix A. Preliminary Failure Modes and Effects Analysis of the Pb-17Li Flow Loop ...................... 67

Appendix B. Preliminary Failure Modes and Effects Analysis of the Helium Flow Loop ...................... 98

Appendix C. Preliminary Failure Modes and Effects Analysis for the TBM Module Box .................... 111

Appendix D. Active Repair Times for Pb-17Li Components .............................................................. 133

\section{FIGURES}

2-1. The Pb-17Li flow loop of the U.S. DCLL TBM. ............................................................................. 5

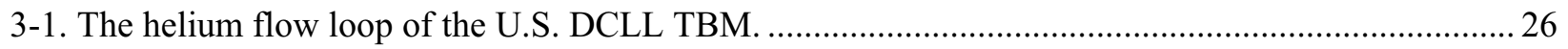

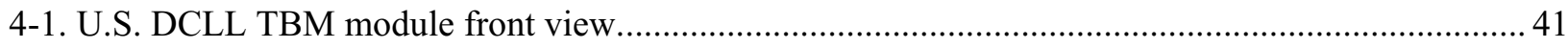

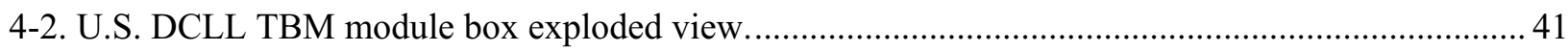

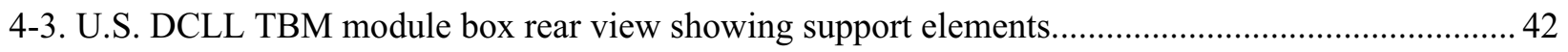

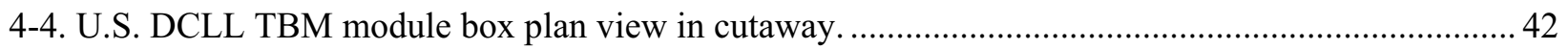

4-5. U.S. DCLL TBM module backplates and helium gas routing....................................................... 43

4-6. U.S. DCLL TBM module box rear view with helium manifolds................................................... 43 


\section{TABLES}

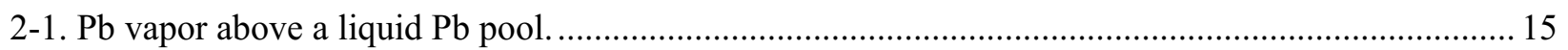

2-2. Pb-17Li loop FMEA Results for postulated initiating events....................................................... 18

3-1. Helium loop FMEA results for postulated initiating events........................................................ 34

4-1. TBM module box FMEA results for postulated initiating events................................................... 55

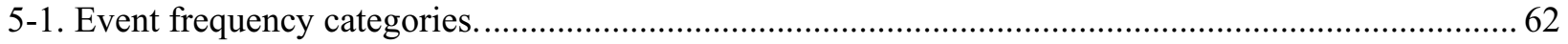




\section{ACRONYMS}

ACGIH American Conference of Governmental Industrial Hygienists

AGR Advanced Gas Reactor

APEX Advanced Power Extraction

ASDEX Axi-symmetric Divertor Experiment

ASME American Society of Mechanical Engineers

ASN Autorite de Surete Nucleaire

AVR Arbeitsgemeinschaft Versuchreaktor

BWR boiling water reactor

CREDO Centralized Reliability Data Organization

D-D deuterium-deuterium

D-T deuterium-tritium

DCLL dual coolant lithium lead

DDD design description document

EBR Experimental Breeder Reactor

EM electromagnetic

FCI flow channel insert

FMEA failure modes and effects analysis

FW first wall

GSSR Generic Site Safety Report

HCPB helium cooled pebble bed

HELOKA Helium Loop Karlsruhe

HIP hot isostatic press

HPS helium purification system

HTTR High Temperature Engineering Test Reactor

IDLH immediately dangerous to life or health

IEEE Institute of Electrical and Electronics Engineers

ITER International Thermonuclear Experimental Reactor

JCT Joint Central Team (ITER)

JET Joint European Torus

LB liquid-breeder-to-helium (heat transport loop)

LOCA loss-of-coolant accident

MTTF mean time to failure

NFPA National Fire Protection Association

PIE postulated initiating event

PWR pressurized water reactor

RAFS reduced activation ferritic steel

RPrS Rapport Preliminarie du Surete

SG steam generator

STP standard temperature and pressure

TBM test blanket module

TCWS Tokamak Cooling Water System

THTR Thorium High Temperature Reactor

TLV threshold limit value

TRITEX Tritium Experiment

TZM titanium zirconium molybdenum

vppm volume parts per million

VV vacuum vessel 


\section{Preliminary Failure Modes and Effects Analysis of the US DCLL Test Blanket Module}

\section{INTRODUCTION}

This report presents the results of a preliminary failure modes and effects analysis (FMEA) of a small tritium-breeding test blanket module. The FMEA was quantified with "generic" component failure rate data, and the failure events are binned into postulated initiating event families and frequency categories for safety assessment. The FMEA pages are given in appendices to this report, and another appendix contains representative repair time data to support a TBM occupational radiation exposure assessment.

The United States is a participant in the International Thermonuclear Experimental Reactor (ITER) construction project. This tokamak experiment will have two operational phases: an initial physics phase where the machine will use hydrogen and then deuterium fuel while exploring the physics of large plasmas, and a high power phase where it will burn deuterium-tritium fuel for long pulses of $\approx 400$ seconds and produce more power than it consumes. One of the technology issues for fusion reactors that follow ITER is production of tritium fuel to meet its own fuel demands, which could be up to several kilograms per year. To investigate tritium production, ITER has a design provision to allow testing of test blanket modules (TBMs). These modules are only a small ( $1.8 \mathrm{~m}$ tall by $0.6 \mathrm{~m}$ wide) portion of the $\approx 700 \mathrm{~m}^{2}$ ITER first wall and are intended to test the most promising ideas for tritium breeding from fusion neutron bombardment.

The U.S. has developed two conceptual TBM designs: a helium-cooled TBM (Ying 2006) and a dual coolant lithium lead (DCLL) and helium TBM (Wong 2006). The DCLL TBM is an interesting candidate option because the dual coolant allows some flexibility in TBM availability. If the lithium-lead ( $\mathrm{Pb}-17 \mathrm{Li}$ ) coolant fails (loss of flow, flow blockage, loss of coolant, loss of heat sink, etc.), the TBM can continue to operate as a small, helium-cooled (non-breeding) first wall module.

Part of the TBM design process is to evaluate the reliability and safety of the candidate designs. The ITER International Team is preparing inputs to a regulatory safety assessment for licensing ITER, the Rapport Preliminarie du Surete (RPrS). The RPrS is to the French Autorite de Surete Nucleaire (ASN) regulators in their licensing process what a preliminary safety analysis report is to the U.S. Nuclear Regulatory Commission. The RPrS will include the TBMs as part of the ITER design. One of the preparations for TBM inclusion in the RPrS is a FMEA. The FMEA is a fundamental type of reliability, and also risk analysis, tool that is used to identify failures of individual system components in a systematic, thorough manner, quantify the failures, and identify possible corrective actions. The FMEA can be used to determine the most hazardous failures of system components (which can be used in risk assessment) and the reliability of a system. Because the TBM designs from the ITER participants are not finalized, the design information for the RPrS is preliminary.

This report presents three FMEAs that were performed on the three main parts of the U.S. DCLL TBM: the Pb-17Li cooling loop, the helium cooling loop, and the TBM module box. These three FMEAs are based on design information from the 2005 U.S. DCLL TBM design description document (DDD) that was compiled by General Atomics in San Diego, California (Wong 2005). 


\subsection{References}

Wong, 2006. C. P. C. Wong, S. Malang, M. Sawan, M. Dagher, S. Smolentsev, B. Merrill, M. Youssef, S. Reyes, D.-K. Sze, N. B. Morley, S. Sharafat, P. Calderoni, G. Sviatoslavsky, R. Kurtz, P. Fogarty, S. Zinkle, and M. Abdou, "An Overview of Dual Coolant Pb-17Li Breeder First Wall and Blanket Concept Development for the U.S. ITER-TBM Design," Fusion Engineering and Design, 81 (2006) 461-467.

Wong, 2005. C. P. C. Wong, et al., Design Description Document for the U.S. Dual Coolant Pb17Li (DCLL) Test Blanket Module, report to the ITER Test Blanket Working Group $(T B W G)$, revision 3, GA-C25027, General Atomics, San Diego, CA, November 15, 2005.

Ying, 2006. A. M. Ying, Abdou, C. Wong, S. Malang, N. Morley, M. Sawan, B. Merrill, D.-K. Sze, R. Kurtz, S. Willms, M. Ulrickson, S. Zinkle, "An Overview of U.S. Test Blanket Module Program," Fusion Engineering and Design, 81 (2006) 433-441. 


\section{PRELIMINARY FMEA ON U.S. DCLL TBM PB-17LI FLOW LOOP}

The FMEA for the TBM Pb-17Li flow loop has investigated potential accident-initiating events. Such events are referred to as postulated initiating events (PIEs) in the ITER safety approach, and are component or human failures that place the facility in an off-normal condition. If redundant systems, backup systems, and/or safety systems function correctly, the facility returns to a stable shutdown condition. If there are additional failures, the accident event could result in small radiological releases to the environment.

\subsection{Pb-17Li Flow Loop Description}

This description was taken from Wong (2005). The U.S. DCLL TBM is designed to fit in a half-port in the ITER blanket/first wall. The TBM module dimensions are $186.4 \mathrm{~cm}$ high by 64.5 $\mathrm{cm}$ wide by $30.5 \mathrm{~cm}$ deep. Helium coolant is used with the Pb-17Li breeder-coolant in the TBM module, giving the dual coolant concept. The helium removes $54 \%$ of the heat from the module via a helium gas heat transfer flow loop and transfers the heat to the Tokamak Cooling Water System (TCWS). The helium loop has tritium extraction, purification, and heat exchange to the TCWS. The Pb-17Li lithium-lead eutectic coolant flow loop also has tritium extraction, coolant purification, and heat exchange to the TCWS. A schematic diagram of the Pb-17Li flow loop is given in Figure 2-1. The $\mathrm{Pb}-17 \mathrm{Li}$ total flow loop volume is $\approx 0.4 \mathrm{~m}^{3}$, the flow rate through the TBM piping is $\approx 2 \mathrm{~m} / \mathrm{s}$ and $0.4 \mathrm{MPa}$ (maximum pressure is $2 \mathrm{MPa}$ ), and the operating temperatures are $340^{\circ} \mathrm{C}$ minimum and $470^{\circ} \mathrm{C}$ maximum (with a design provision to operate at a high temperature plateau of $650^{\circ} \mathrm{C}$ for demonstrating a Brayton thermodynamic cycle and enhancing tritium removal). A $20-\mathrm{kW}$ centrifugal pump drives the $\mathrm{Pb}-17 \mathrm{Li}$ flow through the single-pass flow loop. Piping and components are to be constructed of reduced activation ferritic steel (RAFS) and have 10-15 cm of thermal insulation. As seen in Figure 2-1, the major components of the $\mathrm{Pb}-17 \mathrm{Li}$ flow loop are the pump, cold trap, drain tank, thermal mixing tank, TBM coolant channels, a vacuum permeator for tritium removal, and a $\mathrm{Pb}-17 \mathrm{Li}$-to-helium heat exchanger. The TBM module helium coolant, which operates at $8 \mathrm{MPa}$ as opposed to the $\mathrm{Pb}-17 \mathrm{Li}$ that operates at a maximum of $2 \mathrm{MPa}$, can breach into the $\mathrm{Pb}-17 \mathrm{Li}$ within the TBM module without loss of module integrity (Wong 2005). Any other helium breaches into the Pb-17Li, such as the $8 \mathrm{MPa}$ helium at the heat exchanger, are expected to transmit pressure throughout the highly fluid $\mathrm{Pb}-17 \mathrm{Li}$ (Feuerstein 1988) flow loop quickly, and the gas is expected to deposit itself in the headspace of the centrifugal pump casing or its expansion tank, or the pressure increase could actuate the rupture disk to the drain tank. If the rupture disk opens, the system will depressurize into the drain tank. The heat exchanger helium enters the tubes at $200^{\circ} \mathrm{C}$ and exits at $360^{\circ} \mathrm{C}$ and $8 \mathrm{MPa}$.

The $\mathrm{Pb}-17 \mathrm{Li}$ centrifugal pump is a modest size unit ( $20 \mathrm{~kW}$ or $\approx 25$ horsepower), probably a vertically aligned motor to an overhung shaft with either a magnetic bearing or at least a design provision of no mechanical bearing immersed in the liquid metal. The liquid metal will not touch the pump shaft seal; a cover gas (perhaps helium or argon) will be used to provide a cushion to the shaft seal and pressurize the Pb-17Li. The flow from the pump is $\approx 72 \mathrm{~kg} / \mathrm{s}$. At $340^{\circ} \mathrm{C}$, the density of $\mathrm{Pb}-17 \mathrm{Li}$ is about $9420 \mathrm{~kg} / \mathrm{m}^{3}$, so the flow rate is $7.6 \mathrm{E}-03 \mathrm{~m}^{3} / \mathrm{s}(7.6 \mathrm{~L} / \mathrm{s})$. An expansion tank is mounted in tandem with the pump casing. The expansion tank serves two purposes: smooth pressure pulsations and supply extra liquid to compensate for liquid level (keep the impeller immersed). In the pump casing expansion tank, the helium cover gas also provides an opportunity to draw off radioactive gases from the $\mathrm{Pb}-17 \mathrm{Li}$ and route them to cleanup via the pressure control system. From the pump exit, the flow passes a cold trap, which is expected to be 
a tank with baffles and wire screens to promote precipitation of impurities and any oxides that might form in the $\mathrm{Pb}-17 \mathrm{Li}$. The cold trap lowers the $\mathrm{Pb}-17 \mathrm{Li}$ temperature to approach the freezing point of $\approx 240^{\circ} \mathrm{C}$ but not freeze the alloy. The cooler temperature allows some impurities and oxides to condense out of the liquid alloy. The cold trap can be cooled by forced air, nitrogen, or helium gas; no

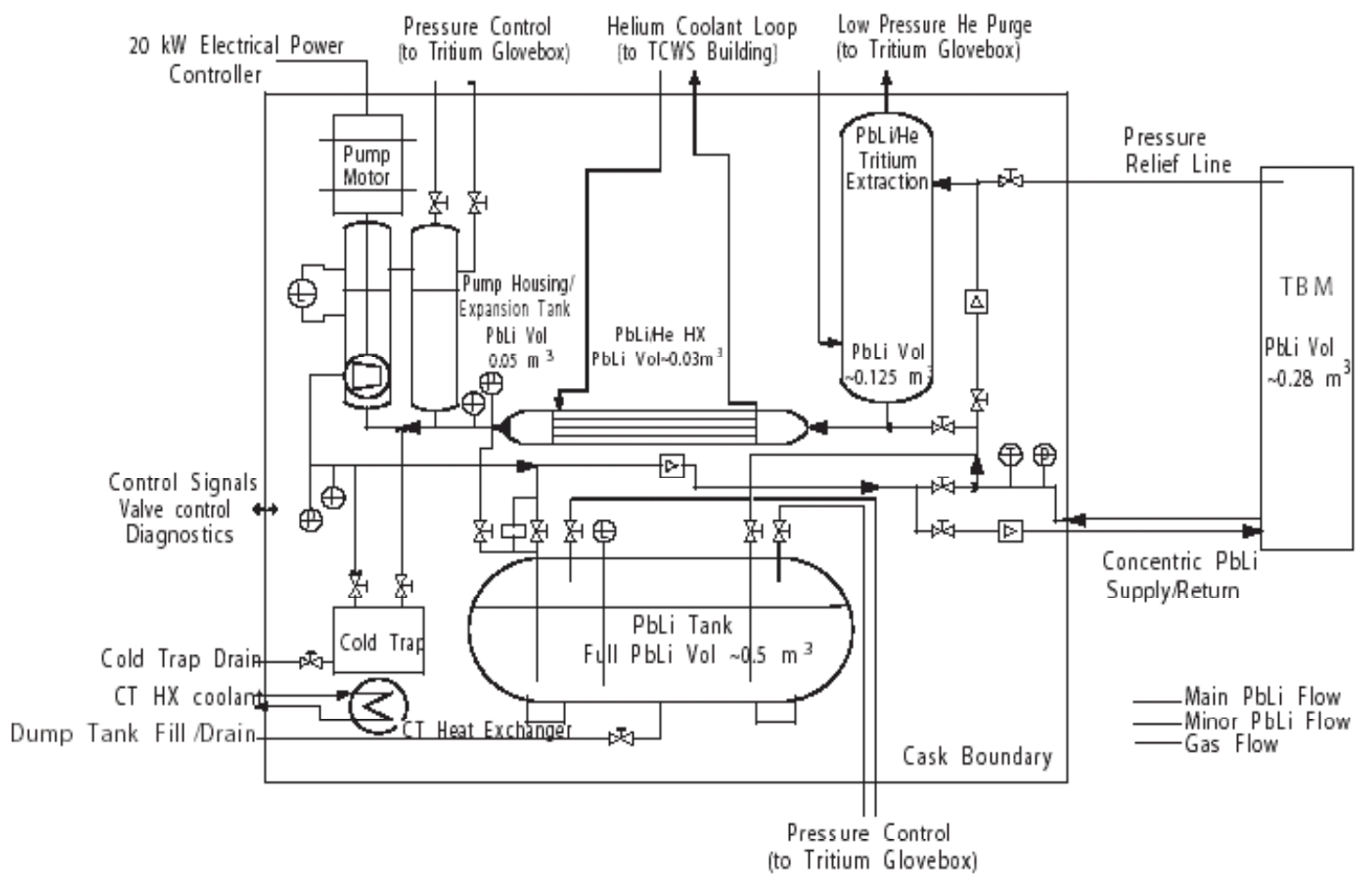

Figure 2-1. The Pb-17Li flow loop of the U.S. DCLL TBM.

special coolants or design provisions are needed for this type of cold trap. Only a percentage of the liquid metal flow routes to the cold trap; other designs have used 5\% flow diversion to the cold trap (Spencer 2000). From there, the flow proceeds toward the TBM module. Some flow will always divert into the mixing tank, which is included in the design as a provision to allow high temperature $\left(650^{\circ} \mathrm{C}\right)$ operation. From the mixing tank, the flow enters a concentric pipe (inner pipe is the outlet flow, the outer pipe annulus is the inlet flow) that connects to the back of the TBM, cools the walls and breeds some tritium, then flows back out to the flow loop. The outlet flow proceeds to a tritium extraction unit, a vacuum permeator. The permeator is designed similar to a heat exchanger. The high temperature $\mathrm{Pb}-17 \mathrm{Li}$ flow enters tubes that allow tritium permeation through the tube walls, and the vacuum pumping equipment connected to the shell draws the gas away for processing. From the permeator, the hot $\mathrm{Pb}-17 \mathrm{Li}\left(470\right.$ up to $\left.650^{\circ} \mathrm{C}\right)$ enters a heat exchanger. Helium at $8 \mathrm{MPa}$ in the tubes enters at $200^{\circ} \mathrm{C}$ and leaves $360^{\circ} \mathrm{C}$, and the $\mathrm{Pb}$ $17 \mathrm{Li}$ leaves at $340^{\circ} \mathrm{C}$. From the heat exchanger, the $\mathrm{Pb}-17 \mathrm{Li}$ returns to the centrifugal pump. A drain tank is also part of the flow loop. The $0.5-\mathrm{m}^{3}$ drain tank is electrically heated by external resistance heaters to keep the $\mathrm{Pb}-17 \mathrm{Li}$ above its freezing point of $\approx 240^{\circ} \mathrm{C}$. External heaters were chosen to enhance reliability and maintainability over that of immersion heaters that would be exposed to the liquid metal. The tank is filled with helium gas at $0.1 \mathrm{MPa}$ to prevent moisture or 
air intrusion while not in use. A relief valve and a rupture disk will allow flow into the drain tank in the event that overpressure is experienced in the flow loop. The rupture disk is located after the heat exchanger so the $\mathrm{Pb}$-17 $\mathrm{Li}$ temperature should be relatively constant in that portion of the flow loop. The rupture disk has a rated burst pressure of 3.5 MPa. Rupture disk burst pressures decrease as the temperatures that the disk is exposed to increase, so keeping a uniform temperature enables proper rupture disk performance. A pressure relief valve on the drain tank lifts at $4 \mathrm{MPa}$ (Wong 2005).

\subsection{TBM Operation}

ITER plans to conduct 3,000 plasma pulses in a year. The dwell time between pulses is $\approx 2,000 \mathrm{~s}$. A typical pulse scenario is $100 \mathrm{~s}$ ramp up, $400 \mathrm{~s}$ pulse flat top, and $100 \mathrm{~s}$ ramp down to the dwell time. Thus, one pulse requires $43.3 \mathrm{~min}$. ITER is also stated to have a $25 \%$ duty factor. GSSR volume IV, "Normal Operation," page 36, states that the planned ITER operation is a 35day operating campaign with 10-hour pulse days, and 20-22 pulses performed per day (ITERJoint Central Team [JCT] 2001). Each campaign will give $\approx 750$ pulses, with four campaigns per year (35 days of operation and 45 days of post-operation shutdown) and the last 3 months of the year being reserved for a long maintenance shutdown. Considering an electricity cost of $\$ 0.15 / \mathrm{kW}-\mathrm{h}$, and a $20 \mathrm{~kW}$ pump motor, the cost of keeping the pump operating for 14 idle hours per operating day is about $\$ 42$. There are 140 operating days per year, giving a total cost of $\$ 5.9 \mathrm{k}$ in additional pump electricity if the pump is started once per campaign. Pump heat can be used to help keep the $\mathrm{Pb}-17 \mathrm{Li}$ liquid in the system. Turning the pump off daily will mean 35 days $\times$ 4 campaigns $=140$ operational start demands per year at a failure rate of $5 \mathrm{E}-03 /$ demand, or an annual failure probability of 0.7 for a specialty pump costing an estimated $\$ 20 \mathrm{k}$ to purchase (assume $\$ 1$ or $2 \mathrm{k}$ for a typical motor replacement and $\$ 2 \mathrm{k}$ for a replacement pump shaft). ITER will have ample downtime to allow pump repairs, the occupational radiation exposure should be somewhat low for this component so far from the ITER vacuum vessel, and the Pb-17Li system is designed with the drain tank to facilitate repairs. The failure rates predict a pump fault requiring maintenance and perhaps spare parts in 1.5 year at the 140/year "on-off" frequency. The economics of the situation show that it would probably be less cost to start/stop the pump and then repair the pump every other year. However, if the pump is specified to throttle back by using a variable speed drive that consumed less $\mathrm{kW}$-h, then the pump could operate at perhaps $10 \%$ of its typical flow rate and would maintain heat in the flow loop during the 14-hour lulls in operations during each campaign day. The liquid metal flow would not be very fast, so corrosion would be minimized.

Smith (1993) discussed that most liquid sodium reactor systems either had pony motors on the pumps to maintain a $10 \%$ flow or used a small electromagnetic pump to flow when the main centrifugal pumps were shut down. The advantage to pump operation is less start-stop wear, which would mean less repair work to perform, less personnel radiation exposure, possibly less $\mathrm{Pb}-17 \mathrm{Li}$ exposure to air during repairs, and less time required to prepare the $\mathrm{Pb}-17 \mathrm{Li}$ loop before each day of pulse operations. Therefore, as a first estimate for operational start/stop demands on the TBM equipment, the pump will operate at reduced capacity for the 14 idle hours between pulse days and there will be four operational start demands per year (not counting any maintenance-related test, or system operability test, starts). The TBM flow loop will start up and operate for the 35-day entire pulse campaign, then shut down for any maintenance or other servicing. It is expected that during the 45-day maintenance outages between campaigns it would be most cost effective to drain the Pb-17Li to the drain tank and shut down the rest of the system. Therefore, the operating hours for the TBM Pb-17Li flow loop will be 35 days $\times 24 \mathrm{hr} /$ day $\times$ 4 campaigns $/ \mathrm{yr}=3,360 \mathrm{hr} / \mathrm{yr}$. This value is used with the hourly failure rates to give frequency 
category estimates. The drain tank would operate for $8,760 \mathrm{hr} / \mathrm{yr}-3,360 \mathrm{hr}=5,400 \mathrm{hr} / \mathrm{yr}$ in storage mode. Therefore, to summarize, the assumed operating scenario is that the TBM is system is prepared and operability tested, and upon successful test completion, it is started for campaign operations. ITER then runs its 35-day campaign and shuts down for a 45-day maintenance period. After a short cooldown, the TBM Pb-17Li is drained to the insulated drain tank. For the long shutdowns of 45 or 90 days, it is probably more economical to allow the $\mathrm{Pb}-17 \mathrm{Li}$ to freeze than it is to keep it heated above $240^{\circ} \mathrm{C}$ until it is needed again. Maintaining the $\mathrm{Pb}-17 \mathrm{Li}$ above freezing would be costly. Allowing the alloy to freeze also poses concerns, however-reliquefying the $\mathrm{Pb}$ 17Li must be performed carefully to avoid undue pipe stresses. Typically, heating from the helium and from the walls will allow the alloy to expand within the drain tank without overstressing the tank walls. When needed, heated helium gas will pressurize the $\mathrm{Pb}-17 \mathrm{Li}$ and force it to flow back into the TBM pipework in preparation for another operating campaign. An estimate of $\approx 1$ shift advance preparation is assumed to heat the $0.5 \mathrm{~m}^{3}$ of $\mathrm{Pb}-17 \mathrm{Li}$, drive it from the drain tank back into the system piping, evolve the helium out of the alloy, test the instrumentation and the mechanical equipment, and prepare for TBM operation.

\subsection{Current Design Information on Pb-alloy Fission Reactors}

Dostal (2004) and Hejzlar (2004) stated that for a Pb-alloy coolant in a fission reactor using HT-9 reduced activation steel, an oxide film forms on the structural material walls and this film protects the structural material from corrosion. If the $\mathrm{Pb}$-alloy flow velocity is too high, the protective oxide layer could be stripped, allowing additional wall corrosion. The authors admitted that current knowledge of the $\mathrm{Pb}$-steel corrosion mechanism was not sufficient to confidently establish a coolant velocity limit, but they chose a maximum velocity of $2 \mathrm{~m} / \mathrm{s} \mathrm{Pb}$-alloy flow as a conservative approach to protect the oxide film. Ballinger and Lim (2004) stated that at high speeds of greater than $\approx 4 \mathrm{~m} / \mathrm{s}$ corrosion is a significant issue in $\mathrm{Pb}-\mathrm{Bi}$ and $\mathrm{Pb}$. Ballinger and $\mathrm{Lim}$ also stated that current operating systems have a practical upper temperature limit of $450^{\circ} \mathrm{C}$, operation in the $450-550^{\circ} \mathrm{C}$ range requires careful oxygen control in the loop, and operation in the $550-650^{\circ} \mathrm{C}$ range is possible in principle for iron-based materials (but may not be possible without materials research and development). Wong (2005) cited that the maximum flow velocity in the $\mathrm{Pb}-17 \mathrm{Li}$ flow loop would be $2 \mathrm{~m} / \mathrm{s}$, which agrees with the fission choice.

Hejlzar (2004) discussed that even in a completely $\mathrm{Pb}$-cooled fission reactor, there would be some polonium generation. Stable $\mathrm{Pb}-208$, which comprises about $50 \%$ of the natural $\mathrm{Pb}$ coolant, would capture a neutron and then beta decay to Bi-209 with a half-life of 3.25 hours. Neutron capture by Bi-209 becomes Bi-210, which beta decays to Po-210 with a half-life of 5 days. The Po-210 is a modestly long-lived alpha emitter (half-life 138 days) that decays to stable $\mathrm{Pb}-206$. Buongiorno (2004) stated that for a typical fission reactor neutron flux, the Po-210 concentration could reside between 1 to $10 \mathrm{Ci} / \mathrm{kg}$ of lead-bismuth eutectic coolant, and that the polonium melting point is $250^{\circ} \mathrm{C}$, making it liquid at $\mathrm{Pb}-17 \mathrm{Li}$ temperatures and too close to the $\mathrm{Pb}-17 \mathrm{Li}$ freezing temperature of $240^{\circ} \mathrm{C}$ to easily plate out in a cold trap. Investigations of the Po210 have shown that the metal forms lead polonide in the $\mathrm{Pb}-17 \mathrm{Li}$ and that very little $(1 \mathrm{E}+06$ times less than calculated by assuming an ideal solution of $\mathrm{Pb}-17 \mathrm{Li}$ eutectic with impurity polonium metal) polonium evaporates to the cover gas in liquid metal systems (Feuerstein 1992). Wong (2005) stated that the Po-210 production would be very low in the DCLL TBM.

Demkowicz stated that the current thinking in $\mathrm{Pb}-\mathrm{Bi}$ coolant system design was to provide a small, sacrificial ingot or set of spheres of $\mathrm{PbO}$, which would be enclosed in and directly 
exposed to the coolant in the fission reactor flow loop ${ }^{\mathrm{a}}$; for example, housed in a piping stub. Small amounts of oxygen from the $\mathrm{PbO}$ would diffuse throughout the system piping due to oxide concentration gradients. This oxygen would form the oxide film that protects the structural materials. When oxygen concentrations equilibrated and the film was intact, the sacrificial $\mathrm{PbO}$ would not be depleted any further. The $\mathrm{PbO}$ would remain available to diffuse more oxygen to correct any small changes to the oxygen concentration or slowly repair any damage to the oxide film. At the same time, the overall oxygen concentration within the liquid metal should be kept below $10 \mathrm{ppm}$ (Spencer 2000) to protect the flow loop structural materials.

Foletti (2006) described some issues with $\mathrm{Pb}-\mathrm{Bi}$ liquid metal. One issue is freezing the alloy in a tank. Lead-bismuth eutectic (LBE) has a property of expansion upon freezing; the alloy re-crystallizes as it cools lower than the freezing temperature. Recrystallization enriches the bismuth phase, and bismuth expands on freezing while lead shrinks. An LBE pool that is undergoing freezing will place stresses on the chamber walls as it expands (Foletti 2006; Glasbrenner 2005); the depth of the pool increases the stresses on the chamber walls. For LBE cylindrical storage tanks, it is preferable to have the storage tank axis aligned horizontally rather than vertically and to fill the tank to less than half capacity. If a tank must be oriented vertically, the tank should be designed so that the minimum ratio of tank diameter to the maximum LBE height in the tank is 0.5 or less (Foletti 2006). Agostini (2004) stated that LBE requires height reduction of the frozen volume, allowance for "crush volumes" (artificial voids can be created in LBE; these implode during solidification and reduce wall stresses), limit of internal parts and instrumentation that would be stressed by inadvertent solidification, and that vessels be kept at $90-120^{\circ} \mathrm{C}$ above the alloy melting point. Since $\mathrm{Pb}-17 \mathrm{Li}$ is a very small weight percent of lithium ( $0.7 \%$ by weight of lithium), while LBE is $55.2 \%$ by weight of bismuth, the LBE effects and design parameters are not directly applicable to $\mathrm{Pb}-17 \mathrm{Li}$. $\mathrm{Pb}-17 \mathrm{Li}$ merely expands $3.5 \%$ by volume on melting, lithium also expands on melting (by 1.5\%) (Malang and Mattas 1995). However, the tank orientation and other practices described above to reduce wall stresses are good design practices.

Foletti (2006) also had some other pertinent operating experiences. The LBE lead corrosion flow loop experiment used K-type thermocouples, electromagnetic and vortex flow meters and pressure transducers. The pressure transducers with small, smooth surface diaphragm surfaces ( $5 \mathrm{~mm}$ diameter) suffered from oxide buildup on the diaphragm surfaces and stopped operating. The pressure transducers with wider, corrugated diaphragms ( $95 \mathrm{~mm}$ dia.) continued to operate. The 12.7-mm diameter electromagnetic flow meters suffered from oxide buildup and read lower and lower values until they erroneously reported zero flow. The 25.4-mm diameter flow meter continued to operate through 5,000 hours, but it was partly attributed to being in a location that did not experience much oxide buildup. The electromagnetic pump experienced deposition of oxides that reduced its efficiency. That pump was replaced with two vertical-axis, submerged impeller pumps. One of these two pumps used a Chesterton oil-cooled pump shaft seal. This pump worked very well, although periodic checking of the oil was recommended to avoid oil contamination of the LBE. The other pump motor was directly connected to the pump casing and it did not perform as well as the oil-cooled shaft seal pump. Oxygen sensors using yttria-zirconia doped ceramic elements were used to sense the oxygen concentration in the LBE. The oxygen concentration had to be kept between that of the scavenger $\mathrm{Mg}$ metal and $\mathrm{PbO}$. This sensor was effective. Oxygen concentration is a balance between corrosion control of the steel by forming and maintaining an oxide layer and avoiding the contamination of slag (solid $\mathrm{PbO}$ particle) formation in the flow loop (Courouau 2002). The large scale venturi flow meter was effective at $40-350 \mathrm{~kg} / \mathrm{s}$ flow rates (uncertainty $\pm 3 \%$ ). The measurement was not reliable below

a. Private communication with P. Demkowicz, Idaho National Laboratory, Setpember 28, 2006. 
$40 \mathrm{~kg} / \mathrm{s}$ due to the loss of sensitivity with this type of instrument. The meter performed well in LBE. Porous mechanical filters were used to remove macroscopic slag from the LBE. The mechanical filters did not plug up in 6,000 hours of operation. A hot trap with a fiberglass filter was effective at trapping small slag. Oxygen was removed from the LBE by adding a stoichiometric amount of $\mathrm{Mg}$ and by bubbling an $\mathrm{Ar} / \mathrm{H}_{2}$ gas mixture through the alloy (Foletti 2006). These experiences demonstrate that oxide accumulation should be given attention because it can foul instruments.

There are two safety concerns regarding spills of $\mathrm{Pb}-17 \mathrm{Li}$ from the flow loop into the port. One concern is that the hot leg $\mathrm{Pb}-17 \mathrm{Li}$ could be at $470-650^{\circ} \mathrm{C}$, and such a high temperature molten metal could threaten equipment in the room, particularly the metal bellows that connects the port frame to the bioshield wall. Overheating and breaching the bellows would result in a loss of cryostat vacuum event. While not a particularly important accident from the public safety perspective, loss of cryostat vacuum that draws metal into the cryostat is a very important accident from the investment protection perspective. The ITER tokamak would benefit from being shut down as quickly as possible and dumping the magnet energy to dump resistors. Inrushing air from the port would freeze onto the magnet cases that are held at $4 \mathrm{~K}$, warming the magnet cases and creating an air plus metal impurity ingress issue that would require months to clean up. Freezing moisture from the air could expand and place extra stress on the magnet cases, which could overstress the magnet insulation and lead to insulation failure. Insulation failure would probably require magnet coil replacement. Given the small amount of liquid metal (0.4 $\mathrm{m}^{3}$ ), protection in the form of a catch pan, a dike, or protective sleeves that create a barrier between the port and the bellows convolutions should be used to preclude a bellows breach event. If sleeves are chosen, they should be removable to allow periodic bellows visual inspections. The second safety concern is loss of control of radioactive materials. The DDD (Wong 2005) stated that there could be some activated mercury (an impurity in the Pb-17Li) and some small amount of tritium in the spilled coolant. Po-210 is expected to remain as lead polonide in the coolant during a spill. The coolant on the floor (at 470 to $650^{\circ} \mathrm{C}$ if spilled from the hot leg, or $340^{\circ} \mathrm{C}$ if spilled from the cold leg) can have some mild, yet exothermic chemical reactions in air (Hubberstey and Sample 1992). Pb-17Li will react with oxygen and oxygen-containing species in air $\left(\mathrm{CO}, \mathrm{CO}_{2}, \mathrm{H}_{2} \mathrm{O}\right)$ to form lithium oxide $\left(\mathrm{Li}_{2} \mathrm{O}\right)$. Jeppson (1989) showed in $\mathrm{kg}$-scale tests that the lithium oxide forms a crust on the molten metal and the crust blocks air from reaching fresh molten metal. As the reaction is slowed and halted due to this oxide cover, the metal has time to cool, reducing its chemical reactivity. Most liquid metal systems use drip pans or catch pans under the piping, and the pan should be insulated so that the concrete floor is not overheated. Floor concrete overheating (above $\approx 200^{\circ} \mathrm{C}$, see Naus, 2006) can cause a reversal of the hydration reaction that formed the concrete and drive water vapor and $\mathrm{CO}_{2}$ back out of the calcium compound. After pressure equilibration in a spill event, air will enter the $\mathrm{Pb}-17 \mathrm{Li}$ piping. Air poses a chemical contamination concern for the $\mathrm{Pb}-17 \mathrm{Li}$. Air intrusion will require extensive cleaning before operation of the $\mathrm{Pb}-17 \mathrm{Li}$ system is possible again.

\subsection{Related Operating Experiences Supporting the FMEA}

The literature was searched for any applicable liquid metal operating experiences with $\mathrm{Pb}$ 17Li or similar coolants. The most applicable experiences located were those of the TRITEX Pb$17 \mathrm{Li}$ flow loop. Otherwise, liquid metals are not widely used outside of the nuclear industry. One nuclear conference proceedings did contain several articles of interest as discussed below. Also, Cadwallader (1999) compiled operating experiences for fission coolants other than water; these experiences were used to recognize faults that could occur with a liquid metal coolant. These findings are described below. 
TRITEX operating experiences are very relevant to the DCLL TBM. While the TRITEX $\mathrm{Pb}-17 \mathrm{Li}$ flow loop was not under neutron irradiation, it did operate at 250 to $550^{\circ} \mathrm{C}$, so its operating temperatures are within the range of the DCLL. The main piping was $15 \mathrm{~mm}$ diameter and the flow rate was 0.1 to $2.5 \mathrm{~L} / \mathrm{min}$., or 1 to $25 \mathrm{~cm} / \mathrm{s}$ flow velocities. The wetted surface area was 1.2 to $1.5 \mathrm{~m}^{2}$. Argon was used as a cover gas at 1 bar pressure, which is less than the DCLL. It is possible that the higher pressure of the DCLL may be conducive to keeping the alloy more pure by protecting against air inleakage. At high temperatures, in the $500^{\circ} \mathrm{C}$ range, the $\mathrm{Pb}-17 \mathrm{Li}$ was found to be very fluid (i.e., low viscosity); it would easily flow out of small cracks or leaks (Feuerstein 1988). Between 1988 and 1996, TRITEX ran for 13,000 hours (Feuerstein 1999). The small loop, small number of components, and low operating time are insufficient to give good component failure rate data statistics, but the operating experiences are indicative of the types of events, equipment failure modes, and problems that could occur with a $\mathrm{Pb}-17 \mathrm{Li}$ flow loop. In the initial operating campaign, the staff determined that the electrical trace heating $(3 \mathrm{~kW})$ and the thermal insulation were insufficient; there was heat leakage. (Note: heat leakage into cryogenic systems and heat leakage out of high-temperature systems has always plagued designers.) A second thermal box was constructed around loop piping runs to prevent heat leakage. Some small leaks of $\mathrm{Pb}-17 \mathrm{Li}$ encountered with the apparatus exhibited a characteristic of solidifying in the thermal insulation and self-sealing the leak location. The self-sealing may have been more easily accomplished because of the low pressure in the system. The electromagnetic pump used on the loop had a titanium zirconium molybdenum (TZM) alloy outlet pipe, which was not compatible with the $\mathrm{Pb}-17 \mathrm{Li}$. It cracked in the first operating period, spilling $\approx 15 \mathrm{~kg}$ of alloy $(15 \%$ of the TRITEX piping inventory). A TZM level indicator in the drain tank also failed and leaked air into the drain tank, where it reacted with the $\mathrm{Pb}-17 \mathrm{Li}$, oxidizing the alloy and depleting the alloy of lithium. About $3.5 \mathrm{~kg}$ of oxides was created and the remaining alloy contained less than 5 atom percent $\mathrm{Li}$. The alloy in the drain tank had to be replaced. The system valves used metal bellows as a secondary seal around the valve stem. Some Pb-17Li got to the bellows and had to be cleaned out. The staff were stated to have been amazed that the electromagnetic (EM) pump electrical components, which had to be used to heat the alloy as well as move alloy, survived for the operating life of the flow loop, 13,000 hr (Feuerstein 1999). The EM pump magnets could reach $400^{\circ} \mathrm{C}$ in normal operation. The TRITEX piping was ferritic steel, and some oxides and corrosion products were evident in the flow, as seen through the quartz viewing window installed in the flow loop. The staff could see oxide particles, which usually went into crusts that were visible through the window, and corrosion product particles in the mirror-like surface of the $\mathrm{Pb}$ 17Li that was reminiscent of liquid mercury. Despite the careful procedures to keep the alloy pure, which included vacuum degassing, argon cover gas, and cleaning the pipework, oxides and corrosion products formed in the un-irradiated loop. The staff noted some issues with valves leaking past their seats - the oxides and corrosion products apparently built up on the valve seats and prevented complete valve closure. One major power outage at the laboratory, due to fault in their electrical distribution equipment, allowed the $\mathrm{Pb}-17 \mathrm{Li}$ to freeze in the entire loop (Feuerstein 1999). This total freeze required careful reheating to not overstress the piping. The original TRITEX design flow rate of $5 \mathrm{~L} / \mathrm{min}$. was not obtainable due to the liquid metal level differences created in the components at high flow rates, and the high temperatures developed in the EM pump when trying to attain high flow rates.

When the TRITEX flow loop piping was drained, a film remained on the pipe surfaces, 87 $\pm 61 \mathrm{mg} / \mathrm{cm}^{2}$, which accounted as $1 \%$ of the $100-\mathrm{kg}$ piping inventory. Even though the drain was performed at $477^{\circ} \mathrm{C}$, the film remained (Feuerstein 1999). This behavior is not uncommon with other liquid metals besides $\mathrm{Pb}-17 \mathrm{Li}$.

Some TRITEX equipment and design practices deserve mention here. Two EM flow meters were used and two mass flow meters were also provided. This redundancy in instruments 
presents costs - purchase cost and maintenance costs - but it can be a virtue in a flow loop. Redundancy increases the operational reliability and reduces concerns that repairs will result in air ingress contamination. Two cold traps using wire mesh and external air cooling (using fins on the casing) were used. The alloy flow velocity in the cold traps was 13 times less than the main piping flow velocity. The cold traps served as deposition regions for impurities (such as $\mathrm{Bi}$ ) and corrosion products (such as $\mathrm{Fe}, \mathrm{Cr}$ ), reaching a low temperature of about $280^{\circ} \mathrm{C}$. Two magnetic traps operating at 650 Gauss were also used: one was simply permanent magnets placed outside sections of the main pipe, another was a small flow chamber placed in the piping; the lid was removable for cleaning adhered particles. The magnetic traps primarily captured iron oxide corrosion products. The laboratory used a non-water fire suppression system because if hightemperature liquid metal spilled, applying water from a fire sprinkler system could lead to a steam pressure explosion. A steel catch pan was used below the experiment. The catch pan was sized to accommodate ten times more liquid metal than the loop held. The loop held about $100 \mathrm{~kg}$ of Pb$17 \mathrm{Li}$ and the drain tank reserve was an additional $20 \mathrm{~kg}$. Considering a potential spill in the ITER port, catch pans and protection of the bellows are needed. A fire suppression gas might be the most favorable firefighting agent to use - powder or dry chemical suppressant would require extensive cleanup, water is contraindicated due to its chemical reactivity with $\mathrm{Pb}-17 \mathrm{Li}$, and water turning to steam could create other concerns in the port such as electrical short circuits. A gas that would not overpressurize the port, perhaps heptafluoropropane (called HFC-227), argonite (argon-nitrogen mixture), or other fire suppression gases, could be used. Inergen (nitrogen-argoncarbon dioxide) is not recommended as a fire suppressant because $\mathrm{Pb}-17 \mathrm{Li}$ reacts exothermically and vigorously with carbon dioxide (Jeppson and Muhlestein 1985).

The TRITEX drain tank was insulated and was continually heated to $350{ }^{\circ} \mathrm{C}$ to avoid thermal shock problems if the alloy had to be dumped to the drain tank on short notice (Feuerstein 1999). This should be a consideration for DCLL TBM designers.

Drobyshev (1969) described some operational problems with liquid metal forcedcirculation flow loops. Drobyshev stated that for personnel protection, all high-temperature portions of liquid metal systems should be placed in inert-gas chambers. This reduces chemical reactions and inert gas zones form personnel exclusion zones. Catch pans should always be used to collect leaks, especially leaks from defects in construction materials-microcracks, micropores, bad weld joints, etc. Drain lines must be heated to a higher temperature than the freezing point of the alloy. An interlock should be used such that when metal alloy leakage is sensed, the drain valves should automatically be opened and the electrical heat tracing should be de-powered. Nichrome heaters wound onto piping have short circuited to the pipe, so voltage was reduced to $\approx 48$ volts to preclude short circuiting.

The former Soviet Union used $\mathrm{Pb}$ and $\mathrm{Pb}-\mathrm{Bi}$ cooled fission reactors in land tests and for naval propulsion plants. There were several operating experiences of relevance to the use of $\mathrm{Pb}$ 17Li in the U.S. TBM. Gromov (1999) discussed the accidents that had occurred with heavy PbBi liquid metal coolants. The first event described occurred in a submarine propulsion reactor, the "Project 645," in 1968. In this event, investigators believed that air had been admitted to the primary coolant piping during pipe repairs. The air had reacted with the $\mathrm{Pb}-\mathrm{Bi}$ to form large amounts of lead oxide that plugged the piping. Also, oil from the shaft seals for the coolant pumps had leaked into the $\mathrm{Pb}-\mathrm{Bi}$, where the high temperatures pyrolyzed the oil into other hydrocarbons. These impurities coated the heat transfer surfaces, greatly retarding heat transfer from the reactor core, and plugged piping. The naval personnel did not understand what was occurring with the fission reactor so they tried to compensate for power decreases by withdrawing control rods. The core overheated and fuel cladding failed. Fuel and fission products circulated in the primary coolant system. 
The lessons that have been learned are

- Use an inert gas blanket when performing maintenance on piping

- Use sensors to detect oxygen in the coolant

- $\quad$ Use gas-tight electric drivers or water seals on pump shafts

- Use a lead oxide recovery system in the coolant purification system

- Use coolant quality control to prevent oxide film formation on heat transfer surfaces

A brief examination of the heats of formation of $\mathrm{Pb}$ and Li oxides (Chemical Rubber Company 1979) shows:

$\begin{array}{lll}\text { - } & \mathrm{PbO} & -52 \\ \text { - } & \mathrm{Pb}_{2} \mathrm{O} & -51 \\ \text { - } & \mathrm{Pb}_{2} \mathrm{O}_{4} & -175 \\ \text { - } & \mathrm{Pb}\left(\mathrm{N}_{3}\right)_{2} & +104 \\ \text { - } & \mathrm{Li}_{2} \mathrm{O} & -142.4 \\ \text { - } & \mathrm{Li}_{2} \mathrm{O}_{2} & -151 \\ \text { - } & \mathrm{Li}_{3} \mathrm{~N} & -47\end{array}$

All values are in $\mathrm{kcal} /$ gram-mole for $25^{\circ} \mathrm{C}$. Negative signs indicate exothermic reactions.

Feuerstein (1988) discussed that air intrusion into the $\mathrm{Pb}-17 \mathrm{Li}$ caused $\mathrm{Li}_{2} \mathrm{O}$ to form and deplete the alloy of lithium. The heats of formation listed above show that $\mathrm{Pb}$ will oxidize at a low rate, lower than lithium. Feuerstein stated that for air ingress to the loop at $550^{\circ} \mathrm{C}, 0.3 \%$ of the total liquid metal inventory would be oxidized within 1 hour, and the oxides would contain $25 \%$ of the total lithium inventory. The Slavic experience shows that $\mathrm{Pb}_{2} \mathrm{O}$ and $\mathrm{PbO}$ buildup will attenuate heat transfer to a large extent. Therefore, the DCLL TBM should avoid trapping air in the $\mathrm{Pb}-17 \mathrm{Li}$ pipework. An oxygen sensor in the liquid metal, as suggested in the Project 645 lessons learned, would be a prudent measure to ensure that no air has intruded into the system. The experience shows that air intrusion will form metal oxides and these oxides can precipitate out of the liquid. A cold trap is included in the DCLL TBM design to remove such impurities.

The second event Gromov (1999) discussed occurred with the "Project 705" submarine in 1971. One of the steam generators ( $\mathrm{Pb}-\mathrm{Bi}$ to water heat exchanger) had a slight leak in an access cover on the steam side due to a gasket flaw, and there was additional steam leakage due to some faulty welds. The compartment housing the steam generator thus tended to be high humidity and there was condensation on the compartment's cool surfaces. The condensed water droplets included chlorides that were present for water chemistry control. The chlorides caused corrosion on the austenitic stainless steel primary circuit and ancillary pipelines. This event has little significance to the TBM; the only water in the TBM design is used to cool the TBM module mounting frame. The TBM frame cooling water may use different methods of chemistry control. 
If that water were to leak, it could conceivably leak from piping into the port where the $\mathrm{Pb}-17 \mathrm{Li}$ loop is housed. The $\mathrm{Pb}-17 \mathrm{Li}$ piping will have insulation on the exterior and, given that the $\mathrm{Pb}-17 \mathrm{Li}$ piping is held at $340^{\circ} \mathrm{C}$ and higher, the insulation will be warm. Any water intruding into the piping thermal insulation is expected to evaporate and deposit its residue chemicals in the insulation, not directly on the piping.

The third event that Gromov (1999) discussed occurred with the "Project 705K" submarine in 1982. This event was a confluence of errors. On this reactor, the primary $\mathrm{Pb}-\mathrm{Bi}$ coolant pump had an adjusting manometer that was only to be used during plant shutdowns (speculation is that this manometer was used to verify proper fill of the pump tank, then it was supposed to be valved out before plant startup). The manometer was rated for $4 \mathrm{~kg} / \mathrm{cm}^{2}$ pressure, which was an adequate rating for shutdown conditions. The fission reactor underwent startup; the manometer had not been valved out as procedures specified. A steam generator tube fault occurred after reactor startup due to water chemistry control problems. The inlet water was supposed to be stripped of free oxygen by an electron-ion-exchanger filter that was charged with copper. Some copper escaped from the filter into the water and caused electro-chemical corrosion of the steam generator tubing. The steam generator tubing was not made of the specified high nickel, corrosion-resistant steel alloy; a fabrication error had allowed the tubing to be constructed of common stainless steel that was more susceptible to copper corrosion. Water, at higher pressure than the $\mathrm{Pb}-\mathrm{Bi}$, penetrated into the $\mathrm{Pb}-\mathrm{Bi}$ coolant and some collected in the pump tank. The pump tank pressure increased to $6 \mathrm{~kg} / \mathrm{cm}^{2}$, and the manometer failed. $\mathrm{Pb}-\mathrm{Bi}$ and steam leaked from the pump tank into the reactor compartment. The crew in the compartment was exposed to radioactive contamination in air, especially Po-210. Fortunately, no one received high exposures; the highest was $10 \%$ of the annual maximum permissible exposure. Gromov did not give the operating temperature of the $\mathrm{Pb}$-Bi coolant, and it is unfortunate that the Po-210 issue is not better explained in Gromov's article. Experiments show that polonium should remain as lead polonide, or at least as a liquid metal in mixture within the $\mathrm{Pb}$-Bi eutectic, but Gromov stated that Po-210 gave a dose. As an alpha particle emitter, Po-210 poses a radiological threat when inhaled or ingested, but not from external radiation. In this event, the steam generator was constructed of incorrect materials and the copper oxygen radical collector had failed, contaminating the secondary coolant system and attacking the steam generator tubes.

Other pertinent design criteria and operating experiences were given by Bagdassarov (1999). He stated that for a lead-cooled reactor, the reactor core $\mathrm{Pb}$ coolant inlet temperature of $420^{\circ} \mathrm{C}$ was too close to the freezing point of lead $\left(327^{\circ} \mathrm{C}\right)$. Reasons were not stated for this design advice, but presumably the liquid metal is such a good conductor of heat that it can transfer enough heat to quickly reduce its temperature to, or near, its freezing point. Bagdassarov stated that the required minimum difference of the low coolant temperature in the system (i.e., the heat exchanger outlet or the core inlet temperature) and the freezing point of the liquid metal should be at least a $\Delta \mathrm{T}$ of $150^{\circ} \mathrm{C}$. It is noted that the U.S. TBM using $\mathrm{Pb}-17 \mathrm{Li}$ has a melting temperature of $\approx 240^{\circ} \mathrm{C}$ and the minimum operating temperature is $340^{\circ} \mathrm{C}$; perhaps using a $\Delta \mathrm{T}$ of only $100^{\circ} \mathrm{C}$ is adequate for $\mathrm{Pb}-17 \mathrm{Li}$. The TBM has the helium gas coolant that is easily warmed and can keep the $\mathrm{Pb}-17 \mathrm{Li}$ temperature high and more constant around $340^{\circ} \mathrm{C}$. Bagdassarov further stated that liquid lead corrosion increases when the $\mathrm{Pb}$ temperature elevates above $540^{\circ} \mathrm{C}$, so a smaller the temperature rise across the heat input section of the flow loop is better to keep structural material corrosion at low levels. This temperature limit would require a higher flow rate than other coolants, which means high pumping power. Compared with liquid sodium coolant, liquid lead requires a significantly higher operating pressure, has higher corrosion activity with structural materials, requires a more complicated system for coolant purification, has much different buoyancy characteristics than alkali metals, and presents a more demanding task to maintain in liquid phase. Fortunately, these issues can be dealt with in design. One of the more intriguing 
issues, the high buoyancy, is not an issue for the TBM because it is a once-through "single pass" flow loop - there are no components that could "float up" in the Pb flow.

\subsubsection{Sodium Liquid Metal Experiences}

Instruments and their penetrations have been the source of some notable failures (Cadwallader 1999). During June 1985, a faulty weld on a thermocouple allowed several cubic centimeters of secondary sodium coolant to escape from the intermediate cooling loop of the Super Phenix reactor in France. In December 1995, a thermocouple fatigue failure allowed $\approx 730$ $\mathrm{kg}$ of sodium to leak from the Monju fast reactor in Japan. While these designs vary a great deal from the TBM, the TBM will also use the typical temperature, pressure, and level instruments, and possibly flow instruments, oxygen monitors, and other instrumentation. King (1985) stated that for Experimental Breeder Reactor (EBR)-II, the original ten flow meters on the primary flow circuit had no provision for repair or replacement. From 1964 to 1985, seven of the ten units had failed, so alternative means had to be devised to determine primary flow. EBR-II began to have concerns about obtaining spare parts for crucial components. In 1985, a spare pump impeller and shaft were delivered to the site, although it is doubted that the staff ever replaced a primary pump shaft.

The Dounreay fast reactor also reported on a failure of the sodium level instrument within a pump casing. The instrument failed due to cross flow on the instrument thimble. The thimble fractured, probably due to imperfect construction (Walford 1978). In another event, "thermal striping" created by a stream of hot sodium (that is, a stripe) onto the walls of a heat exchanger caused concern about potential thermal stress damage to welds; therefore, when the minimum three heat exchangers were in operation, the plant core temperature was limited to lower values to reduce the thermal stress effects on the welds. To keep station efficiency high, this limitation made it very important to keep the maximum six heat exchangers on line.

Dounreay used centrifugal pumps for both primary and secondary coolant. These pumps experienced some trips and unscheduled shutdowns, six trips in 5 years. The trips generally arose from the pump oil systems and other auxiliary systems (Walford 1978). Dounreay pipework had sections that were jacketed for leak detection. The leak detectors were ceramic units with a metal electrode and gave rise to a number of spurious leakage alarms due to faulty detectors. Faulty detectors were bypassed; there was enough redundancy in the detection system to allow that procedure. There were two small leaks in 5 years: one leak was traced to a construction flaw and the other small leak was not described. Walford also mentioned a few small leaks at flanges and actuator shaft seals that were addressed by "gas pressure padding" until more permanent repairs could be performed during a scheduled shutdown. Argon gas was used for padding. If gas pressure padding can be applied to the TBM, it should be noted that while the cost of some increased argon usage is minor compared to that of an unscheduled plant shutdown, any escaping argon could entrain some tritium gas from the $\mathrm{Pb}-17 \mathrm{Li}$. A fission reactor would also have some tritium (created by fission) migrating into the coolant, so presumably the need for gas pressure padding was infrequent and the gas leak rate was small.

As noted with EBR-II (Koch 1988), many liquid metal piping systems have used some provision for accommodating thermal expansion, either a Z-shape or a C-shape in the pipe run that will allow pipe elongation and flex as the piping heats up to operating temperature. The TBM $\mathrm{Pb}-17 \mathrm{Li}$ piping can operate from 470 up to $650^{\circ} \mathrm{C}$, so some design provision will be needed to handle ferritic steel pipe expansion. Some sketches of the TBM show an "S" in the main piping that will relieve the stress of thermal expansion. 
A phenomena reported in the literature is liquid metal flowing into piping thermal insulation and the insulation spreading or "wicking" the liquid so that the liquid is exposed to more air within the insulation (McIntosh 1994). The Institute of Electrical and Electronics Engineers (IEEE) (IEEE 1987) gives some suggested maximum service temperatures for piping thermal insulation; only calcium silicate and mineral wool have temperatures of $677^{\circ} \mathrm{C}$, which is just above the peak TBM fluid temperature of $650^{\circ} \mathrm{C}$. Other well-known insulation choices, such as fiberglass, are only rated for $232^{\circ} \mathrm{C}$. Leaking $\mathrm{Pb}-17 \mathrm{Li}$ to the thermal insulation on the piping may mean dispersion of the liquid metal so that it mixes with copious air and can react easily in air. In such cases, the leak size could be important. Most leaks out of the piping are small; the fluid expends energy traversing the leak path to escape into the room air. The system flows at 77 $\mathrm{kg} / \mathrm{s}$. Analyzing water leak flow rate data from power plant piping (Eide 1991), which are the best data available, shows that the average leak of water is $3 \%$ for boiling water reactors (BWRs) to $5 \%$ for pressurized water reactors (PWRs) of the nominal volumetric pipe flow rate, with the median values being $0.3 \%$ and $0.75 \%$, respectively. Most of the piping was less than $76 \mathrm{~cm}$ ( 3 inch) diameter, assumed to carry up to $45 \mathrm{~kg} / \mathrm{s}$ ( $738 \mathrm{gal} / \mathrm{min}$.) of water. The PWRs provided many data points versus only a few from BWRs, so the PWR data are considered to be the most representative data. These are the best data available for estimating leak rates from pipe breaches based on the nominal system flow rate. Using $0.75 \%$ for a small leak and $5 \%$ for a typical leak gives $0.6 \mathrm{~kg} / \mathrm{s}$ for a small leak of Pb-17Li and $3.85 \mathrm{~kg} / \mathrm{s}$ for a typical leak. Recalling the TRITEX experience, very small leaks tended to cool and freeze in the insulation, plugging the leak location. The larger leak in TRITEX when the EM pump outlet nozzle cracked was $\approx 15 \%$ of the loop inventory; which was a large leak. Such leaks are anticipated to continue until operators act to isolate the leaks by using valves, reducing system pressure, or draining the $\mathrm{Pb}-17 \mathrm{Li}$ to the drain tank. These kg-size leaks should present enough mass intruding into the piping insulation that the insulation will quickly breach and pour the liquid metal to the equatorial port floor (unless other design provisions have been taken, such as a guard pipe, floor liners, catch pans, etc.). Thus, the leak events are expected to result in traditional spills that form pools on the floor. Large leaks or ruptures of water piping are defined to be greater than $50 \mathrm{gal} / \mathrm{min}$. (Eide 1991) or $3 \mathrm{~kg} / \mathrm{s}$ of water flow, based on operating experiences. For $\mathrm{Pb}-17 \mathrm{Li}$, the $50 \mathrm{gal} / \mathrm{min}$. definition of a rupture flow rate converts to $30 \mathrm{~kg} / \mathrm{s}$.

It is noted that $\mathrm{Pb}$ is a hazardous substance. When high-temperature liquid is spilled, there will be vapor above the pool surface. The pressure of saturated vapor in $\mathrm{mm}$ of $\mathrm{Hg}$ above the pool surface is found by this equation (Chemical Rubber Company 1979):

$\log _{10}$ Pressure $=[-(0.05223)(188,500) / T+7.827]$

where $\mathrm{T}$ is in Kelvin.

The results are given in Table 2-1.

Table 2-1. $\mathrm{Pb}$ vapor above a liquid $\mathrm{Pb}$ pool.

\begin{tabular}{|c|c|c|c|}
\hline $\begin{array}{c}\text { Pb Pool Temperature } \\
(\mathrm{C})\end{array}$ & $\begin{array}{c}\text { Pb Vapor pressure } \\
(\mathrm{mm} \mathrm{Hg})\end{array}$ & $\begin{array}{c}\text { Pb Vapor density } \\
\left(\# / \mathrm{m}^{3}\right)\end{array}$ & $\begin{array}{c}\text { Pb concentration } \\
\left(\mathrm{mg} / \mathrm{m}^{3}\right)\end{array}$ \\
\hline 340 & $5.84 \mathrm{E}-09$ & $2 \mathrm{E}+14$ & $6.8 \mathrm{E}-05$ \\
\hline 470 & $3.77 \mathrm{E}-06$ & $1 \mathrm{E}+17$ & 0.034 \\
\hline 650 & $1.45 \mathrm{E}-03$ & $2 \mathrm{E}+19$ & 6.88 \\
\hline
\end{tabular}

The vapor density was read from a graph (Advanced Power Extraction [APEX] 1999). Converting from number of particles in the air over the pool to $\mathrm{mg}$ of $\mathrm{Pb}$ was straightforward 
using the molecular weight. Feuerstein (1991) stated that the majority of the particles would be $\mathrm{Pb}$ rather than $\mathrm{Li}$ because the $\mathrm{Li}$ forms compounds with the liquid $\mathrm{Pb}$ rather than becoming airborne. $\mathrm{Pb}$ is monotomic; its molecular weight is $207.2 \mathrm{~g} / \mathrm{mole}$. The threshold limit value (TLV) for $40 \mathrm{hr} /$ wk occupational exposure to $\mathrm{Pb}$ is $0.05 \mathrm{mg} / \mathrm{m}^{3}$ (American Conference of Industrial Hygienists [ACGIH] 2007). Given the results, a spill at $340^{\circ} \mathrm{C}$, the cold leg temperature, would not pose an occupational chemical exposure threat near the port area. A spill at $470^{\circ} \mathrm{C}$ results in a vapor concentration close to the TLV and would require ventilation control as a precaution to reduce personnel exposure as much as possible. A spill at $650^{\circ} \mathrm{C}$ would result in a concentration more than 100 times above the occupational exposure limit. The immediately dangerous to life or health (IDLH) concentration for $\mathrm{Pb}$ is $100 \mathrm{mg} / \mathrm{m}^{3}$, so there is no immediate health threat from the $6.88 \mathrm{mg} / \mathrm{m}^{3}$ that results from a $650^{\circ} \mathrm{C}$ spill. A possible approach could be to ventilate and filter the air until the room temperature decreases and the spill pool cools. In a chemical reactivity test of $200 \mathrm{~kg}$ of $\mathrm{Pb}-17 \mathrm{Li}$ at $600^{\circ} \mathrm{C}$ with $0.054 \mathrm{~m}^{3}$ of room-temperature basalt concrete, the alloy temperature reduced to $410^{\circ} \mathrm{C}$ in 15 minutes after pouring the pool onto the concrete because of heat transfer into the bare concrete (Jeppson and Muhlestein 1985).

\subsection{FMEA Failure Rate Data}

The component failure rate data used in the FMEA came from several sources. The ITER Project does not have an approved component failure rate database, so data sources most applicable to the TBM components were used. No component failure rate data compilations or reports were found in the literature for $\mathrm{Pb}, \mathrm{Pb}-\mathrm{Bi}$, or other heavy metal coolants, so the data values from alkali metal cooled fission reactors were used. While $\mathrm{Pb}-17 \mathrm{Li}$ and $\mathrm{Na}$ are dissimilar, the sodium-cooled fission reactors do have the applicability of low-pressure and high-temperature operation, the same issues of "wetting" the walls of the flow loop, and molten metal pumping similarities (even though $\mathrm{Pb}-17 \mathrm{Li}$ metal is much denser and has different chemical reactivity concerns). Data from a sodium reactor data compilation report (Eide 1990), the Experimental Breeder Reactor-II probabilistic risk assessment (Argonne National Laboratory 1991), and a few other sources were used in the FMEA. Some data from the Centralized Reliability Data Organization (CREDO) for liquid sodium cooled fission reactors is in the EBR-II risk assessment and a few other values were found in the literature. Work by Boisseau (1982) on failure rates from Euroean Union sodium reactor operating experiences sometimes compared fairly (with 10× of the failure rate used) and usually compared well (within $3 \times$ of the failure rate used) with U.S. data. Buende's data (Buende 1991) was used for weld failure rates even though welding of RAFS may not be as straightforward as welding ordinary carbon steel or stainless steels. These data are considered to be the most representative data available at this time to apply to TBM RAFS components.

\subsection{TBM Preliminary FMEA Results}

The TBM Pb-17Li flow loop FMEA covered the liquid metal flow loop in normal, pulse operation. The TBM module itself was treated as a flow channel in this analysis. If needed, future work can expand the FMEA to cover other $\mathrm{Pb}-17 \mathrm{Li}$ operating modes and also treat the helium coolant portion of the DCLL TBM design.

The preliminary FMEA on the $\mathrm{Pb}-17 \mathrm{Li}$ flow loop is given in Appendix A. The main results were not surprising for this single-pass flow loop that cools a small section of the ITER blanket/first wall. Table 2-2 summarizes the PIEs from the FMEA results. 
From the ITER TBM conference call held on 30 September 2006, the PIE format is four characters:

- Character 1 is alphabetic, the type of event, for example $\mathrm{L}=$ loss, $\mathrm{F}=$ flow, $\mathrm{H}=$ heat

- Character 2 is alphabetic, the system under consideration, here $\mathrm{B}=\mathrm{TBM}, \mathrm{M}=$ liquid metal, $\mathrm{F}=$ first wall

- Character 3 is alphabetic, the location of the event, here $\mathrm{B}=$ blanket as in TBM breeder module box, $\mathrm{V}=$ vessel, $\mathrm{P}=$ port cell, $\mathrm{M}=$ module flow loop, $\mathrm{O}=$ outside, and $\mathrm{I}=$ inside

- $\quad$ Character 4 is numeric, the accident severity, $1=$ most severe event, $2=1$ eak, $3=$ small leak. 
Table 2-2. Pb-17Li Loop FMEA Results for postulated initiating events

\begin{tabular}{|c|c|c|}
\hline PIE Family & FMEA Faults and Annual Frequency & Frequency Summation \\
\hline $\begin{array}{l}\text { LMP2 } \\
\text { Small Pb-17Li } \\
\text { LOCA to } \\
\text { Port Cell }\end{array}$ & $\begin{array}{l}\text { Valve leaks, 3.3E-02 } \\
\text { Pump leak, } 1 \mathrm{E}-02 ; \\
\text { Piping leaks, 6E-03 } \\
\text { Expansion tank leaks, 3.4E-03 } \\
\text { Cold trap leak, 1.7E-03 } \\
\text { Mixing tank leak, 3.4E-04 } \\
\text { Concentric pipe trans. leaks, 1.7E-04 } \\
\text { Temperature instrument leaks, 1E-04 } \\
\text { Concentric pipe run leaks, 6E-05 } \\
\text { Pressure instrument leaks, 1E-05 } \\
\text { Level instrument leaks, 3.4E-06 }\end{array}$ & $\begin{array}{l}5.6 \mathrm{E}-02 / \text { year for small leaks } \\
\text { from the } \mathrm{Pb}-17 \mathrm{Li} \text { system. } \\
\text { Category II }\end{array}$ \\
\hline $\begin{array}{l}\text { LMP1 } \\
\text { Pb-17Li LOCA } \\
\text { to Port Cell }\end{array}$ & $\begin{array}{l}\text { Valve ruptures, } 7.7 \mathrm{E}-03 \\
\text { Cold trap rupture, } 1.7 \mathrm{E}-03 \\
\text { Pump rupture, } 1 \mathrm{E}-03 \\
\text { Expansion tank ruptures, } 3.4 \mathrm{E}-04 \\
\text { Piping ruptures, } 6 \mathrm{E}-05 \\
\text { Mixing tank rupture, } 1.7 \mathrm{E}-05 \\
\text { Concentric pipe trans. rupture, } 1.7 \mathrm{E}-06 \\
\text { Concentric pipe run rupture, } 6 \mathrm{E}-06 \\
\text { Pressure instrument rupture, } 3 \mathrm{E}-07 \\
\text { Level instrument rupture, } 2 \mathrm{E}-07 \\
\text { Temperature instrument rupture, } 1 \mathrm{E}-07\end{array}$ & $\begin{array}{l}1.1 \mathrm{E}-02 / \text { year for large leaks } \\
\text { or ruptures from the } \mathrm{Pb}-17 \mathrm{Li} \\
\text { system. } \\
\text { Category II }\end{array}$ \\
\hline $\begin{array}{l}\text { VMM2 } \\
\text { Small Pb-17Li } \\
\text { LOCA } \\
\text { to VV }\end{array}$ & TBM module box leak, $1 \mathrm{E}-02$ & $\begin{array}{l}1 \mathrm{E}-02 / \text { year for TBM module } \\
\text { leaks to the vacuum vessel. } \\
\text { Category II }\end{array}$ \\
\hline $\begin{array}{l}\text { VMM1 } \\
\text { Pb-17Li LOCA } \\
\text { To VV }\end{array}$ & TBM module box failure, $1 \mathrm{E}-03$ & $\begin{array}{l}1 \mathrm{E}-03 / \text { year for TBM module } \\
\text { large leaks to the vacuum } \\
\text { vessel. } \\
\text { Category III }\end{array}$ \\
\hline $\begin{array}{l}\text { LBB2 } \\
\text { Small He LOCA } \\
\text { in TBM }\end{array}$ & $\begin{array}{l}\text { Helium leak into } \mathrm{Pb}-17 \mathrm{Li} \text {, lose helium } \\
\text { cooling to TBM box, } 1 \mathrm{E}-02\end{array}$ & $\begin{array}{l}1 \mathrm{E}-02 / \text { year for helium leaks } \\
\text { into the } \mathrm{Pb}-17 \mathrm{Li} \text {. } \\
\text { Category II }\end{array}$ \\
\hline $\begin{array}{l}\text { LBB1 } \\
\text { He LOCA in } \\
\text { TBM }\end{array}$ & $\begin{array}{l}\text { Helium rupture to } \mathrm{Pb}-17 \mathrm{Li} \text {, lose helium } \\
\text { cooling to TBM box, } 1 \mathrm{E}-03\end{array}$ & $\begin{array}{l}\text { 1E-03/year for large helium } \\
\text { TBM coolant leaks into the } \\
\text { Pb-17Li. } \\
\text { Category III }\end{array}$ \\
\hline $\begin{array}{l}\text { LMM2 } \\
\text { Small He LOCA } \\
\text { in TBM HX }\end{array}$ & $\begin{array}{l}\mathrm{Pb}-17 \mathrm{Li} \text {-to-He heat exchanger tube } \\
\text { leakage, } 3.3 \mathrm{E}-03\end{array}$ & $\begin{array}{l}3.3 \mathrm{E}-03 / \text { year for secondary } \\
\text { helium leaks into } \mathrm{Pb}-17 \mathrm{Li} \text {. } \\
\text { Category III }\end{array}$ \\
\hline $\begin{array}{l}\text { LMM1 } \\
\text { He LOCA in } \\
\text { TBM HX }\end{array}$ & $\begin{array}{l}\mathrm{Pb}-17 \mathrm{Li} \text {-to-He heat exchanger tube rupture, } \\
3.3 \mathrm{E}-03\end{array}$ & $\begin{array}{l}3.3 \mathrm{E}-03 / \text { year for secondary } \\
\text { helium rupture into } \mathrm{Pb}-17 \mathrm{Li} \text {. } \\
\text { Category III }\end{array}$ \\
\hline
\end{tabular}


Some more detailed PIE definitions (Pinna 2006a; Pinna 2006b) are given below:

- $\quad$ FB1-Loss of He flow in a TBM cooling circuit due to pump seizure

- $\quad$ FB2 - Partial He flow blockage in a TBM cooling circuit due to filter clogging

- $\quad$ HB1 - Loss of heat sink in TBM He cooling circuit

- $\quad$ LBB1-Loss of TBM He cooling circuit inside breeder blanket box, weld rupture

- $\quad$ LBB2 - Loss of TBM He cooling circuit inside breeder blanket box, weld leak

- $\quad$ LBO1 - Loss-of-coolant accident (LOCA) outside vacuum vessel (VV) due to large He pipe rupture in TCWS room

- $\quad$ LBO2 - LOCA outside VV due to small He pipe rupture in TCWS room

- $\quad$ LBO3 - LOCA outside VV due to tube rupture in TBM-He cooling system hx

- $\quad$ LBP1-LOCA outside VV due to rupture of TBM He cooling circuit in port cell

- $\quad$ LBP2 - LOCA outside VV due to small rupture of TBM He cooling circuit in port cell

- $\quad$ LBV1-LOCA inside VV due to He rupture of TBM-first wall into VV

- $\quad$ LBV2 - LOCA inside VV due to He leak of TBM-first wall into VV

- $\quad$ LFP2 - LOCA outside VV due to small rupture of He cooling circuit in port cell

- $\quad$ LFV2 - Small first wall/blanket in-vessel LOCA, break size a few $\mathrm{cm}^{2}$

- $\quad$ LMP2 - Pb-17Li LOCA into port cell due to small break in cooling circuit

- $\quad$ LVP2 - Small rupture of VV He cooling circuit in port cell

- $\quad$ LVV2 - Small rupture of the inner VV shell, break size a few $\mathrm{cm}^{2}$

- $\quad$ VMM1 - Loss of vacuum in VV due to large Pb-17Li ingress from TBM break

- $\quad$ VMM2 - Loss of vacuum in VV due to small Pb-17Li ingress from TBM break

- $\quad$ VVA2 - Small ingress of air into the VV from TBM

- $\quad \mathrm{N} / \mathrm{S}-$ Not safety relevant.

Of these PIEs, only the events involving $\mathrm{Pb}-17 \mathrm{Li}$ are considered in this FMEA. Future work will address the helium cooling system, the secondary heat removal system (i.e., the intermediate helium coolant loop that rejects heat to the TCWS), and the blanket box itself. Therefore, only LMP2, VMM1, VMM2, LBB1, LBB2, and LBO3 are represented in this Pb-17Li FMEA; the initiator LMP1 is added to cover component ruptures of the liquid metal system. Loss 
of $\mathrm{Pb}-17 \mathrm{Li}$ flow is not a safety issue. The alloy has a very high boiling point, over $1300^{\circ} \mathrm{C}$, and can withstand large amounts of heat without failure.

\subsection{Notes from Similar FMEA Studies}

Pinna (2006a) discussed an event where a water cooling line to the ITER first wall/blanket leaks or ruptures in the port cell and exposes the helium cooled pebble bed (HCPB) TBM cooling systems to a steam/water spray/humid air environment. The cooling systems to the ITER first wall and divertor are rated at: $125^{\circ} \mathrm{C}, 3 \mathrm{MPa}, 140 \mathrm{~m}^{3}$ water per cooling loop (ITER-JCT 2001). Given an in-port LOCA, there are concerns about steam damage in the port cell. The liquid metal coolant piping design calls for electrical heat tracing to prevent coolant solidification and thermal insulation over the heat tracing to protect against heat loss-liquid metals transfer heat rather easily so there must be a fairly thick insulation layer to help retain heat and keep the liquid metal at operating temperature. The insulation will probably be several $\mathrm{cm}$ thick, assuming a $\approx 40^{\circ} \mathrm{C}$ outside surface temperature for personnel protection. The steam will likely condense on the insulation and will not transfer much heat away from the $\mathrm{Pb}-17 \mathrm{Li}$ piping. Steam intrusion to the electrical equipment, the pump and valve motors, heater circuits, and instrumentation is likely to be more consequential. However, if the $\mathrm{Pb}-17 \mathrm{Li}$ loop pump experiences a short circuit or other fault due to steam engulfment, the loop flow stagnates. Stagnant $\mathrm{Pb}-17 \mathrm{Li}$ can withstand intense heating (boiling point $\approx 1,700^{\circ} \mathrm{C}$ ) and does not pressurize very much, so there is no threat of radiological or hazardous material escape from the loop during 400 s ITER pulses (Wong 2005) unless there is another failure causing loss of loop integrity. 


\subsection{References}

ACGIH, 2007. 2007 Guide to Occupational Exposure Values, American Conference of Governmental Industrial Hygienists, Cincinnati, Ohio, 2007.

Agostini, 2004. P. Agostini, E. Baicchi, A. Zucchini, and G. Benamati, "The re-crystallization issue in lead-bismuth technology," Journal of Nuclear Materials, 335 (2004) 275-279.

APEX, 1999. D.-K. Sze, R. Moir, S. Zinkle, authors of "Chapter 8: Database for Liquid Breeders and Coolants," in On the Exploration of Innovative Concepts for Fusion Chamber Technology, APEX Interim Report, UCLA-ENG-99-206, November 1999. This report is available at www.fusion.ucla.edu/apex/interim_report.html.

Bagdassarov, 1999. Yu. E. Bagdassarov, I. A. Kuznetsov, A. A. Kamayev, "Comparison of Sodium and Heavy Liquid Metal Fast Reactor Coolants," Proceedings of the Conference on Heavy Liquid Metal Coolants in Nuclear Technology, October 5-9, 1998, Obninsk, Russian Federation, published by the State Scientific Center of Russian Federation Institute for Physics and Power Engineering, 1999, Volume 2, pages 439-454.

Ballinger, 2004. R. G. Ballinger and J. Lim, "An Overview of Corrosion Issues for the Design and Operation of High-Temperature Lead- and Lead-Bismuth-Cooled Reactor Systems," Nuclear Technology, 147 (2004) 418-435.

Boisseau, 1982. J. Boisseau, J. Dorey, F. Hedin, C. Le Floch, "Failure Rate Evaluation for Different Components Operating in Sodium, Based on Operating Experience of the Rapsodie and the Phenix Reactors and the Test Loops," Proceedings of the LMFBR Safety Topical Meeting, presented at Lyon Ecully, France, 19-23 July 1982, published 1982, volume 2, pages 677-686.

Buende, 1991. R. Buende, S. Fabritsiev, and V. Rybin, "Reliability of welds and brazed joints in blankets and its influence on availability," Fusion Engineering and Design, 16 (1991) 5972 .

Buongiorno, 2004. J. Buongiorno, E. P. Loewen, K. Czerwinski, C. Larson, 2004, "Studies of Polonium Removal from Molten Lead-Bismuth for Lead-Alloy-Cooled Reactor Applications," Nuclear Technology, 147 (2004) 406-417.

Cadwallader, 1999. L. C. Cadwallader, Liquid Metal, Gas, Molten Salt, and Organic Cooling System Operating Experience Review for Fusion Applications, INEEL/EXT-99-00144, Idaho National Engineering and Environmental Laboratory, February 1999.

Courouau, 2002. J.-L. Courouau et al., "Impurities and oxygen control in lead alloys," Journal of Nuclear Materials, 301 (2002) 53-59.

Chemical Rubber Company, 1979. Handbook of Chemistry and Physics, $60^{\text {th }}$ edition, Chemical Rubber Company, Boca Raton, Florida, pages D-72 and D-218.

Dostal, 2004. V. Dostal, P. Hejzlar, and N. E. Todreas, "Medium-Power Lead-Alloy Fast Reactor Balance-of-Plant Options," Nuclear Technology, 147 (2004) 388-405. 
Drobyshev, 1969. A. V. Drobyshev, V. A. Kurov, and I. T. Filipov, "Some Problems of Operation and Design of Liquid-Metal Loops," in P. L. Kirillov, V. I. Subbotin, and P. A. Ushakov, editors, Liquid Metals, NASA TT F-522, National Aeronautics and Space Administration Technical Translation series, Washington DC, May 1969.

Argonne National Laboratory, 1991. Experimental Breeder Reactor-II (EBR-II) Level 1 Probabilistic Risk Assessment, Final Draft, EBR-II PRA Revision 2, Argonne National Laboratory, June 1991.

Eide, 1990. S. A. Eide, S. V. Chmielewski, and T. D. Swantz, Generic Component Failure Data Base for Light Water and Liquid Sodium Reactor PRAs, EGG-SSRE-8875, Idaho National Engineering Laboratory, February 1990.

Eide, 1991. S. A. Eide, S. T. Khericha, M. B. Calley, D. A. Johnson, and M. L. Marteeny, Component External Leakage and Rupture Frequency Estimates, EGG-SSRE-9639, Idaho National Engineering Laboratory, November 1991.

Feuerstein, 1988. H. Feuerstein, H. Graebner, and G. Kieser, "TRITEX, a forced convection loop with Pb-17Li," Journal of Nuclear Materials, 155-157 (1988) 520-523.

Feuerstein, 1991. H. Feuerstein, H. Graebner, J. Oschinski, S. Horn, and S. Bender, "Evaporation of lead and lithium from molten $\mathrm{Pb}-17 \mathrm{Li}$-Transport of aerosols," Fusion Engineering and Design, 17 (1991) 203-207.

Feuerstein, 1992. H. Feuerstein, J. Oschinski, and S. Horn, "Behavior of Po-210 in molten Pb17Li," Journal of Nuclear Materials, 191-194 (1992) 288-291.

Feuerstein, 1999. H. Feuerstein, S. Horn, and G. Kieser, TRITEX, a ferritic steel loop with Pb15.8Li, Facility and Operation, FZKA-6286, Forschungszentrum Karlsruhe, May 1999.

Foletti, 2006. C. Foletti, G. Scaddozzo, M. Tarantino, A. Gessi, G. Bertacci, P. Agonstini, and G. Benamati, "ENEA experience in LBE technology," Journal of Nuclear Materials, 356 (2006) 264-272.

Glasbrenner, 2005. H. Glasbrenner, F. Groeschel, H. Grimmer, J. Patorski, M. Rohde, "Expansion of solidified lead bismuth eutectic," Journal of Nuclear Materials, 343 (2005) 341-348.

Gromov, 1999. B. F. Gromov, O. G. Grigoriev, A. V. Dedoul, G. I. Toshinsky, V. S. Stepanov, and L. B. Nikitin, "The Analysis of Operating Experience of Reactor Installations Using Lead-Bismuth Coolant and Accidents Happened," Proceedings of the Conference on Heavy Liquid Metal Coolants in Nuclear Technology, October 5-9, 1998, Obninsk, Russian Federation, published by the State Scientific Center of Russian Federation Institute for Physics and Power Engineering, 1999, Volume 1, pages 60-66.

ITER-JCT, 2001. Generic Site Safety Report, Volume VII, “Analysis of Reference Events,” ITER report G 84 r1 6 01-07-10 R 1.0, 2001, page 82.

Hejzlar, 2004. P. Hejzlar, J. Buongiorno, P. E. MacDonald, and N. E. Todreas, "Design Stratgey and Constraints for Medium-Power Lead-Alloy-Cooled Actinide Burners," Nuclear Technology, 147 (2004) 321-343. 
Hubberstey, 1992. P. Hubberstey, T. Sample, "Thermodynamic and experimental evaluation of the sensitivity of $\mathrm{Pb}-17 \mathrm{Li}$ breeder blankets to atmospheric contamination," Journal of Nuclear Materials, 191-194 (1992) 277-282.

IEEE, 1987, IEEE Recommended Practice for the Design and Installation of Electric Heat Tracing Systems for Nuclear Power Generating Systems, American National Standards Institute, ANSI/IEEE Std 622-1987.

Jeppson, 1985. D. W. Jeppson and L. D. Muhlestein, "Safety Considerations of Lithium Lead Alloy as a Fusion Reactor Breeding Material," Fusion Technology, 8 (1985) 1385-1391.

Jeppson, 1989. D. W. Jeppson, Summary of Lithium-Lead Alloy Safety Compatibility Tests, WHC-EP-0202, Westinghouse Hanford Company, 1989.

King, 1985. R. W. King, "Reliability and Extended Life Potential of EBR-II," CONF-850713-3, presented at the International Conference on Nuclear Power Plant Aging, Availability Factor, and Reliability Analysis, San Diego, CA, July 8-12, 1985, Argonne National Laboratory, 1985.

Koch, 1988. L. J. Koch, EBR-II, Experimental Breeder Reactor-II, an integrated experimental fast reactor nuclear power station, Argonne National Laboratory, 1988.

Malang, 1995. S. Malang and R. Mattas, "Comparison of lithium and the eutectic lead-lithium alloy, two candidate liquid metal breeder materials for self-cooled blankets," Fusion Engineering and Design, 27 (1995) 399-406.

McIntosh, 1994. A. C. McIntosh, M. Bains, W. Crocombie, and J. F. Griffiths, "Autoignition of Combustible Fluids in Porous Insulation Materials," Combustion and Flame, 99 (1994) 541-550.

Naus, 2006. D. J. Naus, The Effect of Elevated Temperature on Concrete Materials and Structures - A Literature Review, NUREG/CR-6900, ORNL/TA-2005/553, US Nuclear Regulatory Commission, March 2006, chapter 3.

Pinna, 2006. T. Pinna, Failure Mode and Effect Analysis for the European Helium Cooled Pebble Bed (HCBP) Test Blanket Module, FUS-TN-SA-SE-R-152, draft report, ENEA Frascati, October 2006.

Pinna, 2006a. T. Pinna, Failure Mode and Effect Analysis for the European Helium Cooled Lithium Lead (HCLL) Test Blanket Module, FUS-TN-SA-SE-R-155, draft report, ENEA Frascati, November 2006.

Smith, 1993. M. S. Smith, D. H. Wood, and J. D. Drischler, “An Assessment of Liquid-Metal Centrifugal Pumps at Three Fast Reactors," Nuclear Technology, 104 (1993) 118-127.

Spencer, 2000. B. W. Spencer, "The Rush to Heavy Liquid Metal Reactor Coolants-Gimmick or Reasoned," Proceedings of the $8^{\text {th }}$ International Conference on Nuclear Engineering (ICONE), paper 8729, Baltimore, MD, April 2-6, 2000. 
Walford, 1978. J. G. Walford, "Five Years Experience of the Operation of the Sodium Circuits of the Dounreay Prototype Fast Reactor (PFR)," NUCLEX 78, Construction and Operating Experience with Prototype-Plants of Fast Breeder and High Temperature Gas-Cooled Reactors, INIS-mf-4857V, GB7900116, 1978.

Wong, 2005. C. P. C. Wong, et al., Design Description Document for the U.S. Dual Coolant Pb17Li (DCLL) Test Blanket Module, report to the ITER Test Blanket Working Group $(T B W G)$, revision 3, GA-C25027, General Atomics, San Diego, CA, November 15, 2005. 


\section{PRELIMINARY FMEA ON U.S. DCLL TBM HELIUM COOLANT LOOP}

This FMEA on the TBM helium coolant loop investigated potential accident-initiating events with the TBM helium coolant loops, both the primary coolant to the TBM module box and the secondary helium coolant to the $\mathrm{Pb}-17 \mathrm{Li}$ loop. The helium coolant to the TBM module box is the primary cooling loop for the TBM, removing $54 \%$ of the total TBM energy at maximum operating levels. The FMEA results provide insights to the possible accident-initiating events that could occur with the TBM.

\subsection{TBM Helium Coolant System Description}

As noted in Section 2, helium coolant is used in separate channels from the $\mathrm{Pb}-17 \mathrm{Li}$ breeder-coolant that also cools the TBM module, giving the dual coolant concept. The helium coolant typically removes $54 \%$ of the heat from the module via a helium gas heat transfer flow loop and transfers the heat to the TCWS. If the Pb-17Li flow or coolant is lost, the helium can remove enough heat that the TBM can continue to operate without risk of overheat damage, but the reverse is not true- - losing helium cooling requires TBM shut down for safety (and ITER shutdown as well). The helium loop has tritium extraction, purification, and heat exchange to the TCWS. The helium loop schematic diagram is given in Figure 3-1. The helium flow loop volume is about $\approx 2.3 \mathrm{~m}^{3}$, the flow rate through the TBM piping is about $\approx 2 \mathrm{~m} / \mathrm{s}$ and $8 \mathrm{MPa}$, and the operating temperatures are $380^{\circ} \mathrm{C}$ minimum and $460^{\circ} \mathrm{C}$ maximum. A gas circulator drives the helium through the single-pass flow loop. Piping and components are to be constructed of RAFS and have $10-15 \mathrm{~cm}$ of thermal insulation to reduce heat radiation to the test port area.

The main components of the TBM first wall helium cooling loop are a heat exchanger, electrical heater, control valves, and pipework. The electrical heater is turned off during normal operations; it is used to raise the helium to the minimum design temperature. The helium purification system (HPS) is small diameter piping with control valves to control flow. The HPS takes a small fraction of the helium coolant as a bypass flow. The helium purification system removes tritium that might diffuse into the helium coolant. There are no filters in the bypass line (e.g., no dust filters like those used in graphite-moderated Magnox and advanced gas-cooled fission reactors) because there are no recognized sources of dust or other contaminants in the TBM flow loop. It is also noted that the Pb-17 $\mathrm{Li}$ coolant operates at a maximum of $2 \mathrm{MPa}$, so if a breach between the helium at $8 \mathrm{MPa}$ and the $\mathrm{Pb}-17 \mathrm{Li}$ occurred within the TBM module then helium would pressurize the liquid metal. The module box is built to withstand such a breach without loss of module integrity (Wong 2005). Any $8 \mathrm{MPa}$ helium breaching into the $2 \mathrm{MPa} \mathrm{Pb}$ 17Li will transmit pressure throughout the high temperature (highly fluid) $\mathrm{Pb}-17 \mathrm{Li}$ flow loop quickly, and the noble gas is expected to deposit itself in the headspace of the centrifugal pump casing or its expansion tank. The pressure increase in the $\mathrm{Pb}-17 \mathrm{Li}$ loop could actuate the $\mathrm{Pb}-17 \mathrm{Li}$ rupture disk to the drain tank. If the rupture disk opens, the system will depressurize into the drain tank. It is not clear how the helium system would respond to such a breach-the helium will initially depressurize into the drained $\mathrm{Pb}-17 \mathrm{Li}$ piping, but there is makeup helium available from the pressure control system. With the $\mathrm{Pb}-17 \mathrm{Li}$ drained, the $\mathrm{Pb}-17 \mathrm{Li}$ flow loop would de-energize and present a stagnant branch to the helium flow loop. In theory, the helium pressure control system could re-establish helium pressure and continue to cool the TBM module; however, the effects of the transient on the gas circulator (e.g., low pressure/overspeed trip?) and on the TBM box temperature transient during undercooling may require a shutdown. Otherwise, the helium pressure control system is used when evacuating the helium flow loop in preparation for long outages, for supplying makeup helium, and for system overpressure protection. 


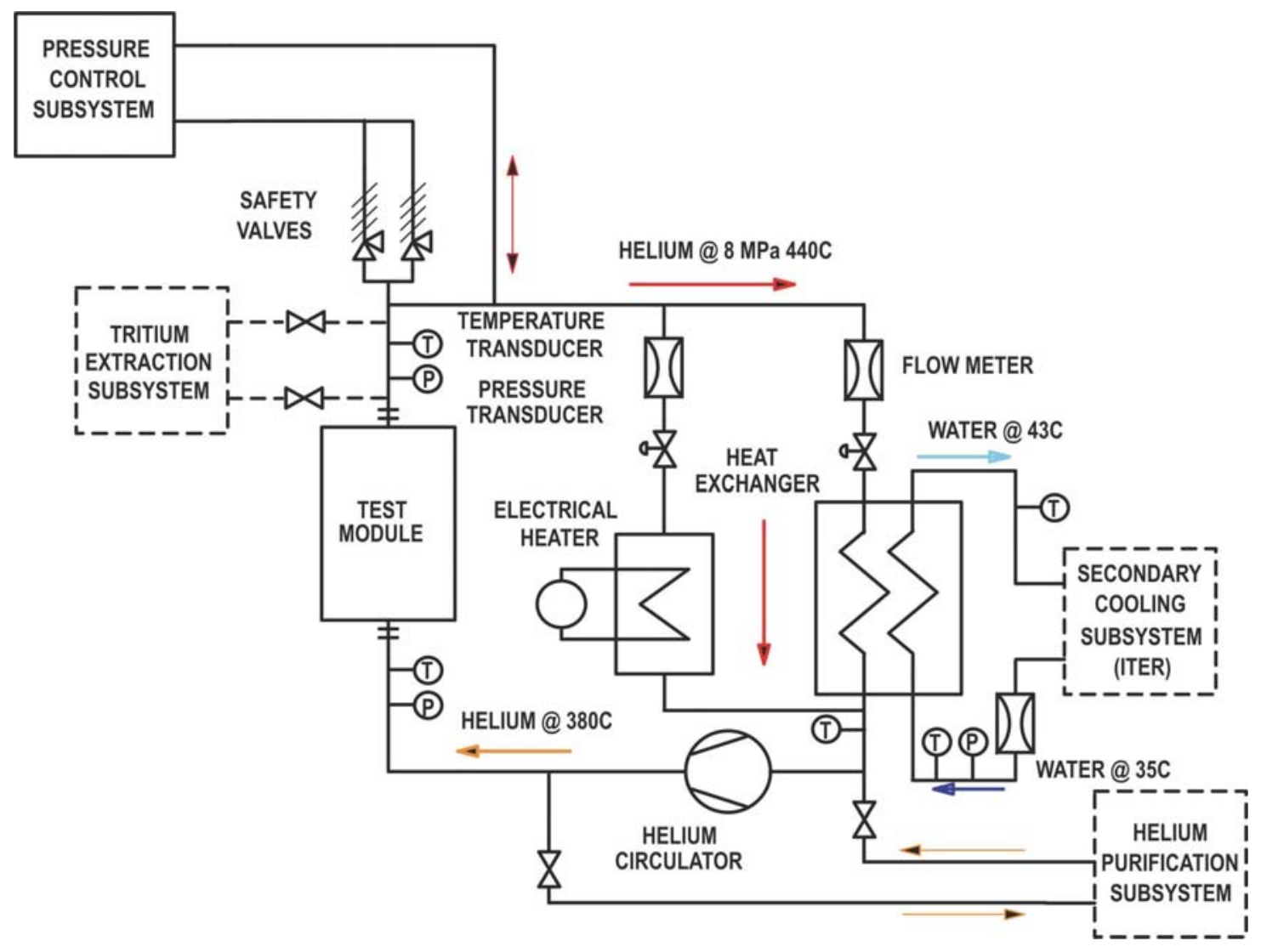

Figure 3-1. The helium flow loop of the U.S. DCLL TBM.

Note that nine helium storage, four helium dump, and one buffer tank(s) are not shown.

The helium coolant flows at $1.76 \mathrm{~kg} / \mathrm{s}$. The helium circulator, located on the cold leg of the flow loop, is encapsulated and uses a vertical shaft. The shaft bearings will either be gas lubricated or magnetic; this has not been decided thus far in the design. The design temperature of the circulator is $440^{\circ} \mathrm{C}$, with a higher maximum temperature to be determined. The circulator is rated for $8 \mathrm{MPa}$ plus a $10 \%$ margin for overpressure control. The circulator can deliver a total mass flow rate of $1.82 \mathrm{~kg} / \mathrm{s}$ at a head of $0.65 \mathrm{MPa}$ at rated (TBD) rpm speed, with $380^{\circ} \mathrm{C}$ at the nozzle outlet. The circulator speed and maximum allowable speed is to be determined. Circulator safety trips also need to be determined. The input power to the circulator drive motor is $295 \mathrm{~kW}$ (assuming a combined motor and circulator efficiency of 0.68 ). The circulator and motor dimensions are expected to be $1.54 \mathrm{~m}$ in diameter by $1.76 \mathrm{~m}$ in height. The gas circulator is expected to give heating power of $80 \mathrm{~kW}$ to the helium gas flowing through the unit.

The electrical heater in the helium flow loop is used to bakeout the TBM first wall at $375^{\circ} \mathrm{C}$ and to increase the temperature of the helium in the loop after complete cooldowns to room temperature. The heater has an electrical power of $170 \mathrm{~kW}$. That heat source and circulator heating will raise the helium temperature at a rate of $200^{\circ} \mathrm{C} /$ hour if uniform heating is assumed. The electrical heater is electrical resistance elements in tubes; the helium flows over the exterior of the set of tubes. The heating rod tubes occupy $18 \%$ of the heater unit, so the pressure drop in the heater is low, only $\approx 500 \mathrm{~Pa}$. 
The main pipework is $114.3 \mathrm{~mm}$ diameter with a wall thickness of $6 \mathrm{~mm}$. The helium flow velocity is between 37.6 and $41.1 \mathrm{~m} / \mathrm{s}$. The pipework length has been estimated to be $100 \mathrm{~m}$ for the hot leg and $95 \mathrm{~m}$ for the cold leg (Table 2.2.2-6 in the DDD gives $180 \mathrm{~m}$ [Wong 2005], but the larger values will be used for conservatism in this preliminary FMEA), with two U-bends for thermal expansion control. There are 44 elbows in the pipework, but these are not evident in Figure 3-1. The bypass line to the heater is about $4 \mathrm{~m}$ in length and is the same $114.3 \mathrm{~mm}$ diameter as the main pipe. The compressed helium volume is $\approx 2.3 \mathrm{~m}^{3}$ with a mass of $16.52 \mathrm{~kg}$.

Valves were minimized in the design to preclude friction pressure drop and to avoid inadvertent valve closure, which would mean a loss of flow. One valve is placed before the heat exchanger and one on the bypass to the electrical heater. These valves are position-controlled. The primary helium system has one heat exchanger, one circulator, one electric heater, nine helium storage tanks, four helium dump tanks, and one buffer tank. Despite this knowledge of the equipment available, the HPS and the pressure control system are not designed in detail at this time and are not treated in detail in this preliminary FMEA.

The secondary helium coolant flow loop is called the liquid-breeder-to-helium heat transport loop (LB). The LB removes heat from the $\mathrm{Pb}-17 \mathrm{Li}$ coolant in a heat exchanger and transfers the heat to the TCWS. The LB traverses about $70 \mathrm{~m}$ from the TBM to the TCWS vault. The LB helium enters the heat exchanger at $8 \mathrm{MPa}$ and $180^{\circ} \mathrm{C}$ and exits at $8 \mathrm{MPa}$ and $300^{\circ} \mathrm{C}$. That helium travels about $70 \mathrm{~m}$ to a water heat exchanger. The water enters at $35^{\circ} \mathrm{C}$ and exits at $70^{\circ} \mathrm{C}$ and less than $1 \mathrm{MPa}$. Because the water heat exchanger is housed in a different room and the helium pressure is much higher than the water pressure, there is no foreseen way to introduce large quantities of water to the helium or liquid metal loops. It is possible that a heat exchanger breach could allow helium to accept some traces of moisture in exchange through a breach location.

\subsection{TBM Operation}

At the end of the operating day and during outages, the helium cooling system will operate at reduced circulator speed to remove decay heat from the TBM module box. If the level of decay heat is low enough, natural circulation will remove the heat and save circulator operating costs. If the helium loop requires repairs, it is cooled and the helium is evacuated; the piping is then opened to air. Startup after repair requires drawing a vacuum to $100 \mathrm{~Pa}$ over 24 hours, then flooding with helium pressurized to $4.5 \mathrm{MPa}$ at $25^{\circ} \mathrm{C}$ and heating with the electric heater and the gas circulator turning at partial speed continues until the gas reaches $380^{\circ} \mathrm{C}$ within a few hours. A bakeout session is then conducted at the $380^{\circ} \mathrm{C}$ temperature with the gas cleanup system operating to remove atmospheric gases and the circulator running up to rated speed. With the temperature at $380^{\circ} \mathrm{C}$ and the pressure at $8 \pm 0.3 \mathrm{MPa}$, the subsystem is ready for operation.

As a first estimate for operational start/stop demands on the helium flow loop equipment, it is noted that the circulator will operate at reduced speed in a decay heat removal mode for the 14 idle hours on pulse days and it will also continue operating into each ITER maintenance shutdown until the decay heat decreases low enough that forced cooling is not needed. Therefore, there will be four operational start demands per year (not counting any maintenance-related test, or system operability test, starts) for the gas circulator. The TBM helium loop will start up and operate for the 35-day entire pulse campaign, then shut down for any maintenance or other servicing. It is expected that $\approx$ one week into a maintenance outage that the decay heat has reduced enough to no longer require active or natural circulation cooling by the helium loop. Therefore 35 days $\times 24 \mathrm{hr} /$ day $\times 4$ campaigns/yr +7 days cooling/outage $\times 24 \mathrm{hr} /$ day $\times$ 4 campaign outages/yr) $=4,032 \mathrm{hr} / \mathrm{yr}$. This value is used with the hourly failure rates to give 
frequency category estimates. For the LB secondary helium cooling loop, the liquid metal does not need to be cooled between pulse days; the assumed mode of operation is to turn the liquid metal pump at reduced speed and slowly circulate the $\mathrm{Pb}-17 \mathrm{Li}$ to keep it in liquid state. Therefore, the LB secondary helium circulator will be turned off each pulse day, so four campaigns per year, 35 days per campaign gives 140 operational starts and stops per year.

As stated previously, the pressure control subsystem is not well defined at this time. There is flow in this system, and the helium flow is cleaned of tritium and particulate. However, the system details are yet to be determined. The pressure control system will not be treated in detail in this preliminary FMEA.

The thermal insulation on the pipe and tank walls is not specified or described well, but the peak insulation surface temperature is given as $68^{\circ} \mathrm{C}$ (Wong 2005, Table 2.2.2-8). This value suggests that the port room will be an exclusion area for industrial safety reasons as well as radiological reasons because the upper bound surface temperature that humans can accommodate is $\approx 40^{\circ} \mathrm{C}$ without protective equipment (e.g., gloves) (Bernard 1993) and $68^{\circ} \mathrm{C}$ heat in a $30^{\circ} \mathrm{C}$ room indicates very short stay times from a personnel heat stress perspective (Bongarra 1985).

\subsection{Design Information of Interest}

It is noted that Section 841.126 of the American Society of Mechanical Engineers (ASME) gas transmission and distribution piping code B31.8 states that gas velocity should not exceed $100 \mathrm{ft} / \mathrm{s}(30.5 \mathrm{~m} / \mathrm{s})$ at peak conditions and that lower velocity values are recommended for natural gas transmission and distribution (ASME 2003). High gas velocities in piping increase turbulence and pressure drop and high velocity contributes to excessive sound pressure levels (aerodynamic noise), which can cause internal pipe wall erosion. Section 841.125 states that upstream dry gas filters should be considered by designers for rotary or turbine flow meters. Particulates and pipe dust can contaminate meter lube oil and other internal meter components. Section 841.127 states that conical reducers downstream of the pressure regulator or control valve will allow more graded expansion of gas to larger piping and reduce turbulence and pressure drop during gas expansion. The National Fire Protection Association (NFPA), Standard 54, National Fuel Gas Code, states that fuel gases shall have at least schedule 40 piping and shall be welded joints if the system is operating at pressure above 5 psig (NFPA 2006).

Several sources were reviewed to determine if any electrical grounding or bonding were needed for the helium gas system, particularly for reducing any chance of corrosion in the piping due to impurity gases being present in the system. Non-cryogenic gas piping system design does not address bonding or grounding. NFPA 54 states that gas system piping likely to become energized shall be grounded, but this system is not viewed as a metal pipe system that is likely to become electrically energized.

Another point to note is that the U.S. Code of Federal Regulations, 29CFR1910.103, discusses gas system design. Gas system components that could affect personnel safety must be designed to the ASME Boiler \& Pressure Vessel Code Section VIII or ASME B31.1 piping code. Shah (2003) noted that these codes do not address all of the materials useful to high-temperature helium design or the highest temperature regimes of operation. Nonetheless, the designers should consider the safety factors specified in these design codes. 


\subsection{Related Operating Experiences Supporting the FMEA}

The literature was searched for any helium operating experiences. The most applicable experiences located were those of the helium-cooled fission reactors, even though many of these reactor plants operated many years ago. The first plant discussed is the Dragon Project, a $20 \mathrm{MW}$ thermal plant in the UK (Gray 1969). The Dragon Project had a helium release design goal of $0.1 \%$ of the helium primary coolant inventory per day, based on allowable leakage carrying radioactive products from the fission fuel (e.g., tritium, krypton and xenon isotopes, etc.) rather than cost of helium gas. When the fuel proved to be more leaktight than anticipated, the helium leakage value was judged on cost rather than fission product release. Dragon operating experience demonstrated that they could operate at a leak rate of $0.046 \%$ /day, easily remaining within the $0.1 \%$ /day value over prolonged operating times. Continuous mass spectrometry of the containment building atmosphere gave early verification of helium leaks and could detect down to $8 \mathrm{grams} / \mathrm{hr}$ of helium leakage $(0.01 \% /$ day $)$. Great care was taken to keep the Dragon helium coolant pure; purging, evacuation, and hot testing helped reduce water and condensable organic compounds. Hygrometers measured water vapor and hydrogen, while gas chromatographs measured other gas concentrations in volume parts per million (vppm). Typical impurities were: $\mathrm{CO}-1 \mathrm{vppm}, \mathrm{CO}_{2}-0.5 \mathrm{vppm}, \mathrm{H}_{2} \mathrm{O}-0.5 \mathrm{vppm}, \mathrm{H}_{2}-1.5 \mathrm{vppm}$, and $\mathrm{CH}_{4}-1 \mathrm{vppm}$. Some of these impurities arose due to fission fuel and graphite, but water vapor is certainly an issue for the TBM to address. The purification system generally acted rapidly to reduce impurities. The purification system had a total cleanup time constant of $0.66 / \mathrm{hr}$. Some of the Dragon valves showed sticking behavior of metal-metal seats when they were opened after remaining closed for long periods of time. The valves exhibiting sticking phenomena were modified so the motor operators would deliver a shock when opening to break the metal-metal contact and there were no problems afterward. There were 250 motor-operated valves in the helium purification systems, but only one failed (and required replacement) in 3 years of plant operations. (Note: this is a $1.5 \mathrm{E}-07 /$ hour 'failure to operate' failure rate for these valves.) The helium circulators operated well; only one 100-hp unit suffered a gas bearing failure in an aggregate 180,000 operating hours. Three of the six 100-hp circulators were overhauled (stripped and rebalanced) in the first 3 years; loose contamination was slight and easily swabbed. The helium to water heat exchangers suffered some tube leaks that were severe enough to prompt replacement of all six heat exchangers after $\approx$ 3 years of operation. The dose rates generated by fission products $(\mathrm{Cr}-51, \mathrm{Mn}-54, \mathrm{Fe}-59$, etc.) at $1 \mathrm{ft}$ from the heat exchangers were $32 \mathrm{mrem} / \mathrm{hr}$ gamma and $30 \mathrm{mrem} / \mathrm{hr}$ beta, and the entire job of six units being replaced spanned 30 days. Gray also noted that Dragon helium coolant had "nonideality," meaning that the ideal gas equation prediction was higher than the actual helium density. At 100 atmospheres pressure the helium density was $10 \%$ below the ideal gas density, and at the operating pressure of 20 atmospheres the helium density was $1 \%$ below ideal gas density. The Dragon also had three purification systems: one for the primary helium coolant, one for gas flow purge directly from the fuel, and one spare system.

The Peach Bottom Unit 1 reactor, a 115 MW-thermal plant, also reported some operating experiences. The piping and gas circulators worked well, but the helium-to-water superheat steam generator tubes suffered from chloride stress corrosion cracking. Hygrometers were used on the helium system to sense moisture intrusion. The main source of moisture was from steam generator tube leakage. Electrolytic hygrometers were used, but these units had short functional life spans that necessitated frequent changeouts, so personnel maintenance time and personnel radiological exposure were both large for these monitors. The plant staff recommended infrared or optical detectors rather than electrolytic units.

It is noted that the Dragon reactor, Peach Bottom, and the Arbeitsgemeinschaft

Versuchreaktor (AVR) (the working group research reactor) plant all described their system leak 
rates. Gray (1969) stated that the $20 \mathrm{MW}$ Dragon reactor had a design goal leak rate of $0.1 \%$ of the primary system helium inventory per day at the operating pressure of 20 atmospheres. In practice, Capp (1976) stated that the actual leak rate could reach about $0.12 \%$ per day (about $0.2 \mathrm{~kg}$ /day from the $\approx 180 \mathrm{~kg}$ helium inventory in the primary system [Capp 1976]). Another $\approx 1$ $\mathrm{kg}$ was taken from the Dragon reactor per day to sample the helium for various activated products and impurities. Green (1969) stated that the $115 \mathrm{MW}$ Peach Bottom plant operated at about 23 atmospheres and had a design leak rate goal of $0.09 \mathrm{~kg}$ /day (this was probably a $0.01 \%$ leak rate per day for a $\approx 900 \mathrm{~kg}$-helium inventory) but in actuality leaked up to $2.7 \mathrm{~kg} / \mathrm{day}$ or $0.3 \% /$ day. Cautius (1969) stated that the $46 \mathrm{MW}$-thermal AVR plant operated at 10.8 atmospheres, and leaked on average one complete helium charge (one primary coolant inventory) of 4,000 cubic meters STP $(\approx 715 \mathrm{~kg}$ helium) per year. That is a leak rate of $0.27 \%$ or $1.96 \mathrm{~kg}$ per day. Shaft penetrations were an issue, and flanges that had to be opened and resealed were another issue.

The Fort St. Vrain plant was a large helium-cooled reactor of 824 MW and 330 MWelectric, this plant had a technical specification overall allowable leak rate of $880 \mathrm{~kg} /$ day. Metallic pressure boundaries in the concrete vessel did not leak, but valve shaft seals gave more than their allocated allowable leak rate. The conventional valve stem packing was replaced with Teflon and metal rings that lowered the leak rate to less than the allocated allowable value. The reciprocating piston helium compressors had major maintenance problems despite design for helium service (Simon 1992). Additionally, Fort St. Vrain had trouble with moisture monitors that required frequent maintenance. Fort St. Vrain also had a few other operating experience suggestions, namely, to use copper oxide beds instead of titanium sponge beds for hydrogen removal from the helium and to use magnetic bearings rather than water-cooled bearings in gas circulators - this would make auxiliary systems to gas circulators simpler (auxiliaries were high failure rate items at this plant) and prevent moisture ingress into the helium coolant (Fuller 1989). Copinger (2004) had some other operating experience data on Fort St. Vrain. The helium purification system must have good moisture removal or the moisture will freeze and plug the cold charcoal beds that capture noble gases. Perhaps ITER TBM coolant will not have any concern about noble gas cleansing, but moisture in a system is problematic for corrosion as well as plugging cryogenic purification units. Other issues with Fort St. Vrain included moisture intrusion from water-cooled bearings on the gas circulators. This must be precluded in the TBM design, perhaps by using either gas-cooled or magnetic bearings.

The High Temperature Engineering Test Reactor (HTTR) in Japan is a helium-cooled high temperature $\left(850\right.$ to $\left.950^{\circ} \mathrm{C}\right)$ reactor presently in operation. This reactor has set goals for helium coolant purity (Sakaba 2004) during operation:

$\begin{array}{ll}\text { Impurity } & \text { Concentration (ppm) } \\ \text { Hydrogen } & 3 \\ \text { Carbon monoxide } & 3 \\ \text { Water vapor } & 0.2 \\ \text { Carbon dioxide } & 0.6 \\ \text { Methane } & 0.5 \\ \text { Nitrogen } & 0.2 \\ \text { Oxygen } & 0.04\end{array}$

The HTTR uses a pre-charcoal trap, an inlet heater, two copper oxide fixed beds, gas coolers, two molecular sieve traps, two cold charcoal traps, and small gas circulators to cleanse the helium gas. Dual units provide the ability to regenerate or service equipment while the system remains on line. The purification system has a $200 \mathrm{~kg} / \mathrm{h}$ flow rate and processes $>10 \%$ of the 
primary coolant inventory each hour. The copper oxide catalyst bed oxidizes hydrogen to water vapor and carbon monoxide to carbon dioxide. The molecular sieve traps water vapor and carbon dioxide. The cold charcoal trap at $-195^{\circ} \mathrm{C}$ adsorbs oxygen and nitrogen (i.e., air), methane, and noble gases. The charcoal trap only flows $50 \mathrm{~kg} / \mathrm{h}$ and bypasses the rest of the helium gas in the purification flow stream. The HTTR has concerns for fission product noble gases (krypton and xenon); these are held on the cold trap for about 50 days and then are sent to the gaseous radwaste treatment system. The HTTR removed about $0.75 \mathrm{~kg}$ of water from the primary system during commissioning tests. Most of the initial impurities were traced to the graphite in the fission reactor core, the heat insulator in the gas duct, and original impurities in the helium gas supply. The HTTR helium coolant is supplied from gas storage tanks. It is noted that other gas-cooled reactors (e.g., the carbon dioxide-cooled Magnox and Advanced Gas Reactor plants) used cryogenic gas supply for enhanced gas purity (Poulter 1963).

\subsection{FMEA Failure Rate Data}

There is no database, similar to the liquid metal CREDO database, for gas components and no compilation of component failure rate data from past helium-cooled fission reactors such as the Peach Bottom and Fort St. Vrain units, nor from the German AVR and Thorium High Ttemperature Reactor (THTR) plants. The newest plants, the Japanese HTTR and Chinese HTR10 , have only operated for about 4 to 8 years - that amount of time may not be adequate to give matured failure rates for small numbers of components in these small reactor plants. The Helium Loop Karlsruhe (HELOKA) is planned to test helium cooling loops and generate reliability data for ITER TBM usage (Ghidersa 2006). At present, the component failure rate data used in this FMEA came from several sources on gas system components. Some data arose from non-nuclear gas applications and some data came from gas systems in use in nuclear and radiological facilities at the Savannah River Site in the U.S. The best available data were used, but these data are generic and are in no way specific to the TBM application. The data sources used here included some sparse helium-cooled and carbon dioxide-cooled fission reactor data (Hannaman 1978), compressed gas system data (Blanton 1993), and some inferred data were taken from water reactor data reports (NUREG 2007). While these coolants are dissimilar, the water-cooled fission reactors do have a wide body of data to draw from. There are a few helium component data values reported in the literature (for example, Bittermann 1977; Solomon 1975) but these are scattered data of unknown origin; the data may or may not come from helium system operating experiences. Component sizes vary widely from the small TBM to the larger power plant scale, but given the sparse data the values were applied to the smaller equipment. The data cited in the preliminary FMEA tables are considered to be the most representative data available at this time to apply to TBM components. Data verification efforts are described below.

To test validity of the data cited in the FMEA, a literature review was performed to identify any gas system component failure rate data generated by operating experiences. One of the most recent documents (Chamberlin 2005) described that compressed natural gas-specific hardware failure rate data would be needed for more detailed quantitative work; for their task the authors used military and chemical industry published data and compiled natural gas vehicle fleet operations experience data to quantify their fire risk fault trees and event trees. Their statement indicates that there is not a recognized source gas system component failure rates. Data from gas system operating experiences were sought in the literature; few reports were found. The author believes the sparse number of data sets is due to the lack of a regulatory mandate to collect and analyze the data. If companies collect data for their own purposes (such as - maintenance planning, spare parts procurement, facility life cycle planning, etc.), then these data are not reaching publication. Some literature that suggested great promise of failure rate data was actually tutorial in nature and contained no data (Wilcox 2001) or the data was expert judgment 
used to determine overall system function, and was not experience-based failure rate data (Deleris 2006). Of the few studies actual failure rate data, two were from Nederlandse Gasunie (Bosman 1985; Lammerse 1985) the Holland natural gas distribution and retail sales company, and two were from Italgas data sets (Piccininni 1988; Scarrone 1989). The components used in natural gas distribution are much, much larger than those in the TBM flow loop, and distribution piping has the additional environment concerns of weather (lightning, wind, ice, etc.), buried pipe corrosion and strikes from unauthorized digging or above-ground pipe concerns of vehicle impact and weather. Bosman gave a mean time to failure (MTTF) of 400 hours (or, 2.5E- $03 / \mathrm{h}$ ) for four large, de Laval reciprocating piston compressors, and he cited instrument, valve, and electrical component failure rates from the UK Atomic Energy Authority data sets from nuclear fission reactor operating experience data. Lammerse gave some data on a larger set of thirteen compressors, MTTF $=680.42 \mathrm{~h}$ (or, $1.5 \mathrm{E}-03 / \mathrm{h}$ ) and a mean time to repair of $6.7 \mathrm{~h}$. Shut-off valves for impulse lines were $2.4 \mathrm{E}-05 / \mathrm{h}$ and gas control valves were $2.7 \mathrm{E}-05 / \mathrm{h}$ as "all modes" failure rates. Temperature sensor-transmitter units were $8 \mathrm{E}-06 / \mathrm{h}$ and pressure transmitters were $2.5 \mathrm{E}-05 / \mathrm{h}$. These values are all greater than the values used in the FMEA tables in the appendix. This discrepancy is believed to be due to two main reasons. First, the Gasunie data is for much larger equipment in a more harsh environment, and sometimes the component designs are very different. Second, the Gasunie data values were reported for "all modes," so decomposition of the values into specific failure modes like those cited in the FMEA would bring the Gasunie data closer to agreement with the values used in the FMEA. The Italgas data was detailed, but treated many components important to gas sales but not used in the TBM gas flow loop-gas pressure regulators (not addressed yet in TBM design), gas monitoring regulators, 'slam-shut' isolation valves, diaphragm vent valves, gas filters, and water intrusion concerns. These data were in the $1 \mathrm{E}-05$ to $1 \mathrm{E}-07 / \mathrm{h}$ range for overall, "all modes" failure rates. The range of data values from the Italgas tables are in cursory agreement with the failure rates in the FMEA table in Appendix B.

Other gas system reliability data was sought. Labath (1986) used nuclear and general chemical industry data to quantify fault trees for a hydrogen sulfide storage plant, as did a 1980's landmark risk study of industrial plants (Risk 1982). Medhekar (1993) used a nuclear plant piping reliability prediction method to apply to liquid and gas products in chemical plants. Simion (1993) evaluated hydrogen cooling systems for generators in nuclear power plants, but used operations experience to give a hydrogen leak frequency with fire or explosion of $6 \mathrm{E}-03 /$ plantyear rather than model the pipework and cooling system components. More recently, Nelson (2007) used a combination of chemical industry and gas reactor-light water reactor data to quantify a hydrogen production plant risk assessment. Given these findings - the sparse data available is a fair comparison to the data used and that several studies have used nuclear power plant data to apply to gas systems, the data used are considered to be reasonable values at present. When more design information on TBM gas loop components is known the data will be revisited and vendors can also be asked to provide data rather than rely on generic data from handbooks and large plant operating experiences.

An important failure rate for this flow loop was the helium circulator failure to operate. It is recognized that the UK has the most experience with gas movers since they have operated a fleet of carbon dioxide-cooled fission reactors for decades. However, no recent information on gas circulator reliability was found in a literature search. An older paper by Cave (1977) gave some data about Magnox gas circulators (axial flow turbomachine units, vertical or horizontal, oil or gas cooled bearings, either steam turbine- or electric motor-driven). These units are large, in the 200 to $500 \mathrm{~kg} / \mathrm{s}$ flow range at 6 to 20 atmospheres pressure. The TBM unit is smaller, less flow (maximum of $1.82 \mathrm{~kg} / \mathrm{s}$ ) and higher pressure-but these fission experiences are the most applicable to estimate reliability of the TBM circulator. Cave (1977) gave 35 individual, electricdriven circulator failures to run at the Berkeley, Bradwell, Hinkley Point A, Trawsfynydd, and 
Sizewell Magnox and Advanced Gas Reactor (AGR) plants. There are 8 gas circulators per reactor (Loftness 1964) and the combined reactor operating time of 117 reactor-years gave 936 circulator-years, or a failure to operate of 3.7E-02/circulator-year. For these plants at that time, a reactor year was $\approx 75 \%$ of a calendar year or $\approx 6,600 \mathrm{~h} /$ year (Dixon 1974). Therefore a failure rate of $3.7 \mathrm{E}-02 /$ circulator-year gave $5.6 \mathrm{E}-06$ failures to run per circulator-hour. It is noted that most of these Magnox plants had two circulators per cooling circuit, so the loss of one unit was not a 'scram' event at most of these fission reactors if the operator could halt reverse gas flow after a circulator outage. There were no common cause failures in these reported failure events. As a comparison, the Japanese HTTR helium cooled fission test reactor had first criticality on November 10, 1998, but has not operated for full calendar years since then. The HTTR has 4 vertical gas circulators, three in the primary coolant system that flow at about $3 \mathrm{~kg} / \mathrm{s}$ at $4 \mathrm{MPa}$, 2,000 to $12,000 \mathrm{rpm}$, and another circulator is in the intermediate cooling loop. These units use gas bearings (Furusawa 2004). Recall that the TBM circulator is $1.76 \mathrm{~kg} / \mathrm{s}$ at $8 \mathrm{MPa}$. Data on HTTR circulator operating experience has not been found in the literature. One internet source noted a trip of one primary gas circulator on May 16, 2003 during plant startup (JAERI 2005). An electric part failed, it was replaced. Electric power parts are outside the component boundary of the circulator; that is, the circulator component itself is not accountable for failing to run if it lost electrical motive power. Assuming no failures of these four units (since no failures have been reported or described in the technical literature) and $\approx 25 \%$ availability of the HTTR (over 8 years of operations) in its lifetime (see JAERI 2002 for an HTTR schedule) gives an average, or $50 \%$, failure rate calculation of $\lambda=\chi^{2}(50 \%, 2 \mathrm{dof}) / 2 \mathrm{~T}$, where 'dof' is degrees of freedom for the chisquared distribution and $\mathrm{T}$ is the accumulated operating hours (equation from IAEA 1992). For zero failures (dof $=2$ ) the $50 \%$ chi-squared distribution tabulation is 1.39 , and the denominator is $2[(8$ years $)(8760 \mathrm{~h} / \mathrm{y})(0.25$ available $)(4$ units $)]$. Making the calculation, the average failure rate from these assumed data is $9.9 \mathrm{E}-06 /$ hour, which is a factor of 1.8 greater than the 117 reactoryear Magnox value. The short operating time HTTR value is reasonably close to the larger population Magnox value, if the reader uses the definition of failure rate good agreement being within a half-order of magnitude $(\sqrt{10}$, or a factor of 3.16). With this good agreement, a judgment is made to use the data with the most experience, since it is expected that as HTTR operates longer the circulator failure rate would decrease. Therefore, the TBM gas circulator 'failure to operate' failure rate is $5.6 \mathrm{E}-06 / \mathrm{h}$. The TBM helium circulator failing to run would be $1.7 \mathrm{E}-02 /$ year, which is a Category II event. This is a somewhat high frequency considering the consequences of loss of TBM helium flow. The TBM designers can either specify a highly reliable circulator that undergoes extensive testing and overhaul, or add a second, independent $100 \%$-flow unit to increase gas flow reliability. A few of the notable gas circulator events on Magnox reactors have been Rizk (1965) where a diffuser channel shell had failed due to fatigue cracking caused by an acoustic-aerodynamic forces. The higher harmonics of blade passing frequency gave excitation to circulator parts, fatiguing the diffusers and spokes. The circulators were redesigned with inlet vanes, flow straighteners, and diffuser channel supports. Gould (1987) discussed that a thrust bearing on a horizontal shaft, axial flow gas circulator at the Oldbury plant failed. The failed bearing allowed the circulator's rotating assembly moved back until the impeller made contact with the circulator diffuser and casing. The impeller rubbed severely before the circulator stopped rotating. The failure occurred in May 1983 and required replacement of the gas circulator unit. The Oldbury plant returned to operation in October 1984investigations, lead time to purchase a new unit, and repair/replacement activities required more than a year. As a comparison, the actual replacement activity took 45 days when the Fort St. Vrain plant replaced a helium circulator (Simon 1992). 


\subsection{TBM Preliminary FMEA Results}

The TBM helium flow loop FMEA covered the gas flow loop in normal, pulse operation. The TBM module itself was treated as a flow channel in this analysis. If needed, future work can expand the FMEA to cover other helium operating modes of the DCLL TBM design, e.g., bakeout.

- The preliminary FMEA on the helium flow loop is given in Appendix A. The main results were not surprising for this single-pass flow loop that cools a small section of the ITER blanket/first wall. There are, however, a number of single faults that result in TBM shutdown with consequent ITER shutdown. The ITER project may not wish to accept this additional unavailability arising from the TBM cooling circuit. Table 3-1 summarizes the PIEs from the FMEA results (the PIE format and definitions are given in Section 2). Only the events involving helium are considered in this FMEA.

Table 3-1. Helium loop FMEA results for postulated initiating events.

\begin{tabular}{|c|c|c|}
\hline PIE Family & FMEA Faults and Annual Frequency & Frequency Summation \\
\hline $\begin{array}{l}\text { LBP2-small } \\
\text { LOCA in port } \\
\text { cell }\end{array}$ & Pipe leaks, $8 \mathrm{E}-03 / \mathrm{yrr}$ & $\begin{array}{l}8 \mathrm{E}-03 / \mathrm{yr} \\
\text { Category III }\end{array}$ \\
\hline $\begin{array}{l}\text { LBP1-LOCA in } \\
\text { port cell }\end{array}$ & Pipe ruptures, $8 \mathrm{E}-04 / \mathrm{yrr}$ & $\begin{array}{l}8 \mathrm{E}-04 / \mathrm{yr} \\
\text { Category III }\end{array}$ \\
\hline $\begin{array}{l}\text { LBO3-heat } \\
\text { exchanger tube } \\
\text { faults }\end{array}$ & $\begin{array}{l}\text { Heat exchanger tube leak, } 0.04 / \mathrm{yr} \\
\text { Heat exchanger tube rupture, } 2 \mathrm{E}-03 / \mathrm{yr}\end{array}$ & $\begin{array}{l}0.042 / \mathrm{yr} \\
\text { Category II }\end{array}$ \\
\hline $\begin{array}{l}\text { LBO2-small } \\
\text { LOCA in TCWS } \\
\text { room }\end{array}$ & $\begin{array}{l}\text { System pipe leaks, } 7.1 \mathrm{E}-02 / \mathrm{yr} \\
\text { Pressure control pipe leaks, } 8 \mathrm{E}-03 / \mathrm{yr} \\
\text { Helium purification pipe leaks, } 8 \mathrm{E}-03 / \mathrm{yr} \\
\text { Relief valve leaks, } 8.4 \mathrm{E}-04 / \mathrm{yr} \\
\text { Valve leaks, } 8.4 \mathrm{E}-04 / \mathrm{yr}\end{array}$ & $\begin{array}{l}9.1 \mathrm{E}-02 / \mathrm{yr} \\
\text { Category II }\end{array}$ \\
\hline $\begin{array}{l}\text { LBO1-LOCA in } \\
\text { TCWS room }\end{array}$ & $\begin{array}{l}\text { Relief valve spurious open, } 8 \mathrm{E}-02 / \mathrm{yr} \\
\text { Relief valve internal rupture, } 4 \mathrm{E}-03 / \mathrm{yr} \\
\text { System pipe ruptures, } 2.4 \mathrm{E}-03 / \mathrm{yr} \\
\text { Relief valve external rupture, } 1 \mathrm{E}-04 / \mathrm{yr} \\
\text { Pressure control pipe ruptures, } \\
2.7 \mathrm{E}-04 / \mathrm{yr} \\
\text { Helium purification pipe ruptures, } \\
2.7 \mathrm{E}-04 / \mathrm{yr}\end{array}$ & $\begin{array}{l}8.7 \mathrm{E}-02 / \mathrm{yr} \\
\text { Category II }\end{array}$ \\
\hline $\begin{array}{l}\text { FB1-loss of } \\
\text { helium flow }\end{array}$ & $\begin{array}{l}\text { Valve failures, } 2.8 \mathrm{E}-02 / \mathrm{yr} \\
\text { Gas circulator faults, } 2.3 \mathrm{E}-02 / \mathrm{yr}\end{array}$ & $\begin{array}{l}5.1 \mathrm{E}-02 / \mathrm{yr} \\
\text { Category II } \\
\end{array}$ \\
\hline $\begin{array}{l}\text { HB1-loss of } \\
\text { heat sink }\end{array}$ & $\begin{array}{l}\text { Valve faults bypass } \mathrm{HX}, 9 \mathrm{E}-02 / \mathrm{yr} \\
\text { Pressure control system fails, } 1 \mathrm{E}-02 / \mathrm{yr} \\
\text { HX tube fouling, } 4 \mathrm{E}-02 / \mathrm{yr} \\
\text { HX tube plugging, } 4 \mathrm{E}-03 / \mathrm{yr} \\
\text { Secondary cooling system fails, } \\
1.2-03 / \mathrm{yr} \\
\text { Heater spurious actuation, } 1.2 \mathrm{E}-03 / \mathrm{yr}\end{array}$ & $\begin{array}{l}0.146 / y r \\
\text { Category II } \\
\text { (could be Category I) }\end{array}$ \\
\hline
\end{tabular}




\subsection{Notes from Similar FMEA Studies}

Pinna (2006) discussed an event where a water cooling line to the ITER first wall/blanket leaks or ruptures in the port cell and exposes the HCPB TBM cooling systems to a steam/water spray/humid air environment. The cooling systems to the ITER first wall and divertor are rated at: $125^{\circ} \mathrm{C}, 3 \mathrm{MPa}, 140 \mathrm{~m}^{3}$ water per cooling loop (GSSR 2001). Given an in-port LOCA, there are concerns about steam damage in the port cell. The outer surface of the insulation on the helium piping will be $68^{\circ} \mathrm{C}$, which is about half the temperature of the intruding steam. Heat transfer is expected to be slow through the pipe and tank insulation to the steam in the room. The effects of steam engulfment of motor-operated valves and the circulator motor are unknown. Certainly this equipment will be required to be operable in harsh environments (such as steam atmospheres) so that the TBM can be safely shut down in case of emergencies.

\subsection{Conclusions}

The helium coolant is the primary cooling system for the DCLL TBM. This preliminary FMEA has shown that there are many single-component faults that will cause the cooling system to give degraded or no cooling performance, thus requiring ITER to shut down to repair the TBM helium cooling loop. Such forced outages may not be tolerable from the ITER operations point of view, since the operators will be striving to maximize machine availability. Also, the frequencies of events are high. This is believed to be due to two factors, assumptions on piping lengths (assumed $600 \mathrm{~m}$ of piping in the helium pressure control and helium purification systems) and the existing component failure rate data. Even with overestimates of pipe length that could be a factor of 3 greater than actual, the resulting frequency Categories would not change. Regarding the failure rate values, the best data sources available were used and applied to this intermediate size system. The cooling system is not large like a power plant, and not small like a laboratory experiment, so the data values may not accurately represent the TBM components. Another factor is that the data sources used did not originate from helium system operating experiences. Certainly most of the helium-cooled power plants (AVR, THTR, HTTR, Peach Bottom) have operated better than these data values would indicate, but no data compilations are available from those fission experiences. The failure rate data used were compared to published natural gas distribution equipment failure rates. The component failure rate values used here were lower than those data, so the results are considered to be reasonable for present purposes.

Based on existing FMEA results, many individual component faults in the helium cooling system will cause the system to stop operating; many of the failures are so-called 'single failures' that will result in taking the TBM off-line and consequently taking ITER off-line. These faults do not necessarily result in radiological releases, but they do impact ITER availability. Based on these results, design consideration should be given to overdesigning some components to be as robust (highly reliable) as possible, performing rigorous maintenance schedules and postmaintenance tests, and considering use of redundant equipment for some components, e.g., gas circulator. 


\subsection{References}

ASME, 2003. Gas Transmission and Distribution Piping Systems, Code B31.8-2003.

Bernard, 1993. R. E. Bernard and M. F. Foley, "Upper acceptable surface temperature for prolonged hand contact," International Journal of Industrial Ergonomics, 11 (1993) 29-36.

Bittermann, 1977. D. Bittermann, J. Wehling, "Reliability Analysis of the Decay Heat Removal Systems of a 1000-MW(e) Gas-Cooled Fast Breeder Reactor," Nuclear Technology, 32 (1977) 247-256.

Blanton, 1993. C. H. Blanton and S. A. Eide, Savannah River Site Generic Data Base Development, WSRC-TR-93-262, Westinghouse Savannah River Company, Aiken, SC, June 30, 1993.

Bongarra, 1985. J. P. Bongarra, Jr. et al., Human Factors Design Guidelines for Maintainability of Department of Energy Nuclear Facilities, UCRL-15673, Lawrence Livermore National Laboratory, June 1985, section 3.2.4.5.

Bosman, 1985. M. Bosman, "Availability Analysis of a Natural Gas Compressor Plant," Reliability Engineering, 11 (1985) 13-26.

Capp, 1976. P. D. Capp and R. A. Simon, "Operational Experience with the Dragon Reactor Experiment of Relevance to Commercial Reactors," paper IAEA-SM-200/19, in GasCooled Reactors with Emphasis on Advanced Systems, IAEA, Vienna, 1976, pages 95-115.

Cautius, 1969. W. Cautius, H. J. Hantke, G. Ivens, and F. Schweiger, "Operational Experience with the AVR Reactor," paper IAEA-SM-111/20, in Advanced and High-Temperature Gas-Cooled Reactors, IAEA, Vienna, 1969, pages 37-50.

Chamberlin, 2005. S. Chamberlin and M. Modarres, "Compressed Natural Gas Bus Safety: A Quantitative Risk Assessment," Risk Analysis, 25 (2005) 377-387.

Copinger, 2004. D. A. Copinger and D. L. Moses, Fort Saint Vrain Gas Cooled Reactor Operational Experience, NUREG/CR-6839, U.S. Nuclear Regulatory Commission, January 2004.

Deleris, 2006. L. A. Deleris, G. L. Yeo, A. Seiver, M. E. Pate-Cornell, "Engineering Risk Analysis of a Hospital Oxygen Supply System," Medical Decision Making, 26 (2006) 162172.

Dixon, 1974. F. Dixon and H. K. Simons, "The Central Electricity Generating Board's nuclear power stations: a review of the first 10 years of Magnox reactor plant performance and reliability," British Nuclear Energy Society Journal, 13 (1974) 9-38.

FMD-97, 1997. Failure Mode/Mechanism Distributions, 1997, FMD-97, Reliability Analysis Center, Rome Laboratory, Rome, New York, December 1997, pages 2-236 to 2-237.

Fuller, 1989. C. H. Fuller, "Fort Saint Vrain Operational Experience," Technical Committee Meeting on Design Requirements, Operation and Maintenance of Gas-Cooled Reactors, San Diego, CA, September 21-23, 1988, published by the International Atomic Energy 
Agency International Working Group on Gas-Cooled Reactors, IWGGCR-19, IAEA, Vienna, Austria, 1989, pages 55-61.

Furusawa, 2004. T. Furusawa, M. Shinozaki, S. Hamamoto, Y. Oota, "Cooling system design and structural integrity evaluation," Nuclear Engineering and Design, 233 (2004) 113-124.

Ghidersa, 2006. B. E. Ghidersa, M. Ionescu-Bujor, and G. Janeschitz, "Helium Loop Karlsruhe (HELOKA): A valuable tool for testing and qualifying ITER components and their $\mathrm{He}$ cooling circuits," Fusion Engineering and Design, 81 (2006) 1471-1476.

Gould, 1987. A. W. Gould, "Gas circulator repairs," Proceedings of the Institution of Mechanical Engineers, 201A (1987) 215-222.

Gray, 1969. P. S. Gray and C. Watts, “Operating Experience with the Dragon Reactor," paper SM-111/66, in Advanced and High-Temperature Gas-Cooled Reactors, IAEA, Vienna, 1969, pages 3-19.

Green, 1969. R. W. Green and J. S. Kemper, "Significant Operating Experiences of the Peach Bottom Atomic Power Station," paper SM-111/74, in Advanced and High-Temperature Gas-Cooled Reactors, IAEA, Vienna, 1969, pages 21-36.

GSSR, 2001. Generic Site Safety Report, Volume VII, “Analysis of Reference Events,” ITER report G 84 r1 6 01-07-10 R 1.0, 2001, page 82.

Hannaman, 1978. G. W. Hannaman, GCR Reliability Data Bank Status Report, GA-A14839, General Atomic Company, San Diego, CA, July 1978.

IAEA, 1992. Manual on reliability data collection for research reactor PSAs, IAEA-TECDOC636, International Atomic Energy Agency, January 1992, chapter 9.

JAERI, 2002. Press Release "The HTTR Passes Pre-Operation Inspection," at the web site http://www.jaeri.go.jp/english/press/2002.html, Figure 3, 'Overall schedule of the HTTR project', visited March 12, 2007.

JAERI, 2005. Japan Atomic Energy Research Institute Annual Report: April 2004-May 2004, section 3 research on High Temperature Engineering, at the web site http://www.jaeri.go.jp/english/annual/2003e/html/chap03.html, visited March 12, 2007.

Labath, 1986. N. A. Labath, M. C. Real, A. J. Huespe, and M. J. Masera, "A Safety and Risk Assessment of a Hydrogen Sulphide Storage Plant Sited at the Boundary of a Nuclear Power Plant," Reliability Engineering, 14 (1986) 223-243.

Lammerse, 1985. H. Lammerse and M. Bosman, "Data of Gas Compressors and Instrumentation-Hard to Collect, Easy to Analyse," Reliability Engineering, 13 (1985) $65-78$.

Loftness, 1964. R. L. Loftness, Nuclear Power Plants: design, operating experience and economics, Van Nostrand Reinhold, New York, 1964, chapter 6. 
Medhekar, 1993. S. R. Medhekar, D. C. Bley, and W. C. Gekler, "Prediction of Vessel and Piping Failure Rates in Chemical Process Plants Using the Thomas Model," Process Safety Progress, 12 (1993) 123-126.

Nelson, 2007. P. F. Nelson, A. Flores, and J. L. Francois, "A design-phase PSA of a nuclearpowered hydrogen plant," Nuclear Engineering and Design, 237 (2007) 219-229.

NFPA, 2006. National Fuel Gas Code, Standard 54, US National Fire Protection Association, Qunicy, MA.

NUREG, 2007. Industry-Average Performance for Components and Initiating Events at U.S. Nuclear Power Plants, NUREG/CR-6928, U.S. Nuclear Regulatory Commission, February 2007.

Piccinini, 1989. N. Piccinini and M. Scarrone, "Availability of a Pressure Regulating Installation on a City Mains,” Reliability Engineering and System Safety, 20 (1989) 303-321.

Pinna, 2006. T. Pinna, Failure Mode and Effect Analysis for the European Helium Cooled Pebble Bed (HCBP) Test Blanket Module, FUS-TN-SA-SE-R-152, draft report, ENEA Frascati, October 2006.

Pinna, 2006a. T. Pinna, Failure Mode and Effect Analysis for the European Helium Cooled Lithium Lead (HCLL) Test Blanket Module, FUS-TN-SA-SE-R-155, draft report, ENEA Frascati, November 2006.

Poulter, 1963. D. R. Poulter, The Design of Gas-Cooled Graphite-Moderated Reactors, Oxford University Press, New York, 1963, chapter 8.

Risk, 1982. Risk Analysis of Six Potentially Hazardous Industrial Objects in the Rijnmond Area, a Pilot Study, a Report to the Rijnmond Public Authority, D. Reidel Publishing Company, Dordrecht, Holland, 1982, appendix IX.

Rizk, 1965. W. Rizk and D. F. Seymour, "Investigations into the Gas Circulator Failures at Hinkley Point," Nuclear Engineering, 10 (May 1965) 180-181.

Sakaba, 2004. N. Sakaba, T. Furusawa, T. Kawamoto, Y. Ishii, Y. Oota, "Short descriptions of other systems of the HTTR," Nuclear Engineering and Design, 233 (2004) 147-154.

Scarrone, 1989. M. Scarrone, N. Piccinini and C. Massobrio, "A reliability data bank for the natural gas distribution industry," Journal of Loss Prevention in the Process Industries, 2 (1989) 235-239.

Shah, 2003. V. N. Shah, S. Majumdar, and K. Natesan, Review and Assessment of Codes and Procedures for HTGR Components, NUREG/CR-6816, U.S. Nuclear Regulatory Commission, Washington, DC, June 2003.

Simion, 1993. G. P. Simion, R. L. Van Horn, C. L. Smith, K. D. Bulmahn, J. H. Bickel, and M. B. Sattison, Risk Analysis of Highly Combustible Gas Storage, Supply, and Distribution Systems in PWR Plants, NUREG/CR-5759, U.S. Nuclear Regulatory Commission, June 1993, page 38. 
Simon, 1992. W. A. Simon, A. J. Kennedy, and D. W. Warembourg, "The Fort St. Vrain Power Station Operating and Maintenance Experience," Proceedings of the $2^{\text {nd }}$ JAERI Symposium on HTGR Technologies, JAERI-M-92-215, October 21-23, 1992, Oarai, Japan, Japan Atomic Energy Institute, pages 255-268.

Solomon, 1975. K. A. Solomon, D. Okrent, W. E. Kastenberg, "HTGR Core Auxiliary Cooling System Availability and Reliability," Nuclear Engineering and Design, 34 (1975) 403-415.

Wilcox, 2001. R. Wilcox, M. Burrows, S. Ghosh, and B. M. Ayyub, "Risk-Based Technology Method for the Safety Assessment of Marine Compressed Natural Gas Fuel Systems," Marine Technology, 38 (2001) 193-207.

Wong, 2005. C. P. C. Wong, et al., Design Description Document for the U.S. Dual Coolant Pb17Li (DCLL) Test Blanket Module, report to the ITER Test Blanket Working Group $(T B W G)$, revision 3, GA-C25027, General Atomics, San Diego, CA, November 15, 2005. 


\section{PRELIMINARY FMEA ON U.S. DCLL TBM MODULE BOX}

The FMEA for the DCLL TBM module box investigated potential accident-initiating events with the TBM module box, which is part of the ITER first wall. The module box is cooled by both helium (primary coolant) and lithium-lead liquid metal (a tritium-breeding coolant). The helium primary coolant to the TBM module box removes $54 \%$ of the total TBM energy at maximum operating levels. The FMEA results provide insights to the possible accident-initiating events that could occur with the TBM. These events are referred to as PIEs in the ITER safety approach, and are component or human failures that place the facility in an off-normal condition. If redundant systems, backup systems, and/or safety systems function correctly, the ITER facility returns to a stable shutdown condition with no damage or releases. If there are additional failures, the accident event could result in small radiological releases to the environment and unintended machine downtime.

\subsection{TBM Module Box Description}

The module box is constructed of low activation ferritic steel. The module is mounted into a water cooled metal frame that supports the TBM module box in proper position. A stainless steel 316 shield plug (, i.e., a steel plate) is inserted behind the TBM module box for shielding and structural support. $\mathrm{Pb}-17 \mathrm{Li}$, the tritium-breeding coolant, flows at low speed poloidally through the TBM module box. Helium coolant is used throughout the TBM module box, including the first wall portion of the box. Helium flows in separate channels from the Pb-17Li breeder-coolant. The helium coolant typically removes $54 \%$ of the heat from the module via a helium gas heat transfer flow loop and transfers the heat to the TCWS. If the $\mathrm{Pb}-17 \mathrm{Li}$ flow or coolant is lost, the helium can remove enough heat that the TBM can continue to operate without risk of overheat damage, but the reverse is not true-losing helium cooling requires TBM shut down for safety (and ITER shutdown as well). The TBM module box is shown in Figures 4-1 through 4-6. The module box consists of 6 subassemblies. The module box sees helium flowing at $8 \mathrm{MPa}, 460^{\circ} \mathrm{C}$, and $65 \mathrm{~m} / \mathrm{s}$, and $\mathrm{Pb}-17 \mathrm{Li}$ at $2 \mathrm{MPa}, 340-460^{\circ} \mathrm{C}$, and $2 \mathrm{~m} / \mathrm{s}$. Helium flows in approximately square cross-section tubes, $4 \mathrm{~mm}$ wall thickness, $20 \mathrm{~mm}$ channel width and $19.25 \mathrm{~mm}$ channel depth. There are 80 of these square tubes stacked upon each other and bonded together to make the module box first wall. The total tubing distance is $(338 \mathrm{~mm}+645 \mathrm{~mm}+$ $338 \mathrm{~mm}) \times 80 \approx 105.7 \mathrm{~m}$. The length of bonding will be $(338 \mathrm{~mm}+645 \mathrm{~mm}+338 \mathrm{~mm}) \mathrm{x} 40 \approx$ $52.8 \mathrm{~m}$, to bond the top and bottom of each square tube and the top and bottom tubes to the module box.

The module box will be heated by flowing hot helium gas to bring its temperature up to operating temperature. An electric heat source warms the helium coolant in the TCWS vault room, and helium coolant circulator heating will also heat the helium. These heat sources will raise the helium temperature at a rate of $200^{\circ} \mathrm{C} /$ hour if uniform heating is assumed (Wong 2005). Due to heat transfer, the module box heating rate will be less than the helium coolant temperature ramp rate but would be a high value nonetheless.

It is possible that a helium-to-water heat exchanger breach could allow the high pressure helium coolant to accept some traces of moisture in a diffusion exchange process through a breach location despite the helium being operated at higher pressure than the water coolant. Fission reactor experience was examined to determine tolerable helium impurity levels from a corrosion perspective, some allowable ppm values were cited in Section 3. 


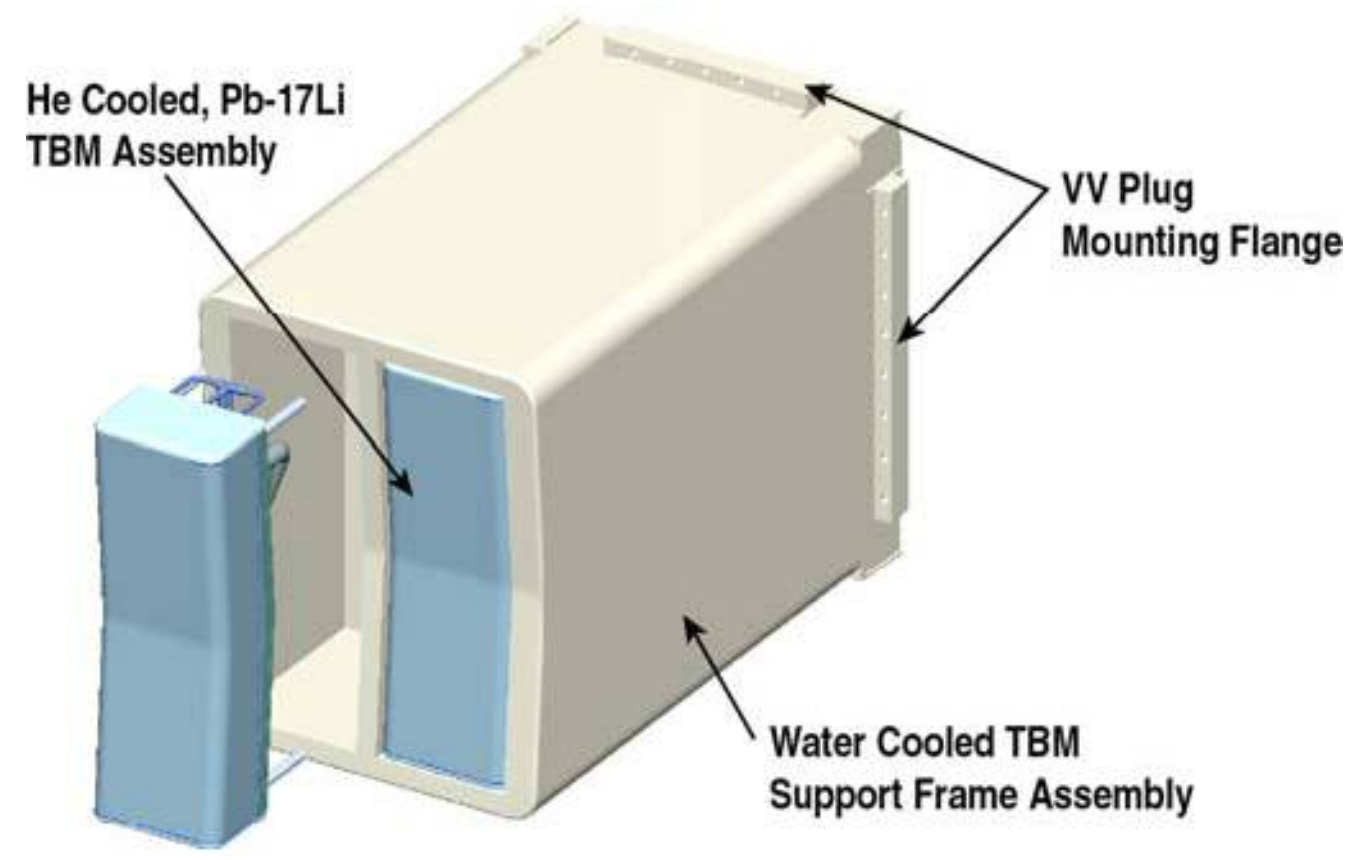

Figure 4-1. U.S. DCLL TBM module front view.

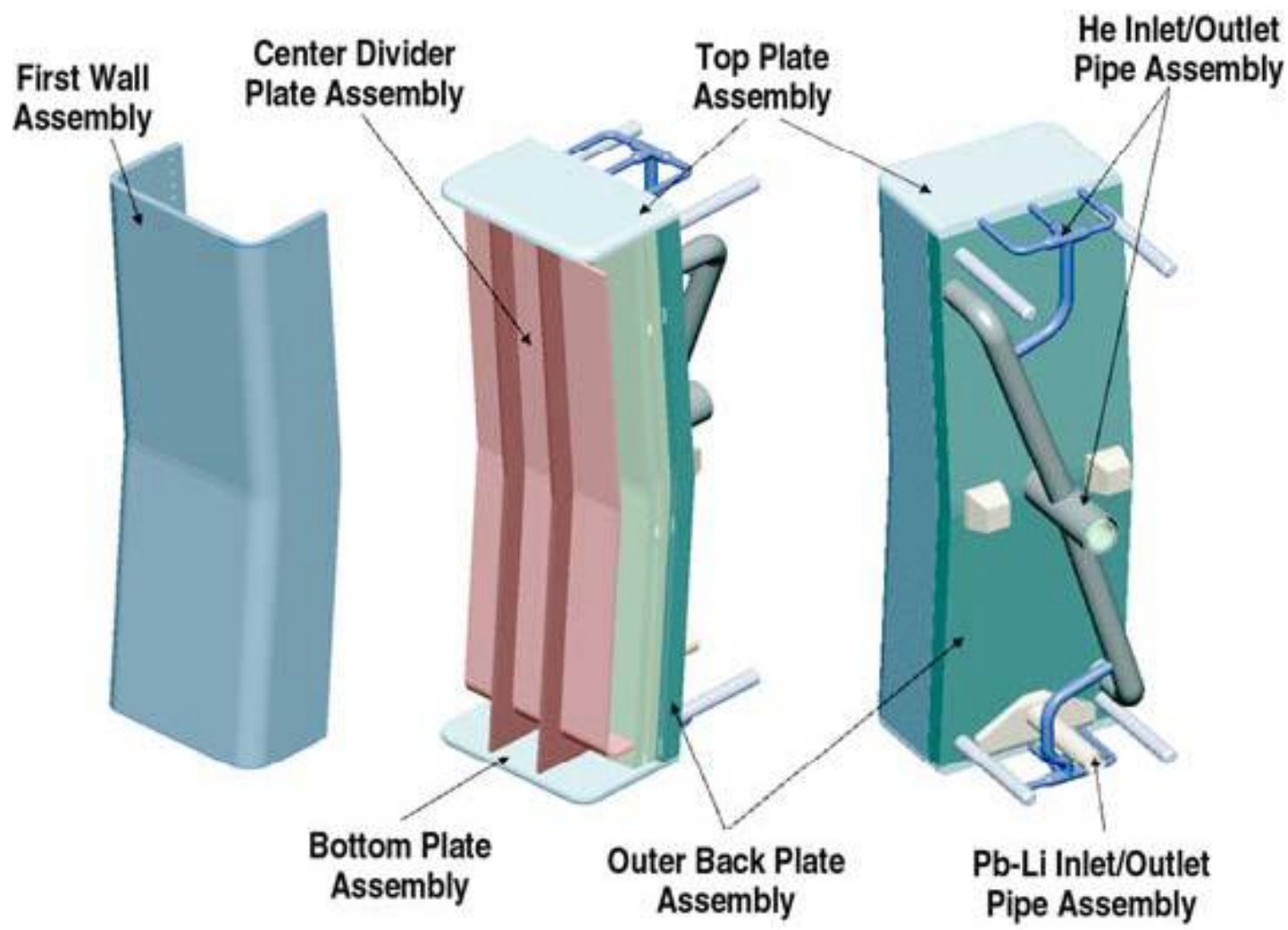

Figure 4-2. U.S. DCLL TBM module box exploded view. 


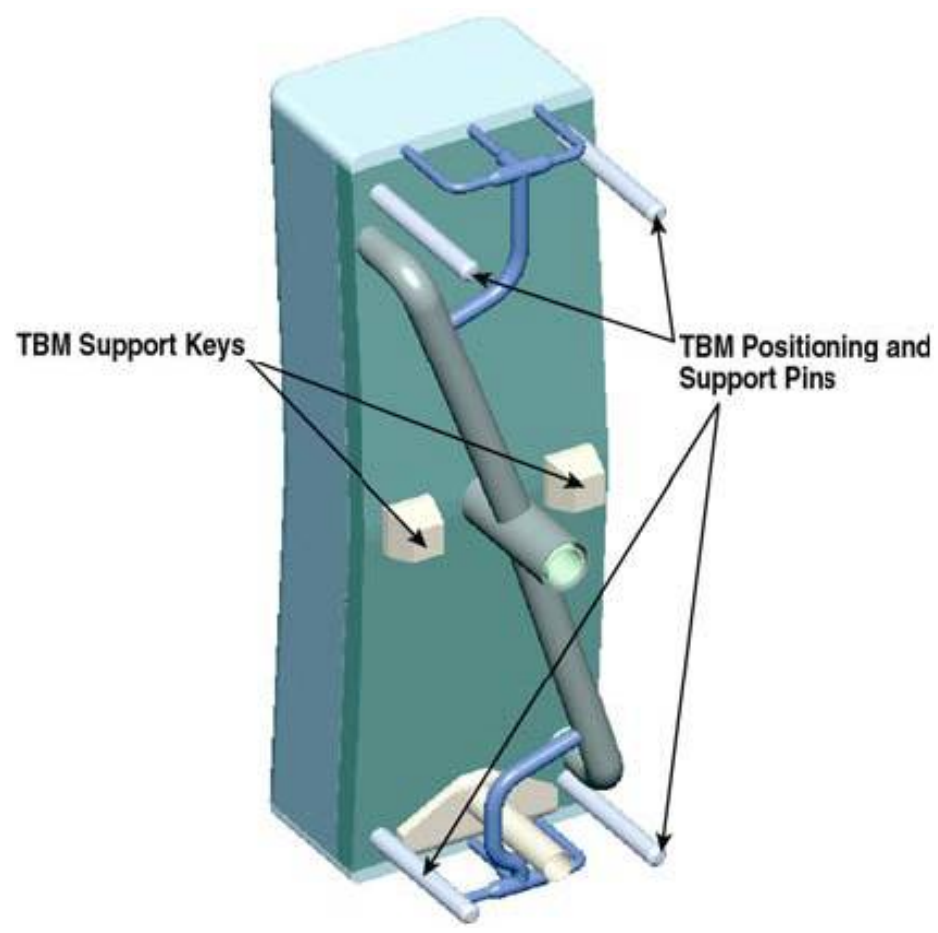

Figure 4-3. U.S. DCLL TBM module box rear view showing support elements.

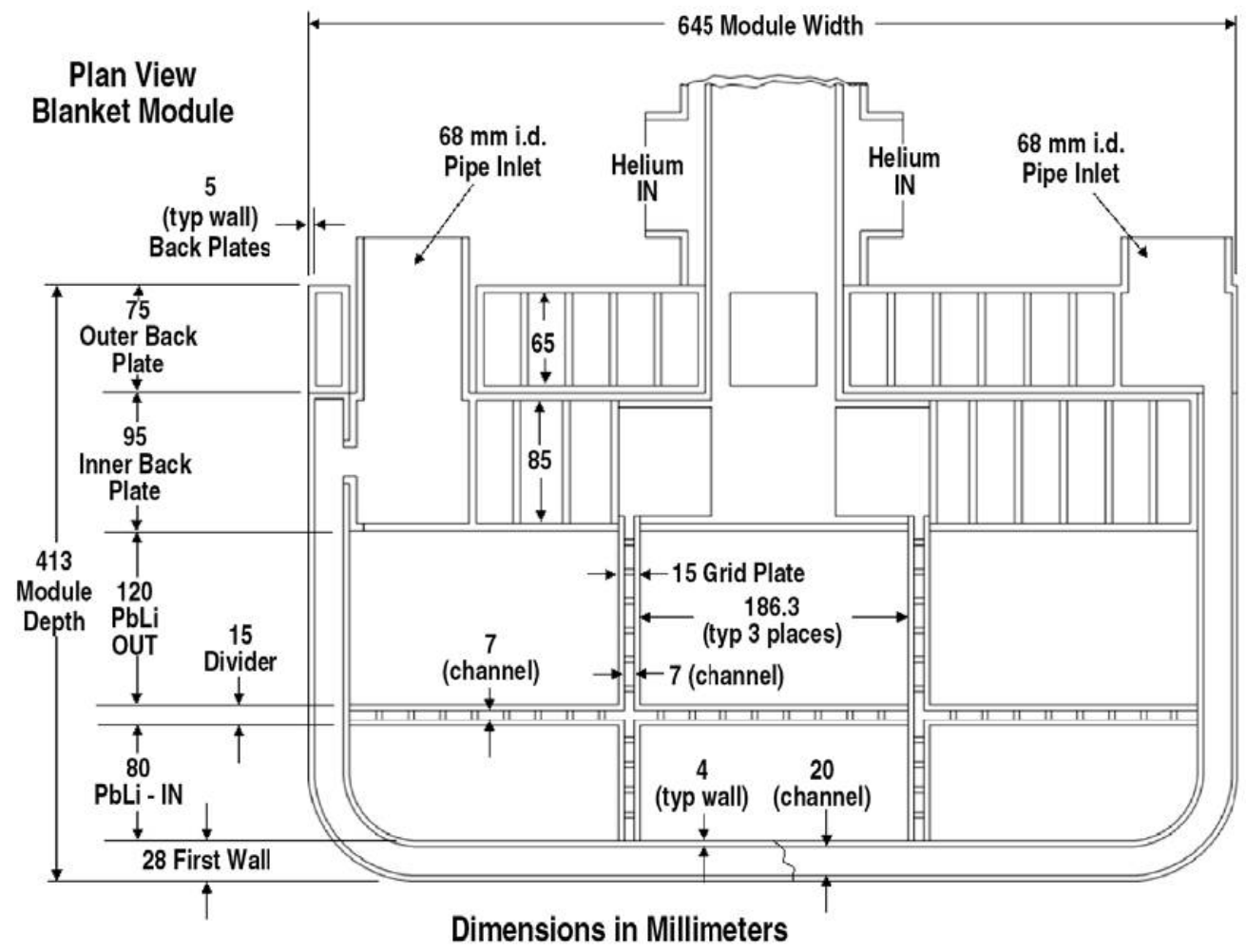

Figure 4-4. U.S. DCLL TBM module box plan view in cutaway. 


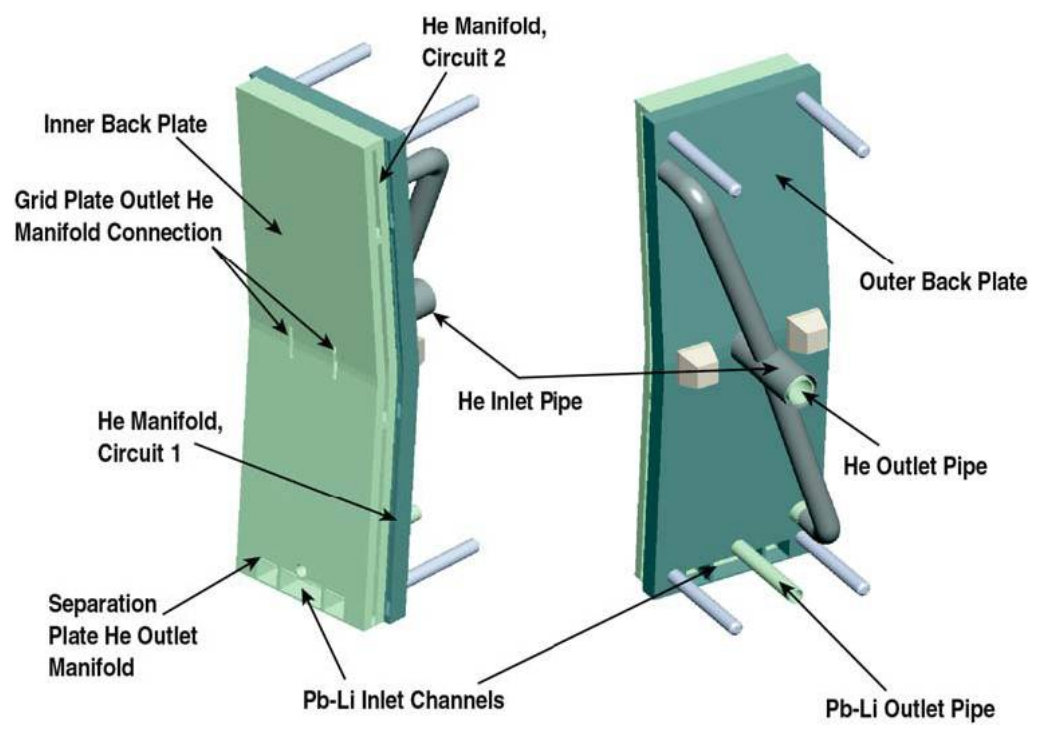

Figure 4-5. U.S. DCLL TBM module backplates and helium gas routing.

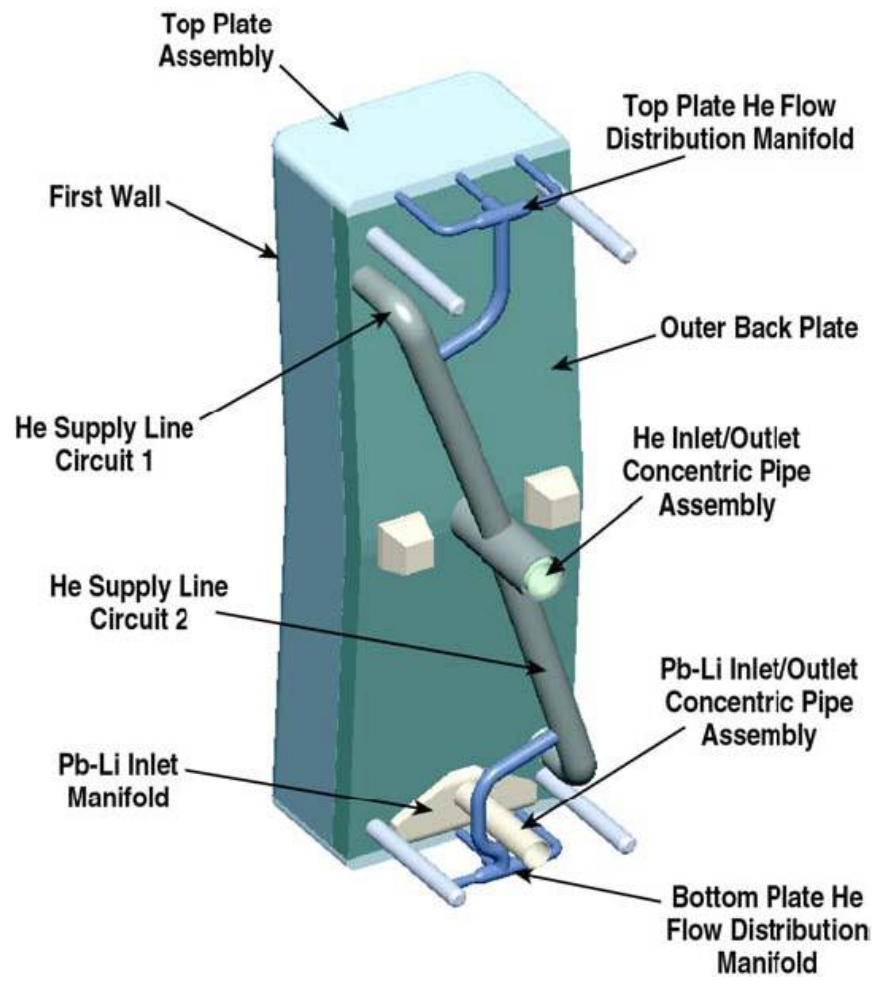

Figure 4-6. U.S. DCLL TBM module box rear view with helium manifolds. 
At the HTTR, the oxide species can be radiolytically decomposed. Such decomposition would pose concerns in the TBM box, so keeping their concentrations low is useful. Keeping oxygen and oxide concentrations low will prevent oxygen interaction with wall materials and reduce concerns about fouling or plugging. Thus far, HTTR operating experience is demonstrating that ppm levels are adequate to keep heat transfer surfaces clean, oxide buildup low, and material corrosion low.

\subsection{TBM Operation}

ITER plans to conduct 3,000 plasma pulses in a year. The dwell time between pulses is $\approx 2,000 \mathrm{~s}$. A typical pulse scenario is $100 \mathrm{~s}$ ramp up, $400 \mathrm{~s}$ pulse flat top, and $100 \mathrm{~s}$ ramp down to the dwell time. Thus, one pulse requires 43.3 minutes. ITER is also stated to have a $25 \%$ duty factor. GSSR volume IV, "Normal Operation," page 36, states that the planned ITER operation is a 35-day operating campaign with 10-hour pulse days, and 20-22 pulses performed per operating day. Each campaign will give $\approx 750$ pulses, with 4 campaigns per year ( 35 days of operation and 45 days of post-operation shutdown) and the last 3 months of the year is reserved for a long maintenance shutdown.

At the end of the operating day and during outages, only the helium cooling system will operate at reduced circulator speed to remove any decay heat from the TBM module box. If the level of decay heat is low enough, natural circulation will remove the heat and save circulator operating costs. If the helium loop requires repairs, it is cooled and the helium is evacuated, then the piping is opened to air. Thus, the module box will be exposed to an air atmosphere on rare occasions. Startup after repair requires drawing a vacuum to $100 \mathrm{~Pa}$ over 24 hours, then flooding with helium pressurized to $4.5 \mathrm{MPa}$ at $25^{\circ} \mathrm{C}$. The helium is heated with the electric heater and the gas circulator turning at partial speed until the gas reaches $380^{\circ} \mathrm{C}$ within a few hours. Then a bakeout session is conducted at the $380^{\circ} \mathrm{C}$ temperature with the gas cleanup system operating to remove atmospheric gases while the circulator runs up to rated speed. With the temperature at $380^{\circ} \mathrm{C}$ and the pressure at $8 \pm 0.3 \mathrm{MPa}$, the subsystem is ready for operation.

\subsection{Design Information of Interest}

In nuclear fission reactor Final Safety Analysis Reports, it is noted that the carbon steel or ferritic steel (clad with stainless steel overlay for corrosion resistance) has limits on allowable heatup and cooldown to keep thermal stresses manageable. For the Advanced Westinghouse 600 MW-electric pressurized water reactor (PWR) design (AP600), the maximum allowed heatup rate is $55.6^{\circ} \mathrm{C}$ /hour (100 F/hour) (Westinghouse 1992). The AP600 also gave a set of cooldown rates: $40,60,80$, and a maximum of $100 \mathrm{~F} /$ hour. Similar rates are also given for existing PWR plants, with a maximum heatup rate of $38.7^{\circ} \mathrm{C} /$ hour $(100 \mathrm{~F} /$ hour $)$, but with a staged cooldown rate of 620 $\mathrm{F}$ to $350 \mathrm{~F}$ in 4 hours $\left(\approx 20^{\circ} \mathrm{C} /\right.$ hour or $\approx 68 \mathrm{~F}$ /hour $)$ and then a slower $350 \mathrm{~F}$ to $140 \mathrm{~F}$ in 36 hours $\left(3.2^{\circ} \mathrm{C}\right.$ /hour or $5.8 \mathrm{~F} /$ hour $)$. This staged cooldown allows the PWR's Residual Heat Removal System to come on line at 4 hours after core shutdown for long-term reactor core fission product decay heat removal. The TBM does not have a reactor core of short- and long-lived fission products adding many $\mathrm{MW}$ of heat, so the $38^{\circ} \mathrm{C} /$ hour cooldown rate is likely to be acceptable down to ambient temperature when ITER shuts down. However, faster heatup or cooldown could create difficult-to-manage thermal stresses. Shah (2003) gives some design guidance for high temperature, helium-cooled fission reactors based on existing pressure vessel design codes that were meant to address light water fission reactors. That guidance for high temperature materials might prove useful to the TBM design community as well. 
Regarding reliability of the gas coolant channels, a similar application is found in rocket nozzle cooling. Spacecraft reusable rocket engines sometimes use integral, machined cooling channels or tubular (both square and circular) cooling channels on the rocket throat and nozzle. Cryogenic liquid hydrogen fuel is first pumped through these channels to cool down the nozzle materials and then the warmed fuel is routed to the nozzle throat to be burned for thrust. These channels have been susceptible to a phenomenon termed "thermal ratcheting". This is a failure mode where cycling cryogenic fuel as a coolant $\left(\mathrm{LH}_{2}\right.$ at $\left.-253^{\circ} \mathrm{C}\right)$ on one side of the channel wall and cycling the very hot combustion reaction products (about $540^{\circ} \mathrm{C}$ ) on the other side of the channel wall over many sessions (dozens of rocket engine operating cycles) causes the wall facing the hot side to begin to deform (Rapp 1993). This is a metal creep failure, a shape change while under stress and strain. The bulging wall has been referred to as 'tenting out' or 'doghouse failure mode' to signify the wall bulging outward toward the high heat flux and giving the appearance of a tent or roof. In some cases, the cooling channel wall deformed enough that it cracked and opened a through-wall breach. Jankovsky (1990) compared machined rocket nozzle channels to brazed tubes and found that the tubes had double the lifetime of channels. The stresses and strains in the tubing walls were 20 to $25 \%$ less than in channels. Fortunately, this failure mode is not expected to occur with the TBM cooling channels for several reasons. The TBM coolant is at elevated temperature (over $400^{\circ} \mathrm{C}$ ) rather than cryogenic temperature (so there is no large thermal gradient on the channel walls), TBM temperatures will remain elevated between plasma shots (less heatup-cooldown thermal stress over the module box lifetime), and rocket cooling lines are often fabricated of copper tubing or milled copper passages for high heat transfer while TBM channels will be fabricated from much stronger and more creep-resistant ferritic steel. The TBM channel wall, at $4 \mathrm{~mm}$, is also much thicker than rocket engine coolant channel walls at $0.89 \mathrm{~mm}$.

There are also irradiation issues of importance for the blanket box. Metals as a class of materials tend to have high thermal conductivity that dissipates radiation heating and avoids radiation heating damage. Metals also tend to have high electrical conductivity that tends to dissipate the effects of charged particles (ions and electrons). The primary concern with radiation damage in metals is displacement of atoms in the metal structure and transmutation effects that change the elements within the metal alloy. As low alloy steels are irradiated past $1 \mathrm{E}+18$ fast neutrons $/ \mathrm{cm}^{2}$, the ultimate tensile strength and yield strength slowly begin to increase; this also means the metal gets more brittle (Ma 1983). Finer grain structures tend to resist the effects of irradiation better than coarse grain steels. The TBM steel in question here also operates at over $400^{\circ} \mathrm{C}$, so there is some radiation damage 'healing' of the metal lattice through high temperature annealing. If ITER has a fast neutron flux of about $1 \mathrm{E}+13 \mathrm{n} / \mathrm{cm}^{2}-\mathrm{s}$ and the TBM lifetime is $3.6 \mathrm{E}+07 \mathrm{~s}\left(10,000\right.$ operating hours) (Wong 2005) then the irradiation damage at $3.6 \mathrm{E}+20 \mathrm{n} / \mathrm{cm}^{2}$ fast neutron fluence is reduced ductility, increased embrittlement, increased yield and tensile strengths. The $1 \mathrm{E}+20$ to $1 \mathrm{E}+22$ fast $\mathrm{n} / \mathrm{cm}^{2}$ range is a threshold level for irradiation effects $(\mathrm{Ma}$ 1983; Kircher 1964; Glasstone 1981). $3.6 \mathrm{E}+20 \mathrm{n} / \mathrm{cm}^{2}$ is at the low end of the irradiation effects range, so the radiation effects of strength change, and ductility change are expected to be mild over the TBM lifetime. Two other issues are swelling and creep. Swelling has been noted to not be significant in Eurofer and other low activation ferritic steels (Schaeublin 2002) and therefore is not expected to be significant for the short lifetime TBM module. Creep is not expected to be an issue for the TBM since the highest accelerating material creep only occurs under neutron irradiation in metals at over half their melting point and at high tensile stresses (Glasstone 1981). The TBM module box will typically operate at $\approx 460$ to $470^{\circ} \mathrm{C}$, and the Eurofer alloy has a melting temperature of $\approx 1500^{\circ} \mathrm{C}$, so the TBM operates at less than one third of the melting temperature. Fernandez (2005) stated that tests of Eurofer showed increased creep at aggressive test values $\left(>500^{\circ} \mathrm{C},>170 \mathrm{MPa}\right)$ over 9,000 hours of testing. Creep strength deteriorated at $500^{\circ} \mathrm{C}, 200 \mathrm{MPa}$, and 15,470 hours of testing. The TBM operates at close to this temperature, but 
at much lower stress and for less than 15,470 hours, so creep is not expected to be a reliability issue. The TBM module box can be changed out if necessary at less than 15,470 hours of operation. Evans (1992) pointed out that oxide dispersion strengthened alloys have good creep resistance at below $525^{\circ} \mathrm{C}$; the TBM module box will operate below this temperature.

\subsection{Related Operating Experiences Supporting the FMEA}

The literature was searched for any similar operating experiences that would help support judgments of module box reliability. The module box is rather unique - a combination of gas and liquid metal coolants, high temperature $\left(470^{\circ} \mathrm{C}\right)$ operation, a new, reduced activation alloy ferritic steel, hot isostatic press bonding, and silicon carbide usage as liner plates in the liquid metal flow channels. Some use of individual aspects of the TBM module box were found in the literature and are discussed in the failure rate data section below. The main promise of the TBM module box is that it consists solely of passive components, no active components like pumps, valves, etc. The cooling loop active components have been addressed in previous chapters.

\subsection{FMEA Failure Rate Data}

There is no database to draw from for the TBM module box components and parts. Nonetheless, an important concern is that without accurate failure rate data applied to the pieces and parts then the overall result will be a large value that is overly conservative (Cadwallader 1996). No published failure rate data on square cross section tubes were found in the literature search, and there are no readily available data on flat plates or manifolds in radiation and high temperature - the $\mathrm{Pb}-17 \mathrm{Li}$ will typically operate at 340 to $470^{\circ} \mathrm{C}$ but can ramp up to $650^{\circ} \mathrm{C}$ contained in its flow channels (Wong 2005), while the helium coolant operates at 380 to $460^{\circ} \mathrm{C}$ in the module box.

Some assumptions have been made to allow an initial quantification of the module box reliability so that the component fault events can be placed in frequency categories. First, the square tubes that comprise the TBM first wall (FW) are similar in width to the circular crosssection tubes used in heat exchangers. As a first approximation, steam generator tube values are applied to the TBM FW tubes. Generally, shell-and-tube heat exchangers in industry have tubes in tube bundles that can be very long (many meters) and are thin-walled, perhaps 0.75 to $1.25 \mathrm{~mm}$ thick, to enhance heat transfer between fluids (Cadwallader 1996a). The TBM square tubes at $4 \mathrm{~mm}$ wall thickness are more robust construction than heat exchanger tubes and operate at lower pressure. Considering that a fission reactor's steam generator could have a $\Delta \mathrm{P}$ of $\approx 8 \mathrm{MPa}$ between primary water and secondary steam and those tubes are $\approx 1 \mathrm{~mm}$ thick inconel 690 alloy, the TBM is built more conservatively. Most U.S. pressurized water reactor (PWR) fission plant steam generators (SGs) are U-tube units having an average $\approx 9,000$ tubes per tube bundle and the tubes can be an average $30 \mathrm{~m}$ long (see the U.S. NRC fact sheet on Steam Generator Tube Issues, at nrc.gov/reading-rm/doc-collections/fact-sheets/steam-gen.html) then some preliminary failure rates for tubes can be obtained. There are typically four SGs per PWR plant. Therefore (4 $\mathrm{SG} /$ plant $)(9,000$ tubes/SG)(30-m/tube) gives $1.08 \mathrm{E}+06 \mathrm{~m}$ of tube run/plant. The operating experience event frequency for steam generator tube rupture is 7E-03/plant-year (Poloski 1999); it is worth noting that earlier work by Adams (1990) gave 9.76E-03/reactor-year. Dividing gives $7 \mathrm{E}-03 /$ plant-year $\div 1.08 \mathrm{E}+06 \mathrm{~m} /$ plant or $6.5 \mathrm{E}-09$ tube ruptures per meter-year. Over the majority of the data collection time, the fission plants operated at $\approx 75 \%$ or more of a calendar year, so roughly 6,570 calendar hours per year. Therefore, the SG tube rupture failure rate is $9.9 \mathrm{E}-13$ rupture/m-h, which is rounded up to $1 \mathrm{E}-12$ tube rupture/m-h for this preliminary estimate. Adams (1990) suggested that multiple tube rupture events would be a factor of 10 less frequent 
than the single tube failure value. Since the TBM square tubes are thick-walled and form a bonded unit, they should be able to meet this $1 \mathrm{E}-12 / \mathrm{m}-\mathrm{h}$ experience value unless outside forces act on the tubes. Another important issue is that a SG tube rupture can release appreciable flow rates, even though they are small diameter. Rupture flow rates up to $79 \mathrm{~kg} / \mathrm{s}$ water (Adams 1990) have been recorded with an average of $\approx 25 \mathrm{~kg} / \mathrm{s}$. The high flow rate is a factor of ten above the makeup water supply capability. Leaks in SG tubes were much smaller flow rates, the lowest reported leak rate was $0.0003 \mathrm{~kg} / \mathrm{s}$ of water and the highest at $2.5 \mathrm{~kg} / \mathrm{s}$. A PWR flows perhaps $17 \mathrm{Mg} / \mathrm{s}$ water in the primary system (Nero 1979). An estimate of typical flow in an individual PWR SG tube during normal plant operation is $(17 \mathrm{Mg} / \mathrm{s} \div 4 \mathrm{SGs})(1 \mathrm{SG} / 9000$ tubes $) \approx 0.5 \mathrm{~kg} / \mathrm{s}$, but a breach opening to lower pressure can increase the flow rate. Using Adams' data, 78 tube leak events in 512 reactor-years would give 0.15 tube leak/reactor-year. Converting the data into tube results: $(0.15$ tube leaks/reactor-year $) /(1.08 \mathrm{E}+06 \mathrm{~m} /$ reactor $)(6570 \mathrm{~h} / \mathrm{yr})$ or $2.1 \mathrm{E}-11$ leaks $/ \mathrm{h}-$ $\mathrm{m}$ for SG tubes. As stated above, for a first approximation these round, thin-walled tubing leak failure rates will be applied to the square, thick-walled TBM tubes to estimate tube failure rate. Note that external forces, such as runaway electrons or plasma disruption energy will be treated separately. Granted, the SG and TBM materials differ; typically incoloy SG tubes versus TBM ferritic steel. The SG secondary side water-steam coolant has had chemical plateout after boiling that has contributed to tube corrosion problems while helium and vacuum should not present such problems for TBM tubes. Both the fission SG and the TBM tubes will experience the environments of high differential pressure, high flow velocity, and vibration. To give a comparison of these results, Marshall (1994) gave suggested failure rates for ferritic steel tubes with helium coolant. The analyst judgment tube leakage value was $5.4 \mathrm{E}-09 / \mathrm{m}-\mathrm{h}$ and tube rupture was a factor of ten lower, $5.4 \mathrm{E}-10 / \mathrm{m}-\mathrm{h}$. The $\mathrm{SG}$ tube operating experience values are $2.1 \mathrm{E}-11 / \mathrm{m}$ $\mathrm{h}$ for leakage and $1 \mathrm{E}-12 / \mathrm{m}-\mathrm{h}$ for rupture, from Adams' data, which are lower values from actual operating experiences. Since the TBM tubing is thick-walled robust construction, the thin-walled SG tube operating experience values will be applied to these tubes as a first approximation. Using Adams' data on SG tube leaks, the average leak rate for all 64 leak events that cited a flow rate was $0.167 \mathrm{~kg} / \mathrm{s}$, or about $33 \%$ of the typical flow rate. The smallest leak event was $0.06 \%$ of the tube flow rate. The helium tubing in the TBM will operate for about 4,032 hours per calendar year. Because the helium in the tubes is operating at $8 \mathrm{MPa}$, if a breach opening occurs, it is assumed that the helium will penetrate past the plasma sprayed beryllium on the tube outer surface. A two-mm thickness of beryllium is plasma sprayed onto the front face of the tubes (Wong 2005). As an initial assumption, given the square nature of the tubes and that the tube-totube bond should be very strong to make the TBM withstand forces acting on it, $25 \%$ of the breach failures are assumed to leak out toward the vacuum vessel and $25 \%$ are assumed to leak in toward the $\mathrm{Pb}-17 \mathrm{Li}$ channels. The leaks upward or downward are believed to encounter strong bonding between tubes and are therefore expected to be halted without any further leakage.

Values to apply to square tubing:

- $\quad 2.1 \mathrm{E}-11 / \mathrm{h}-\mathrm{m}$ leaks, smallest water leak is $0.06 \%$ of tube mass flow rate, average was $33 \%$

- $\quad 1 \mathrm{E}-12 / \mathrm{h}-\mathrm{m}$ ruptures, average water leak is $5000 \%$ of the typical tube mass flow rate

Leakage from the TBM has more concerns than just the module face tubes. Helium could leak out of the module box at many locations. Rivkin (2005) stated that most gas leaks (i.e., small leaks) of process gases leaking from $15 \mathrm{MPa}$ gas cylinders and piping undergo a tortuous leak path and the leaks are on the order of 0.1 to $1.0 \mathrm{ml} /$ minute of escaping gas. This is an STP leak rate; much gas energy is expended to overcome friction and pressure is lost in traversing a tiny leak opening. The STP density of helium is $0.179 \mathrm{~g} / 1$. Therefore, Rivkin's mass leak rate would be $1.79 \mathrm{E}-05$ to $1.79 \mathrm{E}-04 \mathrm{~g} /$ minute. If Rivkin's very small leak rate is applied to ITER with its 
$\approx 43$ minute pulses, then at most $0.008 \mathrm{~g}$ helium could leak into the vacuum vessel during one pulse from a small leak. The helium flowing in the TBM module box is $0.343 \mathrm{~m}^{3} / \mathrm{s}$ volume flow rate, $100 \mathrm{~m} / \mathrm{s}$ velocity, $1.76 \mathrm{~kg} / \mathrm{s}$ mass flow rate, at $8 \mathrm{MPa}$ pressure (which is roughly half of Rivkin's pressure). The helium density is $5.33 \mathrm{~kg} / \mathrm{m}^{3}$. At Rivkin's small helium leak rate, ITER could operate for a year and accumulate $\sim 24 \mathrm{~g}$ helium in the vacuum vessel, and vacuum pumping on the vacuum vessel would remove some of the in-leakage helium each day. However, over time the helium accumulation in the vacuum vessel might interfere with plasma startup, so the small leak might require a maintenance shutdown to make repairs. Nonetheless, the typical small leak rate for gases does not appear to cause concern for inducing plasma disruptions. Merrill (1991) described calculations for water coolant being injected into the edge of an ITER plasma from a first wall cooling line leak. As little as $30 \mathrm{~g}$ of water would create a disruption with twice the disruptive intensity as a typically expected density limit disruption. A 30-g mass will be used as a tentative bound on masses likely to cause disruptions. Using the $0.06 \%$ and $33 \%$ leak rates estimated from tubing leak experience, $(0.0006)(1,760 \mathrm{~g} / \mathrm{s}$ flow rate $)=1.06 \mathrm{~g} / \mathrm{s}$ leak rate of low pressure helium, and $(0.33)(1,760 \mathrm{~g} / \mathrm{s})=580.8 \mathrm{~g} / \mathrm{s}$, both of which will pose a disruption threat at the edge of the ITER plasma over a 400 -second pulse.

The TBM module box bonding method of choice is hot isostatic press (HIP) bonding. Unfortunately, there is little data available on the reliability of HIP joints. There has been some fusion research testing of limited numbers of components for limited numbers of test cycles; however, the testing has not been sufficient to definitely prove that this joining is as reliable as traditional nuclear industry arc welding. At least one researcher commented that HIP was preferred over 'leaky' welds (Lorenzetto 2005), which gives an insight that at least some materials researchers believe that HIP joints could outperform welds. Basically, the TBM module has to perform as well as, or better than, the rest of the ITER first wall. The GSSR volume VII gives a first wall in-vessel leak as a Category III event, which has a frequency band of $1 \mathrm{E}-02$ to $1 \mathrm{E}-04 / \mathrm{yr}$. The TBM is about $1.9 \mathrm{~m}$ tall by $0.65 \mathrm{~m}$ wide, or $1.2 \mathrm{~m}^{2} \mathrm{FW}$ surface area, and the entire FW is $672 \mathrm{~m}^{2}$. Thus, one TBM is $0.18 \%$ of the entire FW. Applying the Category III frequency upper bound of $1 \mathrm{E}-02 / \mathrm{yr}$ times 0.0018 gives a bounding value TBM leak frequency of $1.8 \mathrm{E}-05 / \mathrm{yr}$. Applying this value to the TBM module edges that could leak appreciable amounts of helium into the vacuum vessel gives a result of $1 \mathrm{E}-07 / \mathrm{h}-\mathrm{m}$ for bond leakage. Comparing this value to Buende's weld reliability values (Buende 1991) shows this estimate is at the high end of the range of nuclear-grade arc welding failure rates. Therefore, for this preliminary work, HIP bonds will be assumed to be as good as arc welding and will be given welding failure rates.

ITER is built to withstand thousands of plasma disruptions; plasma disruptions are considered to be part of normal operations (GSSR 2001, section VII.1.2.2). Consequently, the TBM must also withstand disruptions. The ITER GSSR volume III states that approximately $10 \%$ of plasma shots will end in disruptions. This $10 \%$ value has been a long-standing assumption for disruptions and another assumption is that $10 \%$ of shots will be long duration plasma power transient events (Smid 1996). It is expected that most of these disruptions would occur in the H-H and D-D phases of operations, but some level of disruptions will still occur in the high power D-T operation despite efforts at disruption avoidance. Having no better guidance for D-T operation, the GSSR volume III information is used. ITER plans to operate 3,000 pulses/yr. Therefore, we would typically expect 300 disruptions/yr. An exceptionally powerful disruption would be required to lead to damage beyond the planned-for wall erosion. The physicists and machine operators would strive to avoid such high energy disruptions. Considering the rarity of hazardous disruptions that have occurred in existing tokamaks, perhaps a few events in thousands of plasma shots per year - such as the Joint European Torus (JET) experience (Bertolini 1995), and noting disruption statistics in the Axi-Symmetric Divertor Experiment (ASDEX) that showed many moderate-intensity disruptions which did not damage the machine (Zohm 1993), a high energy 
disruption would only occur very rarely. Analyst judgment based on these existing tokamak experiences is that very severe disruptions would occur in perhaps $0.1 \%$ of all disruptions; that assumed likelihood means 0.3 high energy disruptions per year. GSSR volume III also states that $70 \%$ of the disruptions are assumed to deliver their energy to the divertor. The other $30 \%$ of disruptions are assumed to deliver their energy to the FW. Applying the $30 \%$ value to 0.3 high energy disruptions gives $\approx 0.09$ disruption per year on the FW with high energy to damage the FW or TBM. GSSR volume III states to assume a wall surface area of $20 \mathrm{~m}^{2}$ being affected by the disruption for erosion purposes while the 2003 ITER Safety Analysis Data List (SADL 2003), section 2.2, and GSSR volume VII section 1.2.2 both state that the disruption would deliver its thermal energy to the entire $672 \mathrm{~m}^{2}$ (or $680 \mathrm{~m}^{2}$ ) FW. However, for conservatism, a disruptionaffected $20 \mathrm{~m}^{2}$ wall area will be assumed here. Assuming that a high-energy disruption has equal probability of impacting anywhere on the $\mathrm{FW}$, then having some of the $20 \mathrm{~m}^{2}$ disruption area overlay on the TBM face could create TBM damage. An analyst judgment was made that $25 \%$ of the TBM face or more would need to receive the disruption heat energy to cause TBM overheat (differential thermal overstress on the TBM face) damage or failure. Quartering the TBM face and overlaying a corner of a $4.5 \mathrm{~m} \mathrm{x} 4.5 \mathrm{~m}\left(\approx 20 \mathrm{~m}^{2}\right)$ surface for each one-fourth of the TBM gives a total area of $80 \mathrm{~m}^{2}$ the disruption could impinge and affect a portion of the TBM. Using the FW surface area, the likelihood of the TBM being affected is $80 / 672=0.12$. A high energy disruption partially impinging on the TBM is $(0.09$ severe disruptions/yr $)(0.12$ area ratio) $=1.1 \mathrm{E}-02 / \mathrm{yr}$, a Category II event. This is a crude quantification, but satisfactory for the preliminary nature of this assessment.

The TBM must also withstand the electromagnetic jxB plasma forces generated by a plasma disruption. These resulting mechanical forces apply torque to the FW and the TBM box, attempting to rotate the TBM box around the axis of its inlet-outlet pipework. The TBM box is cantilevered in the water-cooled frame, normally with $20 \mathrm{~mm}$ clearance between the box and the frame around the entire periphery of the TBM box. The 4 metal bar support pins and the 2 metal block support keys hold the TBM in place against these forces and the normal vibration forces that occur in plasma operations. As an analyst judgment, having one failed support pin or just one failed support block is insufficient to move the TBM box against the frame. Analyst judgment also concludes that having one failed support pin and one failed support block will allow disruption forces to move the TBM box to contact its water-cooled frame. Having these two lowfailure rate components fail in an overlapping time frame is expected to be a very low probability event. At 300 disruptions per year, it is expected that there will be 1-2 disruptions per operating day. To address consequences of TBM box motion, the water-cooled frame information was examined. The frame wall thickness is stated to be greater than that of the 4-mm-thick TBM wall but the actual thickness was not found in the 2005 TBM design description document. While the distance to travel is small $(20 \mathrm{~mm})$, the forces can be very large over very short disruption times and would lead to high metal-to-metal pressure at contact points. That mechanical pressure and stress could result in tearing the side of the TBM FW face. This is only an analyst judgment at present, calculations must be performed on this postulated event scenario. If the TBM box were to fail, helium would leak to the vacuum vessel. It is possible, although improbable, that the TBM might be sufficiently damaged internally to leak $\mathrm{Pb}-17 \mathrm{Li}$ to the helium coolant passages and eventually leak $\mathrm{Pb}-17 \mathrm{Li}$ to the vacuum vessel. The water-cooled frame must be evaluated to verify that it is robust against such events so that there is not a water leak into the vacuum vessel.

Failure rates for simple mechanical parts are not widely published. It is expected that the failure rates for these simple steel parts can vary due to the service environment (i.e., corrosion, elevated temperature, thermal cycling, pressure cycling, etc.) and planned usage (i.e., stress loading, strain loading). An assumption is also made that these parts fabricated from reduced activation ferritic steel will perform on par with components fabricated from traditional carbon 
steel and low alloy steel. For all of these reasons, quantification of these passive component failure rates is highly preliminary at this time. A few failure rates are shown here (NPRD 1994; Moss 2005; Smith 2005; Green 1972) to provide some insight on elementary mechanical part failure rate magnitudes:

$\begin{array}{ll}\text { Part } & \text { Failure Rate } \\ \text { Machine bolt } & 2 \mathrm{E}-08 / \mathrm{h} \\ \text { Machine nut } & 2 \mathrm{E}-08 / \mathrm{h} \\ \text { Shaft } & 2 \mathrm{E}-08 \text { to } 3 \mathrm{E}-08 / \mathrm{h} \\ \text { Highly stressed shaft } & 2 \mathrm{E}-07 / \mathrm{h} \\ \text { Bracket } & 3 \mathrm{E}-07 / \mathrm{h} \\ \text { Chassis } & 9.2 \mathrm{E}-07 / \mathrm{h} \\ \text { Clevis } & 4.526 \mathrm{E}-07 / \mathrm{h} \\ \text { Pin } & 2.6 \mathrm{E}-09 / \mathrm{h}\end{array}$

These cast shapes, small solid metal mechanical parts, can reach magnitudes of $1 \mathrm{E}-07$ to $1 \mathrm{E}-09 / \mathrm{h}$ for basic "failure to function" failure rates. Bentley (1993) also reported some mechanical component failure rates: nuts, bolts, rods, shafts all had a breakage failure rate of $2 \mathrm{E}-08 / \mathrm{h}$, spring or mechanical joint breakage was $2 \mathrm{E}-07 / \mathrm{h}$. Bentley's values all agree well with those listed above. As a crude comparison, metal part data from Vo (1995) is used. Vo (1995) gave operating experience failure rates and expert elicitation data values on very large metal structural parts used in hydroelectric dam applications where water exerts high stress and also strain on the metal components. A metal gate "all modes" failure rate was $1 \mathrm{E}-05 / \mathrm{h}$, gate pins and beams were $2 \mathrm{E}-06 / \mathrm{h}$, metal supports (ribs, stringers, etc.) for gates were $3 \mathrm{E}-08 / \mathrm{h}$, shear pins were $1 \mathrm{E}-05 / \mathrm{h}$, metal stay vanes were $6 \mathrm{E}-09 / \mathrm{h}$, metal wicket gates were $1.4 \mathrm{E}-07 / \mathrm{h}$, and metal bars were $2 \mathrm{E}-07 / \mathrm{h}$. Vo did not decompose these "all modes" values into their respective failure mode contributions. It is expected that the majority of the failure modes would be failure to function (binding, bending, surface corrosion) rather than catastrophic cracking failure due to fatigue or material flaw (Smith 2005; FMD-97 1997). These values at $1 \mathrm{E}-05$ to $6 \mathrm{E}-09 / \mathrm{h}$ for very large, massive metal parts scatter around those listed above for smaller metal parts (automobile parts, machine parts, etc.) and show that low failure rates on the order of $1 \mathrm{E}-07 / \mathrm{h}$ and lower for mechanical pieces and parts are plausible even on the large scale of hydroelectric dams. For the TBM, a single thickness metal plate failure rate is chosen by the analyst to be $1 \mathrm{E}-08 / \mathrm{h}$ for failure to support or maintain its shape under service conditions; this value is based partially on the list above and on the failure rate range guidance given by Carter (1986). A failure rate of $3 \mathrm{E}-09 / \mathrm{h}$ is used for the welded pins on the TBM box, weighted by the FMD-97 data for pin failure modes (bend, 78\%; break, 22\%). Support keys (steel blocks) are assigned a failure rate of $3 \mathrm{E}-08 / \mathrm{h}$ for failure to function, as an initial approximation. This failure rate is assumed to be $50 \%$ deformation and 50\% cracking, based on similar types of parts described in FMD-97. A butt weld failure rate of $6 \mathrm{E}-09 /$ hour-weld, taken from Buende (1991), is used for the support key and support pin 'detachment' failure mode.

The grid plates and coolant channel plates in the TBM are not as easily quantified for failure rates. These plates are dual-walled units. While the presence of two walls tends to suggest using independent failure rates for two plates, a more conservative assumption of two adjacent plates set side-by-side that experience the same environment - thermal load, thermal cycling, and radiation - are unlikely to have truly independent failure rates. Common causes could occur despite the fact that a material crack cannot propagate through a gap between plates. The typical 'beta factor' method was chosen to address these dual wall components. Vesely (2002) reports a typical beta factor for initial assumptions is 0.1 and Andrews (1993) gives data which shows that most beta factors are less than 0.1 , rather in the 0.04 range. Therefore, using beta $=0.1$ for the 
present time should be a conservative, reasonable assumption. A beta factor of 0.1 on the single plate failure rate has been used to describe the dual-walled unit failure rate, that is $0.1 \mathrm{x}(1 \mathrm{E}-08 / \mathrm{h})$. Therefore, the cruciform grid plate failure rate is $1 \mathrm{E}-09 /$ hour for failure to support and to maintain its shape. The back plates with their coolant channels are also $1 \mathrm{E}-09 / \mathrm{h}$ for failure to support and to maintain shape. It is assumed if the cruciform grid plate deforms, the silicon carbide inserts will fail since ceramic materials tend to be weak against bending stresses. Back plate channel plugging is assigned a failure rate of $3 \mathrm{E}-06 / \mathrm{h}$ from Blanton (1993). Back plate leakage is assumed to be a single wall plate failure rate.

The flow channel inserts are rectangular cross section ducts, or large flow ducts, of silicon carbide with a U-cap beneath the top plate to redirect $\mathrm{Pb}-17 \mathrm{Li}$ flow back down the TBM toward the outlet piping. No failure rate data were found for this rectangular duct component so assumptions are explained here. The silicon carbide "flow channel inserts," or FCIs, have been described as liner plates (see Smolentsev 2006). These have been provided in the design to reduce magnetohydrodynamic effects of flowing $\mathrm{Pb}-17 \mathrm{Li}$ in the ITER magnetic field. The FCIs are an integral part of the MHD pressure drop and thermal profiles of the TBM; any flaws or failures of the FCI significantly impact the MHD and thermal behavior of the TBM (Wong 2005). The four FCI plates fit together as tongue-and-groove connections, there is no bonding, brazing or welding of the composite material. The FCIs have a thin sealing layer of crystal $\mathrm{SiC}$ to prevent penetration of the liquid metal into the $\mathrm{SiC}$ (Smolentsev 2006). The layer is included in the $\mathrm{SiC}$ failure rate. The DCLL TBM FCIs are 5-mm thick, operate in the $650-700^{\circ} \mathrm{C}$ range, and see $\mathrm{Pb}-17 \mathrm{Li}$ coolant moving at only a 6 to $10 \mathrm{~cm} / \mathrm{s}$ flow speed. There is radiation damage in the TBM since it is part of the ITER first wall. Given all of these operating conditions, similar experiences with large-scale usage of $\mathrm{SiC}$ were sought. $\mathrm{SiC}$ has been used to great advantage in gas turbines under very high temperatures $\left(1,200\right.$ to $\left.1,400^{\circ} \mathrm{C}\right)$ and stresses. The slow crack growth phenomena that can lead to catastrophic failure appears to occur only above $1,000^{\circ} \mathrm{C}$ (DOE 1994). Lin (1994) noted that Nicalon fiber-reinforced $\mathrm{SiC}$ composite had reduced strength at elevated temperatures $\left(100 \mathrm{MPa}\right.$ under $950^{\circ} \mathrm{C}$ and $70 \mathrm{MPa}$ at $1,150^{\circ} \mathrm{C}$ ). The $\mathrm{TBM}$ will operate well below the $950^{\circ} \mathrm{C}$ temperature, making slow crack growth a highly unlikely failure mode.

Another use of silicon carbide has been to make electrical "surge arrestor" insulators, which have had very low material failure rates. SiC has also been used to make heat transfer components, notably gas-gas flat plate and also tubular heat exchangers to recover waste heat from flue gases in fossil fuel combustion processes. Silicon carbide has also been tested as a fission reactor fuel pebble cladding material, which would never have been considered if SiC could not function well in high radiation environments with fast neutrons at fluxes equal to and higher than the ITER flux. Fission fuel cladding is also called upon to continue confining the fuel during spent fuel storage, so the cladding must have high longevity. This $\mathrm{SiC}$ application to fission fuel cladding suggests that $\mathrm{SiC}$ material can easily withstand the nuclear environment inside the TBM module box. The failure rates from these applications were studied to support analyst judgment of a flow channel insert failure rate.

Lat (1981) gave some data on power distribution arrestors. These units were estimated to be $0.6-\mathrm{m}$ tall by $0.1-\mathrm{m}$ diameter, used in a $21 \mathrm{kV}$ power distribution system. Taking away moisture ingress failures, vandalism, and lightning strike failure modes left 22 units failed out of 300,000 ceramic units included in a 3-month study. Those data gave a point estimate failure rate of: 22 failures $/[(300,000$ units $)(2190$ hours $)]=3.3 \mathrm{E}-08 /$ unit-hour. Thus, loss of mechanical integrity (cracking, etc.) is a low failure rate. This low failure rate is indicative that $\mathrm{SiC}$ ceramic surge arrestors are passive components that function well when they are kept free of moisture and external influences. 
$\mathrm{SiC}$ heat exchanger tubing in tests have not shown any failures by flaws or subcritical crack growth, but the small numbers of tubes in short duration tests have not accumulated enough time to provide attractively low failure rates. Unfortunately, there is little operating experience data compiled for $\mathrm{SiC}$ tubes. Qualitatively, Reuter (1986) determined that if the $\mathrm{SiC}$ tubes were not overstressed, they could operate indefinitely, at least 12 months ( 8,760 hours) continuous operation, in a high temperature burner-duct recuperator that uses waste heat from an industrial steel soaking pit to preheat air to $1,255 \mathrm{~K}$. Ten thousand hours is only a short time longer than Reuter's prediction and is likely within the useful lifetime bound Reuter was addressing. Seven recuperator tubes were fabricated and exposed to these test conditions:

$\begin{array}{ll}\text { Flue Gas Temperature, K (C) } & \text { Exposure time (hours) } \\ 977(704) & 25 \\ 1086(813) & 360 \\ 1227(954) & 75 \\ 1311(1038) & 25 \\ 1422(1149) & 35 \\ 1533(1260) & 5 \\ \text { Total } & 526 \text { hours of testing }\end{array}$

Note: A 2-hour ramp up to test temperature was performed for each test temperature.

The tubes operated without difficulty; no creep, no corrosion, no thinning of the walls, and no crack propagation was noted. Unfortunately, this amount of operating hours is very low and the number of tubes tested is very small; there is only low confidence in a failure rate estimate from this single batch trial of a few components. As a first attempt at quantification, this data set is analyzed as follows. Considering that $700^{\circ} \mathrm{C}$ is a high temperature for fusion, the exposure time hours are summed as high temperature operation. The tubes were roughly 2 meters long, and 6.35 $\mathrm{mm}$ thick. A simple point estimate for reliability tests with no failures would be to assume a Chisquared distribution (IAEA 1992). A 50\% Chi-squared "average" failure rate would be $0.6931 /$ (number of units tested $\bullet$ test time), giving $0.6931 /(7$ tubes $\bullet 526$ hours $\bullet 2 \mathrm{~m} /$ tube), or $9.4 \mathrm{E}-05 / \mathrm{m}-\mathrm{h}$. A $95 \%$ confidence limit for that failure rate would be $2.9957 /$ (number of units tested $\bullet$ test time), or $2.9957 /(7$ tubes $\bullet 526$ hours $\bullet 2 \mathrm{~m} /$ tube $)=4.1 \mathrm{E}-04$ per $\mathrm{m}$-h for all modes of failure. This average failure rate is rather high for heat exchanger tubing, so it is not an attractive value, but the implication from the test session is that the silicon carbide tubes performed well, showed no degradation after 52 hours, and could have operated much longer at elevated temperature without failure. Therefore, this crude estimate, generated from very sparse data, could be considered as an upper bound tubing failure rate. It is also noted that temperature rampup was 2 hours $\left(1260^{\circ} \mathrm{C}-20^{\circ} \mathrm{C}\right.$ for a delta-temperature of $\left.1240^{\circ} \mathrm{C}\right)$ or $10.3^{\circ} \mathrm{C}$ per minute, which is more aggressive heat-up than is used in the nuclear industry for metals.

Hindman (1995) described an air heat exchanger used on an incinerator to recover heat from the incinerator flue gas. This ceramic tube heat exchanger used SiC-alumina and also zirconia tubes. Seven $\mathrm{SiC}$ tubes were used in a half-year test. Three tubes failed due to steam backflow. Planned weekend outages and air fan trips allowed some steam to enter the tubes on the air side, and the steam condensed as the tubes cooled for a weekend shutdown. During the next incinerator startup, thermal stresses generated by the condensate water heat absorption as it boiled caused the tubes to break. These tubes were replaced (note: apparently these tubes cannot be repaired in-situ, they must be replaced - this is an important consideration for the FCIs in the DCLL TBM, that faulted FCIs will likely require either the $\mathrm{Pb}-17 \mathrm{Li}$ loop to shut down and the TBM continue to operate only on helium cooling or TBM module changeout to repair the FCI in the hot cell). The tube operating time data is given below: 


\begin{tabular}{|l|l|l|}
\hline Number of Tubes & Operating weeks & Total tube length-time (m-h) \\
\hline 4 & 27 & 17,010 \\
\hline 3 & 19 [failed at $19 \mathrm{wks}]$ & $8,977.5$ \\
\hline 3 [replacement tubes] & 8 & 3,780 \\
\hline Total & & $29,767.5$ \\
\hline
\end{tabular}

Note: The tubes were 1.5 meters long. An operating week was about 105 hours (Monday through Friday operation, for 24 hours/day but starting on Monday afternoons). The average week was 105 on-line hours.

The tubes operated with $982^{\circ} \mathrm{C}$ to $1,038^{\circ} \mathrm{C}$ shell-side incinerator flue gas at $1,633 \mathrm{~kg} /$ hour and a pressure drop of 0.046 atmosphere. The tube-side air entered at $425^{\circ} \mathrm{C}$ at $1,633 \mathrm{~kg} /$ hour and a pressure drop of 0.067 atmosphere. The design heat flux for a tube was $17.8 \mathrm{~kW} / \mathrm{m}^{2}$. The tube walls varied between $3.2 \mathrm{~mm}$ and $6.4 \mathrm{~mm}$ thick and had a $10.2 \mathrm{~cm}$ outside diameter. The average tube wall temperature was $516^{\circ} \mathrm{C}$. Air flowed down a metal tube "bayonet" within the ceramic tube and then reversed direction and flowed up the $0.95 \mathrm{~cm}$-width annulus out of the tube. Even with this higher temperature and longer operating time than the Reuter data above, there was no creep, wall thinning, corrosion, or cracking except for the admission of boiling water than induced thermal stress cracking.

Because the tube failures in the Hindman test were due to external operational influences, that is, foreign material intrusion (condensed steam) rather than a tube material flaw, flow vibration, or a design issue, the tube failures are not counted as part of the operating experience for this first approximation of a failure rate to be applied to the TBM. Following the IAEA (1992) guidance, a 50\% Chi-squared failure rate would be $0.6931 /(17,010+8977.5+3780$ meter-hours $)=$ $2.3 \mathrm{E}-05 / \mathrm{m}-\mathrm{h}$. A Chi-squared $95 \%$ upper bound failure rate would be $2.9957 /(2 \cdot 29,767.5)$ or $5 \mathrm{E}-05 / \mathrm{m}-\mathrm{h}$. This average failure rate is over a factor of ten less than the value found in the 526hour test discussed above. This failure rate reduction with additional operating time and more aggressive operating parameters in heat exchange tubes, and the data from Lat (1981) about the very low electrical insulator failure rates, all suggest that the $\mathrm{SiC}$ tubing component could survive longer operating times. There was a concern that running at the design heat flux could cause the tubes to suffer interply or intraply damage, especially transverse to the fiber direction. Those forms of damage would not necessarily cause catastrophic tube wall failure. The test results showed that the tubes could handle more heat load than predicted, there was no interply or intraply damage. Reuter (1986) examined fracture mechanics of $\mathrm{SiC}$ and stated that if a safety factor of 5 to 10 on material stress was used [note - this high safety factor means keeping the tube internal pressure, wall thermal stresses, flow-induced mechanical stresses, and all other stresses low], then the probability of tube failure during its service life would be below $1 \mathrm{E}-04$. Since the TBM would require replacement if there was a fault in the FCIs, it is assumed in this preliminary work that safety factors on the FCIs would be high. This concept of keeping the stress loading small to prolong lifetime has long been used in electronics parts (e.g., parts derating) and has also been seen in C-ring tests of ceramic materials (Sandifer 1994). Considering that the tubing described above operated at similar or higher temperatures than the TBM and that the tube wall thicknesses are very similar to the 5-mm thick TBM FCI, and that the TBM FCIs should experience only low mechanical stress due to close tolerances to their support grid plates, then the $1 \mathrm{E}-04$ cracking failure probability over the TBM service life of 10,000 hours appears to be reasonable to apply to the FCIs. SiC failures due to flaws from inclusions, slow crack growth, or any other inherent faults would be $1 \mathrm{E}-08$ /duct-hour for each of the FCI ducts. It is noted that the "tongue-in-groove" plate connections could provide sites for collecting impurities from the flowing $\mathrm{Pb}-17 \mathrm{Li}$. Any vibration of $\mathrm{SiC}$ duct plates with impurities present could cause scoring of the $\mathrm{SiC}$ if the impurities are sufficiently hard-surfaced, such as metal precipitates or metal oxides. 
Scoring could result in fracture and subsequent failure of the tongue-in-groove joints. Use of magnetic traps or some other type of RAFS metal oxide traps is advisable to capture metal oxides from the flow stream to keep the metals out of the TBM module flow channels.

The dual-walled inner and outer back plates also pose an interesting challenge for quantification. The failure modes of interest are deformation, fracture or cracking, and helium flow failures of plugging or flow blockage, and fouling. Deformation is treated like other plates described above despite the second dual-walled back plate unit being present to give more structural support to the other back plate. Deformation of the inner plate is believed to overstress the FCIs and restrict, but not halt, helium flow within the inner back plate. Deformation of the outer back plate is believed to not overstress the FCIs but is expected to overstress the helium piping connections to the back plate outer wall to the point of multiple leak formation.

The plasma-sprayed beryllium coating on the face of the TBM is also a concern. Castro $(1995,1996,1998,1999)$ tested 4 plasma sprayed samples for 3,000 cycles each at $1 \mathrm{MW} / \mathrm{m}^{2}$ and there were no failures in any of the samples. Ramping up to 3 and $5 \mathrm{MW} / \mathrm{m}^{2}$ for 20 -second cycles led to beryllium damage and hot spot formation on the substrate in only a few cycles. Therefore, assuming that the surface area is not a driving issue for good bonding between plasma-spray and substrate joining, then using the IAEA (1992) approach, the failure rate of debonding is zero failures in $4 \times 3,000$ cycles, or a failure rate of $0.6931 / 12,000=5.8 \mathrm{E}-05$ debondings per cycle. If the TBM lives for 5 years and sees 15,000 pulses, then $(15,000)(5.8 \mathrm{E}-05)=0.87$ chance of coating debonding. The JET experiment has had beryllium metal components and evaporative deposition beryllium coatings in use in both D-D and D-T operations. JET experiences included beryllium droplet intrusion into the plasma; these droplets led to high beryllium concentration in the plasma and reduced fusion neutron production but not plasma disruptions (Loarte 2005). At a beryllium density of $1.85 \mathrm{~g} / \mathrm{cm}^{3}$, and droplets of a reasonably large size, $6.5 \mathrm{~mm}$ diameter (or $0.146 \mathrm{~cm}^{3}$ ), gives 0.27 gram-Be per drop. Therefore, over 100 drops in proximity at the plasma edge would be needed to reach the 30-gram level determined by Merrill (1991). Despite this evidence to the contrary, the TBM safety work (Wong 2005) assumes a plasma disruption occurs if the beryllium coating debonds or melts and sends beryllium out from the TBM face into the edge of the plasma.

\subsection{TBM Preliminary FMEA Results}

The TBM module box FMEA covered the module in normal, pulse operation. If needed, future work can expand the FMEA to cover other helium operating modes of the DCLL TBM design, e.g., bakeout.

The preliminary FMEA on the module box is given in Appendix C. The main results were not surprising for this small portion of the ITER first wall. There are, however, a number of single faults that would prudently result in TBM shutdown with consequent ITER shutdown. The ITER project may not wish to accept this additional unavailability arising from the TBM. Table 4-1 summarizes the PIEs from the module box FMEA results (the PIE format and definitions are given in Section 2). Only the events involving the module box are considered in this FMEA. Because the module box contains both helium and $\mathrm{Pb}-17 \mathrm{Li}$ coolants, there are several initiating event categories included in this FMEA. 
Table 4-1. TBM module box FMEA results for postulated initiating events.

\begin{tabular}{|c|c|c|}
\hline PIE Family & FMEA Faults and Annual Frequency & Frequency Summation \\
\hline $\begin{array}{l}\text { LBV1-rupture } \\
\text { flow out of TBM }\end{array}$ & $\begin{array}{l}\text { Tube rupture, } 1 \mathrm{E}-07 / \mathrm{y} \\
\text { Magnetic-driven missile strikes TBM, } \\
1 \mathrm{E}-04 / \mathrm{y} \\
\text { Plasma disruption on TBM, } 1.2 \mathrm{E}-02 / \mathrm{y} \\
\text { Top/bottom plate rupture, } 1.7 \mathrm{E}-04 / \mathrm{y} \\
\text { Outer back plate rupture, } 4 \mathrm{E}-06 / \mathrm{y} \\
\text { Manifold rupture, } 1.4 \mathrm{E}-05 / \mathrm{y} \\
\text { Supply line rupture, } 2.7 \mathrm{E}-05 / \mathrm{y}\end{array}$ & $\begin{array}{l}1.2 \mathrm{E}-02 / \mathrm{y} \\
\text { Category II }\end{array}$ \\
\hline $\begin{array}{l}\text { LBV2-large } \\
\text { leak out of TBM }\end{array}$ & $\begin{array}{l}\text { Tube large leak, } 2 \mathrm{E}-06 / \mathrm{y} \\
\text { Top/bottom plate leak, } 1.7 \mathrm{E}-03 / \mathrm{y} \\
\text { Outer back plate rupture, } 4 \mathrm{E}-05 / \mathrm{y} \\
\text { Manifold rupture, } 4 \mathrm{E}-04 / \mathrm{y} \\
\text { Supply line rupture, } 8 \mathrm{E}-04 / \mathrm{y}\end{array}$ & $\begin{array}{l}3 \mathrm{E}-03 / \mathrm{y} \\
\text { Category III }\end{array}$ \\
\hline $\begin{array}{l}\text { LBV3-small } \\
\text { leak out of TBM }\end{array}$ & Small tube leak, $2.1 \mathrm{E}-05 / \mathrm{y}$ & $\begin{array}{l}2.1 \mathrm{E}-05 / \mathrm{y} \\
\text { Category IV }\end{array}$ \\
\hline $\begin{array}{l}\text { LBB1-rupture } \\
\text { in TBM }\end{array}$ & $\begin{array}{l}\text { Tube rupture, } 1 \mathrm{E}-07 / \mathrm{y} \\
\text { Top/bottom plate rupture, } 1.7 \mathrm{E}-04 / \mathrm{y} \\
\text { Center plate rupture, } 4 \mathrm{E}-06 / \mathrm{y} \\
\text { Inner/outer back plate rupture, } 8 \mathrm{E}-06 / \mathrm{y}\end{array}$ & $\begin{array}{l}1.7 \mathrm{E}-04 / \mathrm{y} \\
\text { Category III }\end{array}$ \\
\hline $\begin{array}{l}\text { LBB2-large } \\
\text { leak in TBM }\end{array}$ & $\begin{array}{l}\text { Tube leak, 2E-06/y } \\
\text { Top/bottom plate leak, } 1.7 \mathrm{E}-03 / \mathrm{y} \\
\text { Center plate leak, 4E-05/y } \\
\text { Inner/outer back plate leak, } 8 \mathrm{E}-05 / \mathrm{y}\end{array}$ & $\begin{array}{l}1.8 \mathrm{E}-03 / \mathrm{y} \\
\text { Category III }\end{array}$ \\
\hline $\begin{array}{l}\text { LBB3-small } \\
\text { leak into TBM }\end{array}$ & Small tube leak, $2.1 \mathrm{E}-05 / \mathrm{y}$ & $\begin{array}{l}2.1 \mathrm{E}-05 / \mathrm{y} \\
\text { Category IV }\end{array}$ \\
\hline $\begin{array}{l}\text { FB2-partial loss } \\
\text { of flow }\end{array}$ & $\begin{array}{l}\text { Heat transfer surface fouling, } 5 \mathrm{E}-04 / \mathrm{y} \\
\text { Flow blockage, } 6.3 \mathrm{E}-04 / \mathrm{y} \\
\text { Deformation restricts flow, } 8 \mathrm{E}-06 / \mathrm{y} \\
\text { Plate internal flow leak, } 8 \mathrm{E}-04 / \mathrm{y}\end{array}$ & $\begin{array}{l}1.9 \mathrm{E}-03 / \mathrm{y} \\
\text { Category III }\end{array}$ \\
\hline $\begin{array}{l}\text { FB1-loss of } \\
\text { flow }\end{array}$ & $\begin{array}{l}\text { Inner and outer back plate internal ruptures, } \\
8.1 \mathrm{E}-05 / \mathrm{y}\end{array}$ & $\begin{array}{l}8.1 \mathrm{E}-05 / \mathrm{yr} \\
\text { Category IV }\end{array}$ \\
\hline $\begin{array}{l}\text { VVA2-Air } \\
\text { ingress to VV }\end{array}$ & Vessel penetration faults, $1.9 \mathrm{E}-03 / \mathrm{y}$ & $\begin{array}{l}1.9 \mathrm{E}-03 / \mathrm{y} \\
\text { Category III }\end{array}$ \\
\hline
\end{tabular}

\subsection{Conclusions}

The TBM module box itself is an assembly of simple mechanical components, it is a passive component with no moving parts. Passive, mechanical components tend to have low failure rates. Mechanical components tend to have long term, chronic degradations, such as repeated stress cycles, or wear, rather than acute failures. An important degradation for blanket modules is exposure to repeated thermal cycles and plasma disruption forces. The blanket module components themselves have only a few failure modes - leakage, rupture, heat transfer surface fouling, and flow blockage. This preliminary FMEA has shown that there are many singlecomponent faults that will cause the blanket module to give degraded performance, but most of the faults are low frequency, in the Category III and Category IV ranges as seen in Table 4-1. The data sources used in this preliminary FMEA were scattered and the majority of component failure rate values did not originate from fusion blanket testing or any known system operating 
experiences. Based on existing results, some of the identified component faults in the TBM module box will cause the box to overheat and this could lead to mechanical failure due to stresses from thermal expansion. Such failures will result in taking the TBM off-line and consequently taking ITER off-line until the TBM module box can be replaced. Overall, the TBM module box faults do not necessarily result in radiological releases that threaten the public, but they do impact ITER availability. Based on these results, design consideration should be given to testing the TBM components in fusion environments. 


\subsection{References}

Adams, 1990. J. P. Adams and M. B. Sattision, "Frequency and Consequences Associated with a Steam Generator Tube Rupture Event," Nuclear Technology, 90 (1990) 168-185.

Andrews, 1993. J. D. Andrews and T. R. Moss, Reliability and Risk Assessment, Longman Scientific \& Technical, Essex, England (1993) chapter 8.

Bentley, 1993. J. P. Bentley, An Introduction to Reliability and Quality Engineering, Longman Scientific and Technical Publishers, Essex, UK, 1993, table 3.1.

Bertolini, 1995. E. Bertolini, M. Buzio, P. Noll, T. Raimondi, G. Sannazzaro, M. Verrecchia, "Engineering Analysis of JET Operation," Proceedings of the $16^{\text {th }}$ IEEE/NPSS Symposium on Fusion Engineering (SOFE 95), Champaing, IL, October 1-5, 1995, Institute of Electrical and Electronics Engineers, New York (1995) 464-469.

Blanton, 1993. C. H. Blanton and S. A. Eide, Savannah River Site Generic Data Base Development, WSRC-TR-93-262, Westinghouse Savannah River Company, Aiken, SC, June 30, 1993.

Buende, 1991. R. Buende, S. Fabritsiev, and V. Rybin, "Reliability of welds and brazed joints in blankets and its influence on availability," Fusion Engineering and Design, 16 (1991) 5972 .

Cadwallader, 1996. L. C. Cadwallader and T. D. Marshall, "Component Reliability Data Estimation for Fusion Safety and Risk Assessment," Proceedings of the International Topical Meeting on Probabilistic Safety Assessment (PSA '96), Park City, UT, September 29-October 3, 1996, volume 1, pages 637-648.

Cadwallader, 1996a. L. C. Cadwallader, Heat Exchanger Performance, ITER engineering design file ITER/US/96/EN/SA-03, Idaho National Engineering Laboratory, April 29, 1996.

Carter, 1986. A. D. S. Carter, Mechanical Reliability, second edition, John Wiley \& Sons, Inc., New York, 1986, page 177.

Castro, 1995. R. G. Castro, P. W. Stanek, K. E. Elliot, D. L. Youchison, R. D. Watson, D. S. Walsh, "Plasma-Sprayed Beryllium for ITER," Proceedings of the $16^{\text {th }}$ IEEE/NPSS Symposium on Fusion Engineering (SOFE 95), Champaign, IL, October 1-5, 1995, Institute of Electrical and Enectronics Engineers, New York (1995) 381-384.

Castro, 1996. R. G. Castro, P. W. Stanek, and K. E. Elliott, "The Structure, Properties and Performance of Plasma-Sprayed Beryllium for Fusion Applications," Physica Scripta, T64 (1996) 77-83.

Castro, 1998. R. G. Castro, K. E. Elliot, R. D. Watson, D. L. Youchison, K. T. Slattery, "Fabrication and high heat flux testing of plasma sprayed beryllium ITER first wall mockups," Journal of Nuclear Materials, 258-263 (1998) 252-257.

Castro, 1999. R. G. Castro, K. E. Elliott, K. J. Hollis, A. H. Bartlett, and R. D. Watson, "The development of beryllium plasma spray technology for the International Thermonuclear Experimental Reactor," presented at the 1999 Mexican American Engineers and Scientists 
(MAES) International Symposium, Career Fair and Trade Expo, San Antonio, TX, 20-23 January 1999, also LA-UR-99-58, CONF-990109, Los Alamos National Laboratory, Los Alamos, NM (1999).

Derdiger, 1981. J. A. Derdiger, K. H. Bhatt, W. E. Siegfriedt, Component Failure and Repair Data for Coal-Fired Power Units, EPRI-AP-2071, Electric Power Research Institute, Palo Alto, CA, October 1981.

DOE, 1994. Ceramic Stationary Gas Turbine Development, DOE/CE/40960-T2, prepared for the U.S. DOE by Solar Turbines Incorporated, September 1994, chapter 7.

Eide, 1991. S A. Eide et al., Component External Leakage and Rupture Frequency Estimates, EGG-SSRE-9639, Idaho National Engineering Laboratory, November 1991.

Evans, 1992. R. W. Evans, J. Preston, B. Wilshire, and E. A. Little, "Creep transients in a nuclear-grade ODS ferritic steel," Journal of Nuclear Materials, 195 (1992) 24-28.

Fernandez 2005. P. Fernandez, A. M. Lancha, J. Lapena, R. Lindau, M. Rieth, M. Schirra, "Creep strength of reduced activation ferritic/martensitic steel Eurofer'97," Fusion Engineering and Design, 75-79 (2005) 1003-1008.

FMD-97, 1997. Failure Mode/Mechanism Distributions, 1997, FMD-97, Reliability Analysis Center, Rome Laboratory, Rome, New York, December 1997, pages 2-236 to 2-237.

Green, 1972. A. E. Green and A. J. Bourne, Reliability Technology, John Wiley \& Sons, Inc., New York, 1972, Table A7.

GSSR, 2001. Generic Site Safety Report, Volume VII, “Analysis of Reference Events," ITER report G 84 r1 6 01-07-10 R 1.0, 2001, page 82.

Hannaman, 1978. G. W. Hannaman, GCR Reliability Data Bank Status Report, GA-A14839, General Atomic Company, San Diego, CA, July 1978.

HFIR, 1988. The High Flux Isotope Reactor Probabilistic Risk Assessment, final report, PLG0604, Pickard, Lowe and Garrick, Inc., Newport Beach, CA, January 1988.

Hindman, 1995. D. L. Hindman, Research and Development of a Ceramic Fiber Composite Heat Exchanger: Final Report, Phase III, DOE/ID/12868-1, volumes 1 and 2, July 1995.

IAEA, 1992. Manual on reliability data collection for research reactor PSAs, IAEA-TECDOC636, International Atomic Energy Agency, January 1992, chapter 9.

Jankovsky, 1990. R. S. Jankovsky and J. M. Kazaroff, A Life Comparison of Tube and Channel Cooling Passages for Thrust Chambers, NASA TM-103613, accession number N9111059, Lewis Research Center, Cleveland, OH, October 1990.

Lat, 1981. M. V. Lat and J. Kortschinski, "Distribution Arrestor Research," IEEE_Transactions on Power Apparatus and Systems, PAS-100 (1981) 3496-3505. 
Lin, 1994. H.-T. Lin, P. F. Becher, and P. F. Tortorelli, Elevated Temperature Static Fatigue of a Nicalon Fiber-Reinforced SiC Composite, CONF-941144-95, Oak Ridge National Laboratory, 1995.

Loarte, 2005. A. Loarte, G. Saibene, R. Sartori, D. J. Campbell, P. J. Lomas, G. F. Matthews and EFDA-JET workprogramme collaborators, "A new look at JET operation with Be as plasma facing material," Journal of Nuclear Materials, 337-339 (3005) 816-820.

Loftness, 1964. R. L. Loftness, Nuclear Power Plants: design, operating experience and economics, Van Nostrand Reinhold, New York, 1964, chapter 6.

Lorenzetto, 2005. P. Lorenzetto, B. Boireau, C. Boudot, P. Bucci, A. Furmanek, K. Ioki, J. Liimatainen, A. Pecock, P. Sherlock, S. Tahtinen, "Manufacture of blanket shield modules for ITER," Fusion Engineering and Design, $75-79$ (2005) 291-296.

Moss, 2005. T. R. Moss, The Reliability Data Handbook, ASME Press, American Society of Mechanical Engineers, New York, 2005, Appendix G.

Marshall, 1994. T. D. Marshall and L. C. Cadwallader, In-Vessel Tubing Failure Rates for Selected Materials and Coolants, EGG-FSP-10928, Idaho National Engineering Laboratory, March 1994.

Merrill, 1991. B. J. Merrill and S. C. Jardin, "Coolant Ingress Induced Disruption Calculations for ITER,” Fusion Technology, 19 (1991) 1278-1283.

Nero, 1979. A. V. Nero, A Guidebook to Nuclear Reactors, University of California Press, Berkeley, CA, 1979, chapter 5.

NPRD, 1994. Nonelectronic Parts Reliability Data, 1995, NPRD-95, Reliability Analysis Center, Rome, NY, July 1994.

NUREG, 2007. Industry-Average Performance for Components and Initiating Events at U.S. Nuclear Power Plants, NUREG/CR-6928, U.S. Nuclear Regulatory Commission, February 2007.

Pinna, 2006. T. Pinna, Failure Mode and Effect Analysis for the European Helium Cooled Pebble Bed (HCBP) Test Blanket Module, FUS-TN-SA-SE-R-152, draft report, ENEA Frascati, October 2006.

Pinna, 2006a. T. Pinna, Failure Mode and Effect Analysis for the European Helium Cooled Lithium Lead (HCLL) Test Blanket Module, FUS-TN-SA-SE-R-155, draft report, ENEA Frascati, November 2006.

Poloski, 1999. J. P. Poloski, D. G. Marksberry, C. L. Atwood, and W. J. Galyean, Rates of Initiating Events at U.S. Nuclear Power Plants: 1987-1995, NUREG/CR-5750, INEEL/EXT-98-00401, Idaho National Engineering and Environmental Laboratory for the U.S. Nuclear Regulatory Commission, February 1999.

Rapp, 1993. D. C. Rapp, Reliability Assessment of Thrust Chamber Cooling Concepts Using Probabilistic Analysis Techniques, NASA/CR-190785, National Aeronautics and Space Administration, June 1993. 
Rivkin, 2005. C. H. Rivkin, editor, The NFPA Guide to Gas Safety, National Fire Protection Association, Quincy, MA (2005) chapter 8.

Reuter, 1986. W. G. Reuter, Applicability of Fracture Mechanics to Lifetime Prediction of $B \& W$ Ceramic Heat Exchanger Tubes, DOE/ID-10171, U.S. Department of Energy Office of Industrial Programs, November 1986.

SADL, 2003. H.-W. Bartels, H. Okada, L/ Topilski, and V. Barabash, editors, Safety Analysis Data List, version 4.0.3, ITER number G 81 RI 10 03-08-08 W 0.1, International Thermonuclear Experimental Reactor International Team, Safety, Environment and Health Group, Garching, Germany, September 26, 2003.

Sakaba, 2004. N. Sakaba, T. Furusawa, T. Kawamoto, Y. Ishii, Y. Oota, "Short descriptions of other systems of the HTTR," Nuclear Engineering and Design, 233 (2004) 147-154.

Sams, 1980. D. W. Sams and M. Trojovsky, Data Summaries of Licensee Event Reports of Primary Containment Penetrations at U. S. Commercial Nuclear Power Plants, NUREG/CR-1730, U.S. Nuclear Regulatory Commission, Washington, DC, September 1980.

Sandifer, 1994. J. B. Sandifer et al., "High Temperature Life Prediction of Monolithic Silicon Carbide Heat Exchanger Tubes," Life Prediction Methodologies and Data for Ceramic Materials, ASTM STP 1201, 1994; or NASA accession number N96-16246.

Shah, 2003. V. N. Shah, S. Majumdar, and K. Natesan, Review and Assessment of Codes and Procedures for HTGR Components, NUREG/CR-6816, U.S. Nuclear Regulatory Commission, Washington, DC, June 2003.

Smid, 1996. I. Smid, H. D. Pacher, G. Vieder, U. Mszanowski, Y. Igitkhanov, G. Janeschitz, J. Schlosser, L. Plochl, "Lifetime of Be-, CFC- and W-armoured ITER divertor plates," Journal of Nuclear Materials, 233-237 (1996) 701-707.

Smith, 2005. D. J. Smith, Reliability, Maintainability, and Risk, seventh edition, ButterworthHeinemann, London (2005) appendices 4, 5.

Smolentsev, 2006. S. Smolentsev, M. Abdou, N. B. Morley, M. Sawan, S. Malang, and C. Wong, "Numerical analysis of MHD flow and heat transfer in a poloidal channel of the DCLL blanket with a $\mathrm{SiC}_{\mathrm{f}} / \mathrm{SiC}$ flow channel insert," Fusion Engineering and Design, 81 (2006) 549-553.

Solomon, 1975. K. A. Solomon, D. Okrent, W. E. Kastenberg, "HTGR Core Auxiliary Cooling System Availability and Reliability," Nuclear Engineering and Design, 34 (1975) 403-415.

Vesely, 2002. W. Vesely et al., Fault Tree Handbook with Aerospace Applications, version 1.1, National Aeronautics and Space Administration, Washington DC, August 2002, chapters 5 , 12. This document is available at www.hq.nasa.gov/office/codeq/doctree/fthb.pdf.

Vo, 1995. T. V. Vo, T. M. Mitts, H. K. Phan, T. R. Blackburn, and L. O. Casazza, Data Collection and Analysis in Support of Risk Assessment for Hydroelectric Stations, PNLSA-26279, Pacific Northwest Laboratory, October 1995. 
Westinghouse, 1992. Simplified Passive Advanced Light Water Reactor Plant Program, AP600 Standard Safety Analysis Report, Westinghouse, prepared for the U.S. DOE under contract number DE-AC03-90SF18495, June 1992, Chapter 5, "Reactor Coolant System and Connected Systems," Section 5.5.3, "Pressure-Temperature Limits," revision 5, February 1996.

Wong, 2005. C. P. C. Wong, et al., Design Description Document for the U.S. Dual Coolant Pb$17 \mathrm{Li}$ (DCLL) Test Blanket Module, report to the ITER Test Blanket Working Group $(T B W G)$, revision 3, GA-C25027, General Atomics, San Diego, CA, November 15, 2005.

Zohm, 1993. H. Zohm, K. Lackner, and C. Ludescher, "Statistical analysis of disruptions in ASDEX,” Nuclear Fusion, 33 (1993) 655-662. 


\section{FMEA RESULTS}

The preliminary FMEAs for the three DCLL TBM subsystems were completed and presented in the previous chapters. The overall results are given by PIE category and frequency category. The ITER frequency categories are defined in Table 5-1 below (GSSR 2001). The FMEA results are given in Table 5-2. Overall, it is noted that for some TBM faults, the prudent safety measure is to shut down ITER to prevent TBM module box damage and potential ITER invessel contamination from overheated or melted materials. The TBM cooling systems must be built to high standards to preclude ITER shutdowns from TBM issues.

Table 5-1. Event frequency categories.

\begin{tabular}{|c|c|c|c|c|}
\hline Event category & I & II & III & IV \\
\hline $\begin{array}{l}\text { Category } \\
\text { description }\end{array}$ & $\begin{array}{l}\text { Operational } \\
\text { events and plant } \\
\text { conditions } \\
\text { planned and } \\
\text { required for } \\
\text { ITER normal } \\
\text { operation, } \\
\text { including some } \\
\text { fault events } \\
\text { which can occur } \\
\text { as a result of the } \\
\text { ITER } \\
\text { experimental } \\
\text { nature. }\end{array}$ & $\begin{array}{l}\text { Likely event } \\
\text { sequences not } \\
\text { planned but } \\
\text { likely to occur } \\
\text { one or more } \\
\text { times during the } \\
\text { life of the plant } \\
\text { but not included } \\
\text { in Category I. }\end{array}$ & $\begin{array}{l}\text { Unlikely event } \\
\text { sequences that } \\
\text { are postulated } \\
\text { but not likely to } \\
\text { occur during the } \\
\text { life of the plant. }\end{array}$ & $\begin{array}{l}\text { Extremely } \\
\text { unlikely event } \\
\text { sequences that } \\
\text { are postulated } \\
\text { but are not likely } \\
\text { to occur during } \\
\text { the life of the } \\
\text { plant with a very } \\
\text { large margin. }\end{array}$ \\
\hline $\begin{array}{l}\text { Frequency range, } \\
\mathrm{f}\end{array}$ & & $\mathrm{f}>1 \mathrm{E}-02 / \mathrm{yr}$ & $\begin{array}{l}1 \mathrm{E}-02 / \mathrm{yr}>\mathrm{f} \\
>1 \mathrm{E}-04 / \mathrm{yr}\end{array}$ & $\begin{array}{l}1 \mathrm{E}-04 / \mathrm{yr}>\mathrm{f} \\
>1 \mathrm{E}-06 / \mathrm{yr}\end{array}$ \\
\hline $\begin{array}{l}\text { ITER plant } \\
\text { condition }\end{array}$ & $\begin{array}{l}\text { Normal } \\
\text { operation }\end{array}$ & Incident & Accident & Accident \\
\hline
\end{tabular}

To determine the most consequential accident sequences, the most frequent events with the highest inventories are identified. The radiological inventories of the various portions of the TBM system are therefore considered. The helium cooling loop is not expected to have activated corrosion products or activated coolant, so losses of the helium loop are only a concern if such losses allow the TBM face to remain uncooled while the plasma is pulsing, resulting in melting. TBM face melting creates a breach pathway from wherever the helium loop breached (i.e., TCWS vault, port cell, pipe chase, etc.) to the interior of the ITER vacuum vessel. The path is a set of irregular small openings in a small diameter pipe, but it is a path nonetheless. Since that event would be a confinement bypass breach between a heat transfer room (or some other location) to the vacuum vessel, it is an important accident to analyze.

The $\mathrm{Pb}-17 \mathrm{Li}$ loop would have activated coolant, elemental tritium, and activated corrosion products. A breach of this system would release some of that inventory to the VV or Port Cellthe entire $\mathrm{Pb}-17 \mathrm{Li}$ system is housed in the Port Cell. Since loss of flow and loss of heat sink are not consequential for the $\mathrm{Pb}-17 \mathrm{Li}$ system because the liquid metal can withstand very high heat 
Table 5-2. U.S. DCLL TBM preliminary FMEA results.

\begin{tabular}{|c|c|}
\hline ITER Postulated Initiating Event Family & Frequency Category \\
\hline \multicolumn{2}{|c|}{ Pb-17Li Cooling and Breeding Flow Loop } \\
\hline $\begin{array}{l}\text { LMP2 } \\
\text { Small Pb-17Li LOCA to Port Cell }\end{array}$ & $\begin{array}{l}\text { Category II } \\
5.6 \mathrm{E}-02 / \mathrm{yr} \text { for small leaks from the } \mathrm{Pb}-17 \mathrm{Li} \\
\text { system. }\end{array}$ \\
\hline $\begin{array}{l}\text { LMP1 } \\
\text { Pb-17Li LOCA to Port Cell }\end{array}$ & $\begin{array}{l}\text { Category II } \\
1.1 \mathrm{E}-02 / \mathrm{yr} \text { for large leaks or ruptures from the } \\
\mathrm{Pb}-17 \mathrm{Li} \text { system. }\end{array}$ \\
\hline $\begin{array}{l}\text { VMM2 } \\
\text { Small Pb-17Li LOCA to VV }\end{array}$ & $\begin{array}{l}\text { Category II } \\
1 \mathrm{E}-02 / \mathrm{yr} \text { for TBM module leaks to the vacuum } \\
\text { vessel. }\end{array}$ \\
\hline $\begin{array}{l}\text { VMM1 } \\
\text { Pb-17Li LOCA To VV }\end{array}$ & $\begin{array}{l}\text { Category III } \\
1 \mathrm{E}-03 / \mathrm{yr} \text { for TBM module large leaks to the } \\
\text { vacuum vessel. }\end{array}$ \\
\hline $\begin{array}{l}\text { LBB2 } \\
\text { Small He LOCA in TBM }\end{array}$ & $\begin{array}{l}\text { Category II } \\
1 \mathrm{E}-02 / \mathrm{yr} \text { for helium leaks into the } \mathrm{Pb}-17 \mathrm{Li} \text {. }\end{array}$ \\
\hline $\begin{array}{l}\text { LBB1 } \\
\text { He LOCA in TBM }\end{array}$ & $\begin{array}{l}\text { Category III } \\
\text { 1E-03/yr for large helium TBM coolant leaks } \\
\text { into the } \mathrm{Pb}-17 \mathrm{Li} \text {. }\end{array}$ \\
\hline $\begin{array}{l}\text { LMM2 } \\
\text { Small He LOCA in TBM HX }\end{array}$ & $\begin{array}{l}\text { Category III } \\
\text { 3.3E-03/yr for secondary helium leaks into } \mathrm{Pb}- \\
\text { 17Li. }\end{array}$ \\
\hline $\begin{array}{l}\text { LMM1 } \\
\text { He LOCA in TBM HX }\end{array}$ & $\begin{array}{l}\text { Category III } \\
\text { 3.3E-03/yr for secondary helium rupture into } \\
\mathrm{Pb}-17 \mathrm{Li} \text {. }\end{array}$ \\
\hline \multicolumn{2}{|c|}{ Helium Cooling Flow Loop } \\
\hline $\begin{array}{l}\text { LBP2 } \\
\text { Small LOCA in port cell }\end{array}$ & $\begin{array}{l}\text { Category III } \\
8 \mathrm{E}-03 / \mathrm{yr} \text { for pipe leaks. }\end{array}$ \\
\hline $\begin{array}{l}\text { LBP1 } \\
\text { LOCA in port cell }\end{array}$ & $\begin{array}{l}\text { Category III } \\
8 \mathrm{E}-04 / \mathrm{yr} \text { for pipe ruptures. }\end{array}$ \\
\hline $\begin{array}{l}\text { LBO3 } \\
\text { Heat exchanger tube faults }\end{array}$ & $\begin{array}{l}\text { Category II } \\
0.042 / y r \text { for heat exchanger tube leaks and } \\
\text { ruptures. }\end{array}$ \\
\hline $\begin{array}{l}\text { LBO2 } \\
\text { Small LOCA in TCWS room }\end{array}$ & $\begin{array}{l}\text { Category II } \\
9.1 \mathrm{E}-02 / \mathrm{yr} \text { for pipe, interfacing pipe, and valve } \\
\text { leaks. }\end{array}$ \\
\hline $\begin{array}{l}\text { LBO1 } \\
\text { LOCA in TCWS room }\end{array}$ & $\begin{array}{l}\text { Category II } \\
8.7 \mathrm{E}-02 / \mathrm{yr} \text { for relief valve faults, pipe ruptures. }\end{array}$ \\
\hline $\begin{array}{l}\text { FB1 } \\
\text { Loss of helium flow }\end{array}$ & $\begin{array}{l}\text { Category II } \\
5.1 \mathrm{E}-02 / \mathrm{yr} \text { for valve closure failures and gas } \\
\text { circulator failures. }\end{array}$ \\
\hline $\begin{array}{l}\text { HB1 } \\
\text { Loss of heat sink }\end{array}$ & $\begin{array}{l}\text { Category II (may be Category I) } \\
0.146 / y r \text { for valve faults, heat exchanger faults. }\end{array}$ \\
\hline
\end{tabular}


Table 5-2. (continued).

\begin{tabular}{|c|c|}
\hline ITER Postulated Initiating Event Family & Frequency Category \\
\hline \multicolumn{2}{|c|}{ TBM Module Box } \\
\hline $\begin{array}{l}\text { LBV1 } \\
\text { Rupture flow out of TBM }\end{array}$ & $\begin{array}{l}\text { Category II } \\
1.2 \mathrm{E}-02 / \mathrm{y} \text { for plasma events, top or bottom } \\
\text { plate ruptures }\end{array}$ \\
\hline $\begin{array}{l}\text { LBV2 } \\
\text { Large leak out of TBM }\end{array}$ & $\begin{array}{l}\text { Category III } \\
\text { 3E-03/y top or bottom plate leaks, tube leaks }\end{array}$ \\
\hline $\begin{array}{l}\text { LBV3 } \\
\text { Small leak out of TBM }\end{array}$ & $\begin{array}{l}\text { Category IV } \\
2.1 \mathrm{E}-05 / \mathrm{y} \text { for small tube leaks from the TBM. }\end{array}$ \\
\hline $\begin{array}{l}\text { LBB1 } \\
\text { Rupture in TBM }\end{array}$ & $\begin{array}{l}\text { Category III } \\
1.7 \mathrm{E}-04 / \mathrm{y} \text { for tube ruptures, plate cracks. }\end{array}$ \\
\hline $\begin{array}{l}\text { LBB2 } \\
\text { Large leak in TBM }\end{array}$ & $\begin{array}{l}\text { Category III } \\
1.8 \mathrm{E}-03 / \mathrm{y} \text { for tube leaks, plate leaks. }\end{array}$ \\
\hline $\begin{array}{l}\text { LBB3 } \\
\text { Small leak into TBM }\end{array}$ & $\begin{array}{l}\text { Category IV } \\
2.1 \mathrm{E}-05 / \mathrm{y} \text { for small tube leaks, plate leaks. }\end{array}$ \\
\hline $\begin{array}{l}\text { FB2 } \\
\text { Partial loss of flow }\end{array}$ & $\begin{array}{l}\text { Category III } \\
1.9 \mathrm{E}-03 / \mathrm{y} \text { for fouling, flow blockage, } \\
\text { deformation that restricts flow. }\end{array}$ \\
\hline $\begin{array}{l}\text { FB1 } \\
\text { Loss of flow }\end{array}$ & $\begin{array}{l}\text { Category IV } \\
8.1 \mathrm{E}-05 / \mathrm{yr} \text { for inner or outer back plate internal } \\
\text { ruptures. }\end{array}$ \\
\hline $\begin{array}{l}\text { VVA2 } \\
\text { Air ingress to vacuum vessel (VV) }\end{array}$ & $\begin{array}{l}\text { Category III } \\
1.9 \mathrm{E}-03 / \mathrm{y} \text { for VV penetration faults. }\end{array}$ \\
\hline
\end{tabular}

without expansion, thermal decomposition, boiling, etc., then the hazardous and radioactive inventories in the $\mathrm{Pb}-17 \mathrm{Li}$ remain confined in those transients.

From Table 5-2, considering the radiological inventories of the flow loops, the most consequential events are the Category II frequency LOCAs. It is noted that the TBM module box is passive, it has no moving parts, and its failure frequencies tend to be lower than those of the flow loops with active components. The primary safety issue for the TBM module box is that it maintains its confinement function as a part of the ITER first wall. If the TBM box fails (melting, mechanical overstress, seal failure) then the vacuum vessel is breached to the port cell, a Category III event. The TBM module interior should not contain any easily mobilized radioactive or hazardous materials - the liquid metal channels are lined with $\mathrm{SiC}$ (so no corrosion product formation is expected) and any tritium or radiological inventories are mainly in the $\mathrm{Pb}-17 \mathrm{Li}$ or helium coolant channels. Volumetric neutron activation in the TBM, that is, radioactive structural compoents, is not easily mobilized. The TBM failing to confine the ITER vacuum vessel inventories would be the greatest safety issue requiring analysis.

Past TBM work (GSSR 2001a) treated these accidents:

- Helium cooled pebble bed design

- Loss of coolant into the vacuum vessel

- $\quad$ Loss of coolant into breeder box (several leak sizes analyzed)

- $\quad$ Loss of coolant into heat transfer vault (large LOCA) 
- Water cooled lithium lead design

- $\quad$ In-vessel loss of coolant accident

- $\quad$ Loss of coolant inside breeder box

- $\quad$ In-vessel and in-TBM LOCA with rupture of First Wall

- $\quad$ Ex-vessel TBM coolant leaks

- Water cooled pebble bed design

- $\quad$ In-vessel loss of coolant

- $\quad$ Loss of coolant inside the breeder box

- $\quad$ Ex-vessel TBM coolant leaks

- $\quad$ Lithium self-cooled TBM design

- $\quad$ In-vessel loss of coolant, TBM FW break or FW shielding break

- $\quad$ Ex-vessel TBM coolant leaks.

These listed accidents bound the inventory-based safety inspection effort described above. Exvessel events can lead to in-vessel overheat and failure, creating a path from the VV to a heat transport room. In-vessel LOCA events can cause intense disruptions that can potentially damage the ITER vessel and lead to further releases. The TBM breaching the VV wall should be examined as well.

Accident analyses already performed in the DDD (Wong 2005) include DCLL TBM coolant leaks - both in-vessel and ex-vessel - which are expected with cooling flow loops, and internal module box leaks as well. The DDD analysis also includes a complete loss of active cooling event. The DDD events envelope these FMEA findings, including VV breach. All the events analyzed have included aggravating failures (e.g., loss of electrical power, damaging plasma disruption) that would not be identified in a FMEA analysis since the FMEA examines individual component failures rather than multiple, simultaneous faults. Therefore, the analyses already performed are more strict than the FMEA findings. For the DCLL TBM, loss of flow or loss of heat sink events occurring to just one of the coolants are not events of great safety concern, since with typical instrumentation and monitoring called out in the design, the TBM event is sensed and the module and/or ITER can be safely shut down. That is, losing helium cooling will overheat the $\mathrm{Pb}-17 \mathrm{Li}$ but overheated liquid metal does not overpressurize or deform the module. Given the thermal excursion effects on the module box, early changeout would be recommended after one of these events. Likewise, losing Pb-17Li cooling is not a safety consequence, the TBM can continue operating with helium coolant available. The loss of coolant events do pose safety concerns, these events will lead to the highest amount of TBM damage and the highest releases into the VV, cell, or TCWS vault. However, as shown in the DDD (Wong 2005), the TBM radiological inventories are small compared to ITER inventories, so TBM releases should be manageable. Breaching the helium coolant system does not overpressurize the building, and any hydrogen generation from first wall water coolant and TBM metal reactions remains below the ITER limit of $2.5 \mathrm{~kg}$. 


\subsection{References}

GSSR, 2001. Generic Site Safety Report, Volume X, "Sequence Analysis," G 84 RI 9 01-06-26

R1.0, International Thermonuclear Experimental Reactor Team, Garching, Germany, June 26, 2001, section X.2.2.2.

GSSR, 2001a. Generic Site Safety Report, Volume VII, "Reference Events," G 84 RI 6 01-07-10 R1.0, International Thermonuclear Experimental Reactor Team, Garching, Germany, July 10, 2001, Appendix A: Safety Assessment of ITER Test Blanket Modules (TBM).

Wong, 2005. C. P. C. Wong, et al., Design Description Document for the U.S. Dual Coolant Pb17Li (DCLL) Test Blanket Module, report to the ITER Test Blanket Working Group $(T B W G)$, revision 3, GA-C25027, General Atomics, San Diego, CA, November 15. 
Appendix A

Preliminary Failure Modes and Effects Analysis for the Pb-17Li Flow Loop 


\begin{tabular}{|c|c|c|c|c|c|c|c|c|c|c|c|c|}
\hline Component & $\begin{array}{c}\text { Operational } \\
\text { State }\end{array}$ & $\begin{array}{c}\text { Failure } \\
\text { Mode }\end{array}$ & $\begin{array}{c}\text { Frequency } \\
\text { Category }\end{array}$ & Possible Causes & $\begin{array}{c}\text { Preventive } \\
\text { Action on } \\
\text { Possible Causes }\end{array}$ & Consequences & $\begin{array}{c}\text { Corrective or } \\
\text { Preventive Actions } \\
\text { on Consequences }\end{array}$ & $\begin{array}{l}\text { ITER Postulated } \\
\text { Initiating Events }\end{array}$ & Comments & Frequency & $\begin{array}{c}\text { Comment on } \\
\text { frequency } \\
\text { calculation }\end{array}$ & Design comments \\
\hline \multirow[t]{2}{*}{$\begin{array}{l}\text { Pump motor } \\
\text { controller }\end{array}$} & NO & $\begin{array}{l}\text { fails to } \\
\text { operate }\end{array}$ & Category II & $\begin{array}{l}\text { electronic } \\
\text { component } \\
\text { fault, software } \\
\text { error, loss of } \\
\text { control power, } \\
\text { human error }\end{array}$ & $\begin{array}{l}\text { controller } \\
\text { redundancy, } \\
\text { regular } \\
\text { inspection, } \\
\text { software QA, } \\
\text { diverse power } \\
\text { supplies, detailed } \\
\text { operating } \\
\text { procedures }\end{array}$ & $\begin{array}{l}\text { Controller may allow } \\
\text { the pump motor to } \\
\text { continue to run as-is, or } \\
\text { pump motor may slow } \\
\text { to a stop depending on } \\
\text { the controller design } \\
\text { parameter selection. } \\
\text { Possible loss of flow } \\
\text { event. }\end{array}$ & $\begin{array}{l}\text { If the TBM has } \\
\text { helium cooling } \\
\text { available, ITER can } \\
\text { continue to operate } \\
\text { to the end of the } \\
\text { campaign }\end{array}$ & \begin{tabular}{|l|} 
Pb-17Li LOFA but \\
it is not an IE N/S
\end{tabular} & $\begin{array}{l}\text { Despite the low } \\
\text { radiological inventory of } \\
\text { this system, a nuclear- } \\
\text { grade controller failure } \\
\text { rate was chosen. }\end{array}$ & $2.6 \mathrm{E}-05 / \mathrm{h}$ & $\begin{array}{l}\text { NUREG/CR- } \\
4639, \text { vol. } 5 \text {, } \\
\text { page A-4 }\end{array}$ & $\begin{array}{l}\text { Designers must choose how this } \\
\text { unit will control in a failure event, } \\
\text { its failure position: "fails as-is", } \\
\text { "fails on" or "fails off". Fails off is } \\
\text { the most safety conservative failure } \\
\text { state. }\end{array}$ \\
\hline & & $\begin{array}{l}\text { erratic } \\
\text { operation } \\
\text { (overspeed or } \\
\text { underspeed } \\
\text { signals) }\end{array}$ & Category II & $\begin{array}{l}\text { controller fault, } \\
\text { command fault }\end{array}$ & $\begin{array}{l}\text { controller } \\
\text { redundancy, } \\
\text { inspection, } \\
\text { periodic system } \\
\text { testing, software } \\
\text { QA }\end{array}$ & $\begin{array}{l}\text { Overcooling or } \\
\text { undercooling the TBM, } \\
\text { induce thermal stress as } \\
\text { TBM temperature } \\
\text { deviates from normal }\end{array}$ & $\begin{array}{l}\text { Throttle secondary } \\
\text { coolant flow to HX } \\
\text { as needed to decrease } \\
\text { Pb-17Li coolant } \\
\text { temperature } \\
\text { deviations }\end{array}$ & Not an IE N/S & $\begin{array}{l}\text { The TBM Pb-17Li is } \\
\text { very forgiving. It can } \\
\text { stagnate in the TBM } \\
\text { module and accept heat } \\
\text { while not causing } \\
\text { overpressure, a system } \\
\text { breach or release event. }\end{array}$ & $5 \mathrm{E}-06 / \mathrm{h}$ & $\begin{array}{l}\text { WSRC-TR- } \\
93-262\end{array}$ & \\
\hline $\begin{array}{l}\text { Circuit breaker } \\
\text { for pump motor }\end{array}$ & NO & $\begin{array}{l}\text { spurious } \\
\text { operation }\end{array}$ & Category III & $\begin{array}{l}\text { mechanical } \\
\text { failure, } \\
\text { command fault }\end{array}$ & $\begin{array}{l}\text { periodic testing, } \\
\text { inspection, } \\
\text { software QA }\end{array}$ & $\begin{array}{l}\text { De-energizes pump for } \\
\text { a loss of Pb-17Li flow } \\
\text { during ITER operation }\end{array}$ & $\begin{array}{l}\text { If the TBM has } \\
\text { helium cooling } \\
\text { available, ITER can } \\
\text { continue to operate }\end{array}$ & $\begin{array}{l}\mathrm{Pb}-17 \mathrm{Li} \text { LOFA but } \\
\text { it is not an IE N/S }\end{array}$ & $\begin{array}{l}\text { Circuit breaker } \\
\text { spuriously transfers } \\
\text { from closed to open. } \\
\text { The TBM is not } \\
\text { damaged by a loss of } \\
\mathrm{Pb}-17 \mathrm{Li} \text { flow. }\end{array}$ & $3 \mathrm{E}-07 / \mathrm{h}$ & $\begin{array}{l}\text { EGG-SSRE- } \\
8875\end{array}$ & $\begin{array}{l}\text { To include electric power loss, } \\
\text { only a circuit breaker fault is } \\
\text { considered. A more widespread } \\
\text { power outage would affect some or } \\
\text { all of ITER. A widespread power } \\
\text { outage on TRITEX allowed the } \\
\text { entire system to freeze. }\end{array}$ \\
\hline \multirow[t]{2}{*}{$\begin{array}{l}20 \mathrm{~kW} \text { pump } \\
\text { motor }\end{array}$} & NO & fails to start & Category II & $\begin{array}{l}\text { motor winding } \\
\text { fault, shaft } \\
\text { binding, motor } \\
\text { overheated }\end{array}$ & $\begin{array}{l}\text { regular } \\
\text { inspection, } \\
\text { testing }\end{array}$ & $\begin{array}{l}\text { No flow received, but } \\
\text { ITER can continue to } \\
\text { operate if helium } \\
\text { cooling is available }\end{array}$ & $\begin{array}{l}\text { Extend ITER } \\
\text { downtime to repair } \\
\text { the motor }\end{array}$ & Not an IE, N/S & $\begin{array}{l}\text { Assume that the motor } \\
\text { runs continuously during } \\
\text { a pulse campaign, so the } \\
\text { "fails to start" mode } \\
\text { would be discovered at } \\
\text { the beginning of one of } \\
\text { the } 4 \text { annual pulse } \\
\text { campaigns, during } \\
\text { system operability } \\
\text { checks, and discovery } \\
\text { would cause a shift in } \\
\text { ITER operation to not } \\
\text { run the TBM Pb-17Li } \\
\text { loop }\end{array}$ & $5 \mathrm{E}-03 / \mathrm{d}$ & $\begin{array}{l}\text { EGG-SSRE- } \\
8875\end{array}$ & $\begin{array}{l}\text { As a first estimate, use } 4 \\
\text { operational start demands per year } \\
\text { (not counting any maintenance- } \\
\text { related or system operability test } \\
\text { starts). ITER could still operate } \\
\text { without the Pb-17Li loop operable. }\end{array}$ \\
\hline & & fails to stop & Category III & $\begin{array}{l}\text { circuit breaker } \\
\text { fault, command } \\
\text { fault, controller } \\
\text { fault, human } \\
\text { error }\end{array}$ & $\begin{array}{l}\text { regular } \\
\text { inspection, } \\
\text { software QA, } \\
\text { detailed } \\
\text { operating } \\
\text { procedures }\end{array}$ & $\begin{array}{l}\text { This is a post operation } \\
\text { event, overcooling the } \\
\text { TBM, induce thermal } \\
\text { stress as TBM is } \\
\text { overcooled }\end{array}$ & $\begin{array}{l}\text { Open breaker at } 480 \\
\text { Volt MCC or } \\
\text { switchgear to stop } \\
\text { pump. Verify } \\
\text { helium cooling to } \\
\text { TBM is on line. }\end{array}$ & Not an IE, N/S & $\begin{array}{l}\text { Assume that the motor } \\
\text { runs continuously during } \\
\text { a pulse campaign, so the } \\
\text { "fails to stop" mode } \\
\text { would only be } \\
\text { discovered at the } \\
\text { completion of one of the } \\
4 \text { annual pulse } \\
\text { campaigns, during } \\
\text { system shutdown, and } \\
\text { discovery would simply } \\
\text { generate a maintenance } \\
\text { work request for repair. } \\
\end{array}$ & $5 \mathrm{E}-04 / \mathrm{d}$ & $\begin{array}{l}\text { EGG-SSRE- } \\
8875\end{array}$ & $\begin{array}{l}\text { If the TBM is overcooled, there is a } \\
\text { mild concern that thermal stresses } \\
\text { could increase on the TBM frame } \\
\text { or module box. }\end{array}$ \\
\hline Centrifugal pump & NO & $\begin{array}{l}\text { fail to } \\
\text { operate }\end{array}$ & Category II & $\begin{array}{l}\text { command fault, } \\
\text { human error, } \\
\text { shaft seizure, } \\
\text { shaft shear }\end{array}$ & $\begin{array}{l}\text { periodic system } \\
\text { testing, software } \\
\text { QA }\end{array}$ & $\begin{array}{l}\text { Loss of Pb-17Li flow } \\
\text { during ITER operation }\end{array}$ & $\begin{array}{l}\text { Drain Pb-17Li to } \\
\text { drain tank for } \\
\text { remainder of the } \\
\text { ITER campaign }\end{array}$ & $\begin{array}{l}\mathrm{Pb}-17 \mathrm{Li} \text { LOFA but } \\
\text { it is not an IE, N/S }\end{array}$ & $\begin{array}{l}\text { Pump can be repaired in } \\
\text { the next ITER outage. }\end{array}$ & $5 \mathrm{E}-05 / \mathrm{h}$ & $\begin{array}{l}\text { EGG-SSRE- } \\
8875\end{array}$ & $\begin{array}{l}\text { The helium coolant can adequately } \\
\text { cool the TBM module and allow } \\
\text { continued ITER operation. }\end{array}$ \\
\hline
\end{tabular}




\begin{tabular}{|c|c|c|c|c|c|c|c|c|c|c|c|c|}
\hline Component & $\begin{array}{c}\text { Operational } \\
\text { State }\end{array}$ & $\begin{array}{l}\text { Failure } \\
\text { Mode }\end{array}$ & $\begin{array}{l}\text { Frequency } \\
\text { Category }\end{array}$ & Possible Causes & $\begin{array}{c}\text { Preventive } \\
\text { Action on } \\
\text { Possible Causes }\end{array}$ & Consequences & $\begin{array}{c}\text { Corrective or } \\
\text { Preventive Actions } \\
\text { on Consequences }\end{array}$ & $\begin{array}{l}\text { ITER Postulated } \\
\text { Initiating Events }\end{array}$ & Comments & Frequency & $\begin{array}{l}\text { Comment on } \\
\text { frequency } \\
\text { calculation }\end{array}$ & Design comments \\
\hline & & external leak & Category III & $\begin{array}{l}\text { casing crack, } \\
\text { weld failure, } \\
\text { shaft seal failure }\end{array}$ & $\begin{array}{l}\text { Specify high } \\
\text { quality parts, } \\
\text { regular } \\
\text { inspection }\end{array}$ & $\begin{array}{l}\text { Small loss of Pb-17Li } \\
\text { coolant }\end{array}$ & $\begin{array}{l}\text { Shut down Pb-17Li } \\
\text { pump to limit } \\
\text { outflow, open drain } \\
\text { tank valves to } \\
\text { confine coolant }\end{array}$ & $\begin{array}{l}\text { Small LOCA, } \\
\text { LMP2 }\end{array}$ & & $3 \mathrm{E}-06 / \mathrm{h}$ & $\begin{array}{l}\text { EGG-SSRE- } \\
8875\end{array}$ & $\begin{array}{l}\text { The helium coolant can adequately } \\
\text { cool the TBM module and allow } \\
\text { continued ITER operation. }\end{array}$ \\
\hline Centrifugal pump & NO & $\begin{array}{l}\text { external } \\
\text { rupture }\end{array}$ & Category III & $\begin{array}{l}\text { casing } \\
\text { catastrophic } \\
\text { failure, large } \\
\text { weld failure }\end{array}$ & $\begin{array}{l}\text { Specify high } \\
\text { quality parts, } \\
\text { regular } \\
\text { inspection }\end{array}$ & $\begin{array}{l}\text { Large loss of Pb-17Li } \\
\text { coolant }\end{array}$ & $\begin{array}{l}\text { Shut down } \mathrm{Pb}-17 \mathrm{Li} \\
\text { pump to limit } \\
\text { outflow, open drain } \\
\text { tank valves to } \\
\text { confine coolant }\end{array}$ & LOCA, LMP1 & & $3 \mathrm{E}-07 / \mathrm{h}$ & $\begin{array}{l}\text { EGG-SSRE- } \\
8875\end{array}$ & $\begin{array}{l}\text { The helium coolant can adequately } \\
\text { cool the TBM module and allow } \\
\text { continued ITER operation. }\end{array}$ \\
\hline \multirow[t]{3}{*}{$\begin{array}{l}\text { Level instrument } \\
\text { on pump }\end{array}$} & NO & $\begin{array}{l}\text { fails to } \\
\text { operate }\end{array}$ & Category III & $\begin{array}{l}\text { fouling, drift, } \\
\text { calibration error }\end{array}$ & $\begin{array}{l}\text { Coolant cleaning } \\
\text { in the cold trap, } \\
\text { periodic } \\
\text { instrument } \\
\text { recalibration }\end{array}$ & $\begin{array}{l}\text { Loss of sensor data may } \\
\text { cause loop shutdown. } \\
\text { Increasing level will } \\
\text { overfill pump volute; } \\
\text { placing hot } \mathrm{Pb}-17 \mathrm{Li} \text { on } \\
\text { shaft freeze seal and } \\
\text { can lead to premature } \\
\text { shaft seal failure and } \\
\text { require extra } \\
\text { maintenance }\end{array}$ & $\begin{array}{l}\text { Other sensors may } \\
\text { provide enough data } \\
\text { to allow continued } \\
\text { safe TBM } \\
\text { operations. The Pb- } \\
17 \mathrm{Li} \text { coolant system } \\
\text { could be shut down } \\
\text { for the remainder of } \\
\text { the campaign and } \\
\text { repaired in the next } \\
\text { outage. }\end{array}$ & Not an IE, N/S & $\begin{array}{l}\text { Assumes that failure to } \\
\text { operate may cause a } \\
\text { shutdown of the Pb-17Li } \\
\text { loop since level is a } \\
\text { safety indicator of loss } \\
\text { of fluid. Drawing } \\
\text { suggests that the level } \\
\text { sensor is a differential } \\
\text { pressure unit. }\end{array}$ & $1 \mathrm{E}-06 / \mathrm{h}$ & $\begin{array}{l}\text { INEL- } \\
96 / 0295\end{array}$ & $\begin{array}{l}\text { Note on instruments: Placing } \\
\text { redundant sensors would allow the } \\
\text { system to continue operating and } \\
\text { not be placed in standby due to a } \\
\text { sensor failure. Note on fouling: } \\
\text { Instrument lines tend to act as } \\
\text { diffusion cold traps for impurities } \\
\text { in the liquid metal system; keeping } \\
\text { the line temperature above the } \\
\text { saturation temperature of } \\
\text { impurities will reduce impurity } \\
\text { buildup in the lines. Dietrich and } \\
\text { Zinn, "Solid Fuel Reactors", } \\
\text { Addison Wesley Publishers, } \\
\text { Reading, MA, 1958, p } 84 \text {. }\end{array}$ \\
\hline & & $\begin{array}{l}\text { improper } \\
\text { reading }\end{array}$ & Category III & $\begin{array}{l}\text { calibration error, } \\
\text { drift, impurity } \\
\text { buildup on } \\
\text { instrument }\end{array}$ & \begin{tabular}{|l|} 
Periodic \\
recalibration
\end{tabular} & $\begin{array}{l}\text { Reading high or low } \\
\text { will affect volume flow } \\
\text { in the TBM, not a large } \\
\text { concern }\end{array}$ & $\begin{array}{l}\text { Could result in } \\
\text { temperature transient } \\
\text { in the } \mathrm{Pb}-17 \mathrm{Li} \text {. No } \\
\text { immediate effects. }\end{array}$ & Not an IE, N/S & $\begin{array}{l}\text { Assumes that failure to } \\
\text { operate may cause a } \\
\text { shutdown of the Pb-17Li } \\
\text { loop since level is an } \\
\text { indicator of loss of fluid. }\end{array}$ & $1.4 \mathrm{E}-06 / \mathrm{h}$ & $\begin{array}{l}\text { INEL- } \\
96 / 0295\end{array}$ & $\begin{array}{l}\text { Instrument recalibration is an ORE } \\
\text { concern, instruments capable of } \\
\text { remote calibration would reduce } \\
\text { personnel exposure. }\end{array}$ \\
\hline & & external leak & Category IV & $\begin{array}{l}\text { instrument tap } \\
\text { crack, } \\
\text { instrument line } \\
\text { crack, weld } \\
\text { crack, vibration } \\
\text { failure }\end{array}$ & $\begin{array}{l}\text { Materials } \\
\text { selection in } \\
\text { design, pre- } \\
\text { service } \\
\text { inspection, } \\
\text { system } \\
\text { operability } \\
\text { testing, reduce } \\
\text { flow-induced } \\
\text { vibration in } \\
\text { design }\end{array}$ & $\begin{array}{l}\text { An instrument line leak } \\
\text { will either leak inert } \\
\text { gas, depressurizing the } \\
\text { pump, or leak coolant. } \\
\text { A small coolant leak } \\
\text { from the pump volute } \\
\text { could be an operational } \\
\text { concern. }\end{array}$ & $\begin{array}{l}\text { No immediate } \\
\text { actions needed, } \\
\text { assume that a very } \\
\text { small leak can } \\
\text { probably be tolerated } \\
\text { until the end of the } \\
\text { campaign, then shut } \\
\text { down TBM to repair } \\
\text { the leak. }\end{array}$ & $\begin{array}{l}\text { Small LOCA, } \\
\text { LMP2 }\end{array}$ & $\begin{array}{l}\text { At high temperatures } \\
\mathrm{Pb}-17 \mathrm{Li} \text { is reputed to be } \\
\text { very fluid, low viscosity, } \\
\text { so leak flow rates could } \\
\text { be appreciable. }\end{array}$ & $\begin{array}{l}1 \mathrm{E}-09 / \mathrm{h}, \\
\text { assuming }<1 \\
\mathrm{~m} \text { of tubing }\end{array}$ & $\begin{array}{l}\text { WSRC-TR- } \\
93-262\end{array}$ & $\begin{array}{l}\text { The TBM can withstand ITER } \\
\text { pulsing with just helium coolant } \\
\text { operational. The } \mathrm{Pb}-17 \mathrm{Li} \text { flow is } \\
\text { slow, but it is at } 2 \mathrm{MPa} \text { and } \\
\text { breaches to a nominally } 0.1 \mathrm{MPa} \\
\text { room. Instrument leaks should be } \\
\text { very low flow rates, such as } \\
\text { through cracks, assume }<<1 \% \text { of } \\
\text { the coolant flow rate, i.e., } \\
\text { drops/minute. An important issue } \\
\text { is release of activated gases, such } \\
\text { as mercury and tritium, that evolve } \\
\text { from the Pr- } 17 \mathrm{Li} \text {. Amounts of } \\
\text { these gases should be small. }\end{array}$ \\
\hline
\end{tabular}




\begin{tabular}{|c|c|c|c|c|c|c|c|c|c|c|c|c|}
\hline Component & $\begin{array}{c}\text { Operational } \\
\text { State }\end{array}$ & $\begin{array}{c}\text { Failure } \\
\text { Mode }\end{array}$ & $\begin{array}{c}\text { Frequency } \\
\text { Category }\end{array}$ & Possible Causes & $\begin{array}{c}\text { Preventive } \\
\text { Action on } \\
\text { Possible Causes } \\
\end{array}$ & Consequences & $\begin{array}{c}\text { Corrective or } \\
\text { Preventive Actions } \\
\text { on Consequences } \\
\end{array}$ & $\begin{array}{l}\text { ITER Postulated } \\
\text { Initiating Events }\end{array}$ & Comments & Frequency & $\begin{array}{l}\text { Comment on } \\
\text { frequency } \\
\text { calculation } \\
\end{array}$ & Design comments \\
\hline & & $\begin{array}{l}\text { external } \\
\text { rupture }\end{array}$ & $<$ Cat IV & $\begin{array}{l}\text { instrument tap } \\
\text { line material } \\
\text { failure, weld } \\
\text { failure, over- } \\
\text { pressure on } \\
\text { instrument }\end{array}$ & $\begin{array}{l}\text { weld NDT, } \\
\text { reduce flow- } \\
\text { induced } \\
\text { vibration in } \\
\text { design }\end{array}$ & $\begin{array}{l}\text { Instrument line rupture } \\
\text { leakage from pump } \\
\text { volute could be high } \\
\text { volume. }\end{array}$ & \begin{tabular}{|l|} 
Shut down pump, \\
isolate pump. If \\
needed, open drain \\
line to store $\mathrm{Pb}-17 \mathrm{Li}$ \\
in the drain tank. \\
ITER can continue to \\
run. \\
\end{tabular} & LOCA, LMP1 & & $\begin{array}{l}3 \mathrm{E}-11 / \mathrm{h}, \\
\text { assuming }<1 \\
\mathrm{~m} \text { of tubing }\end{array}$ & $\begin{array}{l}\text { WSRC-TR- } \\
93-262\end{array}$ & $\begin{array}{l}\text { The TBM can withstand ITER } \\
\text { pulsing with just helium coolant } \\
\text { operational. }\end{array}$ \\
\hline \multirow[t]{4}{*}{$\begin{array}{l}\text { Pressure } \\
\text { instrument }\end{array}$} & NO & $\begin{array}{l}\text { fails to } \\
\text { operate }\end{array}$ & Category III & $\begin{array}{l}\text { fouling, } \\
\text { calibration error, } \\
\text { power loss }\end{array}$ & $\begin{array}{l}\text { Coolant filtering } \\
\text { and cleaning, } \\
\text { periodic } \\
\text { recalibration, } \\
\text { redundant power } \\
\text { and redundant } \\
\text { sensors }\end{array}$ & $\begin{array}{l}\text { Loss of signal regarding } \\
\text { gas pressure may mean } \\
\text { that the gas pressure is } \\
\text { lost and that air could } \\
\text { intrude into the piping. } \\
\text { Intruding air can react } \\
\text { with the lithium. }\end{array}$ & $\begin{array}{l}\text { Shut down and drain } \\
\text { loop to prevent air } \\
\text { reactions with hot } \\
\mathrm{Pb}-17 \mathrm{Li} \text {. }\end{array}$ & Not an IE, N/S & $\begin{array}{l}\text { Fast fission reactors } \\
\text { have used metal } \\
\text { diaphragm pressure } \\
\text { sensors. These can } \\
\text { operate in the } 2 \mathrm{MPa} \\
\text { range. It must be kept } \\
\text { free of coolant oxide and } \\
\text { crud, and not allow } \\
\text { liquid metal freezing on } \\
\text { the diaphragm. Fiber } \\
\text { optics can be used to } \\
\text { sense the diaphragm } \\
\text { bulging. Sensor } \\
\text { maintenance is an ORE } \\
\text { concern. }\end{array}$ & $1 \mathrm{E}-06 / \mathrm{h}$ & $\begin{array}{l}\text { INEL- } \\
96 / 0295\end{array}$ & $\begin{array}{l}\text { Designers should consider sensor } \\
\text { redundancy in the design, since } \\
\text { replacing failed sensors will be a } \\
\text { difficult task. If penetrations for } \\
\text { sensors are robust (i.e., sensor } \\
\text { 'tree') and common causes of } \\
\text { failure are controlled, then } \\
\text { redundany will allow use of } \\
\text { voting logic to filter out spurious } \\
\text { noise signals and allow continued } \\
\text { TBM operation with a sensor } \\
\text { failure. }\end{array}$ \\
\hline & & $\begin{array}{l}\text { improper } \\
\text { reading }\end{array}$ & Category III & $\begin{array}{l}\text { calibration error, } \\
\text { drift, diaphragm } \\
\text { damage }\end{array}$ & \begin{tabular}{|l|} 
Periodic \\
recalibration
\end{tabular} & $\begin{array}{l}\text { Loss of signal regarding } \\
\text { gas pressure may mean } \\
\text { that the gas pressure is } \\
\text { lost and that air could } \\
\text { intrude into the piping. } \\
\text { Intruding air can react } \\
\text { with the lithium. }\end{array}$ & \begin{tabular}{|l|} 
No immediate \\
actions needed, run \\
to next shutdown \\
period if other \\
sensors can provide \\
adequate information \\
to operate the TBM \\
safely.
\end{tabular} & Not an IE, N/S & $\begin{array}{l}\text { Recalibration activity } \\
\text { could result in a } \\
\text { significant personnel } \\
\text { radiation exposure }\end{array}$ & $1 \mathrm{E}-06 / \mathrm{h}$ & $\begin{array}{l}\text { INEL- } \\
\text { 96/0295 }\end{array}$ & $\begin{array}{l}\text { Use sensors that can be remotely } \\
\text { recalibrated whenever possible to } \\
\text { reduce personnel exposure }\end{array}$ \\
\hline & & external leak & Category IV & $\begin{array}{l}\text { instrument pipe } \\
\text { tap crack, } \\
\text { instrument line } \\
\text { crack, weld } \\
\text { crack }\end{array}$ & $\begin{array}{l}\text { Materials } \\
\text { selection in } \\
\text { design, pre- } \\
\text { service } \\
\text { inspection, low } \\
\text { flow-induced } \\
\text { vibration in } \\
\text { design }\end{array}$ & $\begin{array}{l}\text { Leaks Pb-17Li to the } \\
30 \mathrm{C} \text { air atmosphere in } \\
\text { the equatorial test port. }\end{array}$ & \begin{tabular}{l|} 
Isolate leak if \\
possible, assume that \\
a very small leak can \\
be tolerated until the \\
end of the campaign, \\
then shut down TBM \\
to repair the leak.
\end{tabular} & $\begin{array}{l}\text { Small LOCA, } \\
\text { LMP2 }\end{array}$ & & $\begin{array}{l}1 \mathrm{E}-09 / \mathrm{h}, \\
\text { assuming }<1 \\
\mathrm{~m} \text { of tubing }\end{array}$ & $\begin{array}{l}\text { WSRC-TR- } \\
\text { 93-262 }\end{array}$ & $\begin{array}{l}\text { Instrument leaks should be very } \\
\text { low flow rates, such as through } \\
\text { cracks, assume }<<1 \% \text { of the } \\
\text { coolant flow rate, I.e., drops per } \\
\text { minute. An important issue is } \\
\text { potential release of activated gases, } \\
\text { such as mercury and tritium. }\end{array}$ \\
\hline & & $\begin{array}{l}\text { external } \\
\text { rupture }\end{array}$ & $<$ Cat IV & $\begin{array}{l}\text { instrument tap } \\
\text { material failure, } \\
\text { instrument line } \\
\text { material failure, } \\
\text { weld failure }\end{array}$ & $\begin{array}{l}\text { Same as external } \\
\text { leak, given } \\
\text { above }\end{array}$ & $\begin{array}{l}\text { Leaks moderate to large } \\
\text { amount of } \mathrm{Pb}-17 \mathrm{Li} \text { to } \\
\text { the equatorial test port }\end{array}$ & $\begin{array}{l}\text { Isolate the leak if } \\
\text { possible, open the } \\
\text { drain tank to limit } \\
\text { the release. }\end{array}$ & LOCA, LMP1 & & $\begin{array}{l}3 \mathrm{E}-11 / \mathrm{h}, \\
\text { assuming }<1 \\
\mathrm{~m} \text { of tubing }\end{array}$ & $\begin{array}{l}\text { WSRC-TR- } \\
93-262\end{array}$ & $\begin{array}{l}\text { Hot Pb-17Li leak could threaten } \\
\text { the bellows seal on the port, if the } \\
\text { leak touches the bellows. Some } \\
\text { type of guard pipe, catch pans, or a } \\
\text { protective sleeve for the bellows, } \\
\text { should be considered. }\end{array}$ \\
\hline $\begin{array}{l}\text { Temperature } \\
\text { instrument }\end{array}$ & NO & $\begin{array}{l}\text { fails to } \\
\text { operate }\end{array}$ & Category III & $\begin{array}{l}\text { fouling, drift, } \\
\text { calibration error }\end{array}$ & $\begin{array}{l}\text { Coolant filtering } \\
\text { and cleaning, } \\
\text { periodic } \\
\text { recalibration }\end{array}$ & & $\begin{array}{l}\text { No immediate } \\
\text { actions needed, run } \\
\text { to next shutdown } \\
\text { period if other } \\
\text { sensors can provide } \\
\text { adequate information } \\
\text { to operate the TBM } \\
\text { safely. }\end{array}$ & Not an IE, N/S & $\begin{array}{l}\text { Assume that either a } \\
\text { platinum thermocouple } \\
\text { or RTD will be used for } \\
\text { this } 340 \text { to } 470 \mathrm{C} \text { (or } \\
650 \mathrm{C} \text { ) operating } \\
\text { temperature range. } \\
\text { Sensor maintenance is } \\
\text { an ORE concern. }\end{array}$ & $2.2 \mathrm{E}-06 / \mathrm{h}$ & $\begin{array}{l}\text { INEL- } \\
96 / 0295\end{array}$ & $\begin{array}{l}\text { Several authors noted that } \\
\text { redundant instrumentation was } \\
\text { very useful for flow loop } \\
\text { operations. }\end{array}$ \\
\hline
\end{tabular}




\begin{tabular}{|c|c|c|c|c|c|c|c|c|c|c|c|c|}
\hline Component & $\begin{array}{c}\text { Operational } \\
\text { State }\end{array}$ & $\begin{array}{c}\text { Failure } \\
\text { Mode }\end{array}$ & $\begin{array}{c}\text { Frequency } \\
\text { Category }\end{array}$ & Possible Causes & $\begin{array}{c}\text { Preventive } \\
\text { Action on } \\
\text { Possible Causes } \\
\end{array}$ & Consequences & $\begin{array}{c}\text { Corrective or } \\
\text { Preventive Actions } \\
\text { on Consequences } \\
\end{array}$ & $\begin{array}{l}\text { ITER Postulated } \\
\text { Initiating Events }\end{array}$ & Comments & Frequency & $\begin{array}{l}\text { Comment on } \\
\text { frequency } \\
\text { calculation } \\
\end{array}$ & Design comments \\
\hline & & $\begin{array}{l}\text { improper } \\
\text { reading }\end{array}$ & Category II & $\begin{array}{l}\text { calibration error, } \\
\text { drift, impurity } \\
\text { plateout }\end{array}$ & $\begin{array}{l}\text { Periodic } \\
\text { recalibration }\end{array}$ & $\begin{array}{l}\text { Overcooling or } \\
\text { undercooling transient } \\
\text { with Pb-17Li }\end{array}$ & $\begin{array}{l}\text { No immediate } \\
\text { actions needed, run } \\
\text { to next shutdown } \\
\text { period if other } \\
\text { sensors can provide } \\
\text { adequate information } \\
\text { to operate the TBM } \\
\text { safely. }\end{array}$ & Not an IE, N/S & $\begin{array}{l}\text { Overcooling would } \\
\text { reduce the } 100 \mathrm{C} \text { margin } \\
\text { above melt temperature. }\end{array}$ & $1.7 \mathrm{E}-05 / \mathrm{h}$ & $\begin{array}{l}\text { INEL- } \\
\text { 96/0295 }\end{array}$ & \\
\hline & & external leak & Category II & $\begin{array}{l}\text { instrument tap } \\
\text { line crack, } \\
\text { instrument line } \\
\text { crack, weld } \\
\text { crack }\end{array}$ & $\begin{array}{l}\text { Materials } \\
\text { selection in } \\
\text { design, pre- } \\
\text { service } \\
\text { inspection, low } \\
\text { flow-induced } \\
\text { vibration in } \\
\text { design, NDT }\end{array}$ & $\begin{array}{l}\text { Leaks } \mathrm{Pb}-17 \mathrm{Li} \text { to the } \\
30 \mathrm{C} \text { air atmosphere in } \\
\text { the equatorial test port. }\end{array}$ & $\begin{array}{l}\text { Isolate leak if } \\
\text { possible. Assume } \\
\text { that a small leak can } \\
\text { be tolerated until the } \\
\text { end of the campaign, } \\
\text { then shut down TBM } \\
\text { to repair the leak. }\end{array}$ & $\begin{array}{l}\text { Small LOCA, } \\
\text { LMP2 }\end{array}$ & $\begin{array}{l}\text { Thermocouple fitting is } \\
\text { a flange connection. } \\
\text { Use flange failure rate. }\end{array}$ & $1 \mathrm{E}-08 / \mathrm{h}$ & $\begin{array}{l}\text { EGG-SSRE- } \\
9639\end{array}$ & $\begin{array}{l}\text { Instrument leaks should be very } \\
\text { low flow rates, such as through- } \\
\text { wall cracks or pinhole leaks, } \\
\text { assume }<<1 \% \text { of the coolant flow } \\
\text { rate (I.e., drops/minute). An } \\
\text { important issue is release of } \\
\text { activated gases, such as mercury } \\
\text { and tritium - concentrations should } \\
\text { be low. }\end{array}$ \\
\hline & & $\begin{array}{l}\text { external } \\
\text { rupture }\end{array}$ & Category III & $\begin{array}{l}\text { instrument tap } \\
\text { line material } \\
\text { failure, weld } \\
\text { failure }\end{array}$ & $\begin{array}{l}\text { Materials } \\
\text { selection in } \\
\text { design, pre- } \\
\text { service } \\
\text { inspection, low } \\
\text { flow-induced } \\
\text { vibration in } \\
\text { design, NDT }\end{array}$ & $\begin{array}{l}\text { Leaks moderate to large } \\
\text { amount of } \mathrm{Pb}-17 \mathrm{Li} \text { to } \\
\text { the equatorial test port }\end{array}$ & $\begin{array}{l}\text { Turn off the pump, } \\
\text { isolate leak if } \\
\text { possible, open the } \\
\text { drain tank to capture } \\
\text { Pb-17Li to limit the } \\
\text { release. }\end{array}$ & LOCA, LMP1 & $\begin{array}{l}\text { The TBM DDD stated } \\
\text { that activated mercury } \\
\text { gas could be present, } \\
\text { and small Curie amounts } \\
\text { of tritium might escape } \\
\text { as well. Hot helium gas } \\
\text { at } 340 \text { C or higher would } \\
\text { be a safety concern. }\end{array}$ & $1 \mathrm{E}-10 / \mathrm{h}$ & $\begin{array}{l}\text { EGG-SSRE- } \\
9639\end{array}$ & $\begin{array}{l}\text { Hot }(470 \text { to } 650 \mathrm{C}) \mathrm{Pb}-17 \mathrm{Li} \\
\text { leaking from a } 9.5-\mathrm{mm} \text { instrument } \\
\text { tap onto the bellows that seals the } \\
\text { port from the cryostat could lead to } \\
\text { a bellows breach, which would } \\
\text { lead to a loss of cryostat vacuum. } \\
\text { The vacuum would draw some } \mathrm{Pb}- \\
17 \mathrm{Li} \text { into the cryostat as well as } \\
\text { humid air, all of which would } \\
\text { freeze onto the magnets, creating } \\
\text { contamination issues for the } \\
\text { magnets. Some type of catch pan } \\
\text { or bellows inner sleeve should be } \\
\text { used to preclude contact. }\end{array}$ \\
\hline \multirow[t]{2}{*}{ Piping } & NO & external leak & Category III & $\begin{array}{l}\text { Weld fault, pipe } \\
\text { wall flaw, } \\
\text { construction } \\
\text { fault }\end{array}$ & $\begin{array}{l}\text { Materials } \\
\text { selection in } \\
\text { design, pre- } \\
\text { service } \\
\text { inspection, low } \\
\text { flow-induced } \\
\text { vibration in } \\
\text { design, NDT }\end{array}$ & $\begin{array}{l}\text { Leaks small to } \\
\text { moderate amount of } \mathrm{Pb}- \\
\text { 17Li to the equatorial } \\
\text { test port }\end{array}$ & $\begin{array}{l}\text { Small loss of coolant } \\
\text { accident. Shut down } \\
\text { ITER by the end of } \\
\text { pulse, drain Pb-17Li } \\
\text { to drain tank to limit } \\
\text { release, increase } \\
\text { helium cooling to } \\
\text { TBM and increase } \\
\text { frame cooling. }\end{array}$ & $\begin{array}{l}\text { Small LOCA, } \\
\text { LMP2 }\end{array}$ & $\begin{array}{l}\text { Assume } \approx 200 \mathrm{~m} \text { total } \\
\text { piping length runs and } \\
3360 \mathrm{~h} \text { per year. Even at } \\
650 \mathrm{C}, \mathrm{Pb}-17 \mathrm{Li} \text { is not } \\
\text { very reactive in air and } \\
\text { should not pose a large } \\
\text { chemical reactivity } \\
\text { concern. However, the } \\
\text { spill must be kept from } \\
\text { the bellows seals to the } \\
\text { cryostat. }\end{array}$ & $9 \mathrm{E}-09 / \mathrm{h}-\mathrm{m}$ & $\begin{array}{l}\text { EGG-SSRE- } \\
8875\end{array}$ & $\begin{array}{l}\text { Hot liquid metals can cause weld } \\
\text { slag inclusions to grow into leaks, } \\
\text { and microfissures or flaws in the } \\
\text { pipe wall can propagate into leaks } \\
\text { if there is thermal shocking } \\
\text { (Mausteller, Tepper, and Rodgers, } \\
\text { Alkali Metal Handling and } \\
\text { Systems Operating Techniques, } \\
\text { Gordon and Breach Publishers, } \\
\text { NY, 1967, page 138.). Pb-17Li } \\
\text { leaks near the port bellows could } \\
\text { cause bellows breach and loss of } \\
\text { cryostat vacuum. Use catch pans, } \\
\text { guard pipe, sleeve over bellows, } \\
\text { etc., to preclude contact. }\end{array}$ \\
\hline & & $\begin{array}{l}\text { external } \\
\text { rupture }\end{array}$ & Category III & $\begin{array}{l}\text { Weld failure, } \\
\text { wall cracking, } \\
\text { wall thinning, } \\
\text { construction } \\
\text { fault }\end{array}$ & $\begin{array}{l}\text { Materials } \\
\text { selection in } \\
\text { design, pre- } \\
\text { service } \\
\text { inspection, low } \\
\text { flow-induced } \\
\text { vibration in } \\
\text { design, NDT }\end{array}$ & $\begin{array}{l}\text { Leaks moderate to large } \\
\text { amount of } \mathrm{Pb}-17 \mathrm{Li} \text { to } \\
\text { the equatorial test port }\end{array}$ & $\begin{array}{l}\text { Large loss of coolant } \\
\text { accident. Drain Pb- } \\
\text { 17Li to drain tank to } \\
\text { limit release, verify } \\
\text { helium cooling to } \\
\text { TBM. Shut down } \\
\text { ITER to clean up } \\
\text { spill. }\end{array}$ & LOCA, LMP1 & $\begin{array}{l}\text { Assume } \approx 200 \mathrm{~m} \text { total } \\
\text { piping length runs and } \\
3360 \mathrm{~h} \text { per year }\end{array}$ & $9 \mathrm{E}-10 / \mathrm{h}-\mathrm{m}$ & $\begin{array}{l}\text { EGG-SSRE- } \\
8875\end{array}$ & $\begin{array}{l}\text { Pb-17Li leaks near the port bellows } \\
\text { could cause bellows breach and } \\
\text { loss of cryostat vacuum. Some } \\
\text { type of barrier, either a guard pipe } \\
\text { around the Pb-17Li pipe, catch } \\
\text { pans, or a protective sleeve on the } \\
\text { bellows convolutions is needed to } \\
\text { protect the bellows. }\end{array}$ \\
\hline
\end{tabular}




\begin{tabular}{|c|c|c|c|c|c|c|c|c|c|c|c|c|}
\hline Component & $\begin{array}{c}\text { Operational } \\
\text { State }\end{array}$ & $\begin{array}{c}\text { Failure } \\
\text { Mode }\end{array}$ & $\begin{array}{l}\text { Frequency } \\
\text { Category }\end{array}$ & Possible Causes & $\begin{array}{c}\text { Preventive } \\
\text { Action on } \\
\text { Possible Causes }\end{array}$ & Consequences & $\begin{array}{c}\text { Corrective or } \\
\text { Preventive Actions } \\
\text { on Consequences }\end{array}$ & $\begin{array}{l}\text { ITER Postulated } \\
\text { Initiating Events }\end{array}$ & Comments & Frequency & $\begin{array}{c}\text { Comment on } \\
\text { frequency } \\
\text { calculation }\end{array}$ & Design comments \\
\hline & & plugging & Category III & $\begin{array}{l}\text { impurity } \\
\text { buildup, } \\
\text { corrosion } \\
\text { product buildup, } \\
\text { foreign material } \\
\text { buildup }\end{array}$ & $\begin{array}{l}\text { Good coolant } \\
\text { chemistry } \\
\text { control with cold } \\
\text { trap, keep } \\
\text { temperature up } \\
\text { to prevent } \\
\text { precipitation }\end{array}$ & Loss of Pb-17Li flow & $\begin{array}{l}\text { Decreasing flow } \\
\text { accident. Should } \\
\text { occur gradually, so } \\
\text { record flow and } \\
\text { pumping power and } \\
\text { track changes. ITER } \\
\text { can continue to } \\
\text { operate. }\end{array}$ & LOFA, N/S & $\begin{array}{l}\text { Assume } \approx 200 \mathrm{~m} \text { total } \\
\text { piping length runs and } \\
3360 \mathrm{~h} \mathrm{per} \mathrm{year}\end{array}$ & $3 \mathrm{E}-09 / \mathrm{h}-\mathrm{m}$ & $\begin{array}{l}\text { EGG-SSRE- } \\
8875\end{array}$ & $\begin{array}{l}\text { No flow instrument was shown in } \\
\text { the schematic diagram. Any flow } \\
\text { loop should have at least one flow } \\
\text { instrument. }\end{array}$ \\
\hline \multirow[t]{6}{*}{$\begin{array}{l}\text { Check valve by } \\
\text { heat exchanger } \\
\text { (normally open) }\end{array}$} & NO & fail to open & Category III & $\begin{array}{l}\text { impurity } \\
\text { buildup, } \\
\text { corrosion } \\
\text { product buildup, } \\
\text { hinge fault }\end{array}$ & $\begin{array}{l}\text { Good coolant } \\
\text { chemistry } \\
\text { control with cold } \\
\text { trap, keep } \\
\text { temperature up } \\
\text { to prevent } \\
\text { precipitation }\end{array}$ & $\begin{array}{l}\text { Loss of Pb-17Li flow or } \\
\text { severely limited flow }\end{array}$ & $\begin{array}{l}\text { Condition should be } \\
\text { detected in system } \\
\text { operability testing } \\
\text { and IER can still } \\
\text { start up without the } \\
\text { TBM Pb-17Li loop. }\end{array}$ & Not an IE, N/S & & $1 \mathrm{E}-04 / \mathrm{d}$ & $\begin{array}{l}\text { EGG-SSRE- } \\
8875\end{array}$ & $\begin{array}{l}\text { Assume } 4 \text { demands per year, one } \\
\text { per loop startup after each } \\
\text { maintenance outage }\end{array}$ \\
\hline & & plugging & Category III & $\begin{array}{l}\text { impurity } \\
\text { buildup, } \\
\text { corrosion } \\
\text { product buildup }\end{array}$ & $\begin{array}{l}\text { Good coolant } \\
\text { chemistry } \\
\text { control with cold } \\
\text { trap, keep } \\
\text { temperature up } \\
\text { to prevent } \\
\text { precipitation }\end{array}$ & $\begin{array}{l}\text { Loss of Pb-17Li flow in } \\
\text { this once-through loop }\end{array}$ & $\begin{array}{l}\text { Decreasing flow } \\
\text { accident. Should } \\
\text { occur gradually, } \\
\text { record pumping } \\
\text { power and track } \\
\text { changes. Shut down } \\
\text { the Pb-17Li loop and } \\
\text { continue ITER } \\
\text { operation. }\end{array}$ & $\begin{array}{l}\text { LOFA condition } \\
\text { but not an IE, N/S }\end{array}$ & & $5 \mathrm{E}-07 / \mathrm{h}$ & $\begin{array}{l}\text { EGG-SSRE- } \\
8875\end{array}$ & $\begin{array}{l}\text { ITER can operate with the } \mathrm{Pb}-17 \mathrm{Li} \\
\text { flow loop disabled. }\end{array}$ \\
\hline & & $\begin{array}{l}\text { internal } \\
\text { leakage }\end{array}$ & Category III & $\begin{array}{l}\text { valve seat wear, } \\
\text { impurity or } \\
\text { corrosion } \\
\text { product buildup }\end{array}$ & $\begin{array}{l}\text { Good coolant } \\
\text { chemistry } \\
\text { control with cold } \\
\text { trap, keep } \\
\text { temperature up } \\
\text { to prevent } \\
\text { precipitation }\end{array}$ & $\begin{array}{l}\text { Limited reverse flow } \\
\text { could occur in the Pb- } \\
\text { 17 Li flow loop }\end{array}$ & $\begin{array}{l}\text { No actions to take } \\
\text { for this event }\end{array}$ & Not an IE & & $5 \mathrm{E}-07 / \mathrm{h}$ & $\begin{array}{l}\text { EGG-SSRE- } \\
8875\end{array}$ & $\begin{array}{l}\text { If valve is closed, ITER is in a } \\
\text { shutdown }\end{array}$ \\
\hline & & $\begin{array}{l}\text { internal } \\
\text { rupture }\end{array}$ & Category III & $\begin{array}{l}\text { valve disc } \\
\text { failure, hinge } \\
\text { failure }\end{array}$ & $\begin{array}{l}\text { operations } \\
\text { testing, } \\
\text { inspection, NDT }\end{array}$ & $\begin{array}{l}\text { Reverse flow could } \\
\text { occur in the } \mathrm{Pb}-17 \mathrm{Li} \\
\text { flow loop }\end{array}$ & $\begin{array}{l}\text { No actions to take } \\
\text { for this event }\end{array}$ & Not an IE & & $5 \mathrm{E}-07 / \mathrm{h}$ & $\begin{array}{l}\text { EGG-SSRE- } \\
8875\end{array}$ & \\
\hline & & $\begin{array}{l}\text { external } \\
\text { leakage }\end{array}$ & Category III & $\begin{array}{l}\text { valve body } \\
\text { crack, } \\
\text { maintenance } \\
\text { port leak }\end{array}$ & $\begin{array}{l}\text { operations } \\
\text { testing, } \\
\text { inspection, NDT }\end{array}$ & $\begin{array}{l}\text { Loss of coolant into } \\
\text { equatorial port }\end{array}$ & $\begin{array}{l}\text { Close valves to } \\
\text { isolate the leaking } \\
\text { valve. }\end{array}$ & $\begin{array}{l}\text { Small LOCA, } \\
\text { LMP2 }\end{array}$ & & $5 \mathrm{E}-07 / \mathrm{h}$ & $\begin{array}{l}\text { EGG-SSRE- } \\
8875\end{array}$ & $\begin{array}{l}\text { ITER can operate with the } \mathrm{Pb}-17 \mathrm{Li} \\
\text { flow loop disabled. }\end{array}$ \\
\hline & & $\begin{array}{l}\text { external } \\
\text { rupture }\end{array}$ & Category III & $\begin{array}{l}\text { valve body } \\
\text { failure }\end{array}$ & $\begin{array}{l}\text { operations } \\
\text { testing, } \\
\text { inspection, NDT }\end{array}$ & $\begin{array}{l}\text { Large loss of coolant } \\
\text { into equatorial port }\end{array}$ & $\begin{array}{l}\text { Close valves to } \\
\text { isolate the ruptured } \\
\text { check valve body. }\end{array}$ & LOCA, LMP1 & & $5 \mathrm{E}-07 / \mathrm{h}$ & $\begin{array}{l}\text { EGG-SSRE- } \\
8875\end{array}$ & $\begin{array}{l}\text { ITER can operate with the } \mathrm{Pb}-17 \mathrm{Li} \\
\text { flow loop disabled. }\end{array}$ \\
\hline
\end{tabular}




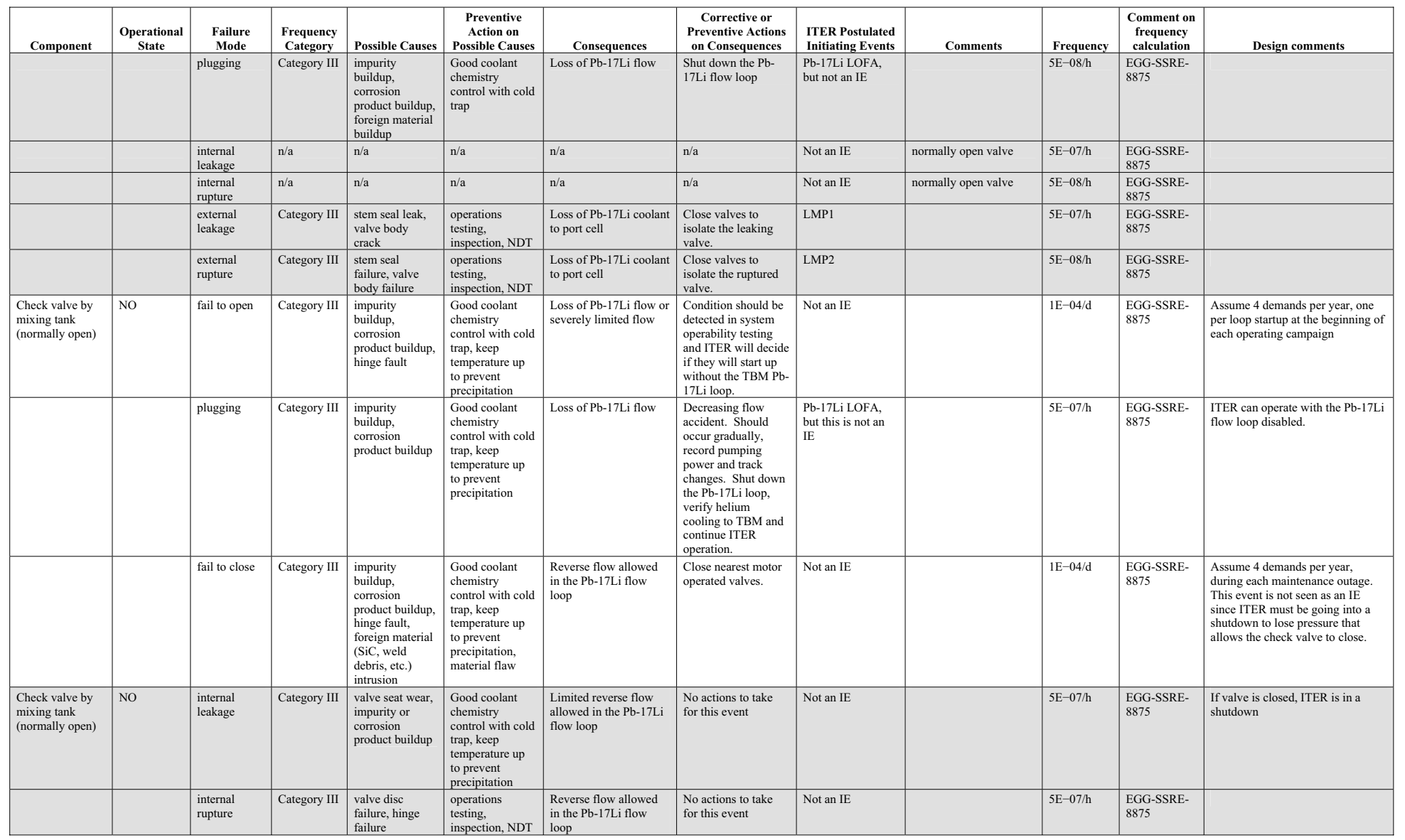




\begin{tabular}{|c|c|c|c|c|c|c|c|c|c|c|c|c|}
\hline Component & $\begin{array}{c}\text { Operational } \\
\text { State }\end{array}$ & $\begin{array}{c}\text { Failure } \\
\text { Mode }\end{array}$ & $\begin{array}{l}\text { Frequency } \\
\text { Category }\end{array}$ & Possible Causes & \begin{tabular}{|c|} 
Preventive \\
Action on \\
Possible Causes \\
\end{tabular} & Consequences & $\begin{array}{c}\text { Corrective or } \\
\text { Preventive Actions } \\
\text { on Consequences }\end{array}$ & $\begin{array}{l}\text { ITER Postulated } \\
\text { Initiating Events }\end{array}$ & Comments & Frequency & $\begin{array}{c}\text { Comment on } \\
\text { frequency } \\
\text { calculation }\end{array}$ & Design comments \\
\hline & & $\begin{array}{l}\text { external } \\
\text { leakage }\end{array}$ & Category III & $\begin{array}{l}\text { valve body } \\
\text { crack, } \\
\text { maintenance } \\
\text { port leak }\end{array}$ & $\begin{array}{l}\text { operations } \\
\text { testing, } \\
\text { inspection, NDT }\end{array}$ & $\begin{array}{l}\text { Loss of } \mathrm{Pb}-17 \mathrm{Li} \text { coolant } \\
\text { into equatorial port }\end{array}$ & $\begin{array}{l}\text { Close valves to } \\
\text { isolate the leaking } \\
\text { valve. }\end{array}$ & $\begin{array}{l}\text { Small Pb-17Li } \\
\text { LOCA, LMP2 }\end{array}$ & & $5 \mathrm{E}-07 / \mathrm{h}$ & $\begin{array}{l}\text { EGG-SSRE- } \\
8875\end{array}$ & $\begin{array}{l}\text { ITER can operate with the Pb-17Li } \\
\text { flow loop disabled. }\end{array}$ \\
\hline & & $\begin{array}{l}\text { external } \\
\text { rupture }\end{array}$ & Category III & $\begin{array}{l}\text { valve body } \\
\text { failure }\end{array}$ & $\begin{array}{l}\text { operations } \\
\text { testing, } \\
\text { inspection, NDT }\end{array}$ & $\begin{array}{l}\text { Large loss of } \mathrm{Pb}-17 \mathrm{Li} \\
\text { coolant into equatorial } \\
\text { port }\end{array}$ & $\begin{array}{l}\text { Close valves to } \\
\text { isolate the ruptured } \\
\text { check valve body. } \\
\text { Verify helium } \\
\text { cooling of TBM. }\end{array}$ & $\begin{array}{l}\text { Pb-17Li LOCA, } \\
\text { LMP1 }\end{array}$ & & $5 \mathrm{E}-07 / \mathrm{h}$ & $\begin{array}{l}\text { EGG-SSRE- } \\
8875\end{array}$ & $\begin{array}{l}\text { ITER can operate with the } \mathrm{Pb}-17 \mathrm{Li} \\
\text { flow loop disabled. }\end{array}$ \\
\hline \multirow[t]{6}{*}{$\begin{array}{l}\text { Mixing tank inlet } \\
\text { flow control } \\
\text { valve }\end{array}$} & NO & fail to open & & \begin{tabular}{l|l} 
valve will \\
always be open \\
to $16 \mathrm{~kg} / \mathrm{s}$ unless \\
plugged
\end{tabular} & not applicable & not applicable & & Not an IE & & $1 \mathrm{E}-03 / \mathrm{d}$ & $\begin{array}{l}\text { EGG-SSRE- } \\
8875\end{array}$ & $\begin{array}{l}\text { This valve is assumed to be sized } \\
\text { to allow at most only } 77 \%(55.5 \\
\mathrm{kg} / \mathrm{s} \text { ) of the total inlet flow into the } \\
\text { mixing tank, so that } \approx 16.5 \mathrm{~kg} / \mathrm{s} \\
\mathrm{Pb}-17 \mathrm{Li} \text { always travels to the } \\
\text { TBM. Perhaps there is a valve disk } \\
\text { stop so that even fully open the } \\
\text { valve still sends } 23 \% \text { flow to the } \\
\text { TBM. It is assumed that the valve } \\
\text { gives a significant pressure drop so } \\
\text { that the TBM outlet Pb-17Li, } \\
\text { which underwent friction and } \\
\text { MHD pressure drop in the TBM, } \\
\text { does not experience flow reversal } \\
\text { by higher pressure Pb-17Li } \\
\text { entering the mixing tank from this } \\
\text { valve. }\end{array}$ \\
\hline & & $\begin{array}{l}\text { spurious } \\
\text { operation }\end{array}$ & Category III & $\begin{array}{l}\text { command fault, } \\
\text { human error, } \\
\text { electronic noise }\end{array}$ & $\begin{array}{l}\text { periodic testing, } \\
\text { software QA }\end{array}$ & $\begin{array}{l}\text { Poor temperature } \\
\text { control in mixing tank, } \\
\text { overcooling the } \mathrm{Pb}- \\
17 \mathrm{Li}\end{array}$ & & Not an IE & & $3 \mathrm{E}-07 / \mathrm{h}$ & $\begin{array}{l}\text { EGG-SSRE- } \\
8875\end{array}$ & $\begin{array}{l}\text { Overcooling does not appear to } \\
\text { present a reliability concern to the } \\
\text { TBM module, silicon carbide FCIs, } \\
\text { or flow loop. }\end{array}$ \\
\hline & & plugging & Category III & $\begin{array}{l}\text { impurity } \\
\text { buildup, } \\
\text { corrosion } \\
\text { product buildup }\end{array}$ & $\begin{array}{l}\text { Good coolant } \\
\text { chemistry } \\
\text { control with cold } \\
\text { trap, keep } \\
\text { temperature up } \\
\text { to prevent } \\
\text { precipitation }\end{array}$ & $\begin{array}{l}\text { If plugged, all flow } \\
\text { routes to the TBM } \\
\text { module, cannot achieve } \\
650 \mathrm{C} \text { operation but the } \\
\text { TBM is adequately } \\
\text { cooled }\end{array}$ & $\begin{array}{l}\text { Note valve condition } \\
\text { for future } \\
\text { maintenance during } \\
\text { an ITER outage }\end{array}$ & Not an IE & & $5 \mathrm{E}-08 / \mathrm{h}$ & $\begin{array}{l}\text { EGG-SSRE- } \\
8875\end{array}$ & \\
\hline & & $\begin{array}{l}\text { internal } \\
\text { leakage or } \\
\text { internal } \\
\text { rupture }\end{array}$ & Category III & material failure & inspection, NDT & $\begin{array}{l}\text { Pb-17Li flow bypasses } \\
\text { TBM }\end{array}$ & $\begin{array}{l}\text { TBM can } \\
\text { accommodate flow } \\
\text { bypassing the TBM } \\
\text { module }\end{array}$ & LOFA, Not an IE & & $5 \mathrm{E}-07 / \mathrm{h}$ & $\begin{array}{l}\text { EGG-SSRE- } \\
8875\end{array}$ & $\begin{array}{l}\text { Due to valve design of always } \\
\text { providing } 16 \mathrm{~kg} / \mathrm{s} \text { through flow, } \\
\text { this failure mode means that higher } \\
\text { flow will enter the mixing tank } \\
\text { than set by operators, a bypass of } \\
\text { the TBM module but this is not a } \\
\text { safety event. }\end{array}$ \\
\hline & & $\begin{array}{l}\text { external } \\
\text { leakage }\end{array}$ & Category III & $\begin{array}{l}\text { valve body } \\
\text { crack, stem } \\
\text { leakage }\end{array}$ & inspection, NDT & $\begin{array}{l}\text { Small loss of coolant } \\
\text { into equatorial port }\end{array}$ & $\begin{array}{l}\text { Close isolation } \\
\text { valves to isolate the } \\
\text { leaking mixing tank } \\
\text { inlet valve. }\end{array}$ & $\begin{array}{l}\text { Small Pb-17Li } \\
\text { LOCA, LMP2 }\end{array}$ & & $1 \mathrm{E}-06 / \mathrm{h}$ & $\begin{array}{l}\text { EGG-SSRE- } \\
8875\end{array}$ & \\
\hline & & $\begin{array}{l}\text { external } \\
\text { rupture }\end{array}$ & Category III & $\begin{array}{l}\text { valve body } \\
\text { failure, total } \\
\text { stem packing } \\
\text { failure }\end{array}$ & inspection, NDT & $\begin{array}{l}\text { Large loss of coolant } \\
\text { into equatorial port }\end{array}$ & $\begin{array}{l}\text { Close isolation } \\
\text { valves to isolate the } \\
\text { ruptured mixing tank } \\
\text { inlet valve, drain } \mathrm{Pb}- \\
17 \mathrm{Li} \text { into drain tank } \\
\text { to limit release. }\end{array}$ & $\begin{array}{l}\text { Pb-17Li LOCA, } \\
\text { LMP1 }\end{array}$ & $\begin{array}{l}\text { If isolation valves are } \\
\text { slow closing units, then } \\
\text { consider draining the } \\
\mathrm{Pb}-17 \mathrm{Li} \text { to the drain } \\
\text { tank. }\end{array}$ & $1 \mathrm{E}-07 / \mathrm{h}$ & $\begin{array}{l}\text { EGG-SSRE- } \\
8875\end{array}$ & $\begin{array}{l}\text { Air will enter the Pb-17Li piping, } \\
\text { so coolant cleanup will be needed } \\
\text { to prepare the } \mathrm{Pb}-17 \mathrm{Li} \text { loop for } \\
\text { operations again. }\end{array}$ \\
\hline
\end{tabular}

74 


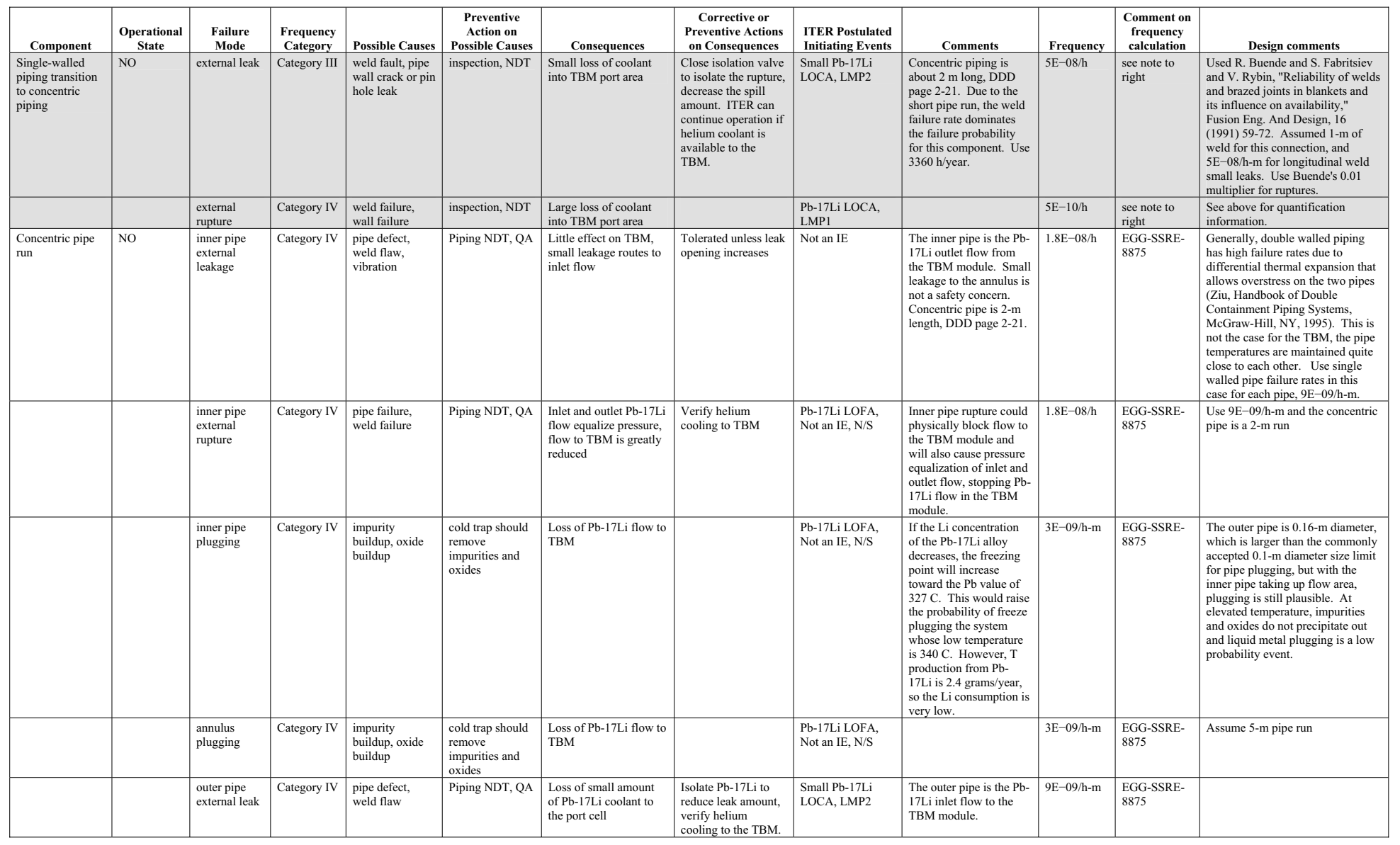




\begin{tabular}{|c|c|c|c|c|c|c|c|c|c|c|c|c|}
\hline Component & $\begin{array}{c}\text { Operational } \\
\text { State }\end{array}$ & $\begin{array}{l}\text { Failure } \\
\text { Mode }\end{array}$ & $\begin{array}{l}\text { Frequency } \\
\text { Category }\end{array}$ & Possible Causes & $\begin{array}{c}\text { Preventive } \\
\text { Action on } \\
\text { Possible Causes }\end{array}$ & Consequences & $\begin{array}{c}\text { Corrective or } \\
\text { Preventive Actions } \\
\text { on Consequences }\end{array}$ & $\begin{array}{l}\text { ITER Postulated } \\
\text { Initiating Events }\end{array}$ & Comments & Frequency & $\begin{array}{l}\text { Comment on } \\
\text { frequency } \\
\text { calculation }\end{array}$ & Design comments \\
\hline & & $\begin{array}{l}\text { outer pipe } \\
\text { external } \\
\text { rupture }\end{array}$ & Category IV & $\begin{array}{l}\text { pipe defect, } \\
\text { weld flaw }\end{array}$ & Piping NDT, QA & $\begin{array}{l}\text { Loss of Pb-17Li coolant } \\
\text { to the port cell }\end{array}$ & $\begin{array}{l}\text { Isolate Pb-17Li leak } \\
\text { location and open } \\
\text { drain tank to reduce } \\
\text { leak amount, verify } \\
\text { helium cooling to the } \\
\text { TBM. }\end{array}$ & $\begin{array}{l}\text { Pb-17Li LOCA, } \\
\text { LMP1 }\end{array}$ & & $9 \mathrm{E}-10 / \mathrm{h}-\mathrm{m}$ & $\begin{array}{l}\text { EGG-SSRE- } \\
8875\end{array}$ & \\
\hline \multirow[t]{2}{*}{$\begin{array}{l}\text { Concentric pipe } \\
\text { inlet connection } \\
\text { to TBM module } \\
\text { box }\end{array}$} & NO & $\begin{array}{l}\text { inner pipe } \\
\text { connection } \\
\text { external } \\
\text { leakage }\end{array}$ & Category II & $\begin{array}{l}\text { pipe defect, } \\
\text { capillary flow }\end{array}$ & Piping NDT, QA & $\begin{array}{l}\text { Little effect on TBM, } \\
\text { leakage of higher } \\
\text { pressure, cooler inlet } \\
\text { flow into the hotter } \\
\text { outlet flow is not } \\
\text { consequential unless it } \\
\text { is a very high flow rate } \\
\text { that bypasses the TBM } \\
\text { module }\end{array}$ & $\begin{array}{l}\text { Tolerated unless leak } \\
\text { opening increases }\end{array}$ & Not an IE & & $3 \mathrm{E}-05 / \mathrm{h}$ & $\begin{array}{l}\text { EGG-SRE- } \\
8875\end{array}$ & $\begin{array}{l}\text { Assume that the freeze seal } \\
\text { connection is not as leak tight as } \\
\text { welded connections. Analyst } \\
\text { judgment to use a gasketed flange } \\
\text { failure rate. }\end{array}$ \\
\hline & & $\begin{array}{l}\text { inner pipe } \\
\text { connection } \\
\text { external } \\
\text { rupture }\end{array}$ & Category II & pipe failure & Piping NDT, QA & $\begin{array}{l}\text { Inlet and outlet Pb-17Li } \\
\text { flow equalize pressure, } \\
\text { flow to TBM is greatly } \\
\text { reduced }\end{array}$ & $\begin{array}{l}\text { Verify helium } \\
\text { cooling to TBM }\end{array}$ & Not an IE & & $3 \mathrm{E}-06 / \mathrm{h}$ & $\begin{array}{l}\text { analyst } \\
\text { judgment }\end{array}$ & \\
\hline \multirow[t]{4}{*}{$\begin{array}{l}\text { TBM flow } \\
\text { passages }\end{array}$} & NO & $\begin{array}{l}\text { internal } \\
\text { leakage }\end{array}$ & Category III & $\begin{array}{l}\text { weld flaw, } \\
\text { material flaw }\end{array}$ & $\begin{array}{l}\text { weld and } \\
\text { material NDT, } \\
\text { QA }\end{array}$ & $\begin{array}{l}\text { helium at } 8 \mathrm{MPa} \text { leaks } \\
\text { into Pb-17Li at } 2 \mathrm{MPa}\end{array}$ & $\begin{array}{l}\text { Helium pressure } \\
\text { opens rupture disk to } \\
\text { drain tank, shut } \\
\text { down ITER pulse } \\
\text { due to loss of helium } \\
\text { cooling in TBM }\end{array}$ & $\begin{array}{l}\text { Helium small } \\
\text { LOCA, LBB2 }\end{array}$ & $\begin{array}{l}\text { Assume that a small } \\
\text { helium leak cools the } \\
\text { TBM adequately for an } \\
\text { orderly plasma } \\
\text { shutdown. }\end{array}$ & $4 \mathrm{E}-06 / \mathrm{h}$ & $\begin{array}{l}\text { OREDA } \\
2002, \text { page } \\
387\end{array}$ & $\begin{array}{l}\text { The TBM module is a unique } \\
\text { design that uses helium in flow } \\
\text { tubing and Pb-17Li in larger } \\
\text { channels. The TBM can tolerate } \\
\text { helium inleakage that raises the } \\
\text { pressure from } 2 \text { MPa to colose to } 8 \\
\text { MPa. The TBM module is roughly } \\
\text { similar to a flat plate heat } \\
\text { exchanger; analyst judgment is to } \\
\text { use those data from the OREDA } \\
2002 \text { book as initial quantification. } \\
\text { If more refinement is needed, the } \\
\text { TBM module box failure rate can } \\
\text { be calculated by summing } \\
\text { component and weld failure rates. }\end{array}$ \\
\hline & & $\begin{array}{l}\text { internal } \\
\text { rupture }\end{array}$ & Category III & $\begin{array}{l}\text { weld failure, } \\
\text { material failure }\end{array}$ & $\begin{array}{l}\text { weld and } \\
\text { material NDT, } \\
\text { QA }\end{array}$ & $\begin{array}{l}\text { large leak of helium at } \\
8 \mathrm{MPa} \text { into } \mathrm{Pb}-17 \mathrm{Li} \text { at } 2 \\
\mathrm{MPa}\end{array}$ & $\begin{array}{l}\text { Helium pressure } \\
\text { opens rupture disk to } \\
\text { drain tank, shut } \\
\text { down ITER pulse } \\
\text { due to loss of helium } \\
\text { cooling in TBM }\end{array}$ & $\begin{array}{l}\text { Helium large } \\
\text { LOCA, LBB1 }\end{array}$ & $\begin{array}{l}\text { A large helium leak will } \\
\text { probably need a rapid } \\
\text { plasma shutdown to } \\
\text { avoid melting part of the } \\
\text { TBM. }\end{array}$ & $4 \mathrm{E}-07 / \mathrm{h}$ & $\begin{array}{l}\text { analyst } \\
\text { judgment }\end{array}$ & $\begin{array}{l}\text { Based on the OREDA value and } \\
\text { typically a factor of ten reduction } \\
\text { in failure rate from a leak to a } \\
\text { rupture, see Eide et al., EGG- } \\
\text { SSRE-9639, } 1991 \text {. }\end{array}$ \\
\hline & & plugging & Category III & $\begin{array}{l}\text { impurity } \\
\text { buildup, oxide } \\
\text { buildup, foreign } \\
\text { materials ( } \mathrm{SiC} \\
\text { pieces) }\end{array}$ & $\begin{array}{l}\text { cold trap } \\
\text { removes } \\
\text { impurities and } \\
\text { oxides, consider } \\
\text { strainer for } \\
\text { pieces of } \\
\text { insulator }\end{array}$ & $\begin{array}{l}\text { Pb-17Li flow passage } \\
\text { blockage by foreign } \\
\text { material; overheating } \\
\text { TBM that leads to } \\
\text { warping and flow } \\
\text { channel collapse }\end{array}$ & $\begin{array}{l}\text { Verify helium flow } \\
\text { to TBM, continue } \\
\text { ITER operation }\end{array}$ & $\begin{array}{l}\text { Pb-17Li LOFA, } \\
\text { not an IE }\end{array}$ & & $2 \mathrm{E}-06 / \mathrm{h}$ & $\begin{array}{l}\text { OREDA } \\
2002 \text {, page } \\
387\end{array}$ & $\begin{array}{l}\text { Suggest a strainer in the design to } \\
\text { catch possible FCI (flow channel } \\
\text { insert) pieces, if these were to fail. } \\
\text { Impurity buildup in the TBM is not } \\
\text { expected since the TBM operates } \\
\text { at high temperature; impurities and } \\
\text { oxides do not plate out in high } \\
\text { temperature regions. }\end{array}$ \\
\hline & & $\begin{array}{l}\text { external } \\
\text { leakage }\end{array}$ & Category III & $\begin{array}{l}\text { plasma damage, } \\
\text { thermal } \\
\text { overstress, weld } \\
\text { flaw, material } \\
\text { flaw }\end{array}$ & $\begin{array}{l}\text { conservative } \\
\text { approach to } \\
\text { ITER operation; } \\
\text { inspection, QA }\end{array}$ & $\begin{array}{l}\text { leak of Pb-17Li into } \\
\text { vacuum vessel }\end{array}$ & $\begin{array}{l}\text { Drain the Pb-17Li } \\
\text { loop to limit release, } \\
\text { shut down ITER to } \\
\text { clean up leak }\end{array}$ & \begin{tabular}{|l|} 
Pb-17Li LOCA \\
into VV, VMM2
\end{tabular} & & $3 \mathrm{E}-06 / \mathrm{h}$ & $\begin{array}{l}\text { OREDA } \\
2002 \text {, page } \\
387\end{array}$ & $\begin{array}{l}\text { Used failure rate for flat plate heat } \\
\text { exchanger as initial quantification } \\
\text { for these flow channels in the TBM } \\
\text { module }\end{array}$ \\
\hline
\end{tabular}




\begin{tabular}{|c|c|c|c|c|c|c|c|c|c|c|c|c|}
\hline Component & $\begin{array}{c}\text { Operational } \\
\text { State }\end{array}$ & $\begin{array}{c}\text { Failure } \\
\text { Mode }\end{array}$ & $\begin{array}{c}\text { Frequency } \\
\text { Category }\end{array}$ & Possible Causes & $\begin{array}{c}\text { Preventive } \\
\text { Action on } \\
\text { Possible Causes }\end{array}$ & Consequences & $\begin{array}{c}\text { Corrective or } \\
\text { Preventive Actions } \\
\text { on Consequences }\end{array}$ & $\begin{array}{l}\text { ITER Postulated } \\
\text { Initiating Events }\end{array}$ & Comments & Frequency & $\begin{array}{c}\text { Comment on } \\
\text { frequency } \\
\text { calculation }\end{array}$ & Design comments \\
\hline & & $\begin{array}{l}\text { external } \\
\text { rupture }\end{array}$ & Category III & $\begin{array}{l}\text { extreme plasma } \\
\text { damage, high } \\
\text { thermal } \\
\text { overstress, weld } \\
\text { failure, material } \\
\text { failure }\end{array}$ & $\begin{array}{l}\text { conservative } \\
\text { approach to } \\
\text { ITER operation, } \\
\text { inspection, QA }\end{array}$ & $\begin{array}{l}\text { large leak of } \mathrm{Pb}-17 \mathrm{Li} \\
\text { into vacuum vessel }\end{array}$ & $\begin{array}{l}\text { Drain the Pb-17Li } \\
\text { loop to limit release, } \\
\text { shut down ITER to } \\
\text { clean up leak }\end{array}$ & $\begin{array}{l}\mathrm{Pb}-17 \mathrm{Li} \text { large } \\
\text { LOCA into VV, } \\
\text { VMM1 }\end{array}$ & & $3 \mathrm{E}-07 / \mathrm{h}$ & $\begin{array}{l}\text { analyst } \\
\text { judgment }\end{array}$ & $\begin{array}{l}\text { Based on the OREDA value and } \\
\text { typically a factor of ten reduction } \\
\text { in failure rate from a leak to a } \\
\text { rupture, see Eide et al., EGG- } \\
\text { SSRE-9639, } 1991 \text {. }\end{array}$ \\
\hline & & $\begin{array}{l}\text { increased } \\
\text { friction } \\
\text { pressure drop }\end{array}$ & Category IV & $\begin{array}{l}\text { flow channel } \\
\text { insert failure } \\
\text { due to flow } \\
\text { induced } \\
\text { vibration or } \\
\text { other causes }\end{array}$ & inspection, QA & $\begin{array}{l}\text { failure of MHD } \\
\text { insulating panel or } \\
\text { panels, MHD forces } \\
\text { increase on } \mathrm{Pb}-17 \mathrm{Li} \text {, } \\
\text { difficult to pump the } \\
\text { fluid }\end{array}$ & $\begin{array}{l}\text { Shut down the Pb- } \\
17 \mathrm{Li} \text { loop until } \\
\text { repairs can be made } \\
\text { on the TBM module. } \\
\text { Operate ITER with } \\
\text { helium cooling to } \\
\text { TBM. }\end{array}$ & $\begin{array}{l}\text { Pb-17Li LOFA, } \\
\text { not an IE }\end{array}$ & $\begin{array}{l}\text { FCIs provide thermal } \\
\text { insulation to the TBM } \\
\text { module and to the } \\
\text { helium gas from the } \\
\text { higher temperature Pb- } \\
\text { 17Li (DDD 2.2.1.1.4). }\end{array}$ & $1 \mathrm{E}-04 /$ year & $\begin{array}{l}\text { analyst } \\
\text { judgment }\end{array}$ & $\begin{array}{l}\text { Judgment based on } \mathrm{SiC} \text { ceramic } \\
\text { heat exchanger tubes. Basis } \\
\text { explained in the FMEA text. }\end{array}$ \\
\hline \multirow[t]{2}{*}{$\begin{array}{l}\text { TBM flow } \\
\text { passage } \mathrm{SiC} \\
\text { plates }\end{array}$} & NO & cracking & Category III & $\begin{array}{l}\text { included flaws, } \\
\text { vibration }\end{array}$ & inspection, QA & cracks in $\mathrm{SiC}$ & $\begin{array}{l}\text { Shut down the Pb- } \\
\text { 17Li loop until } \\
\text { repairs can be made } \\
\text { on the TBM module. } \\
\text { Operate ITER with } \\
\text { helium cooling to } \\
\text { TBM. }\end{array}$ & Not an IE & $\begin{array}{l}\text { If MHD effects increase, } \\
\text { cannot flow Pb-17Li } \\
\text { through TBM module } \\
\text { without excessive pump } \\
\text { power. Shut down the } \\
\text { Pb-17Li loop until the } \\
\text { module can be repaired } \\
\text { or replaced. }\end{array}$ & $1.32 \mathrm{E}-07 / \mathrm{h}$ & $\begin{array}{l}\text { analyst } \\
\text { judgment }\end{array}$ & $\begin{array}{l}\text { Silicon Carbide is used as an } \\
\text { insulator to reduce MHD effects in } \\
\text { the Pb- } 17 \mathrm{Li} \text { flowing in high } \\
\text { magnetic fields. The operating } \\
\text { environment in } \approx 700 \mathrm{C}, 1 \mathrm{~cm} / \mathrm{s} \\
\text { flow of heavy metal in the } \mathrm{SiC} \text {, } \\
\text { with irradiation damage over time. } \\
\text { Analyst judgment is to use } \mathrm{SiC} \\
\text { insulator values for cracking as } \\
\text { loss of mechanical integrity, } \\
\text { estimate } \approx 4 \text { insulators to a flow } \\
\text { channel and } 3.3 \mathrm{E}-08 \mathrm{~h} \text { per } \\
\text { insulator, or } 1.32 \mathrm{E}-07 / \mathrm{h}\end{array}$ \\
\hline & & $\begin{array}{l}\text { catastrophic } \\
\text { failure }\end{array}$ & Category IV & $\begin{array}{l}\text { overstress, } \\
\text { subcritical crack } \\
\text { growth, } \\
\text { vibration }\end{array}$ & inspection, QA & $\begin{array}{l}\text { SiC pieces separate, } \\
\text { enter flow. If no } \\
\text { strainer is in the design, } \\
\text { shut down the pump to } \\
\text { limit } \mathrm{SiC} \text { debris in the } \\
\text { system and protect } \\
\text { pump impeller, heat } \\
\text { exchanger tubing, etc. }\end{array}$ & $\begin{array}{l}\text { Shut down the Pb- } \\
\text { 17Li loop until } \\
\text { repairs can be made } \\
\text { on the TBM module. } \\
\text { Operate ITER with } \\
\text { helium cooling to } \\
\text { TBM. }\end{array}$ & Not an IE & $\begin{array}{l}\text { SiC pieces in the flow } \\
\text { can cause damage. Shut } \\
\text { down the } \mathrm{Pb}-17 \mathrm{Li} \text { flow } \\
\text { loop, drain to the drain } \\
\text { tank }\end{array}$ & $\begin{array}{l}< \\
1 \mathrm{E}-04 / \text { year }\end{array}$ & $\begin{array}{l}\text { analyst } \\
\text { judgment }\end{array}$ & $\begin{array}{l}\text { SiC has been used successfully in } \\
1,200 \mathrm{C} \text { applications in combustion } \\
\text { turbine rotors and stators, with over } \\
30,000 \text { hours lifetime. Reducing } \\
\text { the temperature will greatly add to } \\
\text { the service lifetime of the SiC. SiC } \\
\text { is also radiation resistant since it is } \\
\text { used as an impervious fission fuel } \\
\text { pebble cladding material. }\end{array}$ \\
\hline $\begin{array}{l}\text { Concentric pipe } \\
\text { outlet connection } \\
\text { from TBM }\end{array}$ & NO & $\begin{array}{l}\text { external } \\
\text { rupture }\end{array}$ & Category IV & $\begin{array}{l}\text { Material failure, } \\
\text { thermal } \\
\text { overstress }\end{array}$ & inspection, QA & $\begin{array}{l}\text { inlet flow bypasses the } \\
\text { TBM and proceeds } \\
\text { directly to outlet flow. }\end{array}$ & $\begin{array}{l}\text { Verify TBM cooling } \\
\text { by helium and that } \\
\text { frame is cooled. } \\
\text { ITER can continue to } \\
\text { operate. }\end{array}$ & $\begin{array}{l}\text { Pb-17Li LOFA, } \\
\text { not an IE }\end{array}$ & $\begin{array}{l}\text { Sliding seal for the inner } \\
\text { tube outflow. Some } \\
\text { small leakage is } \\
\text { expected cross this seal } \\
\text { from the high P cold } \\
\text { side to the low P hot } \\
\text { side (TBM DDD, page } \\
\text { C-4) }\end{array}$ & $\begin{array}{l}< \\
1 \mathrm{E}-04 / \text { year }\end{array}$ & $\begin{array}{l}\text { analyst } \\
\text { judgment }\end{array}$ & $\begin{array}{l}\text { External leakage is expected and } \\
\text { small amounts are not } \\
\text { consequential to TBM operations, } \\
\text { so there is no external leakage } \\
\text { failure mode. The inner pipe is } \\
\text { held in place by the applied force } \\
\text { from the concentric pipe transition } \\
\text { and the TBM joint. Failure of this } \\
\text { sliding seal is considered to be a } \\
\text { low value in the extremely unlikely } \\
\text { frequency range. }\end{array}$ \\
\hline
\end{tabular}




\begin{tabular}{|c|c|c|c|c|c|c|c|c|c|c|c|c|}
\hline Component & $\begin{array}{c}\text { Operational } \\
\text { State }\end{array}$ & $\begin{array}{c}\text { Failure } \\
\text { Mode }\end{array}$ & $\begin{array}{c}\text { Frequency } \\
\text { Category }\end{array}$ & Possible Causes & $\begin{array}{c}\text { Preventive } \\
\text { Action on } \\
\text { Possible Causes }\end{array}$ & Consequences & $\begin{array}{c}\text { Corrective or } \\
\text { Preventive Actions } \\
\text { on Consequences }\end{array}$ & $\begin{array}{l}\text { ITER Postulated } \\
\text { Initiating Events }\end{array}$ & Comments & Frequency & $\begin{array}{c}\text { Comment on } \\
\text { frequency } \\
\text { calculation }\end{array}$ & Design comments \\
\hline \multirow[t]{3}{*}{ Mixing tank } & NO & $\begin{array}{l}\text { external } \\
\text { leakage }\end{array}$ & Category III & $\begin{array}{l}\text { Thermal } \\
\text { "striping" of hot } \\
\text { flow on welds } \\
\text { before flow } \\
\text { mixes in tank, } \\
\text { material flaw, } \\
\text { corrosion such } \\
\text { as a pin hole } \\
\text { leak, faulty weld } \\
\end{array}$ & $\begin{array}{l}\text { Good design to } \\
\text { prevent hot Pb- } \\
\text { 17Li impinge- } \\
\text { ment on tank } \\
\text { walls, material } \\
\text { selection and } \\
\text { inspection, NDT } \\
\text { of welds }\end{array}$ & $\begin{array}{l}\text { Small loss of coolant } \\
\text { accident, } \mathrm{Pb}-17 \mathrm{Li} \\
\text { temperature at } 470 \mathrm{C} \text {. }\end{array}$ & $\begin{array}{l}\text { Verify TBM cooling } \\
\text { by helium and that } \\
\text { frame is cooled. } \\
\text { ITER can continue to } \\
\text { operate. }\end{array}$ & $\begin{array}{l}\text { Pb-17Li Small } \\
\text { LOCA, LMP2 }\end{array}$ & $\begin{array}{l}\text { Provide catch pans } \\
\text { under mixing tank. } \\
\text { Catch pans should be } \\
\text { insulated to keep } \\
\text { concrete beneath them } \\
\text { cool. }\end{array}$ & $1 \mathrm{E}-07 / \mathrm{h}$ & $\begin{array}{l}\text { EGG-SSRE- } \\
8875\end{array}$ & $\begin{array}{l}\text { Mixing tank is a design provision } \\
\text { to allow higher temperature } \\
\text { operation of the } \mathrm{Pb}-17 \mathrm{Li} \text { TBM up } \\
\text { to } 650 \mathrm{C} \text {. The tank accepts } 650 \mathrm{C} \\
\text { inlet } \mathrm{Pb}-17 \mathrm{Li} \text { and mixes it with } \\
\text { cooler } 340 \mathrm{CPb}-17 \mathrm{Li} \text { so that the } \\
\text { outlet liquid remains at } \approx 470 \mathrm{C} \text {, } \\
\text { which is acceptable from a } \\
\text { corrosion point of view. }\end{array}$ \\
\hline & & $\begin{array}{l}\text { external } \\
\text { rupture }\end{array}$ & Category IV & $\begin{array}{l}\text { Material failure, } \\
\text { weld failure, } \\
\text { high corrosion } \\
\text { (wall thinning } \\
\text { can occur at } \\
\text { high temper- } \\
\text { ature) }\end{array}$ & & $\begin{array}{l}\text { Large loss of coolant } \\
\text { accident, with a Pb- } \\
\text { 17Li peak temperature } \\
\text { of } 650 \mathrm{C} \text {. The peak } \\
\text { temperature could be } \\
\text { reduced to } 470 \mathrm{C} \text { by the } \\
\text { larger inventory of Pb- } \\
\text { 17Li in the tank. }\end{array}$ & $\begin{array}{l}\text { Verify TBM cooling } \\
\text { by helium and that } \\
\text { frame is cooled. } \\
\text { ITER can continue to } \\
\text { operate. }\end{array}$ & $\begin{array}{l}\text { Pb-17Li LOCA, } \\
\text { LMP1 }\end{array}$ & $\begin{array}{l}\text { Provide catch pans } \\
\text { under mixing tank. } \\
\text { Catch pans should be } \\
\text { insulated to keep } \\
\text { concrete beneath them } \\
\text { cool. }\end{array}$ & $5 \mathrm{E}-09 / \mathrm{h}$ & $\begin{array}{l}\text { EGG-SSRE- } \\
8875\end{array}$ & \\
\hline & & overfill & Category III & $\begin{array}{l}\text { operational } \\
\text { error, valve fault }\end{array}$ & \begin{tabular}{|l|} 
Operating \\
procedures, \\
sensor alarms
\end{tabular} & $\begin{array}{l}\text { If the tank overfills, } \\
\text { tank pressure could } \\
\text { increase to the point } \\
\text { where the low pressure } \\
\mathrm{Pb}-17 \mathrm{Li} \text { flow from the } \\
\mathrm{TBM} \text { module cannot } \\
\text { easily enter the tank } \\
\text { and TBM cooling flow } \\
\text { slows. }\end{array}$ & $\begin{array}{l}\text { The TBM Pb-17Li } \\
\text { coolant can } \\
\text { withstand a large } \\
\text { amount of heat input. } \\
\text { ITER can continue to } \\
\text { operate if helium is } \\
\text { cooling the TBM } \\
\text { module. }\end{array}$ & $\begin{array}{l}\text { Pb-17Li LOFA, } \\
\text { not an IE }\end{array}$ & & $\begin{array}{l}\text { operator } \\
\text { error, } \\
\text { median } \\
\text { estimate of } \\
1 \mathrm{E}-03 / \mathrm{d}\end{array}$ & $\begin{array}{l}\text { analyst } \\
\text { judgment }\end{array}$ & $\begin{array}{l}\text { Assume that there are } 4 \\
\text { opportunities per year to } \\
\text { misposition the valve, and the } \\
\text { human error will be larger than the } \\
\text { valve failure rate. If the inlet valve } \\
\text { is sized to allow a fixed minimum } \\
\text { flow of } 16 \mathrm{~kg} / \mathrm{s} \text { to flow to the TBM } \\
\text { module, then the mixing tank can } \\
\text { not be underfilled. There is no } \\
\text { 'underfill' failure mode listed. }\end{array}$ \\
\hline \multirow[t]{2}{*}{$\begin{array}{l}\text { Pressure } \\
\text { instrument }\end{array}$} & NO & $\begin{array}{l}\text { fails to } \\
\text { operate }\end{array}$ & Category III & $\begin{array}{l}\text { fouling, } \\
\text { calibration error, } \\
\text { power loss }\end{array}$ & $\begin{array}{l}\text { Coolant filtering } \\
\text { and cleaning, } \\
\text { periodic } \\
\text { recalibration, } \\
\text { redundant power } \\
\text { and redundant } \\
\text { sensors }\end{array}$ & $\begin{array}{l}\text { Forces operators to rely } \\
\text { on other pressure } \\
\text { sensors. Suggest } \\
\text { redundancy in sensors. }\end{array}$ & $\begin{array}{l}\text { No immediate } \\
\text { actions needed, run } \\
\text { to next shutdown } \\
\text { period if other } \\
\text { sensors can provide } \\
\text { adequate information } \\
\text { to safely operate the } \\
\text { TBM. }\end{array}$ & Not an IE & $\begin{array}{l}\text { Fast fission reactors } \\
\text { have used metal } \\
\text { diaphragm pressure } \\
\text { sensors. Such an } \\
\text { instrument can operate } \\
\text { in the } 2 \text { MPa range. It } \\
\text { must be kept free of } \\
\text { coolant oxide and rrud, } \\
\text { and not allow liquid } \\
\text { metal freezing on the } \\
\text { diaphragm. Fiber optics } \\
\text { can be used to sense the } \\
\text { diaphragm bulging. } \\
\end{array}$ & $1 \mathrm{E}-06 / \mathrm{h}$ & $\begin{array}{l}\text { INEL- } \\
96 / 0295\end{array}$ & $\begin{array}{l}\text { Designers should consider sensor } \\
\text { redundancy in the design, since } \\
\text { replacing failed sensors will be a } \\
\text { difficult task. If penetrations for } \\
\text { sensors are robust and common } \\
\text { causes of failure are controlled, } \\
\text { then redundancy will allow use of } \\
\text { voting logic to filter out spurious } \\
\text { noise signals and allow continued } \\
\text { TBM operation with a sensor } \\
\text { failure. }\end{array}$ \\
\hline & & $\begin{array}{l}\text { improper } \\
\text { reading }\end{array}$ & Category III & $\begin{array}{l}\text { calibration error, } \\
\text { drift, diaphragm } \\
\text { damage }\end{array}$ & \begin{tabular}{|l} 
Periodic \\
recalibration
\end{tabular} & $\begin{array}{l}\text { Forces operators to rely } \\
\text { on other pressure } \\
\text { sensors. Suggest } \\
\text { redundancy in sensors. }\end{array}$ & $\begin{array}{l}\text { No immediate } \\
\text { actions needed, run } \\
\text { to next shutdown } \\
\text { period if other } \\
\text { sensors can provide } \\
\text { adequate information } \\
\text { to operate the TBM. }\end{array}$ & Not an IE, N/S & $\begin{array}{l}\text { Recalibration activity } \\
\text { could result in a } \\
\text { significant personnel } \\
\text { radiation exposure }\end{array}$ & $1 \mathrm{E}-06 / \mathrm{h}$ & $\begin{array}{l}\text { INEL- } \\
\text { 96/0295 }\end{array}$ & $\begin{array}{l}\text { Use sensors that can be remotely } \\
\text { recalibrated whenever possible to } \\
\text { reduce personnel exposure }\end{array}$ \\
\hline
\end{tabular}




\begin{tabular}{|c|c|c|c|c|c|c|c|c|c|c|c|c|}
\hline Component & $\begin{array}{c}\text { Operational } \\
\text { State }\end{array}$ & $\begin{array}{l}\text { Failure } \\
\text { Mode }\end{array}$ & $\begin{array}{c}\text { Frequency } \\
\text { Category }\end{array}$ & Possible Causes & $\begin{array}{c}\text { Preventive } \\
\text { Action on } \\
\text { Possible Causes }\end{array}$ & Consequences & $\begin{array}{c}\text { Corrective or } \\
\text { Preventive Actions } \\
\text { on Consequences }\end{array}$ & $\begin{array}{l}\text { ITER Postulated } \\
\text { Initiating Events }\end{array}$ & Comments & Frequency & $\begin{array}{l}\text { Comment on } \\
\text { frequency } \\
\text { calculation }\end{array}$ & Design comments \\
\hline & & external leak & Category IV & $\begin{array}{l}\text { instrument pipe } \\
\text { tap crack, } \\
\text { instrument line } \\
\text { crack, weld } \\
\text { crack }\end{array}$ & $\begin{array}{l}\text { Materials } \\
\text { selection in } \\
\text { design, pre- } \\
\text { service } \\
\text { inspection, low } \\
\text { flow-induced } \\
\text { vibration in } \\
\text { design }\end{array}$ & $\begin{array}{l}\text { Leaks } \mathrm{Pb}-17 \mathrm{Li} \text { to the } \\
30 \mathrm{C} \text { air atmosphere in } \\
\text { the equatorial test port. }\end{array}$ & $\begin{array}{l}\text { No immediate } \\
\text { actions needed, } \\
\text { assume that a small } \\
\text { leak can probably be } \\
\text { tolerated until the } \\
\text { end of the campaign, } \\
\text { then shut down TBM } \\
\text { to repair the leak. }\end{array}$ & $\begin{array}{l}\text { Small Pb-17Li } \\
\text { LOCA, LMP2 }\end{array}$ & & $\begin{array}{l}1 \mathrm{E}-09 / \mathrm{h}, \\
\text { assuming }<1 \\
\mathrm{~m} \text { of tubing }\end{array}$ & $\begin{array}{l}\text { WSRC-TR- } \\
\text { 93-262 }\end{array}$ & $\begin{array}{l}\text { Instrument leaks should be very } \\
\text { low flow rates, such as through } \\
\text { cracks, assume }<<1 \% \text { of the } \\
\text { coolant flow rate, I.e., drops per } \\
\text { minute. An important issue is } \\
\text { potential release of activated gases, } \\
\text { such as mercury and tritium. }\end{array}$ \\
\hline & & $\begin{array}{l}\text { external } \\
\text { rupture }\end{array}$ & $<$ Cat IV & $\begin{array}{l}\text { instrument tap } \\
\text { material failure, } \\
\text { instrument line } \\
\text { material failure, } \\
\text { weld failure }\end{array}$ & $\begin{array}{l}\text { Same as external } \\
\text { leak, given } \\
\text { above }\end{array}$ & $\begin{array}{l}\text { Leaks moderate to large } \\
\text { amount of } \mathrm{Pb}-17 \mathrm{Li} \text { to } \\
\text { the equatorial test port }\end{array}$ & $\begin{array}{l}\text { Shut down ITER } \\
\text { pulse as fast as } \\
\text { possible, increase } \\
\text { helium cooling flow } \\
\text { and TBM frame } \\
\text { coolant flow. Flow } \\
\text { the Pb-17Li to the } \\
\text { drain tank to limit } \\
\text { the release. }\end{array}$ & $\begin{array}{l}\text { Pb-17Li LOCA, } \\
\text { LMP1 }\end{array}$ & & $\begin{array}{l}3 \mathrm{E}-11 / \mathrm{h}, \\
\text { assuming }<1 \\
\mathrm{~m} \text { of tubing }\end{array}$ & $\begin{array}{l}\text { WSRC-TR- } \\
93-262\end{array}$ & \\
\hline \multirow[t]{4}{*}{$\begin{array}{l}\text { Temperature } \\
\text { instrument }\end{array}$} & NO & $\begin{array}{l}\text { fails to } \\
\text { operate }\end{array}$ & Category III & $\begin{array}{l}\text { fouling, drift, } \\
\text { calibration error }\end{array}$ & $\begin{array}{l}\text { Coolant filtering } \\
\text { and cleaning, } \\
\text { periodic } \\
\text { recalibration }\end{array}$ & & $\begin{array}{l}\text { No immediate } \\
\text { actions needed, run } \\
\text { to next shutdown } \\
\text { period if other } \\
\text { sensors can provide } \\
\text { adequate information } \\
\text { to safely operate the } \\
\text { TBM. }\end{array}$ & Not an IE & $\begin{array}{l}\text { Assume that either a } \\
\text { thermocouple or RTD } \\
\text { will be used for this } 340 \\
\text { to } 470 \text { C (or 650 C) } \\
\text { temperature operating } \\
\text { temperature range }\end{array}$ & $1 \mathrm{E}-07 / \mathrm{h}$ & $\begin{array}{l}\text { INEL- } \\
96 / 0295\end{array}$ & \\
\hline & & $\begin{array}{l}\text { improper } \\
\text { reading }\end{array}$ & Category II & $\begin{array}{l}\text { calibration error, } \\
\text { drift }\end{array}$ & \begin{tabular}{|l|} 
Periodic \\
recalibration
\end{tabular} & & $\begin{array}{l}\text { No immediate } \\
\text { actions needed, run } \\
\text { to next shutdown } \\
\text { period if other } \\
\text { sensors can provide } \\
\text { adequate information } \\
\text { to operate the TBM. }\end{array}$ & Not an IE & & $1 \mathrm{E}-05 / \mathrm{h}$ & $\begin{array}{l}\text { INEL- } \\
96 / 0295\end{array}$ & \\
\hline & & external leak & Category II & $\begin{array}{l}\text { instrument tap } \\
\text { line crack, } \\
\text { instrument line } \\
\text { crack, weld } \\
\text { crack }\end{array}$ & $\begin{array}{l}\text { Materials } \\
\text { selection in } \\
\text { design, pre- } \\
\text { service } \\
\text { inspection, low } \\
\text { flow-induced } \\
\text { vibration in } \\
\text { design, NDT }\end{array}$ & $\begin{array}{l}\text { Leaks } \mathrm{Pb}-17 \mathrm{Li} \text { to the } \\
30 \mathrm{C} \text { air atmosphere in } \\
\text { the equatorial test port. }\end{array}$ & $\begin{array}{l}\text { No immediate } \\
\text { actions needed, } \\
\text { assume that a small } \\
\text { leak can probably be } \\
\text { tolerated until the } \\
\text { end of the campaign, } \\
\text { then shut down TBM } \\
\text { to repair the leak. }\end{array}$ & $\begin{array}{l}\text { Small Pb-17Li } \\
\text { LOCA, LMP2 }\end{array}$ & & $3 \mathrm{E}-05 / \mathrm{h}$ & $\begin{array}{l}\text { EGG-SSRE- } \\
8875\end{array}$ & $\begin{array}{l}\text { Instrument leaks should be very } \\
\text { low flow rates, such as through } \\
\text { cracks, assume }<<1 \% \text { of the } \\
\text { coolant flow rate. An important } \\
\text { issue is potential release of } \\
\text { activated gases, such as mercury } \\
\text { and tritium. }\end{array}$ \\
\hline & & $\begin{array}{l}\text { external } \\
\text { rupture }\end{array}$ & Category III & $\begin{array}{l}\text { instrument tap } \\
\text { line material } \\
\text { failure, weld } \\
\text { failure }\end{array}$ & $\begin{array}{l}\text { Materials } \\
\text { selection in } \\
\text { design, } \\
\text { prE-service } \\
\text { inspection, low } \\
\text { flow-induced } \\
\text { vibration in } \\
\text { design, NDT }\end{array}$ & $\begin{array}{l}\text { Leaks moderate to large } \\
\text { amount of } \mathrm{Pb}-17 \mathrm{Li} \text { to } \\
\text { the equatorial test port }\end{array}$ & $\begin{array}{l}\text { Shut down ITER } \\
\text { pulse as fast as } \\
\text { possible, increase } \\
\text { helium cooling flow } \\
\text { and TBM frame } \\
\text { coolant flow. Flow } \\
\text { the Pb-17Li to the } \\
\text { drain tank to limit } \\
\text { the release. }\end{array}$ & $\begin{array}{l}\text { Pb-17Li LOCA, } \\
\text { LMP1 }\end{array}$ & & $1 \mathrm{E}-06 / \mathrm{h}$ & $\begin{array}{l}\text { analyst } \\
\text { judgment }\end{array}$ & \\
\hline
\end{tabular}




\begin{tabular}{|c|c|c|c|c|c|c|c|c|c|c|c|c|}
\hline Component & $\begin{array}{c}\text { Operational } \\
\text { State }\end{array}$ & $\begin{array}{c}\text { Failure } \\
\text { Mode }\end{array}$ & $\begin{array}{c}\text { Frequency } \\
\text { Category }\end{array}$ & Possible Causes & $\begin{array}{c}\text { Preventive } \\
\text { Action on } \\
\text { Possible Causes }\end{array}$ & Consequences & $\begin{array}{c}\text { Corrective or } \\
\text { Preventive Actions } \\
\text { on Consequences }\end{array}$ & $\begin{array}{l}\text { ITER Postulated } \\
\text { Initiating Events }\end{array}$ & Comments & Frequency & $\begin{array}{l}\text { Comment on } \\
\text { frequency } \\
\text { calculation }\end{array}$ & Design comments \\
\hline \multirow{5}{*}{$\begin{array}{l}\text { TBM outlet flow } \\
\text { isolation valve } \\
\text { (normally closed, } \\
\text { allows some flow } \\
\text { to bypass the } \\
\text { TBM so that a } \\
\text { lower amount of } \\
\text { Pb-17Li flow is } \\
\text { heated to higher } \\
\text { temperature) }\end{array}$} & NO & fail to open & Category III & $\begin{array}{l}\text { valve disk } \\
\text { binding due to } \\
\text { crud or metal } \\
\text { buildup, valve } \\
\text { stem shear, } \\
\text { valve operator } \\
\text { fault, power loss }\end{array}$ & $\begin{array}{l}\text { testing, } \\
\text { inspection, QA }\end{array}$ & $\begin{array}{l}\text { This failure mode } \\
\text { would preclude high } \\
\text { temperature Pb-17Li in } \\
\text { normal operations }\end{array}$ & $\begin{array}{l}\text { No actions to take } \\
\text { during normal } \\
\text { operations }\end{array}$ & Not an IE & & $1 \mathrm{E}-03 / \mathrm{d}$ & $\begin{array}{l}\text { EGG-SSRE- } \\
8875\end{array}$ & $\begin{array}{l}\text { Valve would not be opened unless } \\
\text { ITER was in shutdown operations, } \\
4 \text { demands/year. }\end{array}$ \\
\hline & & plugging & Category III & $\begin{array}{l}\text { impurities } \\
\text { buildup, oxides } \\
\text { buildup }\end{array}$ & $\begin{array}{l}\text { periodic } \\
\text { regeneration of } \\
\text { cold trap }\end{array}$ & $\begin{array}{l}\text { This failure mode } \\
\text { would not be } \\
\text { discovered during } \\
\text { normal operations }\end{array}$ & $\begin{array}{l}\text { No actions to take } \\
\text { during normal } \\
\text { operations }\end{array}$ & Not an IE & & $5 \mathrm{E}-08 / \mathrm{h}$ & $\begin{array}{l}\text { EGG-SSRE- } \\
8875\end{array}$ & \\
\hline & & $\begin{array}{l}\text { internal } \\
\text { leakage }\end{array}$ & Category III & $\begin{array}{l}\text { material flaw, } \\
\text { weld flaw, valve } \\
\text { seat flaw }\end{array}$ & $\begin{array}{l}\text { inspection, } \\
\text { testing, QA }\end{array}$ & $\begin{array}{l}\text { Lose small amount of } \\
\text { Pb-17Li across valve } \\
\text { seat }\end{array}$ & $\begin{array}{l}\text { ITER can continue to } \\
\text { operate if helium } \\
\text { cooling system is } \\
\text { available }\end{array}$ & Not an IE & & $5 \mathrm{E}-07 / \mathrm{h}$ & $\begin{array}{l}\text { EGG-SSRE- } \\
8875\end{array}$ & $\begin{array}{l}\text { If valve is leaking past its seat, the } \\
\text { leakage Pb-17Li could be very low } \\
\text { pressure after traversing the valve } \\
\text { seat. Actual flow could be very } \\
\text { small and not a safety concern. }\end{array}$ \\
\hline & & $\begin{array}{l}\text { external } \\
\text { leakage }\end{array}$ & Category III & $\begin{array}{l}\text { material flaw, } \\
\text { weld flaw, stem } \\
\text { seal flaw }\end{array}$ & $\begin{array}{l}\text { inspection, } \\
\text { testing, QA }\end{array}$ & $\begin{array}{l}\text { Lose small amount of } \\
\mathrm{Pb}-17 \mathrm{Li} \text { from valve } \\
\text { stem or through flaw in } \\
\text { valve body to equatorial } \\
\text { port }\end{array}$ & $\begin{array}{l}\text { Isolate line and open } \\
\text { drain tank to limit } \\
\text { release. ITER can } \\
\text { continue to operate if } \\
\text { helium cooling } \\
\text { system is available. } \\
\end{array}$ & $\begin{array}{l}\text { Pb-17Li Small } \\
\text { LOCA, LMP2 }\end{array}$ & & $5 \mathrm{E}-07 / \mathrm{h}$ & $\begin{array}{l}\text { EGG-SSRE- } \\
8875\end{array}$ & \\
\hline & & $\begin{array}{l}\text { external } \\
\text { rupture }\end{array}$ & Category III & $\begin{array}{l}\text { material failure, } \\
\text { weld failure, } \\
\text { stem seal failure }\end{array}$ & $\begin{array}{l}\text { inspection, } \\
\text { testing, QA }\end{array}$ & $\begin{array}{l}\mathrm{Pb}-17 \mathrm{Li} \text { coolant is } \\
\text { draining from the loop } \\
\text { to the equatorial port }\end{array}$ & $\begin{array}{l}\text { Isolate line and open } \\
\text { drain tank to limit } \\
\text { release. ITER can } \\
\text { continue to operate if } \\
\text { helium cooling } \\
\text { system is available. }\end{array}$ & $\begin{array}{l}\text { Pb-17Li LOCA, } \\
\text { LMP1 }\end{array}$ & & $5 \mathrm{E}-08 / \mathrm{h}$ & $\begin{array}{l}\text { EGG-SSRE- } \\
8875\end{array}$ & \\
\hline \multirow[t]{2}{*}{$\begin{array}{l}\text { Tritium } \\
\text { extraction tank } \\
\text { bypass valve } \\
\text { (normally closed) }\end{array}$} & NO & fail to open & Category III & $\begin{array}{l}\text { valve disk } \\
\text { binding due to } \\
\text { crud or metal } \\
\text { buildup, valve } \\
\text { stem shear, } \\
\text { value operator } \\
\text { fault, power loss }\end{array}$ & $\begin{array}{l}\text { testing, } \\
\text { inspection, QA }\end{array}$ & $\begin{array}{l}\text { This failure mode } \\
\text { would not occur in } \\
\text { normal operations }\end{array}$ & $\begin{array}{l}\text { No actions to take } \\
\text { during normal } \\
\text { operations }\end{array}$ & Not an IE & & $1 \mathrm{E}-03 / \mathrm{d}$ & $\begin{array}{l}\text { EGG-SSRE- } \\
8875\end{array}$ & $\begin{array}{l}\text { Valve would not be opened unless } \\
\text { ITER was in shutdown operations, } \\
4 \text { demands/year. }\end{array}$ \\
\hline & & $\begin{array}{l}\text { spurious } \\
\text { operation }\end{array}$ & Category III & $\begin{array}{l}\text { command fault, } \\
\text { human error, } \\
\text { electronic noise }\end{array}$ & $\begin{array}{l}\text { periodic testing, } \\
\text { procedures, } \\
\text { software QA }\end{array}$ & $\begin{array}{l}\mathrm{Pb}-17 \mathrm{Li} \text { coolant is } \\
\text { bypassing the tritium } \\
\text { extraction tank }\end{array}$ & $\begin{array}{l}\text { Some tritium will } \\
\text { come out in the } \\
\text { plenums with helium } \\
\text { gas pressure. ITER } \\
\text { can continue to } \\
\text { operate if the helium } \\
\text { cooling system is } \\
\text { available }\end{array}$ & $\begin{array}{l}\text { Pb-17Li LOCA, } \\
\text { LMP1 }\end{array}$ & & $5 \mathrm{E}-07 / \mathrm{h}$ & $\begin{array}{l}\text { EGG-SSRE- } \\
8875\end{array}$ & $\begin{array}{l}\text { ITER can continue to operate since } \\
\text { the tritium production in the TBM } \\
\text { is small, } 1.59 \mathrm{E}-06 \mathrm{~g} / \mathrm{s} \text { (DDD } \\
\text { section } 3.1 .2 \text { ). This can also be } \\
\text { written as } 0.6 \mathrm{mg} \text { per pulse or } 6.4 \\
\text { Curies per pulse. }\end{array}$ \\
\hline
\end{tabular}




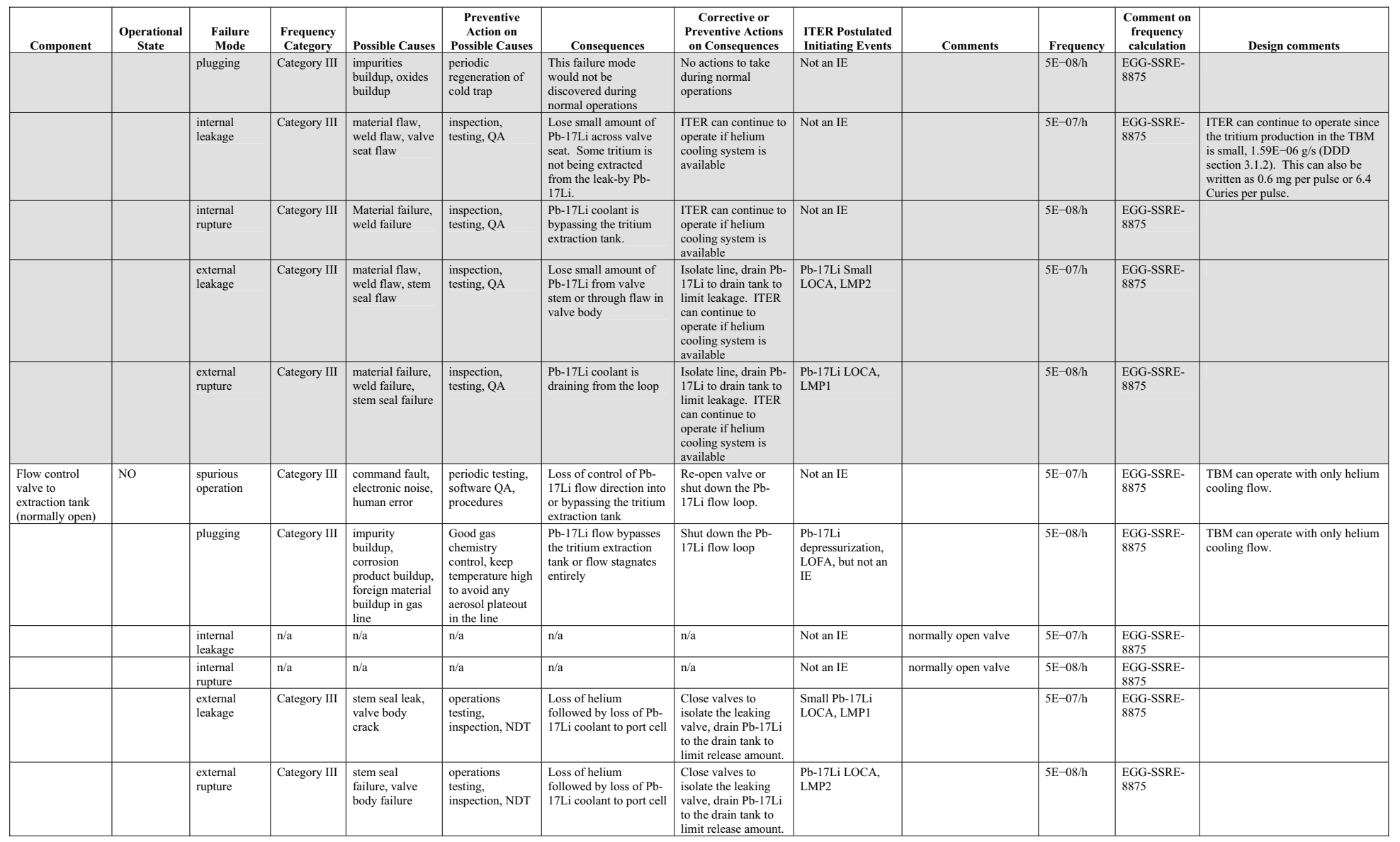




\begin{tabular}{|c|c|c|c|c|c|c|c|c|c|c|c|c|}
\hline Component & $\begin{array}{c}\text { Operational } \\
\text { State }\end{array}$ & $\begin{array}{c}\text { Failure } \\
\text { Mode }\end{array}$ & $\begin{array}{c}\text { Frequency } \\
\text { Category }\end{array}$ & Possible Causes & $\begin{array}{c}\text { Preventive } \\
\text { Action on } \\
\text { Possible Causes }\end{array}$ & Consequences & $\begin{array}{c}\text { Corrective or } \\
\text { Preventive Actions } \\
\text { on Consequences }\end{array}$ & $\begin{array}{l}\text { ITER Postulated } \\
\text { Initiating Events }\end{array}$ & Comments & Frequency & $\begin{array}{c}\text { Comment on } \\
\text { frequency } \\
\text { calculation }\end{array}$ & Design comments \\
\hline \multirow[t]{6}{*}{ Check valve } & NO & fail to open & & $\begin{array}{l}\text { impurity } \\
\text { buildup, } \\
\text { corrosion } \\
\text { product buildup, } \\
\text { hinge fault }\end{array}$ & $\begin{array}{l}\text { Good coolant } \\
\text { chemistry } \\
\text { control with cold } \\
\text { trap, keep } \\
\text { temperature up } \\
\text { to prevent } \\
\text { precipitation }\end{array}$ & $\begin{array}{l}\text { Loss of Pb-17Li flow or } \\
\text { severely limited flow }\end{array}$ & $\begin{array}{l}\text { Condition should be } \\
\text { detected in system } \\
\text { operability testing } \\
\text { and ITER will not } \\
\text { start up without } \\
\text { proper TBM Pb-17Li } \\
\text { flow. }\end{array}$ & Not an IE & & $1 \mathrm{E}-04 / \mathrm{d}$ & $\begin{array}{l}\text { EGG-SSRE- } \\
8875\end{array}$ & \\
\hline & & plugging & Category III & $\begin{array}{l}\text { impurity } \\
\text { buildup, } \\
\text { corrosion } \\
\text { product buildup }\end{array}$ & $\begin{array}{l}\text { Good coolant } \\
\text { chemistry } \\
\text { control with cold } \\
\text { trap, keep } \\
\text { temperature up } \\
\text { to prevent } \\
\text { precipitation }\end{array}$ & $\begin{array}{l}\text { Loss of Pb-17Li flow in } \\
\text { this once-through loop }\end{array}$ & $\begin{array}{l}\text { Decreasing flow } \\
\text { accident. Should } \\
\text { occur gradually, } \\
\text { record pumping } \\
\text { power and track } \\
\text { changes. Verify } \\
\text { helium cooling to } \\
\text { TBM and ITER can } \\
\text { continue to operate. }\end{array}$ & $\begin{array}{l}\text { Pb-17Li LOFA, } \\
\text { Not an IE }\end{array}$ & & $5 \mathrm{E}-07 / \mathrm{h}$ & $\begin{array}{l}\text { EGG-SSRE- } \\
8875\end{array}$ & \\
\hline & & fail to close & & $\begin{array}{l}\text { impurity } \\
\text { buildup, } \\
\text { corrosion } \\
\text { product buildup, } \\
\text { hinge fault }\end{array}$ & $\begin{array}{l}\text { Good coolant } \\
\text { chemistry } \\
\text { control with cold } \\
\text { trap, keep } \\
\text { temperature up } \\
\text { to prevent } \\
\text { precipitation, } \\
\text { material flaw }\end{array}$ & $\begin{array}{l}\text { Reverse flow allowed } \\
\text { in the Pb-17Li flow } \\
\text { loop }\end{array}$ & $\begin{array}{l}\text { Close nearest motor } \\
\text { operated valves. } \\
\text { Shut down ITER as } \\
\text { quickly as possible, } \\
\text { increase helium gas } \\
\text { coolant to remove } \\
\text { heat from TBM. }\end{array}$ & Not an IE & & $1 \mathrm{E}-04 / \mathrm{d}$ & $\begin{array}{l}\text { EGG-SSRE- } \\
8875\end{array}$ & \\
\hline & & $\begin{array}{l}\text { internal } \\
\text { rupture }\end{array}$ & Category III & $\begin{array}{l}\text { valve disc } \\
\text { failure, hinge } \\
\text { failure }\end{array}$ & inspection, QA & $\begin{array}{l}\text { Reverse flow allowed } \\
\text { in the } \mathrm{Pb}-17 \mathrm{Li} \text { flow } \\
\text { loop }\end{array}$ & $\begin{array}{l}\text { Close motor operated } \\
\text { valves to isolate leak. } \\
\text { Verify helium gas } \\
\text { coolant to remove } \\
\text { heat from TBM. }\end{array}$ & Not an IE & & $5 \mathrm{E}-07 / \mathrm{h}$ & $\begin{array}{l}\text { EGG-SSRE- } \\
8875\end{array}$ & \\
\hline & & $\begin{array}{l}\text { external } \\
\text { leakage }\end{array}$ & Category III & $\begin{array}{l}\text { valve body } \\
\text { crack, } \\
\text { maintenance } \\
\text { port leak }\end{array}$ & inspection, QA & $\begin{array}{l}\text { Loss of coolant into } \\
\text { equatorial port }\end{array}$ & $\begin{array}{l}\text { Close valves to } \\
\text { isolate the leaking } \\
\text { valve. Orderly } \\
\text { shutdown of ITER } \\
\text { pulse. }\end{array}$ & $\begin{array}{l}\text { Small Pb-17Li } \\
\text { LOCA, LMP2 }\end{array}$ & & $5 \mathrm{E}-07 / \mathrm{h}$ & $\begin{array}{l}\text { EGG-SSRE- } \\
8875\end{array}$ & \\
\hline & & $\begin{array}{l}\text { external } \\
\text { rupture }\end{array}$ & Category III & $\begin{array}{l}\text { valve body } \\
\text { failure }\end{array}$ & inspection, QA & $\begin{array}{l}\text { Large loss of coolant } \\
\text { into equatorial port }\end{array}$ & $\begin{array}{l}\text { Close valves to } \\
\text { isolate the ruptured } \\
\text { check valve body. } \\
\text { Fast shut down of } \\
\text { ITER, increase } \\
\text { helium cooling of } \\
\text { TBM. }\end{array}$ & $\begin{array}{l}\text { Pb-17Li LOCA, } \\
\text { LMP1 }\end{array}$ & & $5 \mathrm{E}-07 / \mathrm{h}$ & $\begin{array}{l}\text { EGG-SSRE- } \\
8875\end{array}$ & \\
\hline
\end{tabular}




\begin{tabular}{|c|c|c|c|c|c|c|c|c|c|c|c|c|}
\hline Component & $\begin{array}{c}\text { Operational } \\
\text { State }\end{array}$ & $\begin{array}{c}\text { Failure } \\
\text { Mode }\end{array}$ & $\begin{array}{c}\text { Frequency } \\
\text { Category }\end{array}$ & Possible Causes & $\begin{array}{c}\text { Preventive } \\
\text { Action on } \\
\text { Possible Causes } \\
\end{array}$ & Consequences & $\begin{array}{c}\text { Corrective or } \\
\text { Preventive Actions } \\
\text { on Consequences }\end{array}$ & $\begin{array}{l}\text { ITER Postulated } \\
\text { Initiating Events }\end{array}$ & Comments & Frequency & $\begin{array}{c}\text { Comment on } \\
\text { frequency } \\
\text { calculation }\end{array}$ & Design comments \\
\hline \multirow[t]{5}{*}{$\begin{array}{l}\text { PbLi Tritium } \\
\text { Extraction Tank, } \\
\text { vacuum } \\
\text { permeator }\end{array}$} & NO & $\begin{array}{l}\text { external } \\
\text { leakage }\end{array}$ & Category III & $\begin{array}{l}\text { material flaw, } \\
\text { material crack, } \\
\text { weld flaw }\end{array}$ & $\begin{array}{l}\text { Shell-side } \\
\text { vacuum is } \\
\text { degraded, unit } \\
\text { functions poorly. }\end{array}$ & $\begin{array}{l}\text { Tritium extraction } \\
\text { permeator could be } \\
\text { bypassed and the TBM } \\
\text { could finish the ITER } \\
\text { operating campaign. } \\
\text { Some tritium could be } \\
\text { drawn from the } \\
\text { pressure control system } \\
\text { out of the headspace of } \\
\text { the pump's expansion } \\
\text { tank. }\end{array}$ & $\begin{array}{l}\text { Bypass the tritium } \\
\text { extraction tank so no } \\
\text { tritium is released to } \\
\text { the port cell. }\end{array}$ & Not an IE & & $1 \mathrm{E}-03 /$ year & $\begin{array}{l}\text { EGG-FSP- } \\
11037\end{array}$ & $\begin{array}{l}\text { Assume vacuum permeator } \\
\text { concept is used for this tank. } \\
\text { Experience with this type of } \\
\text { equipment has shown that tubes } \\
\text { can crack and poisoning can occur } \\
\text { (Penzhorn et al., "Long-term } \\
\text { Permeator Experiment PETRA at } \\
\text { the TLK: Commissioning Tests } \\
\text { with Tritium," Fusion Tech., vol. } \\
\text { 28, October 1995, p 723-731.) }\end{array}$ \\
\hline & & $\begin{array}{l}\text { external } \\
\text { rupture }\end{array}$ & Category IV & $\begin{array}{l}\text { material failure, } \\
\text { weld failure }\end{array}$ & $\begin{array}{l}\text { Vacuum is lost, } \\
\text { small amount of } \\
\text { tritium could } \\
\text { escape to room. }\end{array}$ & $\begin{array}{l}\text { Tritium extraction } \\
\text { permeator could be } \\
\text { bypassed and the TBM } \\
\text { could finish the ITER } \\
\text { operating campaign. } \\
\text { Some tritium could be } \\
\text { drawn from the } \\
\text { pressure control in the } \\
\text { headspace of the } \\
\text { pump's expansion tank. }\end{array}$ & $\begin{array}{l}\text { Bypass the tritium } \\
\text { extraction tank so no } \\
\text { tritium is released to } \\
\text { the port cell. }\end{array}$ & Not an IE & & $1 \mathrm{E}-05 /$ year & $\begin{array}{l}\text { EGG-FSP- } \\
11037\end{array}$ & \\
\hline & & tube leakage & Category III & $\begin{array}{l}\text { material flaw, } \\
\text { crack, or tube- } \\
\text { to-tubesheet } \\
\text { weld flaw }\end{array}$ & $\begin{array}{l}\text { Small amount of } \\
\mathrm{Pb}-17 \mathrm{Li} \text { flows } \\
\text { into vacuum } \\
\text { shell. This is a } \\
\text { small LOCA for } \\
\text { the flow loop } \\
\text { and loss of } \\
\text { function for the } \\
\text { permeator. }\end{array}$ & $\begin{array}{l}\mathrm{Pb}-17 \mathrm{Li} \text { has a low } \\
\text { vapor pressure even } \\
\text { under vacuum } \\
\text { conditions. Any gases } \\
\text { (Hg, T, etc) are still } \\
\text { confined in the vacuum } \\
\text { permeator shell with the } \\
\mathrm{Pb}-17 \mathrm{Li} \text {. }\end{array}$ & $\begin{array}{l}\text { Isolate Pb-17Li flow } \\
\text { to the tritium } \\
\text { extraction permeator } \\
\text { to limit the quantity } \\
\text { leaking into the shell. } \\
\text { Verify that helium } \\
\text { cooling to the TBM } \\
\text { is available. }\end{array}$ & $\begin{array}{l}\text { This is a small Pb- } \\
\text { 17Li LOCA, but } \\
\text { no release to the } \\
\text { room atmosphere. } \\
\text { Not an IE }\end{array}$ & & $1 \mathrm{E}-06 / \mathrm{h}$ & $\begin{array}{l}\text { EGG-SSRE- } \\
8875\end{array}$ & $\begin{array}{l}\text { The vacuum permeator outer tank } \\
\text { or shell must be able to withstand } \\
\text { the highest temperature } \mathrm{Pb}-17 \mathrm{Li} \\
(\approx 670 \mathrm{C}) \text { in case of tube leakage. }\end{array}$ \\
\hline & & tube rupture & Category III & $\begin{array}{l}\text { material failure, } \\
\text { crack, or tube- } \\
\text { to-tubesheet } \\
\text { weld failure }\end{array}$ & $\begin{array}{l}\text { Loss of coolant } \\
\text { from the flow } \\
\text { loop to the } \\
\text { permeator shell. }\end{array}$ & $\begin{array}{l}\text { Isolate } \mathrm{Pb}-17 \mathrm{Li} \text { flow to } \\
\text { the tritium permeator. }\end{array}$ & $\begin{array}{l}\text { Isolate } \mathrm{Pb}-17 \mathrm{Li} \text { flow } \\
\text { to the tritium } \\
\text { extraction permeator } \\
\text { to limit the quantity } \\
\text { flowing into the } \\
\text { shell. Verify that } \\
\text { helium cooling to the } \\
\text { TBM is available. }\end{array}$ & $\begin{array}{l}\text { This is a small Pb- } \\
\text { 17Li LOCA, but } \\
\text { no release to the } \\
\text { room atmosphere. } \\
\text { Not an IE }\end{array}$ & & $1 \mathrm{E}-06 / \mathrm{h}$ & $\begin{array}{l}\text { EGG-SSRE- } \\
8875\end{array}$ & \\
\hline & & $\begin{array}{l}\text { tube } \\
\text { plugging }\end{array}$ & Category III & $\begin{array}{l}\text { impurity } \\
\text { buildup, oxide } \\
\text { buildup }\end{array}$ & $\begin{array}{l}\text { Loss of flow } \\
\text { through the } \\
\text { permeator tubes }\end{array}$ & $\begin{array}{l}\text { Isolate } \mathrm{Pb}-17 \mathrm{Li} \text { flow to } \\
\text { the tritium permeator. } \\
\text { Bypass the permeator to } \\
\text { finish the ITER } \\
\text { operating campaign. }\end{array}$ & $\begin{array}{l}\text { The tube plugging } \\
\text { causes the permeator } \\
\text { to bypass itself. } \\
\text { Close the valves to } \\
\text { positively bypass the } \\
\text { permeator. Verify } \\
\text { that helium cooling } \\
\text { to the TBM is } \\
\text { available. }\end{array}$ & Not an IE & & $1 \mathrm{E}-07 / \mathrm{h}$ & $\begin{array}{l}\text { see note at } \\
\text { right. }\end{array}$ & $\begin{array}{l}\text { System design regulates the } \\
\text { temperature of the inlet fluid to } 470 \\
\text { C, so precipitation of oxides or } \\
\text { impurities should not be a large } \\
\text { concern. EGG-SSRE- } 8875 \text { for } \\
\text { sodium reactors had a value of } \\
1 \mathrm{E}-06 / \mathrm{h} \text { for tube plugging, analyst } \\
\text { judgment reduced the value by } 10 \mathrm{x} \\
\text { to account for the small size of the } \\
\text { permeator, its few aluminum tubes. }\end{array}$ \\
\hline $\begin{array}{l}\text { PbLi-He heat } \\
\text { exchanger }\end{array}$ & NO & $\begin{array}{l}\text { tube surface } \\
\text { fouling }\end{array}$ & Category III & $\begin{array}{l}\text { impurity } \\
\text { buildup, oxide } \\
\text { buildup }\end{array}$ & $\begin{array}{l}\text { cold trap } \\
\text { removes } \\
\text { impurities and } \\
\text { oxides }\end{array}$ & $\begin{array}{l}\text { Loss of heat transfer to } \\
\text { the secondary helium } \\
\text { coolant, P-17Li } \\
\text { overheating }\end{array}$ & & $\begin{array}{l}\text { Over temperature } \\
\text { (similar to LOFA) }\end{array}$ & $\begin{array}{l}\text { Shell and tube heat } \\
\text { exchanger. The Pb-17Li } \\
\text { is on the shell side, high } \\
\text { pressure helium is in the } \\
\text { Aluminum tubes. }\end{array}$ & $1 \mathrm{E}-06 / \mathrm{h}$ & $\begin{array}{l}\text { EGG-SSRE- } \\
8875\end{array}$ & $\begin{array}{l}\text { Helium enters the } \mathrm{HX} \text { at } 200 \mathrm{C} \text {, } \\
\text { exits at } 360 \mathrm{C} \text {. Portions of the heat } \\
\text { exchanger tubes could be cool } \\
\text { enough to condense out impurities } \\
\text { and oxides from the Pb-17Li. }\end{array}$ \\
\hline
\end{tabular}




\begin{tabular}{|c|c|c|c|c|c|c|c|c|c|c|c|c|}
\hline Component & $\begin{array}{c}\text { Operational } \\
\text { State }\end{array}$ & $\begin{array}{c}\text { Failure } \\
\text { Mode }\end{array}$ & $\begin{array}{c}\text { Frequency } \\
\text { Category }\end{array}$ & Possible Causes & $\begin{array}{c}\text { Preventive } \\
\text { Action on } \\
\text { Possible Causes }\end{array}$ & Consequences & $\begin{array}{c}\text { Corrective or } \\
\text { Preventive Actions } \\
\text { on Consequences }\end{array}$ & $\begin{array}{l}\text { ITER Postulated } \\
\text { Initiating Events }\end{array}$ & Comments & Frequency & $\begin{array}{l}\text { Comment on } \\
\text { frequency } \\
\text { calculation }\end{array}$ & Design comments \\
\hline & & shell leakage & Category III & $\begin{array}{l}\text { material flaw, } \\
\text { weld flaw }\end{array}$ & $\begin{array}{l}\text { inspection, } \\
\text { testing, QA }\end{array}$ & Loss of $\mathrm{Pb}-17 \mathrm{Li}$ & & $\begin{array}{l}\text { Small Pb-17Li } \\
\text { LOCA, LMM2 }\end{array}$ & & $1 \mathrm{E}-06 / \mathrm{h}$ & $\begin{array}{l}\text { EGG-SSRE- } \\
8875\end{array}$ & \\
\hline & & shell rupture & Category III & $\begin{array}{l}\text { material failure, } \\
\text { weld failure }\end{array}$ & $\begin{array}{l}\text { inspection, } \\
\text { testing, QA }\end{array}$ & $\begin{array}{l}\text { Loss of large amount of } \\
\mathrm{Pb}-17 \mathrm{Li}\end{array}$ & & $\begin{array}{l}\text { Pb-17Li LOCA, } \\
\text { LMM1 }\end{array}$ & & $1 \mathrm{E}-07 / \mathrm{h}$ & $\begin{array}{l}\text { EGG-SSRE- } \\
8875\end{array}$ & \\
\hline & & tube leakage & Category III & $\begin{array}{l}\text { weld flaw, tube } \\
\text { flaw }\end{array}$ & $\begin{array}{l}\text { inspection, } \\
\text { testing, QA }\end{array}$ & $\begin{array}{l}\text { Helium inleakage to } \\
\mathrm{Pb}-17 \mathrm{Li} \text {, will pressurize } \\
\text { the liquid metal, open } \\
\text { the rupture disk to the } \\
\text { drain tank }\end{array}$ & $\begin{array}{l}\text { Increase helium } \\
\text { cooling to the TBM } \\
\text { module, can continue } \\
\text { to run the TBM with } \\
\mathrm{Pb}-17 \mathrm{Li} \text { drained }\end{array}$ & $\begin{array}{l}\text { Small secondary } \\
\text { helium LOCA, } \\
\text { LMM2 }\end{array}$ & $\begin{array}{l}\text { Failure rate is per tube } \\
\text { bundle in the heat } \\
\text { exchanger }\end{array}$ & $1 \mathrm{E}-06 / \mathrm{h}$ & $\begin{array}{l}\text { EGG-SSRE- } \\
8875\end{array}$ & $\begin{array}{l}\text { Helium inleakage at } 8 \mathrm{MPa} \text { will } \\
\text { pressurize the } 2 \mathrm{MPa} \text { liquid metal, } \\
\text { however the inert helium gas will } \\
\text { likely separate out in the pump } \\
\text { housing/expansion tank after the } \\
\text { heat exchanger. The helium would } \\
\text { go to the pressure control system. } \\
\text { If the helium communicates its } \\
\text { pressure throughout the liquid } \\
\text { metal, the rupture disk should } \\
\text { actuate at } 3.5 \mathrm{MPa} \text {, draining the } \\
\text { Pb-17Li to the drain tank during } \\
\text { ITER operation. }\end{array}$ \\
\hline & & tube rupture & Category III & $\begin{array}{l}\text { weld failure, } \\
\text { tube failure, } \\
\text { tube } \\
\text { overheating, } \\
\text { helium } \\
\text { overpressure } \\
\text { from TBM } \\
\text { module breach }\end{array}$ & $\begin{array}{l}\text { inspection, } \\
\text { testing, QA }\end{array}$ & $\begin{array}{l}\text { Helium inleakage to } \\
\mathrm{Pb}-17 \mathrm{Li} \text {, will pressurize } \\
\text { the liquid metal, open } \\
\text { the rupture disk to the } \\
\text { drain tank }\end{array}$ & $\begin{array}{l}\text { Increase helium } \\
\text { cooling to the TBM } \\
\text { module, can continue } \\
\text { to run the TBM with } \\
\mathrm{Pb}-17 \mathrm{Li} \text { drained }\end{array}$ & $\begin{array}{l}\text { Pb-17Li LOCA, } \\
\text { LMM1 }\end{array}$ & $\begin{array}{l}\text { Failure rate is per tube } \\
\text { bundle in the heat } \\
\text { exchanger }\end{array}$ & $1 \mathrm{E}-06 / \mathrm{h}$ & $\begin{array}{l}\text { EGG-SSRE- } \\
8875\end{array}$ & $\begin{array}{l}\text { The tubes must be able to } \\
\text { withstand } 8 \mathrm{MPa} \text { helium that could } \\
\text { leak into the Pb-17Li from a TBM } \\
\text { fault. }\end{array}$ \\
\hline & & $\begin{array}{l}\text { tube } \\
\text { plugging }\end{array}$ & Cat IV & $\begin{array}{l}\text { foreign material } \\
\text { intrusion, } \\
\text { impurities, } \\
\text { oxide buildup }\end{array}$ & $\begin{array}{l}\text { keep secondary } \\
\text { helium clean, } \\
\text { moisture free }\end{array}$ & $\begin{array}{l}\text { Loss of heat transfer to } \\
\text { the secondary helium } \\
\text { coolant }\end{array}$ & $\begin{array}{l}\text { Increase helium } \\
\text { cooling of the TBM } \\
\text { module, increase } \\
\text { TBM frame cooling, } \\
\text { shut down ITER } \\
\text { after the pulse to } \\
\text { restore cooling }\end{array}$ & $\begin{array}{l}\text { Over temperature } \\
\text { (similar to LOFA). } \\
\text { Not an IE }\end{array}$ & $\begin{array}{l}\text { Helium is quite clean, no } \\
\text { plugging of the helium } \\
\text { side of the tubes is } \\
\text { expected. }\end{array}$ & $1 \mathrm{E}-04 /$ year & & $\begin{array}{l}\text { EGG-SSRE-8 } 875 \text { listed } 1 \mathrm{E}-06 / \mathrm{h}, \\
\text { but with helium (rather than water) } \\
\text { as the secondary coolant, plugging } \\
\text { is considered to be an improbable } \\
\text { event. Moisture could react with } \\
\text { the hot tube walls and form oxide } \\
\text { coatings, but moisture can be kept } \\
\text { from the helium, use } 1 \mathrm{E}-04 / \text { year as } \\
\text { a judgment value }\end{array}$ \\
\hline \multirow[t]{2}{*}{$\begin{array}{l}\begin{array}{l}\text { Pressure } \\
\text { instrument }\end{array} \\
\end{array}$} & NO & $\begin{array}{l}\text { fails to } \\
\text { operate }\end{array}$ & Category III & $\begin{array}{l}\text { fouling, } \\
\text { calibration error, } \\
\text { power loss }\end{array}$ & $\begin{array}{l}\text { Coolant filtering } \\
\text { and cleaning, } \\
\text { periodic } \\
\text { recalibration, } \\
\text { redundant power } \\
\text { and redundant } \\
\text { sensors }\end{array}$ & $\begin{array}{l}\text { Forces operators to rely } \\
\text { on other pressure } \\
\text { sensors. Suggest } \\
\text { redundancy in sensors. }\end{array}$ & $\begin{array}{l}\text { No immediate } \\
\text { actions needed, run } \\
\text { to next shutdown } \\
\text { period if other } \\
\text { sensors can provide } \\
\text { adequate information } \\
\text { to operate the TBM. }\end{array}$ & Not an IE & $\begin{array}{l}\text { Fast fission reactors } \\
\text { have used metal } \\
\text { diaphragm pressure } \\
\text { sensors. Such an } \\
\text { instrument can operate } \\
\text { in the } 2 \text { MPa range. It } \\
\text { must be kept free of } \\
\text { coolant oxide and crud, } \\
\text { and not allow liquid } \\
\text { metal freezing on the } \\
\text { diaphragm. Fiber optics } \\
\text { can be used to sense the } \\
\text { diaphragm bulging }\end{array}$ & $1 \mathrm{E}-06 / \mathrm{h}$ & $\begin{array}{l}\text { INEL- } \\
96 / 0295\end{array}$ & $\begin{array}{l}\text { Designers should consider sensor } \\
\text { redundancy in the design, since } \\
\text { replacing failed sensors will be a } \\
\text { difficult task. If penetrations for } \\
\text { sensors are robust and common } \\
\text { causes of failure are controlled, } \\
\text { then redundancy will allow use of } \\
\text { voting logic to filter out spurious } \\
\text { noise signals and allow continued } \\
\text { TBM operation with a sensor } \\
\text { failure. }\end{array}$ \\
\hline & & $\begin{array}{l}\text { improper } \\
\text { reading }\end{array}$ & & $\begin{array}{l}\text { calibration error, } \\
\text { drift, diaphragm } \\
\text { damage }\end{array}$ & \begin{tabular}{|l|} 
Periodic \\
recalibration
\end{tabular} & $\begin{array}{l}\text { Forces operators to rely } \\
\text { on other pressure } \\
\text { sensors. Suggest } \\
\text { redundancy in sensors. }\end{array}$ & $\begin{array}{l}\text { No immediate } \\
\text { actions needed, run } \\
\text { to next shutdown } \\
\text { period if other } \\
\text { sensors can provide } \\
\text { adequate information } \\
\text { to operate the TBM. }\end{array}$ & Not an IE & $\begin{array}{l}\text { Recalibration activity } \\
\text { could result in a } \\
\text { significant personnel } \\
\text { radiation exposure }\end{array}$ & & & \\
\hline
\end{tabular}




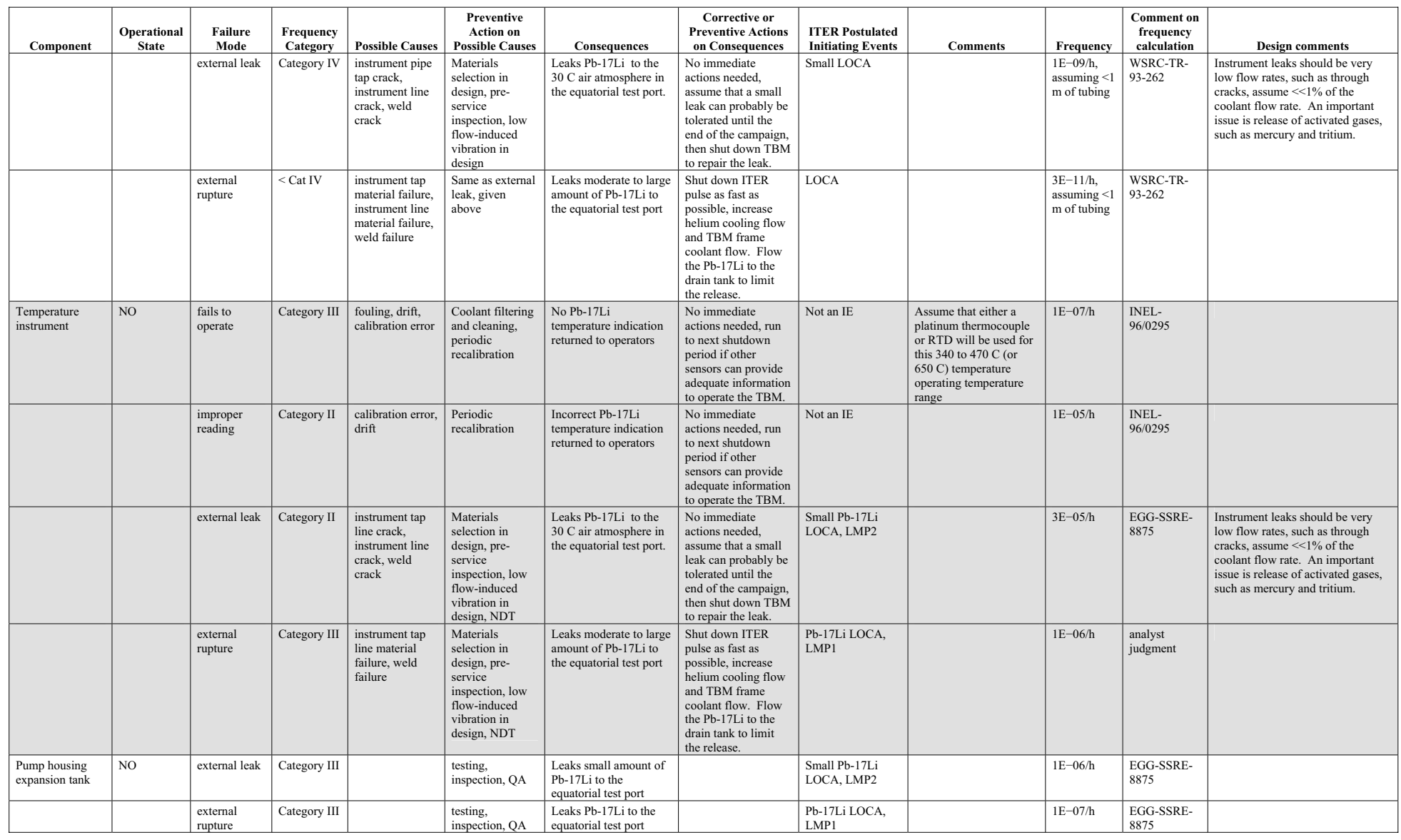




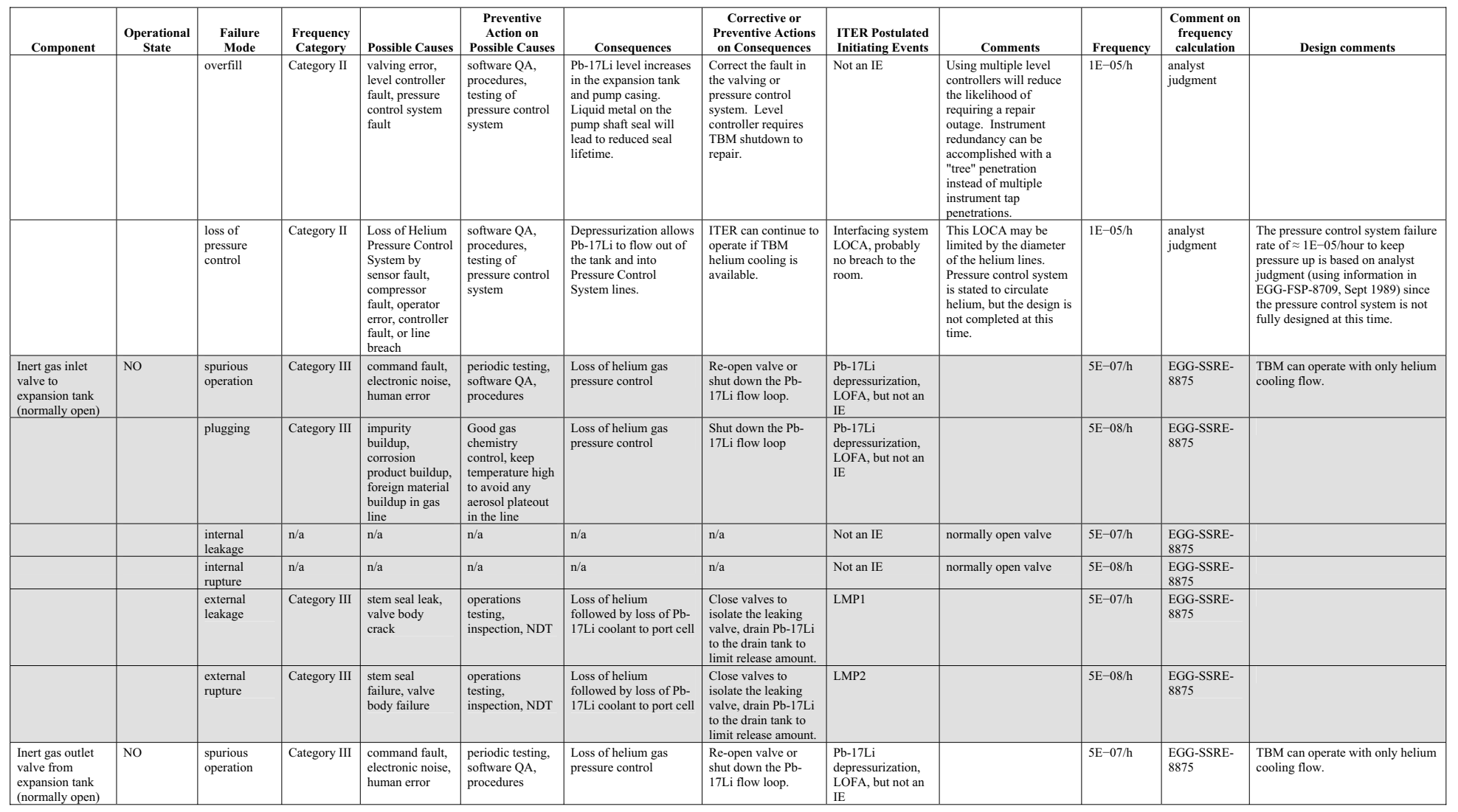




\begin{tabular}{|c|c|c|c|c|c|c|c|c|c|c|c|c|}
\hline Component & $\begin{array}{c}\text { Operational } \\
\text { State }\end{array}$ & $\begin{array}{c}\text { Failure } \\
\text { Mode }\end{array}$ & $\begin{array}{c}\text { Frequency } \\
\text { Category }\end{array}$ & Possible Causes & $\begin{array}{c}\text { Preventive } \\
\text { Action on } \\
\text { Possible Causes } \\
\end{array}$ & Consequences & $\begin{array}{c}\text { Corrective or } \\
\text { Preventive Actions } \\
\text { on Consequences }\end{array}$ & $\begin{array}{l}\text { ITER Postulated } \\
\text { Initiating Events }\end{array}$ & Comments & Frequency & $\begin{array}{c}\text { Comment on } \\
\text { frequency } \\
\text { calculation }\end{array}$ & Design comments \\
\hline & & plugging & Category III & $\begin{array}{l}\text { impurity } \\
\text { buildup, } \\
\text { corrosion } \\
\text { product buildup, } \\
\text { foreign material } \\
\text { buildup } \\
\end{array}$ & $\begin{array}{l}\text { Good coolant } \\
\text { chemistry } \\
\text { control with cold } \\
\text { trap }\end{array}$ & $\begin{array}{l}\text { Loss of helium gas } \\
\text { pressure control }\end{array}$ & $\begin{array}{l}\text { Shut down the Pb- } \\
\text { 17Li flow loop }\end{array}$ & $\begin{array}{l}\mathrm{Pb}-17 \mathrm{Li} \\
\text { depressurization, } \\
\text { LOFA, but not an } \\
\mathrm{IE}\end{array}$ & & $5 \mathrm{E}-08 / \mathrm{h}$ & $\begin{array}{l}\text { EGG-SSRE- } \\
8875\end{array}$ & \\
\hline & & $\begin{array}{l}\text { internal } \\
\text { leakage }\end{array}$ & $\mathrm{n} / \mathrm{a}$ & $\mathrm{n} / \mathrm{a}$ & n/a & $\mathrm{n} / \mathrm{a}$ & n/a & Not an IE & normally open valve & $5 \mathrm{E}-07 / \mathrm{h}$ & $\begin{array}{l}\text { EGG-SSRE- } \\
8875\end{array}$ & \\
\hline & & $\begin{array}{l}\text { internal } \\
\text { rupture }\end{array}$ & $n / a$ & $\mathrm{n} / \mathrm{a}$ & $\mathrm{n} / \mathrm{a}$ & $\mathrm{n} / \mathrm{a}$ & n/a & Not an IE & normally open valve & $5 \mathrm{E}-08 / \mathrm{h}$ & $\begin{array}{l}\text { EGG-SSRE- } \\
8875\end{array}$ & \\
\hline & & $\begin{array}{l}\text { external } \\
\text { rupture }\end{array}$ & Category III & $\begin{array}{l}\text { stem seal } \\
\text { failure, valve } \\
\text { body failure }\end{array}$ & $\begin{array}{l}\text { operations } \\
\text { testing, } \\
\text { inspection, NDT }\end{array}$ & $\begin{array}{l}\text { Loss of helium } \\
\text { followed by loss of } \mathrm{Pb}- \\
\text { 17Li coolant to port cell }\end{array}$ & $\begin{array}{l}\text { Close valves to } \\
\text { isolate the leaking } \\
\text { valve, drain } \mathrm{Pb}-17 \mathrm{Li} \\
\text { to the drain tank to } \\
\text { limit release amount. }\end{array}$ & LMP2 & & $5 \mathrm{E}-08 / \mathrm{h}$ & $\begin{array}{l}\text { EGG-SSRE- } \\
8875\end{array}$ & \\
\hline \multirow[t]{5}{*}{$\begin{array}{l}\text { Cold trap inlet } \\
\text { isolation valve } \\
\text { (normally open) }\end{array}$} & NO & fail to close & Category II & $\begin{array}{l}\text { valve disk } \\
\text { binding due to } \\
\text { crud or metal } \\
\text { buildup, valve } \\
\text { stem shear, } \\
\text { value operator } \\
\text { fault, power loss } \\
\end{array}$ & $\begin{array}{l}\text { testing, } \\
\text { inspection, QA }\end{array}$ & $\begin{array}{l}\text { No operational } \\
\text { consequences }\end{array}$ & $\begin{array}{l}\text { Not an operational } \\
\text { concern. }\end{array}$ & Not an IE & & $1 \mathrm{E}-03 / \mathrm{d}$ & $\begin{array}{l}\text { EGG-SSRE- } \\
8875\end{array}$ & $\begin{array}{l}\text { Valve would not be closed unless } \\
\text { the cold trap was being cleaned, } \\
\text { and it would not be cleaned unless } \\
\text { ITER was in shutdown operations }\end{array}$ \\
\hline & & $\begin{array}{l}\text { spurious } \\
\text { operation }\end{array}$ & Category III & $\begin{array}{l}\text { command fault, } \\
\text { human error, } \\
\text { electronic noise }\end{array}$ & $\begin{array}{l}\text { periodic testing, } \\
\text { QA on control } \\
\text { system, operator } \\
\text { procedures }\end{array}$ & $\begin{array}{l}\text { isolates cold trap from } \\
\mathrm{Pb}-17 \mathrm{Li} \text { flow loop, so } \\
\text { there is no PbLi } \\
\text { cleanup. Leads to } \\
\text { plateout in coolest parts } \\
\text { of the system, such as } \\
\text { the heat exchanger, } \\
\text { instrument lines. }\end{array}$ & $\begin{array}{l}\text { Slow progression } \\
\text { event. No actions to } \\
\text { take. Impurities and } \\
\text { oxides will build up } \\
\text { in other parts of the } \\
\text { flow loop. Prudent to } \\
\text { shut down Pb- } 17 \mathrm{Li} \\
\text { until the cold trap } \\
\text { can be repaired. }\end{array}$ & Not an IE & & $5 \mathrm{E}-07 / \mathrm{h}$ & $\begin{array}{l}\text { EGG-SSRE- } \\
8875\end{array}$ & \\
\hline & & plugging & Category III & $\begin{array}{l}\text { impurities } \\
\text { buildup, oxides } \\
\text { buildup }\end{array}$ & $\begin{array}{l}\text { periodic testing, } \\
\text { QA on control } \\
\text { system, operator } \\
\text { procedures }\end{array}$ & $\begin{array}{l}\text { isolates cold trap from } \\
\mathrm{Pb}-17 \mathrm{Li} \text { flow loop, so } \\
\text { there is no PbLi } \\
\text { cleanup. Leads to } \\
\text { plateout in coolest parts } \\
\text { of the system, such as } \\
\text { the heat exchanger, } \\
\text { instrument lines. }\end{array}$ & $\begin{array}{l}\text { Slow progression } \\
\text { event. No actions to } \\
\text { take. Impurities and } \\
\text { oxides will build up } \\
\text { in other parts of the } \\
\text { flow loop over time. }\end{array}$ & Not an IE & & $5 \mathrm{E}-08 / \mathrm{h}$ & $\begin{array}{l}\text { EGG-SSRE- } \\
8875\end{array}$ & $\begin{array}{l}\text { In some cold traps, the impurity } \\
\text { plateout occurred at the cold trap } \\
\text { throat instead of on the screens in } \\
\text { the tank. }\end{array}$ \\
\hline & & $\begin{array}{l}\text { external } \\
\text { leakage }\end{array}$ & Category III & $\begin{array}{l}\text { material flaw, } \\
\text { weld flaw, stem } \\
\text { seal flaw }\end{array}$ & $\begin{array}{l}\text { testing, } \\
\text { inspection, QA }\end{array}$ & $\begin{array}{l}\text { Leaks high pressure } \mathrm{Pb} \text { - } \\
17 \mathrm{Li} \text { into equatorial } \\
\text { port }\end{array}$ & $\begin{array}{l}\text { Turn off pump to } \\
\text { limit release. Verify } \\
\text { helium cooling to } \\
\text { TBM. }\end{array}$ & $\begin{array}{l}\text { Small Pb-17Li } \\
\text { LOCA, LMP2 }\end{array}$ & & $5 \mathrm{E}-07 / \mathrm{h}$ & $\begin{array}{l}\text { EGG-SSRE- } \\
8875\end{array}$ & \\
\hline & & $\begin{array}{l}\text { external } \\
\text { rupture }\end{array}$ & Category III & $\begin{array}{l}\text { material failure, } \\
\text { weld failure, } \\
\text { stem seal failure }\end{array}$ & $\begin{array}{l}\text { testing, } \\
\text { inspection, QA }\end{array}$ & $\begin{array}{l}\text { Leaks high pressure } \mathrm{Pb} \text { - } \\
17 \mathrm{Li} \text { into equatorial } \\
\text { port }\end{array}$ & $\begin{array}{l}\text { Turn off pump and } \\
\text { open drain tank to } \\
\text { limit release. Verify } \\
\text { helium cooling to } \\
\text { TBM. }\end{array}$ & $\begin{array}{l}\text { Pb-17Li LOCA, } \\
\text { LMP1 }\end{array}$ & & $5 \mathrm{E}-08 / \mathrm{h}$ & $\begin{array}{l}\text { EGG-SSRE- } \\
8875\end{array}$ & \\
\hline
\end{tabular}




\begin{tabular}{|c|c|c|c|c|c|c|c|c|c|c|c|c|}
\hline Component & $\begin{array}{c}\text { Operational } \\
\text { State }\end{array}$ & $\begin{array}{c}\text { Failure } \\
\text { Mode }\end{array}$ & $\begin{array}{l}\text { Frequency } \\
\text { Category }\end{array}$ & Possible Causes & $\begin{array}{c}\text { Preventive } \\
\text { Action on } \\
\text { Possible Causes } \\
\end{array}$ & Consequences & $\begin{array}{c}\text { Corrective or } \\
\text { Preventive Actions } \\
\text { on Consequences }\end{array}$ & $\begin{array}{l}\text { ITER Postulated } \\
\text { Initiating Events }\end{array}$ & Comments & Frequency & $\begin{array}{c}\text { Comment on } \\
\text { frequency } \\
\text { calculation }\end{array}$ & Design comments \\
\hline \multirow[t]{4}{*}{$\begin{array}{l}\text { Cold trap outlet } \\
\text { isolation valve } \\
\text { (normally open) }\end{array}$} & NO & $\begin{array}{l}\text { fail to } \\
\text { transfer } \\
\text { position }\end{array}$ & Category II & \begin{tabular}{l|} 
valve disk \\
binding due to \\
crud or metal \\
buildup, valve \\
stem shear, \\
value operator \\
fault, power loss \\
\end{tabular} & $\begin{array}{l}\text { testing, } \\
\text { inspection, QA }\end{array}$ & $\begin{array}{l}\text { Cannot close valve to } \\
\text { flush cold trap for } \\
\text { cleaning. }\end{array}$ & $\begin{array}{l}\text { Not an operational } \\
\text { concern. }\end{array}$ & Not an IE & & $1 \mathrm{E}-03 / \mathrm{d}$ & $\begin{array}{l}\text { EGG-SSRE- } \\
8875\end{array}$ & $\begin{array}{l}\text { Valve would not be opened unless } \\
\text { ITER was in shutdown operations }\end{array}$ \\
\hline & & $\begin{array}{l}\text { spurious } \\
\text { operation }\end{array}$ & Category III & $\begin{array}{l}\text { command fault, } \\
\text { human error, } \\
\text { electronic noise }\end{array}$ & $\begin{array}{l}\text { periodic testing, } \\
\text { QA on control } \\
\text { system, operator } \\
\text { procedures }\end{array}$ & $\begin{array}{l}\text { isolates cold trap from } \\
\mathrm{Pb}-17 \mathrm{Li} \text { flow loop, so } \\
\text { there is no PbLi } \\
\text { cleanup. Leads to } \\
\text { plateout in coolest parts } \\
\text { of the system, such as } \\
\text { the heat exchanger, } \\
\text { instrument lines. }\end{array}$ & $\begin{array}{l}\text { Slow progression } \\
\text { event. No actions to } \\
\text { take. Impurities and } \\
\text { oxides will build up } \\
\text { in other parts of the } \\
\text { flow loop. }\end{array}$ & Not an IE & & $5 \mathrm{E}-07 / \mathrm{h}$ & $\begin{array}{l}\text { EGG-SSRE- } \\
8875\end{array}$ & \\
\hline & & plugging & Category III & $\begin{array}{l}\text { impurities } \\
\text { buildup, oxides } \\
\text { buildup }\end{array}$ & $\begin{array}{l}\text { periodic testing, } \\
\text { QA on control } \\
\text { system, operator } \\
\text { procedures }\end{array}$ & $\begin{array}{l}\text { isolates cold trap from } \\
\text { Pb-17Li flow loop, so } \\
\text { there is no PbLi } \\
\text { cleanup. Leads to } \\
\text { plateout in coolest parts } \\
\text { of the system, such as } \\
\text { the heat exchanger, } \\
\text { instrument lines. }\end{array}$ & $\begin{array}{l}\text { Slow progression } \\
\text { event. No actions to } \\
\text { take. Impurities and } \\
\text { oxides will build up } \\
\text { in other parts of the } \\
\text { flow loop. }\end{array}$ & Not an IE & & $5 \mathrm{E}-08 / \mathrm{h}$ & $\begin{array}{l}\text { EGG-SSRE- } \\
8875\end{array}$ & \\
\hline & & $\begin{array}{l}\text { external } \\
\text { rupture }\end{array}$ & Category III & $\begin{array}{l}\text { material failure, } \\
\text { weld failure, } \\
\text { stem seal failure }\end{array}$ & $\begin{array}{l}\text { testing, } \\
\text { inspection, QA }\end{array}$ & $\begin{array}{l}\text { Leaks high pressure } \mathrm{Pb}- \\
17 \mathrm{Li} \text { into equatorial } \\
\text { port }\end{array}$ & $\begin{array}{l}\text { Turn off pump and } \\
\text { open drain tank to } \\
\text { limit release. Verify } \\
\text { helium cooling and } \\
\text { frame cooling to } \\
\text { TBM. }\end{array}$ & $\begin{array}{l}\text { Pb-17Li LOCA, } \\
\text { LMP1 }\end{array}$ & & $5 \mathrm{E}-08 / \mathrm{h}$ & $\begin{array}{l}\text { EGG-SSRE- } \\
8875\end{array}$ & \\
\hline \multirow[t]{3}{*}{ Cold trap } & NO & failure to trap & Category III & $\begin{array}{l}\text { trap saturated, } \\
\text { temperature too } \\
\text { high }\end{array}$ & $\begin{array}{l}\text { measure oxygen } \\
\text { \% in coolant; } \\
\text { measure, control } \\
\text { trap temperature }\end{array}$ & $\begin{array}{l}\text { periodic regeneration if } \\
\text { necessary }\end{array}$ & $\begin{array}{l}\text { Slow progression } \\
\text { event. No actions to } \\
\text { take. Impurities and } \\
\text { oxides will build up } \\
\text { in other parts of the } \\
\text { flow loop. }\end{array}$ & Not an IE & $\begin{array}{l}\text { Note that Boisseau } \\
\text { (1982) data on sodium } \\
\text { cold traps gave a failure } \\
\text { rate of } 1.5 \mathrm{E}-06 / \mathrm{h} \text { for all } \\
\text { failure modes. }\end{array}$ & $5 \mathrm{E}-07 / \mathrm{h}$ & $\begin{array}{l}\text { EGG-SSRE- } \\
8875\end{array}$ & $\begin{array}{l}\text { In some cold traps, the impurity } \\
\text { plateout occurred at the cold trap } \\
\text { throat instead of on the screens in } \\
\text { the tank. Loss of the cold trap } \\
\text { function will present concerns } \\
\text { about impurities and oxides, but } \\
\text { this is not a rapid transient event. }\end{array}$ \\
\hline & & $\begin{array}{l}\text { external } \\
\text { leakage }\end{array}$ & Category III & $\begin{array}{l}\text { vessel wall } \\
\text { cracking, weld } \\
\text { flaw }\end{array}$ & $\begin{array}{l}\text { materials } \\
\text { selection, } \\
\text { inspection, QA }\end{array}$ & $\begin{array}{l}\text { Leaks high pressure } \mathrm{Pb}- \\
17 \mathrm{Li} \text { into equatorial } \\
\text { port }\end{array}$ & $\begin{array}{l}\text { Turn off pump to } \\
\text { limit release. Verify } \\
\text { helium cooling to } \\
\text { TBM. }\end{array}$ & $\begin{array}{l}\text { Small Pb-17Li } \\
\text { LOCA, LMP2 }\end{array}$ & & $5 \mathrm{E}-07 / \mathrm{h}$ & $\begin{array}{l}\text { EGG-SSRE- } \\
8875\end{array}$ & \\
\hline & & $\begin{array}{l}\text { external } \\
\text { rupture }\end{array}$ & Category III & $\begin{array}{l}\text { vessel severe } \\
\text { cracking, weld } \\
\text { failure }\end{array}$ & $\begin{array}{l}\text { materials } \\
\text { selection, } \\
\text { inspection, QA }\end{array}$ & $\begin{array}{l}\text { Leaks high pressure } \mathrm{Pb}- \\
17 \mathrm{Li} \text { into equatorial } \\
\text { port }\end{array}$ & $\begin{array}{l}\text { Turn off pump and } \\
\text { open drain tank to } \\
\text { limit release. Verify } \\
\text { helium cooling to } \\
\text { TBM. }\end{array}$ & $\begin{array}{l}\text { Pb-17Li LOCA, } \\
\text { LMP1 }\end{array}$ & & $5 \mathrm{E}-07 / \mathrm{h}$ & $\begin{array}{l}\text { EGG-SSRE- } \\
8875\end{array}$ & \\
\hline
\end{tabular}




\begin{tabular}{|c|c|c|c|c|c|c|c|c|c|c|c|c|}
\hline Component & $\begin{array}{c}\text { Operational } \\
\text { State }\end{array}$ & $\begin{array}{c}\text { Failure } \\
\text { Mode }\end{array}$ & $\begin{array}{c}\text { Frequency } \\
\text { Category }\end{array}$ & Possible Causes & $\begin{array}{c}\text { Preventive } \\
\text { Action on } \\
\text { Possible Causes } \\
\end{array}$ & Consequences & $\begin{array}{c}\text { Corrective or } \\
\text { Preventive Actions } \\
\text { on Consequences }\end{array}$ & $\begin{array}{l}\text { ITER Postulated } \\
\text { Initiating Events }\end{array}$ & Comments & Frequency & $\begin{array}{c}\text { Comment on } \\
\text { frequency } \\
\text { calculation }\end{array}$ & Design comments \\
\hline & & plugging & Category III & \begin{tabular}{l|} 
fouling by \\
foreign material, \\
impurity or \\
oxide plateout in \\
throat of cold \\
trap chamber
\end{tabular} & $\begin{array}{l}\begin{array}{l}\text { measure, control } \\
\text { trap temperature }\end{array} \\
\end{array}$ & $\begin{array}{l}\text { Loss of function. } \\
\text { Isolates cold trap from } \\
\mathrm{Pb}-17 \mathrm{Li} \text { flow loop, so } \\
\text { there is no } \mathrm{PbLi} \\
\text { cleanup. Leads to } \\
\text { plateout in coolest parts } \\
\text { of the system, such as } \\
\text { the heat exchanger, } \\
\text { instrument lines. }\end{array}$ & $\begin{array}{l}\text { Slow progression } \\
\text { event. No actions to } \\
\text { take. Impurities and } \\
\text { oxides will build up } \\
\text { in other parts of the } \\
\text { flow loop over time. }\end{array}$ & Not an IE & & $1 \mathrm{E}-05 / \mathrm{h}$ & $\begin{array}{l}\text { EGG-SSRE- } \\
8875\end{array}$ & $\begin{array}{l}\text { Loss of function will present } \\
\text { concerns about impurities and } \\
\text { oxides, but this is not a rapid } \\
\text { transient event. }\end{array}$ \\
\hline \multirow[t]{2}{*}{$\begin{array}{l}\text { Cold trap heat } \\
\text { exchanger }\end{array}$} & NO & $\begin{array}{l}\text { external } \\
\text { leakage }\end{array}$ & & $\begin{array}{l}\text { jacket crack, } \\
\text { construction } \\
\text { flaw, weld flaw }\end{array}$ & $\begin{array}{l}\text { inspection, NDT, } \\
\text { QA }\end{array}$ & Leak helium to the port & $\begin{array}{l}\mathrm{Pb}-17 \mathrm{Li} \text { loop can } \\
\text { continue to operate }\end{array}$ & Not an IE & $\begin{array}{l}\text { It is not clear how } 200 \mathrm{C} \\
\text { helium will affect port } \\
\text { equipment, notably the } \\
\text { bellows }\end{array}$ & $1 \mathrm{E}-06 / \mathrm{h}$ & $\begin{array}{l}\text { EGG-SSRE- } \\
8875\end{array}$ & $\begin{array}{l}\text { Assume gaseous helium at } 8 \mathrm{MPa} \text {, } \\
200 \mathrm{C} \text {, is used for the cold trap } \\
\text { coolant. The design may be as } \\
\text { simple as a jacket on the cold trap } \\
\text { vessel. The jacket routes helium } \\
\text { coolant around the vessel. }\end{array}$ \\
\hline & & $\begin{array}{l}\text { external } \\
\text { rupture }\end{array}$ & & $\begin{array}{l}\text { jacket failure, } \\
\text { construction } \\
\text { flaw, weld } \\
\text { failure }\end{array}$ & $\begin{array}{l}\text { inspection, NDT, } \\
\text { QA }\end{array}$ & $\begin{array}{l}\text { trap does not remove } \\
\text { impurities, this means a } \\
\text { slow degradation of the } \\
\text { system }\end{array}$ & $\begin{array}{l}\text { Shut down } \mathrm{Pb}-17 \mathrm{Li} \\
\text { loop }\end{array}$ & Not an IE & $\begin{array}{l}\text { It is not clear how a } \\
\text { large amount of } 200 \mathrm{C} \\
\text { helium will affect port } \\
\text { equipment, notably the } \\
\text { bellows }\end{array}$ & $1 \mathrm{E}-07 / \mathrm{h}$ & $\begin{array}{l}\text { EGG-SSRE- } \\
8875\end{array}$ & \\
\hline \multirow[t]{5}{*}{$\begin{array}{l}\text { Cold trap drain } \\
\text { valve (normally } \\
\text { closed) }\end{array}$} & NO & fail to open & Category III & $\begin{array}{l}\text { valve disk } \\
\text { binding due to } \\
\text { crud or metal } \\
\text { buildup, valve } \\
\text { stem shear, } \\
\text { valve operator } \\
\text { fault, power loss }\end{array}$ & $\begin{array}{l}\text { testing, } \\
\text { inspection, QA }\end{array}$ & $\begin{array}{l}\text { This failure mode } \\
\text { would not occur in } \\
\text { normal operations }\end{array}$ & $\begin{array}{l}\text { No actions to take } \\
\text { during normal } \\
\text { operations }\end{array}$ & Not an IE & & $1 \mathrm{E}-03 / \mathrm{d}$ & $\begin{array}{l}\text { EGG-SSRE- } \\
8875\end{array}$ & $\begin{array}{l}\text { Valve would not be opened unless } \\
\text { ITER was in shutdown operations, } \\
4 \text { demands/year. }\end{array}$ \\
\hline & & $\begin{array}{l}\text { spurious } \\
\text { operation }\end{array}$ & Category III & $\begin{array}{l}\text { command fault, } \\
\text { human error, } \\
\text { electronic noise }\end{array}$ & $\begin{array}{l}\text { periodic testing, } \\
\text { procedures, } \\
\text { software QA }\end{array}$ & $\begin{array}{l}\mathrm{Pb}-17 \mathrm{Li} \text { coolant is } \\
\text { draining from the loop } \\
\text { through the cold trap }\end{array}$ & $\begin{array}{l}\text { Isolate cold trap to } \\
\text { limit leakage. ITER } \\
\text { can continue to } \\
\text { operate if helium } \\
\text { cooling system is } \\
\text { available }\end{array}$ & $\begin{array}{l}\text { Pb-17Li LOCA, } \\
\text { LMP1 }\end{array}$ & & $5 \mathrm{E}-07 / \mathrm{h}$ & $\begin{array}{l}\text { EGG-SSRE- } \\
8875\end{array}$ & \\
\hline & & plugging & Category III & $\begin{array}{l}\text { impurities } \\
\text { buildup, oxides } \\
\text { buildup }\end{array}$ & $\begin{array}{l}\text { periodic } \\
\text { regeneration of } \\
\text { cold trap }\end{array}$ & $\begin{array}{l}\text { This failure mode } \\
\text { would not be } \\
\text { discovered during } \\
\text { normal operations }\end{array}$ & $\begin{array}{l}\text { Perform cold trap } \\
\text { cleaning during an } \\
\text { ITER outage }\end{array}$ & Not an IE & & $5 \mathrm{E}-08 / \mathrm{h}$ & $\begin{array}{l}\text { EGG-SSRE- } \\
8875\end{array}$ & \\
\hline & & $\begin{array}{l}\text { internal } \\
\text { leakage }\end{array}$ & Category III & $\begin{array}{l}\text { material flaw, } \\
\text { weld flaw, valve } \\
\text { seat flaw }\end{array}$ & $\begin{array}{l}\text { inspection, } \\
\text { testing, QA }\end{array}$ & $\begin{array}{l}\text { Lose small amount of } \\
\text { Pb-17Li across valve } \\
\text { seat }\end{array}$ & $\begin{array}{l}\text { Isolate cold trap to } \\
\text { limit leakage. ITER } \\
\text { can continue to } \\
\text { operate if helium } \\
\text { cooling system is } \\
\text { available }\end{array}$ & $\begin{array}{l}\text { Pb-17Li Small } \\
\text { LOCA, LMP2 }\end{array}$ & & $5 \mathrm{E}-07 / \mathrm{h}$ & $\begin{array}{l}\text { EGG-SSRE- } \\
8875\end{array}$ & \\
\hline & & $\begin{array}{l}\text { internal } \\
\text { rupture }\end{array}$ & Category III & $\begin{array}{l}\text { Material failure, } \\
\text { weld failure }\end{array}$ & $\begin{array}{l}\text { inspection, } \\
\text { testing, QA }\end{array}$ & $\begin{array}{l}\mathrm{Pb}-17 \mathrm{Li} \text { coolant is } \\
\text { draining from the loop } \\
\text { through the cold trap }\end{array}$ & $\begin{array}{l}\text { Isolate cold trap to } \\
\text { limit leakage. ITER } \\
\text { can continue to } \\
\text { operate if helium } \\
\text { cooling system is } \\
\text { available }\end{array}$ & $\begin{array}{l}\text { Pb-17Li LOCA, } \\
\text { LMP1 }\end{array}$ & & $5 \mathrm{E}-08 / \mathrm{h}$ & $\begin{array}{l}\text { EGG-SSRE- } \\
8875\end{array}$ & \\
\hline
\end{tabular}




\begin{tabular}{|c|c|c|c|c|c|c|c|c|c|c|c|c|}
\hline Component & $\begin{array}{c}\text { Operational } \\
\text { State }\end{array}$ & $\begin{array}{c}\text { Failure } \\
\text { Mode }\end{array}$ & $\begin{array}{c}\text { Frequency } \\
\text { Category }\end{array}$ & Possible Causes & $\begin{array}{c}\text { Preventive } \\
\text { Action on } \\
\text { Possible Causes } \\
\end{array}$ & Consequences & $\begin{array}{c}\text { Corrective or } \\
\text { Preventive Actions } \\
\text { on Consequences } \\
\end{array}$ & $\begin{array}{l}\text { ITER Postulated } \\
\text { Initiating Events }\end{array}$ & Comments & Frequency & $\begin{array}{l}\text { Comment on } \\
\text { frequency } \\
\text { calculation } \\
\end{array}$ & Design comments \\
\hline & & $\begin{array}{l}\text { external } \\
\text { leakage }\end{array}$ & Category III & $\begin{array}{l}\text { material flaw, } \\
\text { weld flaw, stem } \\
\text { seal flaw }\end{array}$ & $\begin{array}{l}\text { inspection, } \\
\text { testing, QA }\end{array}$ & $\begin{array}{l}\text { Lose small amount of } \\
\mathrm{Pb}-17 \mathrm{Li} \text { from valve } \\
\text { stem or through flaw in } \\
\text { valve body }\end{array}$ & $\begin{array}{l}\text { Isolate cold trap to } \\
\text { limit leakage. ITER } \\
\text { can continue to } \\
\text { operate if helium } \\
\text { cooling system is } \\
\text { available }\end{array}$ & \begin{tabular}{|l|} 
Pb-17Li Small \\
LOCA, LMP2
\end{tabular} & & $5 \mathrm{E}-07 / \mathrm{h}$ & \begin{tabular}{|l|} 
EGG-SSRE- \\
8875
\end{tabular} & \\
\hline & & $\begin{array}{l}\text { external } \\
\text { rupture }\end{array}$ & Category III & $\begin{array}{l}\text { material failure, } \\
\text { weld failure, } \\
\text { stem seal failure }\end{array}$ & $\begin{array}{l}\text { inspection, } \\
\text { testing, QA }\end{array}$ & $\begin{array}{l}\mathrm{Pb}-17 \mathrm{Li} \text { coolant is } \\
\text { draining from the loop } \\
\text { through the cold trap }\end{array}$ & $\begin{array}{l}\text { Isolate cold trap to } \\
\text { limit leakage. ITER } \\
\text { can continue to } \\
\text { operate if helium } \\
\text { cooling system is } \\
\text { available }\end{array}$ & $\begin{array}{l}\text { Pb-17Li LOCA, } \\
\text { LMP1 }\end{array}$ & & $5 \mathrm{E}-08 / \mathrm{h}$ & $\begin{array}{l}\text { EGG-SSRE- } \\
8875\end{array}$ & \\
\hline \multirow[t]{2}{*}{ PbLi Drain Tank } & NO & $\begin{array}{l}\text { external } \\
\text { leakage }\end{array}$ & Category III & $\begin{array}{l}\text { material flaw, } \\
\text { weld flaw, } \\
\text { construction } \\
\text { fault }\end{array}$ & inspection, NDT & $\begin{array}{l}\text { drain tank is normally } \\
\text { valved off from } \mathrm{Pb}- \\
\text { 17Li flow loop, no } \\
\text { immediate concern }\end{array}$ & $\begin{array}{l}\text { ITER can continue to } \\
\text { operate }\end{array}$ & Not an IE & & $1 \mathrm{E}-06 / \mathrm{h}$ & $\begin{array}{l}\text { EGG-SSRE- } \\
8875\end{array}$ & $\begin{array}{l}\text { The TRITEX Pb-17Li flow loop } \\
\text { kept the drain tank above the } \\
\text { melting temperature of Pb-17Li by } \\
\text { use of electric heaters. There was a } \\
\text { concern for thermal shock if a } \\
\text { dump quickly placed high } \\
\text { temperature alloy in a room } \\
\text { temperature tank. }\end{array}$ \\
\hline & & $\begin{array}{l}\text { external } \\
\text { rupture }\end{array}$ & Category III & $\begin{array}{l}\text { material failure, } \\
\text { weld failure }\end{array}$ & inspection, NDT & $\begin{array}{l}\text { drain tank is normally } \\
\text { valved off from } \mathrm{Pb}- \\
17 \mathrm{Li} \text { flow loop, no } \\
\text { immediate concern }\end{array}$ & $\begin{array}{l}\text { ITER can continue to } \\
\text { operate }\end{array}$ & Not an IE & & $1 \mathrm{E}-07 / \mathrm{h}$ & \begin{tabular}{|l} 
EGG-SSRE- \\
8875
\end{tabular} & \\
\hline \multirow{5}{*}{$\begin{array}{l}\text { PbLi drain tank } \\
\text { inlet valve from } \\
\text { HX (normally } \\
\text { closed) }\end{array}$} & & $\begin{array}{l}\text { spurious } \\
\text { operation }\end{array}$ & Category III & $\begin{array}{l}\text { command fault, } \\
\text { human error, } \\
\text { electronic noise }\end{array}$ & $\begin{array}{l}\text { periodic testing, } \\
\text { QA on control } \\
\text { system, operator } \\
\text { procedures }\end{array}$ & $\begin{array}{l}\text { Drains Pb-17Li to the } \\
\text { drain tank during ITER } \\
\text { operation. Regarding } \\
\text { the heat transfer loop, } \\
\text { this is a LOCA. }\end{array}$ & $\begin{array}{l}\text { ITER can continue to } \\
\text { operate if the helium } \\
\text { cooling system is } \\
\text { operating }\end{array}$ & $\begin{array}{l}\text { Pb-17Li LOCA, } \\
\text { LMP1 }\end{array}$ & & $5 \mathrm{E}-07 / \mathrm{h}$ & $\begin{array}{l}\text { EGG-SSRE- } \\
8875\end{array}$ & $\begin{array}{l}\text { Opening the low point valve on the } \\
\text { tank while the tank is merely under } \\
0.1 \text { MPa gas pressure will allow } \\
\text { liquid metal admission to the tank. }\end{array}$ \\
\hline & & fail to close & & $\begin{array}{l}\text { command fault, } \\
\text { human error, } \\
\text { electronic noise }\end{array}$ & $\begin{array}{l}\text { periodic testing, } \\
\text { QA on control } \\
\text { system, operator } \\
\text { procedures }\end{array}$ & $\begin{array}{l}\text { This failure mode } \\
\text { would not occur during } \\
\text { ITER operation. }\end{array}$ & $\begin{array}{l}\text { No actions to take } \\
\text { for this failure mode } \\
\text { during ITER } \\
\text { operation }\end{array}$ & Not an IE & & $1 \mathrm{E}-03 / \mathrm{d}$ & $\begin{array}{l}\text { EGG-SSRE- } \\
8875\end{array}$ & $\begin{array}{l}\text { Assume one fill or refill operation } \\
\text { per campaign, so } 4 \text { demands to } \\
\text { close the valve per year. Failure to } \\
\text { close would only occur during } \\
\text { ITER outages. }\end{array}$ \\
\hline & & plugging & & $\begin{array}{l}\text { impurity } \\
\text { buildup, oxide } \\
\text { buildup }\end{array}$ & $\begin{array}{l}\text { cold trap cleans } \\
\text { the coolant }\end{array}$ & $\begin{array}{l}\text { This failure mode } \\
\text { would not be } \\
\text { discovered during } \\
\text { normal ITER operation. }\end{array}$ & $\begin{array}{l}\text { Clean valve during } \\
\text { an ITER outage }\end{array}$ & Not an IE & & $5 \mathrm{E}-08 / \mathrm{h}$ & $\begin{array}{l}\text { EGG-SSRE- } \\
8875\end{array}$ & $\begin{array}{l}\text { Assume that operational evolutions } \\
\text { requiring the drain valve to open } \\
\text { are during ITER outages, not } \\
\text { during ITER TBM operating time. }\end{array}$ \\
\hline & & $\begin{array}{l}\text { internal } \\
\text { leakage }\end{array}$ & Category III & $\begin{array}{l}\text { valve seat flaw } \\
\text { or wear, valve } \\
\text { disk flaw }\end{array}$ & $\begin{array}{l}\text { inspection, } \\
\text { periodic } \\
\text { testing,QA on } \\
\text { construction }\end{array}$ & $\begin{array}{l}\text { Drains } \mathrm{Pb}-17 \mathrm{Li} \text { to the } \\
\text { drain tank during ITER } \\
\text { operation. }\end{array}$ & $\begin{array}{l}\text { ITER can continue to } \\
\text { operate if the helium } \\
\text { cooling system is } \\
\text { operating }\end{array}$ & Not an IE & $\begin{array}{l}\text { Not an IE since Pb-17Li } \\
\text { is not lost from the } \\
\text { system, no leak into the } \\
\text { Port Cell }\end{array}$ & $5 \mathrm{E}-07 / \mathrm{h}$ & $\begin{array}{l}\text { EGG-SSRE- } \\
8875\end{array}$ & $\begin{array}{l}\text { Helium inert gas is in the tank and } \\
\text { this gas would leak out past the } \\
\text { valve seat. }\end{array}$ \\
\hline & & $\begin{array}{l}\text { internal } \\
\text { rupture }\end{array}$ & Category III & $\begin{array}{l}\text { valve disk } \\
\text { failure }\end{array}$ & $\begin{array}{l}\text { inspection, } \\
\text { periodic testing, } \\
\text { QA on } \\
\text { construction }\end{array}$ & $\begin{array}{l}\text { Drains Pb-17Li to the } \\
\text { drain tank during ITER } \\
\text { operation. }\end{array}$ & $\begin{array}{l}\text { ITER can continue to } \\
\text { operate if the helium } \\
\text { cooling system is } \\
\text { operating }\end{array}$ & Not an IE & $\begin{array}{l}\text { Not an IE since Pb-17Li } \\
\text { is not lost from the } \\
\text { system, no leak into the } \\
\text { Port Cell }\end{array}$ & $5 \mathrm{E}-08 / \mathrm{h}$ & $\begin{array}{l}\text { EGG-SSRE- } \\
8875\end{array}$ & \\
\hline
\end{tabular}




\begin{tabular}{|c|c|c|c|c|c|c|c|c|c|c|c|c|}
\hline Component & $\begin{array}{c}\text { Operational } \\
\text { State }\end{array}$ & $\begin{array}{c}\text { Failure } \\
\text { Mode }\end{array}$ & $\begin{array}{l}\text { Frequency } \\
\text { Category }\end{array}$ & Possible Causes & $\begin{array}{c}\text { Preventive } \\
\text { Action on } \\
\text { Possible Causes }\end{array}$ & Consequences & $\begin{array}{c}\text { Corrective or } \\
\text { Preventive Actions } \\
\text { on Consequences }\end{array}$ & $\begin{array}{l}\text { ITER Postulated } \\
\text { Initiating Events }\end{array}$ & Comments & Frequency & $\begin{array}{c}\text { Comment on } \\
\text { frequency } \\
\text { calculation }\end{array}$ & Design comments \\
\hline & & $\begin{array}{l}\text { external } \\
\text { leakage }\end{array}$ & Category III & $\begin{array}{l}\text { valve stem } \\
\text { packing flaw, } \\
\text { valve body flaw }\end{array}$ & $\begin{array}{l}\text { inspection, } \\
\text { periodic testing, } \\
\text { QA on } \\
\text { construction } \\
\end{array}$ & $\begin{array}{l}\text { Drains } \mathrm{Pb}-17 \mathrm{Li} \text { to the } \\
\text { equatorial port }\end{array}$ & $\begin{array}{l}\text { ITER can continue to } \\
\text { operate if the helium } \\
\text { cooling system is } \\
\text { operating }\end{array}$ & $\begin{array}{l}\text { Pb-17Li small } \\
\text { LOCA, LMP2 }\end{array}$ & & $5 \mathrm{E}-07 / \mathrm{h}$ & $\begin{array}{l}\text { EGG-SSRE- } \\
8875\end{array}$ & \\
\hline & & $\begin{array}{l}\text { external } \\
\text { rupture }\end{array}$ & Category III & $\begin{array}{l}\text { valve steam } \\
\text { packing failure, } \\
\text { valve body } \\
\text { failure }\end{array}$ & $\begin{array}{l}\text { inspection, } \\
\text { periodic testing, } \\
\text { QA on } \\
\text { construction }\end{array}$ & $\begin{array}{l}\text { Drains } \mathrm{Pb}-17 \mathrm{Li} \text { to the } \\
\text { equatorial port }\end{array}$ & $\begin{array}{l}\text { ITER can continue to } \\
\text { operate if the helium } \\
\text { cooling system is } \\
\text { operating }\end{array}$ & $\begin{array}{l}\text { Pb-17Li LOCA, } \\
\text { LMP1 }\end{array}$ & & $5 \mathrm{E}-08 / \mathrm{h}$ & $\begin{array}{l}\text { EGG-SSRE- } \\
8875\end{array}$ & \\
\hline \multirow[t]{8}{*}{$\begin{array}{l}\text { PbLi drain tank } \\
\text { inlet valve from } \\
\text { pump outlet } \\
\text { (normally closed) }\end{array}$} & NO & fail to open & Category III & $\begin{array}{l}\text { command fault, } \\
\text { human error, } \\
\text { electronic noise }\end{array}$ & $\begin{array}{l}\text { periodic testing, } \\
\text { QA on control } \\
\text { system, operator } \\
\text { procedures }\end{array}$ & $\begin{array}{l}\text { No consequences } \\
\text { during normal plant } \\
\text { operation }\end{array}$ & $\begin{array}{l}\text { No actions to take } \\
\text { for this failure mode } \\
\text { during ITER } \\
\text { operation } \\
\end{array}$ & Not an IE & & $1 \mathrm{E}-03 / \mathrm{d}$ & $\begin{array}{l}\text { EGG-SSRE- } \\
8875\end{array}$ & $\begin{array}{l}\text { Assume one fill or refill operation } \\
\text { per year, so one demand to open } \\
\text { the valve during } 4 \text { annual ITER } \\
\text { shutdown periods }\end{array}$ \\
\hline & & $\begin{array}{l}\text { spurious } \\
\text { operation }\end{array}$ & Category III & $\begin{array}{l}\text { command fault, } \\
\text { human error, } \\
\text { electronic noise }\end{array}$ & $\begin{array}{l}\text { periodic testing, } \\
\text { QA on control } \\
\text { system, operator } \\
\text { procedures }\end{array}$ & $\begin{array}{l}\text { Drains Pb-17Li from } \\
\text { piping to drain tank }\end{array}$ & $\begin{array}{l}\text { ITER can continue to } \\
\text { operate if helium } \\
\text { cooling is operating }\end{array}$ & $\begin{array}{l}\text { Pb-17Li LOCA, } \\
\text { LMP1 }\end{array}$ & & $5 \mathrm{E}-07 / \mathrm{h}$ & $\begin{array}{l}\text { EGG-SSRE- } \\
8875\end{array}$ & \\
\hline & & fail to close & Category III & $\begin{array}{l}\text { command fault, } \\
\text { human error, } \\
\text { electronic noise }\end{array}$ & $\begin{array}{l}\text { periodic testing, } \\
\text { QA on control } \\
\text { system, operator } \\
\text { procedures }\end{array}$ & $\begin{array}{l}\text { No consequences } \\
\text { during normal plant } \\
\text { operation }\end{array}$ & $\begin{array}{l}\text { No actions to take } \\
\text { for this failure mode } \\
\text { during ITER } \\
\text { operation }\end{array}$ & Not an IE & & $1 \mathrm{E}-03 / \mathrm{d}$ & $\begin{array}{l}\text { EGG-SSRE- } \\
8875\end{array}$ & $\begin{array}{l}\text { Assume one fill or refill operation } \\
\text { per year, so one demand to close } \\
\text { the valve. Failure to close would } \\
\text { occur during ITER outage work so } \\
\text { this is not an initiating event. }\end{array}$ \\
\hline & & plugging & Category III & $\begin{array}{l}\text { impurity } \\
\text { buildup, oxide } \\
\text { buildup }\end{array}$ & periodic testing & $\begin{array}{l}\text { No consequences } \\
\text { during normal plant } \\
\text { operation }\end{array}$ & $\begin{array}{l}\text { No actions to take } \\
\text { for this failure mode } \\
\text { during ITER } \\
\text { operation }\end{array}$ & Not an IE & & $5 \mathrm{E}-08 / \mathrm{h}$ & $\begin{array}{l}\text { EGG-SSRE- } \\
8875\end{array}$ & $\begin{array}{l}\text { Assume that operational evolutions } \\
\text { requiring the drain valve to open } \\
\text { are during ITER outages, not } \\
\text { during ITER TBM operating time. } \\
\text { This would be a latent fault, if the } \\
\text { valve was needed during Pb-17Li } \\
\text { loop operation, a plugged valve } \\
\text { would be inoperable so the other } \\
\text { inlet valve and the rupture disk } \\
\text { would be relied on. }\end{array}$ \\
\hline & & $\begin{array}{l}\text { internal } \\
\text { leakage }\end{array}$ & Category III & $\begin{array}{l}\text { valve seat flaw } \\
\text { or wear, valve } \\
\text { disk flaw }\end{array}$ & $\begin{array}{l}\text { inspection, } \\
\text { periodic testing, } \\
\text { QA on } \\
\text { construction }\end{array}$ & $\begin{array}{l}\text { Slow leak of Pb-17Li to } \\
\text { the drain tank }\end{array}$ & $\begin{array}{l}\text { ITER can continue to } \\
\text { operate if helium } \\
\text { cooling is operating }\end{array}$ & Not an IE & $\begin{array}{l}\text { Not an IE since Pb-17Li } \\
\text { is not lost from the } \\
\text { system, no leak into the } \\
\text { Port Cell }\end{array}$ & $5 \mathrm{E}-07 / \mathrm{h}$ & $\begin{array}{l}\text { EGG-SSRE- } \\
8875\end{array}$ & \\
\hline & & $\begin{array}{l}\text { internal } \\
\text { rupture }\end{array}$ & Category III & $\begin{array}{l}\text { valve disk } \\
\text { failure }\end{array}$ & $\begin{array}{l}\text { inspection, } \\
\text { periodic testing, } \\
\text { QA on } \\
\text { construction }\end{array}$ & $\begin{array}{l}\text { Large leak of } \mathrm{Pb}-17 \mathrm{Li} \\
\text { to the drain tank }\end{array}$ & $\begin{array}{l}\text { ITER can continue to } \\
\text { operate if helium } \\
\text { cooling is operating }\end{array}$ & Not an IE & $\begin{array}{l}\text { Not an IE since Pb-17Li } \\
\text { is not lost from the } \\
\text { system, no leak into the } \\
\text { Port Cell }\end{array}$ & $5 \mathrm{E}-08 / \mathrm{h}$ & $\begin{array}{l}\text { EGG-SSRE- } \\
8875\end{array}$ & \\
\hline & & $\begin{array}{l}\text { external } \\
\text { leakage }\end{array}$ & Category III & $\begin{array}{l}\text { valve stem } \\
\text { packing flaw, } \\
\text { valve body flaw }\end{array}$ & $\begin{array}{l}\text { inspection, } \\
\text { periodic testing, } \\
\text { QA on } \\
\text { construction } \\
\end{array}$ & $\begin{array}{l}\text { Slow leak of Pb-17Li to } \\
\text { the port }\end{array}$ & $\begin{array}{l}\text { ITER can continue to } \\
\text { operate if helium } \\
\text { cooling is operating }\end{array}$ & $\begin{array}{l}\text { Pb-17Li Small } \\
\text { LOCA, LMP2 }\end{array}$ & & $5 \mathrm{E}-07 / \mathrm{h}$ & $\begin{array}{l}\text { EGG-SSRE- } \\
8875\end{array}$ & \\
\hline & & $\begin{array}{l}\text { external } \\
\text { rupture }\end{array}$ & Category III & $\begin{array}{l}\text { valve stem } \\
\text { packing failure, } \\
\text { valve body } \\
\text { failure }\end{array}$ & $\begin{array}{l}\text { inspection, } \\
\text { periodic testing, } \\
\text { QA on } \\
\text { construction }\end{array}$ & $\begin{array}{l}\text { Large leak of } \mathrm{Pb}-17 \mathrm{Li} \\
\text { to the port }\end{array}$ & $\begin{array}{l}\text { ITER can continue to } \\
\text { operate if helium } \\
\text { cooling is operating }\end{array}$ & $\begin{array}{l}\text { Pb-17Li LOCA, } \\
\text { LMP1 }\end{array}$ & & $5 \mathrm{E}-08 / \mathrm{h}$ & $\begin{array}{l}\text { EGG-SSRE- } \\
8875\end{array}$ & \\
\hline
\end{tabular}




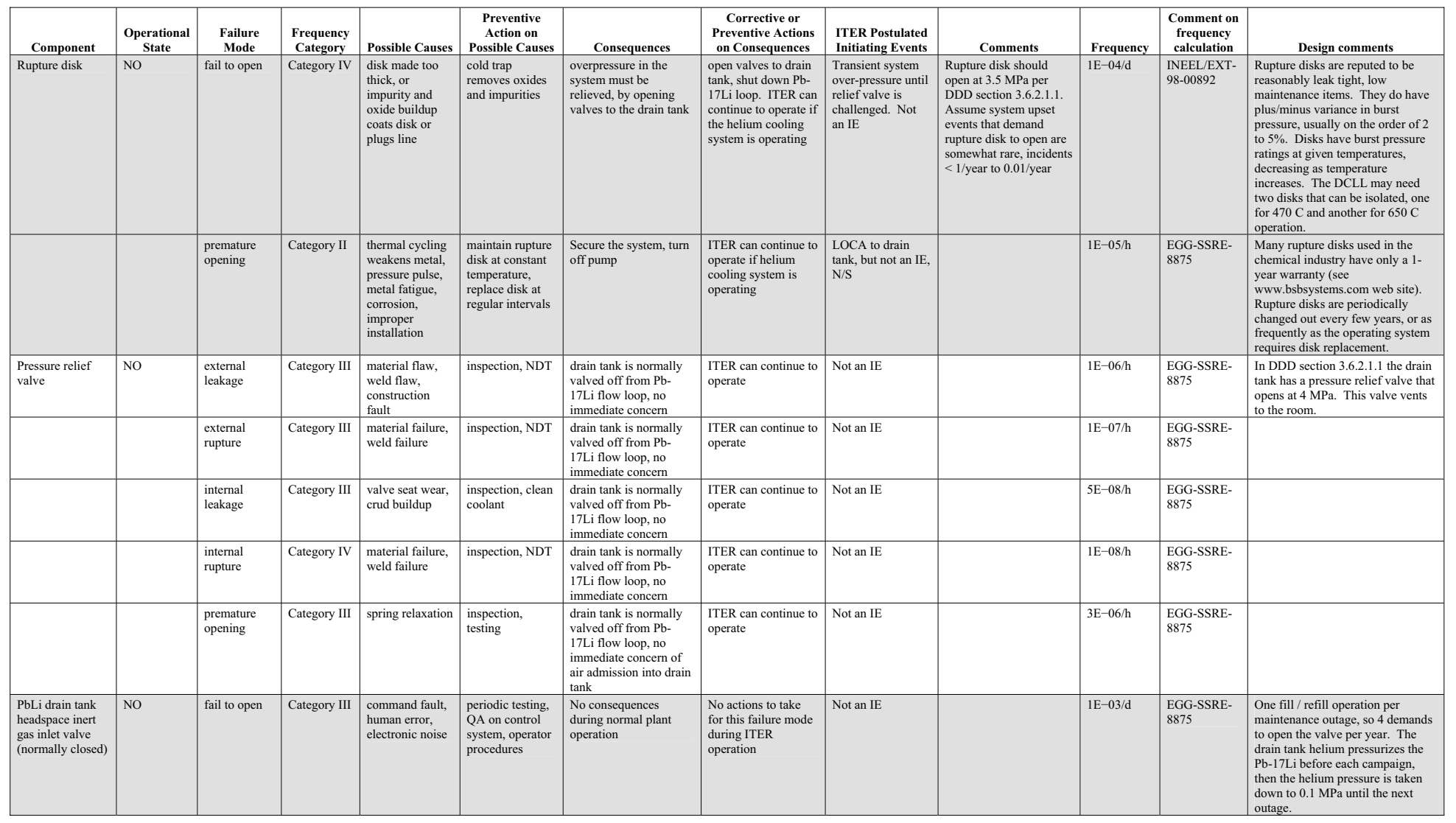




\begin{tabular}{|c|c|c|c|c|c|c|c|c|c|c|c|c|}
\hline Component & $\begin{array}{c}\text { Operational } \\
\text { State }\end{array}$ & $\begin{array}{c}\text { Failure } \\
\text { Mode }\end{array}$ & $\begin{array}{c}\text { Frequency } \\
\text { Category }\end{array}$ & Possible Causes & $\begin{array}{c}\text { Preventive } \\
\text { Action on } \\
\text { Possible Causes } \\
\end{array}$ & Consequences & $\begin{array}{c}\text { Corrective or } \\
\text { Preventive Actions } \\
\text { on Consequences }\end{array}$ & $\begin{array}{l}\text { ITER Postulated } \\
\text { Initiating Events }\end{array}$ & Comments & Frequency & $\begin{array}{l}\text { Comment on } \\
\text { frequency } \\
\text { calculation }\end{array}$ & Design comments \\
\hline & & $\begin{array}{l}\text { spurious } \\
\text { operation }\end{array}$ & Category III & $\begin{array}{l}\text { command fault, } \\
\text { human error, } \\
\text { electronic noise }\end{array}$ & $\begin{array}{l}\text { periodic testing, } \\
\text { QA on control } \\
\text { system, operator } \\
\text { procedures }\end{array}$ & $\begin{array}{l}\text { No consequences } \\
\text { during normal plant } \\
\text { operation }\end{array}$ & $\begin{array}{l}\text { No actions to take } \\
\text { for this failure mode } \\
\text { during ITER } \\
\text { operation }\end{array}$ & Not an IE & & $5 \mathrm{E}-07 / \mathrm{h}$ & $\begin{array}{l}\text { EGG-SSRE- } \\
8875\end{array}$ & $\begin{array}{l}\text { Opening the headspace valve on } \\
\text { the tank while the tank is merely } \\
\text { under gas pressure will vent the gas } \\
\text { in the tank. The rupture disk at } \\
\text { burst pressure of } 3.5 \mathrm{MPa} \text { is not } \\
\text { threatened at the } 0.1 \mathrm{MPa} \\
\text { backpressure loss. }\end{array}$ \\
\hline & & fail to close & Category III & $\begin{array}{l}\text { command fault, } \\
\text { human error, } \\
\text { electronic noise }\end{array}$ & $\begin{array}{l}\text { periodic testing, } \\
\text { QA on control } \\
\text { system, operator } \\
\text { procedures }\end{array}$ & $\begin{array}{l}\text { No consequences } \\
\text { during normal plant } \\
\text { operation }\end{array}$ & $\begin{array}{l}\text { No actions to take } \\
\text { for this failure mode } \\
\text { during ITER } \\
\text { operation }\end{array}$ & Not an IE & & $1 \mathrm{E}-03 / \mathrm{d}$ & $\begin{array}{l}\text { EGG-SSRE- } \\
8875\end{array}$ & $\begin{array}{l}\text { One fill / refill operation per } \\
\text { maintenance outage, so } 4 \text { demands } \\
\text { to close the valve per year. Failure } \\
\text { to close would occur during ITER } \\
\text { outage work so this is not an } \\
\text { initiating event. }\end{array}$ \\
\hline & & plugging & Category III & $\begin{array}{l}\text { impurity } \\
\text { buildup, oxide } \\
\text { buildup }\end{array}$ & $\begin{array}{l}\text { cold trap cleans } \\
\text { the coolant }\end{array}$ & $\begin{array}{l}\text { No consequences } \\
\text { during normal plant } \\
\text { operation }\end{array}$ & \begin{tabular}{|l|} 
No actions to take \\
for this failure mode \\
during ITER \\
operation \\
\end{tabular} & Not an IE & & $5 \mathrm{E}-08 / \mathrm{h}$ & $\begin{array}{l}\text { EGG-SSRE- } \\
8875\end{array}$ & $\begin{array}{l}\text { Operational evolutions requiring } \\
\text { the gas valve to open are just } \\
\text { during ITER outages, not during } \\
\text { ITER TBM operating time. }\end{array}$ \\
\hline & & $\begin{array}{l}\text { internal } \\
\text { leakage }\end{array}$ & Category III & $\begin{array}{l}\text { valve seat flaw } \\
\text { or wear, valve } \\
\text { disk flaw }\end{array}$ & $\begin{array}{l}\text { inspection, } \\
\text { periodic testing, } \\
\text { QA on } \\
\text { construction }\end{array}$ & $\begin{array}{l}\text { No consequences } \\
\text { during normal plant } \\
\text { operation }\end{array}$ & \begin{tabular}{|l|} 
No actions to take \\
for this failure mode \\
during ITER \\
operation \\
\end{tabular} & Not an IE & & $5 \mathrm{E}-07 / \mathrm{h}$ & $\begin{array}{l}\text { EGG-SSRE- } \\
8875\end{array}$ & $\begin{array}{l}\text { Helium inert gas is within the tank } \\
\text { and this gas would leak out past the } \\
\text { valve seat to the pressure control } \\
\text { system. }\end{array}$ \\
\hline & & $\begin{array}{l}\text { internal } \\
\text { rupture }\end{array}$ & Category III & $\begin{array}{l}\text { valve disk } \\
\text { failure }\end{array}$ & $\begin{array}{l}\text { inspection, } \\
\text { periodic testing, } \\
\text { QA on } \\
\text { construction }\end{array}$ & $\begin{array}{l}\text { No consequences } \\
\text { during normal plant } \\
\text { operation }\end{array}$ & $\begin{array}{l}\text { No actions to take } \\
\text { for this failure mode } \\
\text { during ITER } \\
\text { operation }\end{array}$ & Not an IE & & $5 \mathrm{E}-08 / \mathrm{h}$ & $\begin{array}{l}\text { EGG-SSRE- } \\
8875\end{array}$ & $\begin{array}{l}\text { Helium inert gas is within the tank } \\
\text { and this gas would leak out through } \\
\text { the faulted valve to the pressure } \\
\text { control system. }\end{array}$ \\
\hline & & $\begin{array}{l}\text { external } \\
\text { leakage }\end{array}$ & Category III & $\begin{array}{l}\text { valve stem } \\
\text { packing flaw, } \\
\text { valve body flaw }\end{array}$ & $\begin{array}{l}\text { inspection, } \\
\text { periodic testing, } \\
\text { QA on } \\
\text { construction }\end{array}$ & $\begin{array}{l}\text { Leaks helium cover gas } \\
\text { to the equatorial port }\end{array}$ & $\begin{array}{l}\text { Operators can isolate } \\
\text { helium supply }\end{array}$ & Not an IE & $\begin{array}{l}\text { A large amount of } \\
\text { elevated temperature gas } \\
\text { leaking into the port } \\
\text { could be a personnel } \\
\text { hazard, but this area } \\
\text { should be a personnel } \\
\text { exclusion zone during } \\
\text { ITER operation. }\end{array}$ & $5 \mathrm{E}-07 / \mathrm{h}$ & $\begin{array}{l}\text { EGG-SSRE- } \\
8875\end{array}$ & $\begin{array}{l}\text { Helium inert gas is within the tank } \\
\text { and this gas would leak out past the } \\
\text { valve seat. With helium bled out, } \\
\text { air will slowly enter the tank so the } \\
\text { tank requires cleaning before next } \\
\text { use. }\end{array}$ \\
\hline & & $\begin{array}{l}\text { external } \\
\text { rupture }\end{array}$ & Category III & $\begin{array}{l}\text { valve steam } \\
\text { packing failure, } \\
\text { valve body } \\
\text { failure }\end{array}$ & $\begin{array}{l}\text { inspection, } \\
\text { periodic testing, } \\
\text { QA on } \\
\text { construction }\end{array}$ & $\begin{array}{l}\text { Leaks helium cover gas } \\
\text { to the equatorial port }\end{array}$ & $\begin{array}{l}\text { Operators can isolate } \\
\text { helium supply }\end{array}$ & Not an IE & $\begin{array}{l}\text { A large amount of } \\
\text { elevated temperature gas } \\
\text { leaking into the port } \\
\text { could be a personnel } \\
\text { hazard, but no personnel } \\
\text { should be in the area } \\
\text { during ITER operation. }\end{array}$ & $5 \mathrm{E}-08 / \mathrm{h}$ & $\begin{array}{l}\text { EGG-SSRE- } \\
8875\end{array}$ & $\begin{array}{l}\text { Helium inert gas is within the tank } \\
\text { and this gas would leak out past the } \\
\text { valve seat. With helium bled out, } \\
\text { air will slowly enter the tank so the } \\
\text { tank requires cleaning before next } \\
\text { use. }\end{array}$ \\
\hline $\begin{array}{l}\text { Level instrument } \\
\text { on drain tank }\end{array}$ & NO & $\begin{array}{l}\text { fails to } \\
\text { operate }\end{array}$ & Category III & $\begin{array}{l}\text { fouling, drift, } \\
\text { calibration error }\end{array}$ & $\begin{array}{l}\text { Coolant filtering } \\
\text { and cleaning, } \\
\text { periodic } \\
\text { recalibration }\end{array}$ & $\begin{array}{l}\text { Deprives operators of } \\
\text { accurate information on } \\
\mathrm{Pb}-17 \mathrm{Li} \text { depth in the } \\
\text { drain tank, whether the } \\
\text { liquid is in storage in } \\
\text { the tank or where it is } \\
\text { during an off-normal } \\
\text { event }\end{array}$ & $\begin{array}{l}\text { Other indications } \\
\text { may provide enough } \\
\text { data to allow } \\
\text { operators to assess } \\
\text { the TBM flow loop } \\
\text { conditions. The } \\
\text { TBM should shut } \\
\text { down at the end of } \\
\text { the campaign to } \\
\text { allow for repairs. }\end{array}$ & Not an IE & & $1 \mathrm{E}-06 / \mathrm{h}$ & $\begin{array}{l}\text { INEL- } \\
\text { 96/0295 }\end{array}$ & $\begin{array}{l}\text { Note on fouling: Instrument lines } \\
\text { tend to act as diffusion cold traps } \\
\text { for impurities in the liquid metal } \\
\text { system; keeping the line } \\
\text { temperature above the saturation } \\
\text { temperature of impurities will } \\
\text { reduce impurity buildup in the } \\
\text { lines. Dietrich and Zinn, "Solid } \\
\text { Fuel Reactors", Addison Wesley } \\
\text { Publishers, Reading, MA, 1958, } \\
\text { page } 84 \text {. }\end{array}$ \\
\hline
\end{tabular}




\begin{tabular}{|c|c|c|c|c|c|c|c|c|c|c|c|c|}
\hline Component & $\begin{array}{c}\text { Operational } \\
\text { State }\end{array}$ & $\begin{array}{c}\text { Failure } \\
\text { Mode }\end{array}$ & $\begin{array}{l}\text { Frequency } \\
\text { Category }\end{array}$ & Possible Causes & $\begin{array}{c}\text { Preventive } \\
\text { Action on } \\
\text { Possible Causes } \\
\end{array}$ & Consequences & $\begin{array}{c}\text { Corrective or } \\
\text { Preventive Actions } \\
\text { on Consequences }\end{array}$ & $\begin{array}{l}\text { ITER Postulated } \\
\text { Initiating Events }\end{array}$ & Comments & Frequency & $\begin{array}{c}\text { Comment on } \\
\text { frequency } \\
\text { calculation }\end{array}$ & Design comments \\
\hline & & $\begin{array}{l}\text { improper } \\
\text { reading }\end{array}$ & Category III & $\begin{array}{l}\text { calibration error, } \\
\text { drift, impurity } \\
\text { buildup on } \\
\text { instrument }\end{array}$ & \begin{tabular}{|l|} 
Periodic \\
recalibration
\end{tabular} & $\begin{array}{l}\text { Reading high or low } \\
\text { will affect volume flow } \\
\text { in the TBM }\end{array}$ & $\begin{array}{l}\text { Could result in } \\
\text { temperature transient } \\
\text { in the } \mathrm{Pb}-17 \mathrm{Li} \text {. }\end{array}$ & Not an IE & & $1.4 \mathrm{E}-06 / \mathrm{h}$ & $\begin{array}{l}\text { INEL- } \\
96 / 0295\end{array}$ & $\begin{array}{l}\text { Instrument recalibration is an ORE } \\
\text { concern, remote instruments would } \\
\text { reduce personnel exposure. }\end{array}$ \\
\hline & & external leak & Category IV & $\begin{array}{l}\text { instrument tap } \\
\text { crack, } \\
\text { instrument line } \\
\text { crack, weld } \\
\text { crack }\end{array}$ & $\begin{array}{l}\text { Materials } \\
\text { selection in } \\
\text { design, pre- } \\
\text { service } \\
\text { inspection, } \\
\text { system } \\
\text { operability } \\
\text { testing, reduce } \\
\text { flow-induced } \\
\text { vibration in } \\
\text { design } \\
\end{array}$ & $\begin{array}{l}\text { An instrument line leak } \\
\text { will either leak inert } \\
\text { gas, depressurizing the } \\
\text { drain tank, or leak the } \\
\text { 'heel' liquid from the } \\
\text { drain tank. A coolant } \\
\text { leak of limited amount } \\
\text { from the drain tank } \\
\text { does not pose large } \\
\text { concerns. }\end{array}$ & $\begin{array}{l}\text { No immediate } \\
\text { actions needed, } \\
\text { assume that a small } \\
\text { leak can probably be } \\
\text { tolerated until the } \\
\text { end of the campaign, } \\
\text { then shut down TBM } \\
\text { to repair the leak. }\end{array}$ & Not an IE & $\begin{array}{l}\text { Do not expect much Pb- } \\
17 \mathrm{Li} \text { to be in the drain } \\
\text { tank during normal } \\
\text { operation, and kept at } \\
\text { below } 8 \text { MPa pressure. } \\
\text { Leakage should be } \\
\text { minor, not an IE. }\end{array}$ & $\begin{array}{l}1 \mathrm{E}-09 / \mathrm{h}, \\
\text { assuming }<1 \\
\mathrm{~m} \text { of tubing }\end{array}$ & $\begin{array}{l}\text { WSRC-TR- } \\
93-262\end{array}$ & $\begin{array}{l}\text { An important issue is release of } \\
\text { activated gases, such as mercury } \\
\text { and tritium. }\end{array}$ \\
\hline & & $\begin{array}{l}\text { external } \\
\text { rupture }\end{array}$ & $<$ Cat IV & $\begin{array}{l}\text { instrument tap } \\
\text { line material } \\
\text { failure, weld } \\
\text { failure, over- } \\
\text { pressure on } \\
\text { instrument }\end{array}$ & $\begin{array}{l}\text { weld NDT, } \\
\text { reduce flow- } \\
\text { induced } \\
\text { vibration in } \\
\text { design }\end{array}$ & $\begin{array}{l}\text { Instrument line rupture } \\
\text { leakage from the drain } \\
\text { tank in normal } \\
\text { operation is not high } \\
\text { volume. }\end{array}$ & $\begin{array}{l}\text { Shut down pump, } \\
\text { isolate inflow to } \\
\text { pump, and open } \\
\text { drain line as quickly } \\
\text { as possible to limit } \\
\text { release amount. } \\
\text { ITER can continue to } \\
\text { operate if TBM } \\
\text { helium system is } \\
\text { operating. }\end{array}$ & Not an IE & & $\begin{array}{l}3 \mathrm{E}-11 / \mathrm{h}, \\
\text { assuming }<1 \\
\mathrm{~m} \text { of tubing }\end{array}$ & $\begin{array}{l}\text { WSRC-TR- } \\
93-262\end{array}$ & \\
\hline \multirow[t]{5}{*}{$\begin{array}{l}\text { PbLi drain tank } \\
\text { inlet valve from } \\
\text { mixing tank } \\
\text { (normally closed) } \\
\end{array}$} & NO & fail to open & Category III & $\begin{array}{l}\text { command fault, } \\
\text { human error, } \\
\text { electronic noise }\end{array}$ & $\begin{array}{l}\text { periodic testing, } \\
\text { QA on control } \\
\text { system, operator } \\
\text { procedures }\end{array}$ & $\begin{array}{l}\text { No operational } \\
\text { consequences }\end{array}$ & $\begin{array}{l}\text { No actions to take } \\
\text { during operations }\end{array}$ & Not an IE & & $1 \mathrm{E}-03 / \mathrm{d}$ & $\begin{array}{l}\text { EGG-SSRE- } \\
8875\end{array}$ & $\begin{array}{l}\text { One fill / refill operation per year, } \\
\text { so one demand to open the valve }\end{array}$ \\
\hline & & $\begin{array}{l}\text { spurious } \\
\text { operation }\end{array}$ & Category III & $\begin{array}{l}\text { command fault, } \\
\text { human error, } \\
\text { electronic noise }\end{array}$ & $\begin{array}{l}\text { periodic testing, } \\
\text { QA on control } \\
\text { system, operator } \\
\text { procedures }\end{array}$ & $\begin{array}{l}\text { Drains } \mathrm{Pb}-17 \mathrm{Li} \text { from } \\
\text { piping to drain tank }\end{array}$ & $\begin{array}{l}\text { ITER can continue to } \\
\text { operate if helium } \\
\text { cooling is operating }\end{array}$ & LOCA, LMP1 & & $5 \mathrm{E}-07 / \mathrm{h}$ & $\begin{array}{l}\text { EGG-SSRE- } \\
8875\end{array}$ & \\
\hline & & fail to close & Category III & $\begin{array}{l}\text { command fault, } \\
\text { human error, } \\
\text { electronic noise }\end{array}$ & $\begin{array}{l}\text { periodic testing, } \\
\text { QA on control } \\
\text { system, operator } \\
\text { procedures }\end{array}$ & $\begin{array}{l}\text { No consequences } \\
\text { during normal plant } \\
\text { operation }\end{array}$ & $\begin{array}{l}\text { No actions to take } \\
\text { for this failure mode } \\
\text { during IIER } \\
\text { operation }\end{array}$ & Not an IE & & $1 \mathrm{E}-03 / \mathrm{d}$ & $\begin{array}{l}\text { EGG-SSRE- } \\
8875\end{array}$ & $\begin{array}{l}\text { One fill / refill operation per year, } \\
\text { so one demand to close the valve. } \\
\text { Failure to close would occur during } \\
\text { ITER outage work so this is not an } \\
\text { initiating event. }\end{array}$ \\
\hline & & plugging & Category III & $\begin{array}{l}\text { impurity } \\
\text { buildup, oxide } \\
\text { buildup }\end{array}$ & $\begin{array}{l}\text { cold trap cleans } \\
\text { the coolant }\end{array}$ & $\begin{array}{l}\text { No consequences } \\
\text { during normal plant } \\
\text { operation }\end{array}$ & $\begin{array}{l}\text { No actions to take } \\
\text { for this failure mode } \\
\text { during ITER } \\
\text { operation }\end{array}$ & Not an IE & & $5 \mathrm{E}-08 / \mathrm{h}$ & $\begin{array}{l}\text { EGG-SSRE- } \\
8875\end{array}$ & $\begin{array}{l}\text { Operational evolutions requiring } \\
\text { the drain valve to open are during } \\
\text { ITER outages, not during ITER } \\
\text { TBM operating time. This would } \\
\text { be a latent fault, if the valve was } \\
\text { needed during Pb-17Li loop } \\
\text { operation, a plugged valve would } \\
\text { be inoperable so the other inlet } \\
\text { valve and the rupture disk would } \\
\text { be relied on. }\end{array}$ \\
\hline & & $\begin{array}{l}\text { internal } \\
\text { leakage }\end{array}$ & Category III & $\begin{array}{l}\text { valve seat flaw } \\
\text { or wear, valve } \\
\text { disk flaw }\end{array}$ & $\begin{array}{l}\text { inspection, } \\
\text { periodic testing, } \\
\text { QA on } \\
\text { construction }\end{array}$ & $\begin{array}{l}\text { Slow leak of Pb-17Li to } \\
\text { the drain tank }\end{array}$ & $\begin{array}{l}\text { ITER can continue to } \\
\text { operate if helium } \\
\text { cooling is operating }\end{array}$ & Not an IE & $\begin{array}{l}\text { Not an IE since Pb-17Li } \\
\text { is not lost from the } \\
\text { system, no leak into the } \\
\text { Port Cell }\end{array}$ & $5 \mathrm{E}-07 / \mathrm{h}$ & $\begin{array}{l}\text { EGG-SSRE- } \\
8875\end{array}$ & \\
\hline
\end{tabular}




\begin{tabular}{|c|c|c|c|c|c|c|c|c|c|c|c|c|}
\hline Component & $\begin{array}{c}\text { Operational } \\
\text { State }\end{array}$ & $\begin{array}{c}\text { Failure } \\
\text { Mode }\end{array}$ & $\begin{array}{l}\text { Frequency } \\
\text { Category }\end{array}$ & Possible Causes & $\begin{array}{c}\text { Preventive } \\
\text { Action on } \\
\text { Possible Causes } \\
\end{array}$ & Consequences & $\begin{array}{c}\text { Corrective or } \\
\text { Preventive Actions } \\
\text { on Consequences } \\
\end{array}$ & $\begin{array}{l}\text { ITER Postulated } \\
\text { Initiating Events }\end{array}$ & Comments & Frequency & $\begin{array}{l}\text { Comment on } \\
\text { frequency } \\
\text { calculation } \\
\end{array}$ & Design comments \\
\hline & & $\begin{array}{l}\text { internal } \\
\text { rupture }\end{array}$ & Category III & $\begin{array}{l}\text { valve disk } \\
\text { failure }\end{array}$ & \begin{tabular}{|l|} 
inspection, \\
periodic testing, \\
QA on \\
construction \\
\end{tabular} & $\begin{array}{l}\text { Large leak of Pb-17Li } \\
\text { to the drain tank }\end{array}$ & $\begin{array}{l}\text { ITER can continue to } \\
\text { operate if helium } \\
\text { cooling is operating }\end{array}$ & Not an IE & $\begin{array}{l}\text { Not an IE since Pb-17Li } \\
\text { is not lost from the } \\
\text { system, no leak into the } \\
\text { Port Cell } \\
\end{array}$ & $5 \mathrm{E}-08 / \mathrm{h}$ & $\begin{array}{l}\text { EGG-SSRE- } \\
8875\end{array}$ & \\
\hline & & $\begin{array}{l}\text { external } \\
\text { leakage }\end{array}$ & Category III & $\begin{array}{l}\text { valve stem } \\
\text { packing flaw, } \\
\text { valve body flaw }\end{array}$ & $\begin{array}{l}\text { inspection, } \\
\text { periodic testing, } \\
\text { QA on } \\
\text { construction }\end{array}$ & $\begin{array}{l}\text { Slow leak of Pb-17Li to } \\
\text { the port }\end{array}$ & \begin{tabular}{|l|} 
ITER can continue to \\
operate if helium \\
cooling is operating
\end{tabular} & $\begin{array}{l}\text { Small LOCA, } \\
\text { LMP2 }\end{array}$ & & $5 \mathrm{E}-07 / \mathrm{h}$ & $\begin{array}{l}\text { EGG-SSRE- } \\
8875\end{array}$ & \\
\hline & & $\begin{array}{l}\text { external } \\
\text { rupture }\end{array}$ & Category III & $\begin{array}{l}\text { valve steam } \\
\text { packing failure, } \\
\text { valve body } \\
\text { failure }\end{array}$ & $\begin{array}{l}\text { inspection, } \\
\text { periodic testing, } \\
\text { QA on } \\
\text { construction } \\
\end{array}$ & $\begin{array}{l}\text { Large leak of } \mathrm{Pb}-17 \mathrm{Li} \\
\text { to the port }\end{array}$ & $\begin{array}{l}\text { ITER can continue to } \\
\text { operate if helium } \\
\text { cooling is operating }\end{array}$ & LOCA, LMP1 & & $5 \mathrm{E}-08 / \mathrm{h}$ & $\begin{array}{l}\text { EGG-SSRE- } \\
8875\end{array}$ & \\
\hline \multirow[t]{7}{*}{$\begin{array}{l}\text { PbLi drain tank } \\
\text { headspace inert } \\
\text { gas outlet valve } \\
\text { (normally closed) }\end{array}$} & NO & fail to open & Category III & $\begin{array}{l}\text { command fault, } \\
\text { human error, } \\
\text { electronic noise }\end{array}$ & $\begin{array}{l}\text { periodic testing, } \\
\text { QA on control } \\
\text { system, operator } \\
\text { procedures }\end{array}$ & $\begin{array}{l}\text { No consequences } \\
\text { during normal plant } \\
\text { operation }\end{array}$ & $\begin{array}{l}\text { No actions to take } \\
\text { for this failure mode } \\
\text { during ITER } \\
\text { operation }\end{array}$ & Not an IE & & $1 \mathrm{E}-03 / \mathrm{d}$ & $\begin{array}{l}\text { EGG-SSRE- } \\
8875\end{array}$ & $\begin{array}{l}\text { One fill / refill operation per } \\
\text { maintenance outage, so } 4 \text { demands } \\
\text { to open the valve per year. The } \\
\text { drain tank helium pressurizes the } \\
\text { Pb-17Li before each campaign, } \\
\text { then the helium pressure is taken } \\
\text { down to } 0.1 \mathrm{MPa} \text { until the next } \\
\text { outage. }\end{array}$ \\
\hline & & $\begin{array}{l}\text { spurious } \\
\text { operation }\end{array}$ & Category III & $\begin{array}{l}\text { command fault, } \\
\text { human error, } \\
\text { electronic noise }\end{array}$ & $\begin{array}{l}\text { periodic testing, } \\
\text { QA on control } \\
\text { system, operator } \\
\text { procedures }\end{array}$ & $\begin{array}{l}\text { No consequences } \\
\text { during normal plant } \\
\text { operation }\end{array}$ & $\begin{array}{l}\text { No actions to take } \\
\text { for this failure mode } \\
\text { during ITER } \\
\text { operation }\end{array}$ & Not an IE & & $5 \mathrm{E}-07 / \mathrm{h}$ & $\begin{array}{l}\text { EGG-SSRE- } \\
8875\end{array}$ & $\begin{array}{l}\text { Opening the headspace valve on } \\
\text { the tank while the tank is merely } \\
\text { under gas pressure will vent the gas } \\
\text { in the tank. The rupture disk at } \\
\text { burst pressure of } 3.5 \mathrm{MPa} \text { is not } \\
\text { threatened at the } 0.1 \mathrm{MPa} \\
\text { backpressure loss. }\end{array}$ \\
\hline & & fail to close & Category III & $\begin{array}{l}\text { command fault, } \\
\text { human error, } \\
\text { electronic noise }\end{array}$ & $\begin{array}{l}\text { periodic testing, } \\
\text { QA on control } \\
\text { system, operator } \\
\text { procedures }\end{array}$ & $\begin{array}{l}\text { No consequences } \\
\text { during normal plant } \\
\text { operation }\end{array}$ & $\begin{array}{l}\text { No actions to take } \\
\text { for this failure mode } \\
\text { during ITER } \\
\text { operation }\end{array}$ & Not an IE & & $1 \mathrm{E}-03 / \mathrm{d}$ & $\begin{array}{l}\text { EGG-SSRE- } \\
8875\end{array}$ & $\begin{array}{l}\text { One fill / refill operation per } \\
\text { maintenance outage, so } 4 \text { demands } \\
\text { to close the valve per year. Failure } \\
\text { to close would occur during ITER } \\
\text { outage work so this is not an } \\
\text { initiating event. }\end{array}$ \\
\hline & & plugging & Category III & $\begin{array}{l}\text { impurity } \\
\text { buildup, oxide } \\
\text { buildup }\end{array}$ & $\begin{array}{l}\text { cold trap cleans } \\
\text { the coolant }\end{array}$ & $\begin{array}{l}\text { No consequences } \\
\text { during normal plant } \\
\text { operation }\end{array}$ & $\begin{array}{l}\text { No actions to take } \\
\text { for this failure mode } \\
\text { during ITER } \\
\text { operation } \\
\end{array}$ & Not an IE & & $5 \mathrm{E}-08 / \mathrm{h}$ & $\begin{array}{l}\text { EGG-SSRE- } \\
8875\end{array}$ & $\begin{array}{l}\text { Operational evolutions requiring } \\
\text { the gas valve to open are just } \\
\text { during ITER outages, not during } \\
\text { ITER TBM operating time. }\end{array}$ \\
\hline & & $\begin{array}{l}\text { internal } \\
\text { leakage }\end{array}$ & Category III & $\begin{array}{l}\text { valve seat flaw } \\
\text { or wear, valve } \\
\text { disk flaw }\end{array}$ & $\begin{array}{l}\text { inspection, } \\
\text { periodic testing, } \\
\text { QA on } \\
\text { construction }\end{array}$ & $\begin{array}{l}\text { No consequences } \\
\text { during normal plant } \\
\text { operation }\end{array}$ & $\begin{array}{l}\text { No actions to take } \\
\text { for this failure mode } \\
\text { during ITER } \\
\text { operation }\end{array}$ & Not an IE & & $5 \mathrm{E}-07 / \mathrm{h}$ & $\begin{array}{l}\text { EGG-SSRE- } \\
8875\end{array}$ & $\begin{array}{l}\text { Helium inert gas is within the tank } \\
\text { and this gas would leak out past the } \\
\text { valve seat to the pressure control } \\
\text { system. }\end{array}$ \\
\hline & & $\begin{array}{l}\text { internal } \\
\text { rupture }\end{array}$ & Category III & $\begin{array}{l}\text { valve disk } \\
\text { failure }\end{array}$ & $\begin{array}{l}\text { inspection, } \\
\text { periodic testing, } \\
\text { QA on } \\
\text { construction } \\
\end{array}$ & $\begin{array}{l}\text { No consequences } \\
\text { during normal plant } \\
\text { operation }\end{array}$ & $\begin{array}{l}\text { No actions to take } \\
\text { for this failure mode } \\
\text { during ITER } \\
\text { operation }\end{array}$ & Not an IE & & $5 \mathrm{E}-08 / \mathrm{h}$ & $\begin{array}{l}\text { EGG-SSRE- } \\
8875\end{array}$ & $\begin{array}{l}\text { Helium inert gas is within the tank } \\
\text { and this gas would leak out through } \\
\text { the faulted valve to the pressure } \\
\text { control system. }\end{array}$ \\
\hline & & $\begin{array}{l}\text { external } \\
\text { leakage }\end{array}$ & Category III & $\begin{array}{l}\text { valve stem } \\
\text { packing flaw, } \\
\text { valve body flaw }\end{array}$ & $\begin{array}{l}\text { inspection, } \\
\text { periodic testing, } \\
\text { QA on } \\
\text { construction }\end{array}$ & $\begin{array}{l}\text { Leaks helium cover gas } \\
\text { to the equatorial port }\end{array}$ & $\begin{array}{l}\text { Operators can isolate } \\
\text { helium supply }\end{array}$ & Not an IE & $\begin{array}{l}\text { A large amount of } \\
\text { elevated temperature gas } \\
\text { leaking into the port } \\
\text { could be a personnel } \\
\text { hazard, but no personnel } \\
\text { should be in the area } \\
\text { during ITER operation. } \\
\end{array}$ & $5 \mathrm{E}-07 / \mathrm{h}$ & $\begin{array}{l}\text { EGG-SSRE- } \\
8875\end{array}$ & $\begin{array}{l}\text { Helium inert gas is within the tank } \\
\text { and this gas would leak out past the } \\
\text { valve seat. With helium bled out, } \\
\text { air will slowly enter the tank so the } \\
\text { tank requires cleaning before next } \\
\text { use. }\end{array}$ \\
\hline
\end{tabular}




\begin{tabular}{|c|c|c|c|c|c|c|c|c|c|c|c|c|}
\hline Component & $\begin{array}{c}\text { Operational } \\
\text { State }\end{array}$ & $\begin{array}{c}\text { Failure } \\
\text { Mode }\end{array}$ & $\begin{array}{c}\text { Frequency } \\
\text { Category }\end{array}$ & Possible Causes & $\begin{array}{c}\text { Preventive } \\
\text { Action on } \\
\text { Possible Causes }\end{array}$ & Consequences & $\begin{array}{c}\text { Corrective or } \\
\text { Preventive Actions } \\
\text { on Consequences }\end{array}$ & $\begin{array}{l}\text { ITER Postulated } \\
\text { Initiating Events }\end{array}$ & Comments & Frequency & $\begin{array}{l}\text { Comment on } \\
\text { frequency } \\
\text { calculation } \\
\end{array}$ & Design comments \\
\hline & & $\begin{array}{l}\text { external } \\
\text { rupture }\end{array}$ & Category III & $\begin{array}{l}\text { valve steam } \\
\text { packing failure, } \\
\text { valve body } \\
\text { failure }\end{array}$ & $\begin{array}{l}\text { inspection, } \\
\text { periodic testing, } \\
\text { QA on } \\
\text { construction }\end{array}$ & $\begin{array}{l}\text { Leaks helium cover gas } \\
\text { to the equatorial port }\end{array}$ & $\begin{array}{l}\text { Operators can isolate } \\
\text { helium supply }\end{array}$ & Not an IE & $\begin{array}{l}\text { A large amount of } \\
\text { elevated temperature gas } \\
\text { leaking into the port } \\
\text { could be a personnel } \\
\text { hazard, but no personnel } \\
\text { should be in the area } \\
\text { during ITER operation. }\end{array}$ & $5 \mathrm{E}-08 / \mathrm{h}$ & $\begin{array}{l}\text { EGG-SSRE- } \\
8875\end{array}$ & $\begin{array}{l}\text { Helium inert gas is within the tank } \\
\text { and this gas would flow out the } \\
\text { damaged valve. With helium bled } \\
\text { out, air will slowly enter the tank } \\
\text { so the tank requires cleaning before } \\
\text { next use. }\end{array}$ \\
\hline \multirow[t]{8}{*}{$\begin{array}{l}\text { Low point Pb- } \\
17 \mathrm{Li} \text { fill/drain } \\
\text { valve (normally } \\
\text { closed) }\end{array}$} & NO & fail to open & Category III & $\begin{array}{l}\text { command fault, } \\
\text { human error, } \\
\text { electronic noise }\end{array}$ & $\begin{array}{l}\text { periodic testing, } \\
\text { QA on control } \\
\text { system, operator } \\
\text { procedures }\end{array}$ & $\begin{array}{l}\text { No consequences } \\
\text { during normal plant } \\
\text { operation }\end{array}$ & $\begin{array}{l}\text { No actions to take } \\
\text { for this failure mode } \\
\text { during ITER } \\
\text { operation }\end{array}$ & Not an IE & & $1 \mathrm{E}-03 / \mathrm{d}$ & $\begin{array}{l}\text { EGG-SSRE- } \\
8875\end{array}$ & $\begin{array}{l}\text { One fill / refill operation per } \\
\text { maintenance outage, so } 4 \text { demands } \\
\text { to open the valve per year. The } \\
\text { drain tank helium pressurizes the } \\
\text { Pb-17Li before each campaign, } \\
\text { then the helium pressure is taken } \\
\text { down to } 0.1 \mathrm{MPa} \text { until the next } \\
\text { outage. }\end{array}$ \\
\hline & & $\begin{array}{l}\text { spurious } \\
\text { operation }\end{array}$ & Category III & $\begin{array}{l}\text { command fault, } \\
\text { human error, } \\
\text { electronic noise }\end{array}$ & $\begin{array}{l}\text { periodic testing, } \\
\text { QA on control } \\
\text { system, operator } \\
\text { procedures }\end{array}$ & $\begin{array}{l}\text { No consequences } \\
\text { during normal plant } \\
\text { operation }\end{array}$ & $\begin{array}{l}\text { No actions to take } \\
\text { for this failure mode } \\
\text { during ITER } \\
\text { operation }\end{array}$ & Not an IE & & $5 \mathrm{E}-07 / \mathrm{h}$ & $\begin{array}{l}\text { EGG-SSRE- } \\
8875\end{array}$ & \\
\hline & & fail to close & Category III & $\begin{array}{l}\text { command fault, } \\
\text { human error, } \\
\text { electronic noise }\end{array}$ & $\begin{array}{l}\text { periodic testing, } \\
\text { QA on control } \\
\text { system, operator } \\
\text { procedures }\end{array}$ & $\begin{array}{l}\text { No consequences } \\
\text { during normal plant } \\
\text { operation }\end{array}$ & $\begin{array}{l}\text { No actions to take } \\
\text { for this failure mode } \\
\text { during ITER } \\
\text { operation }\end{array}$ & Not an IE & & $1 \mathrm{E}-03 / \mathrm{d}$ & $\begin{array}{l}\text { EGG-SSRE- } \\
8875\end{array}$ & $\begin{array}{l}\text { One fill / refill operation per } \\
\text { maintenance outage, so } 4 \text { demands } \\
\text { to close the valve per year. Failure } \\
\text { to close would occur during ITER } \\
\text { outage work so this is not an } \\
\text { initiating event. }\end{array}$ \\
\hline & & plugging & Category III & $\begin{array}{l}\text { impurity } \\
\text { buildup, oxide } \\
\text { buildup }\end{array}$ & $\begin{array}{l}\text { cold trap cleans } \\
\text { the coolant }\end{array}$ & $\begin{array}{l}\text { No consequences } \\
\text { during normal plant } \\
\text { operation }\end{array}$ & $\begin{array}{l}\text { No actions to take } \\
\text { for this failure mode } \\
\text { during ITER } \\
\text { operation }\end{array}$ & Not an IE & & $5 \mathrm{E}-08 / \mathrm{h}$ & $\begin{array}{l}\text { EGG-SSRE- } \\
8875\end{array}$ & $\begin{array}{l}\text { Assume that operational evolutions } \\
\text { requiring the drain valve to open } \\
\text { are during ITER outages, not } \\
\text { during ITER TBM operating time. }\end{array}$ \\
\hline & & $\begin{array}{l}\text { internal } \\
\text { leakage }\end{array}$ & Category III & $\begin{array}{l}\text { valve seat flaw } \\
\text { or wear, valve } \\
\text { disk flaw }\end{array}$ & $\begin{array}{l}\text { inspection, } \\
\text { periodic testing, } \\
\text { QA on } \\
\text { construction }\end{array}$ & $\begin{array}{l}\text { No consequences } \\
\text { during normal plant } \\
\text { operation }\end{array}$ & $\begin{array}{l}\text { No actions to take } \\
\text { for this failure mode } \\
\text { during ITER } \\
\text { operation }\end{array}$ & Not an IE & & $5 \mathrm{E}-07 / \mathrm{h}$ & $\begin{array}{l}\text { EGG-SSRE- } \\
8875\end{array}$ & $\begin{array}{l}\text { Helium gas is within the tank and } \\
\text { this gas would leak out past the } \\
\text { valve seat. }\end{array}$ \\
\hline & & $\begin{array}{l}\text { internal } \\
\text { rupture }\end{array}$ & Category III & $\begin{array}{l}\text { valve disk } \\
\text { failure }\end{array}$ & $\begin{array}{l}\text { inspection, } \\
\text { periodic testing, } \\
\text { QA on } \\
\text { construction }\end{array}$ & $\begin{array}{l}\text { No consequences } \\
\text { during normal plant } \\
\text { operation }\end{array}$ & $\begin{array}{l}\text { No actions to take } \\
\text { for this failure mode } \\
\text { during ITER } \\
\text { operation }\end{array}$ & Not an IE & & $5 \mathrm{E}-08 / \mathrm{h}$ & $\begin{array}{l}\text { EGG-SSRE- } \\
8875\end{array}$ & $\begin{array}{l}\text { Helium gas in the tank would flow } \\
\text { out the damaged valve }\end{array}$ \\
\hline & & $\begin{array}{l}\text { external } \\
\text { leakage }\end{array}$ & Category III & $\begin{array}{l}\text { valve stem } \\
\text { packing flaw, } \\
\text { valve body flaw }\end{array}$ & $\begin{array}{l}\text { inspection, } \\
\text { periodic testing, } \\
\text { QA on } \\
\text { construction }\end{array}$ & $\begin{array}{l}\text { Leaks helium cover gas } \\
\text { to the equatorial port }\end{array}$ & $\begin{array}{l}\text { Operators can isolate } \\
\text { helium supply }\end{array}$ & Not an IE & & $5 \mathrm{E}-07 / \mathrm{h}$ & $\begin{array}{l}\text { EGG-SSRE- } \\
8875\end{array}$ & $\begin{array}{l}\text { Helium inert gas is within the tank } \\
\text { and this gas would leak out past the } \\
\text { valve seat. With helium bled out, } \\
\text { air will slowly enter the tank so the } \\
\text { tank requires cleaning before next } \\
\text { use. }\end{array}$ \\
\hline & & $\begin{array}{l}\text { external } \\
\text { rupture }\end{array}$ & Category III & $\begin{array}{l}\text { valve stem } \\
\text { packing failure, } \\
\text { valve body } \\
\text { failure }\end{array}$ & $\begin{array}{l}\text { inspection, } \\
\text { periodic testing, } \\
\text { QA on } \\
\text { construction }\end{array}$ & $\begin{array}{l}\text { Leaks helium cover gas } \\
\text { to the equatorial port }\end{array}$ & $\begin{array}{l}\text { Operators can isolate } \\
\text { helium supply }\end{array}$ & Not an IE & & $5 \mathrm{E}-08 / \mathrm{h}$ & $\begin{array}{l}\text { EGG-SSRE- } \\
8875\end{array}$ & $\begin{array}{l}\text { Helium inert gas is within the tank } \\
\text { and this gas would flow out the } \\
\text { damaged valve. With helium bled } \\
\text { out, air will slowly enter the tank } \\
\text { so the tank requires cleaning before } \\
\text { next use. }\end{array}$ \\
\hline
\end{tabular}




\begin{tabular}{|c|c|c|c|c|c|c|c|c|c|c|c|c|}
\hline Component & $\begin{array}{c}\text { Operational } \\
\text { State }\end{array}$ & $\begin{array}{c}\text { Failure } \\
\text { Mode }\end{array}$ & $\begin{array}{c}\text { Frequency } \\
\text { Category }\end{array}$ & Possible Causes & $\begin{array}{c}\text { Preventive } \\
\text { Action on } \\
\text { Possible Causes }\end{array}$ & Consequences & $\begin{array}{c}\text { Corrective or } \\
\text { Preventive Actions } \\
\text { on Consequences }\end{array}$ & $\begin{array}{l}\text { ITER Postulated } \\
\text { Initiating Events }\end{array}$ & Comments & Frequency & $\begin{array}{l}\text { Comment on } \\
\text { frequency } \\
\text { calculation }\end{array}$ & Design comments \\
\hline \multirow[t]{2}{*}{$\begin{array}{l}\text { PbLi drain tank } \\
\text { heaters }\end{array}$} & NO & $\begin{array}{l}\text { fail to } \\
\text { operate }\end{array}$ & Category III & $\begin{array}{l}\text { electrical fault, } \\
\text { control fault, } \\
\text { human error, } \\
\text { power loss }\end{array}$ & $\begin{array}{l}\text { periodic testing, } \\
\text { QA on control } \\
\text { system, operator } \\
\text { procedures }\end{array}$ & $\begin{array}{l}\text { Cannot maintain liquid } \\
\text { temperature or melt the } \\
\mathrm{Pb}-17 \mathrm{Li} \text { in the tank }\end{array}$ & $\begin{array}{l}\text { No actions to take } \\
\text { for this failure mode } \\
\text { during ITER } \\
\text { operation }\end{array}$ & Not an IE & $\begin{array}{l}\text { Surface heaters (versus } \\
\text { immersion heaters) were } \\
\text { chosen for easier } \\
\text { maintenance. }\end{array}$ & $5.6 \mathrm{E}-07 / \mathrm{h}$ & $\begin{array}{l}\text { IAEA } \\
\text { TECDOC } \\
478, \text { page } 139\end{array}$ & $\begin{array}{l}\text { Normally, the helium coolant and } \\
\text { pipework electrical heat tracing can } \\
\text { be used to warm the Pb-17Li, but } \\
\text { in the drain tank the Pb-17Li is } \\
\text { separated from the helium flow } \\
\text { loop. Cannot start up the tritium } \\
\text { breeding portion of the TBM if the } \\
\text { Pb-17Li cannot be melted and } \\
\text { driven from the tank by pressurized } \\
\text { helium. The TRITEX Pb-17Li } \\
\text { loop kept its drain tank at elevated } \\
\text { temperature to avoid thermal shock } \\
\text { to the tank if the tank was needed } \\
\text { in an emergency dump situation. }\end{array}$ \\
\hline & & $\begin{array}{l}\text { spurious } \\
\text { operation }\end{array}$ & Category III & $\begin{array}{l}\text { control fault, } \\
\text { human error }\end{array}$ & $\begin{array}{l}\text { QA on control } \\
\text { system, operator } \\
\text { procedures }\end{array}$ & $\begin{array}{l}\text { Heat tank with or } \\
\text { without Pb-17Li } \\
\text { present. If helium gas } \\
\text { overheats, it increases } \\
\text { tank pressure }\end{array}$ & $\begin{array}{l}\text { Operator intervene to } \\
\text { depower heaters, } \\
\text { repair heaters before } \\
\text { next ITER outage. }\end{array}$ & Not an IE & $\begin{array}{l}\text { The spurious operation } \\
\text { failure mode has been } \\
\text { equated to runaway } \\
\text { operation. }\end{array}$ & $\approx 1 \mathrm{E}-06 / \mathrm{h}$ & $\begin{array}{l}\text { analyst } \\
\text { judgment }\end{array}$ & $\begin{array}{l}\text { The maximum runaway tank } \\
\text { temperature (per IEEE Std-515- } \\
\text { 1997) from the heater spurious } \\
\text { operation has not been set by the } \\
\text { designers at this time. Assume } \\
\text { heaters can reach a maximum of } \\
470 \mathrm{C} \text {. At that temperature, the } \\
\text { trapped } \approx 56 \mathrm{~g} \text { of helium in the } 0.6 \\
\mathrm{~m} 3 \text { tank will only reach } 1.4 \mathrm{MPa} \text {, } \\
\text { so the rupture disk should not } \\
\text { actuate with that backpressure. }\end{array}$ \\
\hline
\end{tabular}




\section{Appendix B}

Preliminary Failure Modes and Effects Analysis for the Helium Flow Loop 


\begin{tabular}{|c|c|c|c|c|c|c|c|c|c|c|c|c|}
\hline Component & $\begin{array}{c}\text { Operational } \\
\text { State }\end{array}$ & $\begin{array}{c}\text { Failure } \\
\text { Mode }\end{array}$ & $\begin{array}{c}\text { Frequency } \\
\text { Category }\end{array}$ & Possible Causes & $\begin{array}{c}\text { Preventive } \\
\text { Action on } \\
\text { Possible Causes }\end{array}$ & Consequences & $\begin{array}{c}\text { Corrective or } \\
\text { Preventive Actions } \\
\text { on Consequences }\end{array}$ & $\begin{array}{c}\text { ITER } \\
\text { Postulated } \\
\text { Initiating } \\
\text { Events }\end{array}$ & Comments & Frequency & $\begin{array}{c}\text { Comment on } \\
\text { frequency } \\
\text { calculation }\end{array}$ & Design comments \\
\hline \multirow[t]{5}{*}{$\begin{array}{l}\text { Pressure } \\
\text { instrument after } \\
\text { the TBM module } \\
\text { box, total of two } \\
\text { units in the loop }\end{array}$} & NO & $\begin{array}{l}\text { fails to } \\
\text { operate }\end{array}$ & $\begin{array}{l}\text { Category } \\
\text { III }\end{array}$ & $\begin{array}{l}\text { calibration error, } \\
\text { power loss, drift }\end{array}$ & $\begin{array}{l}\text { periodic } \\
\text { recalibration, } \\
\text { redundant power } \\
\text { and redundant } \\
\text { sensors }\end{array}$ & $\begin{array}{l}\text { No immediate } \\
\text { consequences from a } \\
\text { failed sensor. } \\
\text { Operator must verify } \\
\text { proper functioning of } \\
\text { the helium cooling } \\
\text { system. }\end{array}$ & $\begin{array}{l}\text { Verify helium } \\
\text { pressure is adequate } \\
\text { with other pressure } \\
\text { sensors. }\end{array}$ & $\begin{array}{l}\text { Not an IE, } \\
\text { N/S }\end{array}$ & & $1 \mathrm{E}-06 / \mathrm{h}$ & INEL-96/0295 & $\begin{array}{l}\text { Designers should consider sensor } \\
\text { redundancy in the design, since } \\
\text { replacing failed sensors will be a } \\
\text { difficult task. If penetrations for } \\
\text { sensors are robust (i.e., sensor 'tree') } \\
\text { and common causes of failure are } \\
\text { controlled, then redundancy will allow } \\
\text { use of voting logic to filter out } \\
\text { spurious noise signals and allow } \\
\text { continued TBM operation with a } \\
\text { sensor failure. }\end{array}$ \\
\hline & & $\begin{array}{l}\text { spurious } \\
\text { alarm }\end{array}$ & $\begin{array}{l}\text { Category } \\
\text { III }\end{array}$ & $\begin{array}{l}\text { electronic noise } \\
\text { from EM or } \\
\text { ionizing } \\
\text { radiation, } \\
\text { pressure pulsation } \\
\text { from pressure } \\
\text { control system, } \\
\text { drift }\end{array}$ & $\begin{array}{l}\text { periodic } \\
\text { recalibration, } \\
\text { selection of } \\
\text { setpoints, } \\
\text { redundant sensor } \\
\text { voting logic, } \\
\text { sensor shielding } \\
\text { from noise } \\
\end{array}$ & $\begin{array}{l}\text { Operator must verify } \\
\text { proper functioning of } \\
\text { the helium cooling } \\
\text { system }\end{array}$ & $\begin{array}{l}\text { Verify helium } \\
\text { pressure is adequate } \\
\text { with other pressure } \\
\text { sensors. }\end{array}$ & $\begin{array}{l}\text { Not an IE, } \\
\text { N/S }\end{array}$ & & $5 \mathrm{E}-06 / \mathrm{h}$ & $\begin{array}{l}\text { WSRC-TR- } \\
\text { 93-262 }\end{array}$ & $\begin{array}{l}\text { Sensor voting logic or output } \\
\text { comparisons will reduce the number of } \\
\text { false alarms }\end{array}$ \\
\hline & & $\begin{array}{l}\text { improper } \\
\text { reading }\end{array}$ & $\begin{array}{l}\text { Category } \\
\text { III }\end{array}$ & $\begin{array}{l}\text { calibration error, } \\
\text { drift, instrument } \\
\text { damage, foreign } \\
\text { material } \\
\text { accumulation }\end{array}$ & $\begin{array}{l}\text { Periodic } \\
\text { recalibration, } \\
\text { testing, gas } \\
\text { purification }\end{array}$ & $\begin{array}{l}\text { No immediate } \\
\text { consequences from an } \\
\text { improper reading. } \\
\text { Operator must verify } \\
\text { proper functioning of } \\
\text { the helium cooling } \\
\text { system. }\end{array}$ & \begin{tabular}{l|} 
No immediate actions \\
needed, run to next \\
shutdown period if \\
other gas sensors can \\
provide adequate \\
information to \\
operate the TBM \\
safely.
\end{tabular} & $\begin{array}{l}\text { Not an IE, } \\
\text { N/S }\end{array}$ & $\begin{array}{l}\text { Recalibration activity could } \\
\text { result in a significant } \\
\text { personnel radiation } \\
\text { exposure }\end{array}$ & $1 \mathrm{E}-06 / \mathrm{h}$ & INEL-96/0295 & $\begin{array}{l}\text { Use sensors that can be remotely } \\
\text { recalibrated whenever possible to } \\
\text { reduce personnel exposure }\end{array}$ \\
\hline & & $\begin{array}{l}\text { external } \\
\text { leakage }\end{array}$ & $\begin{array}{l}\text { Category } \\
\text { IV }\end{array}$ & $\begin{array}{l}\text { instrument pipe } \\
\text { tap crack, } \\
\text { instrument line } \\
\text { crack, weld crack }\end{array}$ & $\begin{array}{l}\text { Materials } \\
\text { selection in } \\
\text { design, pre- } \\
\text { service } \\
\text { inspection, low } \\
\text { acoustic vibration } \\
\text { in design }\end{array}$ & $\begin{array}{l}\text { Leaks helium to the } \\
30 \mathrm{C} \text { air atmosphere } \\
\text { in the equatorial test } \\
\text { port. }\end{array}$ & $\begin{array}{l}\text { Isolate leak if } \\
\text { possible, shut down } \\
\text { TBM to repair the } \\
\text { leak. }\end{array}$ & $\begin{array}{l}\text { Small } \\
\text { Helium } \\
\text { LOCA, } \\
\text { LBO2 }\end{array}$ & & $\begin{array}{l}1 \mathrm{E}-09 / \mathrm{h}, \\
\text { assuming } \\
<1 \mathrm{~m} \text { of } \\
\text { tubing }\end{array}$ & $\begin{array}{l}\text { WSRC-TR- } \\
93-262\end{array}$ & $\begin{array}{l}\text { Instrument leaks should be very low } \\
\text { flow rates, such as through cracks, } \\
\text { assume }<<1 \% \text { of the coolant flow rate, } \\
\text { i.e., cc's per minute. An important } \\
\text { issue is potential release of any tritium } \\
\text { gas that migrated into the helium } \\
\text { coolant. }\end{array}$ \\
\hline & & $\begin{array}{l}\text { external } \\
\text { rupture }\end{array}$ & $<$ Cat IV & $\begin{array}{l}\text { instrument tap } \\
\text { material failure, } \\
\text { instrument line } \\
\text { material failure, } \\
\text { weld failure }\end{array}$ & $\begin{array}{l}\text { Materials } \\
\text { selection in } \\
\text { design, pre- } \\
\text { service } \\
\text { inspection, low } \\
\text { acoustic vibration } \\
\text { in design } \\
\end{array}$ & $\begin{array}{l}\text { Leaks moderate to } \\
\text { large amount of } \\
\text { helium to the } \\
\text { equatorial test port }\end{array}$ & $\begin{array}{l}\text { Isolate the leak if } \\
\text { possible, flood with } \\
\text { helium to keep air out } \\
\text { of the system. ITER } \\
\text { must shut down to } \\
\text { prevent TBM box } \\
\text { damage. }\end{array}$ & $\begin{array}{l}\text { Helium } \\
\text { LOCA, } \\
\text { LBO1 }\end{array}$ & $\begin{array}{l}\text { Increasing the Pb-17Li } \\
\text { cooling will not be } \\
\text { adequate to remove all the } \\
\text { heat from the TBM box. }\end{array}$ & $\begin{array}{l}3 \mathrm{E}-11 / \mathrm{h}, \\
\text { assuming } \\
<1 \mathrm{~m} \text { of } \\
\text { tubing }\end{array}$ & $\begin{array}{l}\text { WSRC-TR- } \\
\text { 93-262 }\end{array}$ & \\
\hline
\end{tabular}




\begin{tabular}{|c|c|c|c|c|c|c|c|c|c|c|c|c|}
\hline Component & $\begin{array}{c}\text { Operational } \\
\text { State }\end{array}$ & $\begin{array}{c}\text { Failure } \\
\text { Mode }\end{array}$ & $\begin{array}{c}\text { Frequency } \\
\text { Category }\end{array}$ & Possible Causes & $\begin{array}{c}\text { Preventive } \\
\text { Action on } \\
\text { Possible Causes } \\
\end{array}$ & Consequences & $\begin{array}{c}\text { Corrective or } \\
\text { Preventive Actions } \\
\text { on Consequences }\end{array}$ & $\begin{array}{c}\text { ITER } \\
\text { Postulated } \\
\text { Initiating } \\
\text { Events } \\
\end{array}$ & Comments & Frequency & $\begin{array}{c}\text { Comment on } \\
\text { frequency } \\
\text { calculation }\end{array}$ & Design comments \\
\hline \multirow[t]{5}{*}{$\begin{array}{l}\text { Temperature } \\
\text { instrument after } \\
\text { the TBM module } \\
\text { box, a total of } 3 \\
\text { units in the flow } \\
\text { loop }\end{array}$} & NO & $\begin{array}{l}\text { fails to } \\
\text { operate }\end{array}$ & $\begin{array}{l}\text { Category } \\
\text { III }\end{array}$ & $\begin{array}{l}\text { drift, calibration } \\
\text { error }\end{array}$ & $\begin{array}{l}\text { Periodic } \\
\text { recalibration }\end{array}$ & $\begin{array}{l}\text { No immediate } \\
\text { consequences from a } \\
\text { failed sensor. } \\
\text { Operator must verify } \\
\text { proper functioning of } \\
\text { the helium cooling } \\
\text { system. }\end{array}$ & $\begin{array}{l}\text { No immediate actions } \\
\text { needed, run to next } \\
\text { shutdown period if } \\
\text { other sensors can } \\
\text { provide adequate } \\
\text { information to } \\
\text { operate the TBM } \\
\text { safely. }\end{array}$ & $\begin{array}{l}\text { Not an IE, } \\
\text { N/S }\end{array}$ & $\begin{array}{l}\text { Assume that either a } \\
\text { platinum thermocouple or } \\
\text { RTD will be used for this } \\
380 \text { to } 440 \mathrm{C} \text { operating } \\
\text { temperature range. Sensor } \\
\text { maintenance is an ORE } \\
\text { concern. }\end{array}$ & $2.2 \mathrm{E}-06 / \mathrm{h}$ & INEL-96/0295 & $\begin{array}{l}\text { Several authors noted that redundant } \\
\text { instrumentation was very useful for } \\
\text { flow loop operations. }\end{array}$ \\
\hline & & $\begin{array}{l}\text { improper } \\
\text { reading }\end{array}$ & Category II & $\begin{array}{l}\text { calibration error, } \\
\text { drift, impurity } \\
\text { plateout }\end{array}$ & $\begin{array}{l}\text { Periodic } \\
\text { recalibration }\end{array}$ & $\begin{array}{l}\text { No immediate } \\
\text { consequences from an } \\
\text { improper reading. } \\
\text { Operator must verify } \\
\text { proper functioning of } \\
\text { the helium cooling } \\
\text { system. }\end{array}$ & \begin{tabular}{|l|} 
No immediate actions \\
needed, run to next \\
shuddown period if \\
other sensors can \\
provide adequate \\
information to \\
operate the TBM \\
safely.
\end{tabular} & $\begin{array}{l}\text { Not an IE, } \\
\text { N/S }\end{array}$ & & $1.7 \mathrm{E}-05 / \mathrm{h}$ & INEL-96/0295 & \\
\hline & & $\begin{array}{l}\text { spurious } \\
\text { alarm }\end{array}$ & Category II & $\begin{array}{l}\text { electronic noise } \\
\text { from EM or } \\
\text { ionizing } \\
\text { radiation, } \\
\text { pressure pulsation } \\
\text { from pressure } \\
\text { control system, } \\
\text { drift }\end{array}$ & $\begin{array}{l}\text { periodic } \\
\text { recalibration, } \\
\text { selection of } \\
\text { setpoints, } \\
\text { redundant sensor } \\
\text { voting logic, } \\
\text { sensor shielding } \\
\text { from noise }\end{array}$ & $\begin{array}{l}\text { Operator must verify } \\
\text { proper functioning of } \\
\text { the helium cooling } \\
\text { system }\end{array}$ & $\begin{array}{l}\text { Verify helium } \\
\text { pressure is adequate } \\
\text { with other pressure } \\
\text { sensors. }\end{array}$ & $\begin{array}{l}\text { Not an IE, } \\
\text { N/S }\end{array}$ & & $5 \mathrm{E}-06 / \mathrm{h}$ & $\begin{array}{l}\text { WSRC-TR- } \\
93-262\end{array}$ & $\begin{array}{l}\text { Sensor voting logic or output } \\
\text { comparisons will reduce the number of } \\
\text { false alarms }\end{array}$ \\
\hline & & $\begin{array}{l}\text { external } \\
\text { leakage }\end{array}$ & $\begin{array}{l}\text { Category } \\
\text { IV }\end{array}$ & $\begin{array}{l}\text { instrument tap } \\
\text { line crack, } \\
\text { instrument line } \\
\text { crack, weld crack }\end{array}$ & $\begin{array}{l}\text { Materials } \\
\text { selection in } \\
\text { design, pre- } \\
\text { service } \\
\text { inspection, low } \\
\text { flow-induced } \\
\text { vibration in } \\
\text { design, NDT }\end{array}$ & $\begin{array}{l}\text { Leaks helium to the } \\
30 \mathrm{C} \text { air atmosphere } \\
\text { in the equatorial test } \\
\text { port. }\end{array}$ & $\begin{array}{l}\text { Isolate leak if } \\
\text { possible. Inject more } \\
\text { helium to give time } \\
\text { for a benign ITER } \\
\text { shutdown. Shut } \\
\text { down ITER and then } \\
\text { the helium circulator. } \\
\text { Repair the leak. }\end{array}$ & $\begin{array}{l}\text { Small } \\
\text { Helium } \\
\text { LOCA, } \\
\text { LBO2 }\end{array}$ & $\begin{array}{l}\text { Little tritium gas is } \\
\text { expected to be present in } \\
\text { the helium. Hot helium gas } \\
\text { at } 340 \mathrm{C} \text { or higher and } 8 \\
\text { MPa would also pose a } \\
\text { personnel safety concern. }\end{array}$ & $\begin{array}{l}1 \mathrm{E}-09 / \mathrm{h}, \\
\text { assuming } \\
<1 \mathrm{~m} \text { of } \\
\text { tubing }\end{array}$ & $\begin{array}{l}\text { WSRC-TR- } \\
93-262\end{array}$ & $\begin{array}{l}\text { Instrument leaks should be very low } \\
\text { flow rates, such as through cracks, } \\
\text { assume } \approx 1 \% \text { of the coolant flow rate, } \\
\text { i.e., cc's per minute. An important } \\
\text { issue is potential release of any tritium } \\
\text { gas that migrated into the helium } \\
\text { coolant. }\end{array}$ \\
\hline & & $\begin{array}{l}\text { external } \\
\text { rupture }\end{array}$ & $<$ Cat IV & $\begin{array}{l}\text { instrument tap } \\
\text { line material } \\
\text { failure, weld } \\
\text { failure }\end{array}$ & $\begin{array}{l}\text { Materials } \\
\text { selection in } \\
\text { design, pre- } \\
\text { service } \\
\text { inspection, low } \\
\text { flow-induced } \\
\text { vibration in } \\
\text { design, NDT }\end{array}$ & $\begin{array}{l}\text { Leaks moderate to } \\
\text { large amount of } \\
\text { helium to the } \\
\text { equatorial test port }\end{array}$ & $\begin{array}{l}\text { Shut down ITER } \\
\text { quickly. Then } \\
\text { shutdown the helium } \\
\text { circulator to reduce } \\
\text { pressure and reduce } \\
\text { helium loss. }\end{array}$ & $\begin{array}{l}\text { Helium } \\
\text { LOCA, } \\
\text { LBO1 }\end{array}$ & $\begin{array}{l}\text { Little tritium gas is } \\
\text { expected to be present in } \\
\text { the helium. Hot helium gas } \\
\text { at } 340 \mathrm{C} \text { or higher and } 8 \\
\text { MPa would also pose a } \\
\text { personnel safety concern. }\end{array}$ & $\begin{array}{l}3 \mathrm{E}-11 / \mathrm{h}, \\
\text { assuming } \\
<1 \mathrm{~m} \text { of } \\
\text { tubing }\end{array}$ & $\begin{array}{l}\text { WSRC-TR- } \\
93-262\end{array}$ & \\
\hline $\begin{array}{l}\text { Safety relief } \\
\text { valve to pressure } \\
\text { control system } \\
\text { storage tanks, a } \\
\text { total of two units } \\
\text { in the helium } \\
\text { loop }\end{array}$ & NO & $\begin{array}{l}\text { internal } \\
\text { leakage }\end{array}$ & Category II & $\begin{array}{l}\text { valve seat seal } \\
\text { deterioration, } \\
\text { spring tension } \\
\text { relaxation }\end{array}$ & $\begin{array}{l}\text { Routine } \\
\text { inspection of } \\
\text { seals and springs }\end{array}$ & $\begin{array}{l}\text { Leaks small amount } \\
\text { of helium to the } \\
\text { pressure control } \\
\text { system storage tanks }\end{array}$ & $\begin{array}{l}\text { Verify helium } \\
\text { pressure is adequate } \\
\text { with makeup from the } \\
\text { pressure control } \\
\text { system }\end{array}$ & Not an IE & $\begin{array}{l}\text { The helium system has } \\
\text { reserve tanks to make up } \\
\text { small loses of helium and } \\
\text { continue to operate the } \\
\text { TBM. Assume that this } \\
\text { leak, which is captured in } \\
\text { the pressure control system } \\
\text { storage tanks, can be made } \\
\text { up. This event is not a } \\
\text { small LOCA. }\end{array}$ & $1 \mathrm{E}-05 / \mathrm{h}$ & $\begin{array}{l}\text { WSRC-TR- } \\
93-262\end{array}$ & \\
\hline
\end{tabular}




\begin{tabular}{|c|c|c|c|c|c|c|c|c|c|c|c|c|}
\hline Component & $\begin{array}{c}\text { Operational } \\
\text { State }\end{array}$ & $\begin{array}{c}\text { Failure } \\
\text { Mode }\end{array}$ & $\begin{array}{c}\text { Frequency } \\
\text { Category }\end{array}$ & Possible Causes & $\begin{array}{c}\text { Preventive } \\
\text { Action on } \\
\text { Possible Causes }\end{array}$ & Consequences & $\begin{array}{c}\text { Corrective or } \\
\text { Preventive Actions } \\
\text { on Consequences }\end{array}$ & $\begin{array}{c}\text { ITER } \\
\text { Postulated } \\
\text { Initiating } \\
\text { Events } \\
\end{array}$ & Comments & Frequency & $\begin{array}{c}\text { Comment on } \\
\text { frequency } \\
\text { calculation }\end{array}$ & $\begin{array}{l}\text { Design comments } \\
\end{array}$ \\
\hline & & $\begin{array}{l}\text { internal } \\
\text { rupture }\end{array}$ & $\begin{array}{l}\text { Category } \\
\text { III }\end{array}$ & $\begin{array}{l}\text { valve disk failure, } \\
\text { valve shaft failure }\end{array}$ & $\begin{array}{l}\text { Routine } \\
\text { inspection of } \\
\text { valve disk and } \\
\text { shaft }\end{array}$ & $\begin{array}{l}\text { Leaks large amount of } \\
\text { helium to the pressure } \\
\text { control system storage } \\
\text { tanks, large } \\
\text { depressurization event }\end{array}$ & $\begin{array}{l}\text { Helium makeup from } \\
\text { pressure control } \\
\text { system to keep TBM } \\
\text { heat transfer high } \\
\text { during ITER } \\
\text { shutdown } \\
\end{array}$ & $\begin{array}{l}\text { Helium } \\
\text { LOCA, } \\
\text { LBO1 }\end{array}$ & $\begin{array}{l}\text { Helium is not lost from the } \\
\text { pipework. Helium pressure } \\
\text { in the cooling loop will } \\
\text { fluctuate, but should } \\
\text { stabilize at a new lower } \\
\text { level. }\end{array}$ & $5 \mathrm{E}-07 / \mathrm{h}$ & $\begin{array}{l}\text { WSRC-TR- } \\
\text { 93-262 }\end{array}$ & $\begin{array}{l}\text { Prudent operations will call for a TBM } \\
\text { shutdown and consequently an ITER } \\
\text { shutdown. }\end{array}$ \\
\hline & & $\begin{array}{l}\text { external } \\
\text { leakage }\end{array}$ & $\begin{array}{l}\text { Category } \\
\text { III }\end{array}$ & $\begin{array}{l}\text { valve body crack, } \\
\text { attachment weld } \\
\text { leak }\end{array}$ & $\begin{array}{l}\text { Routine } \\
\text { inspection of } \\
\text { valve body and } \\
\text { welds }\end{array}$ & $\begin{array}{l}\text { Leaks small amount } \\
\text { of helium to the room, } \\
\text { may release some } \\
\text { tritium and other } \\
\text { gases }\end{array}$ & \begin{tabular}{|l|} 
Depressurize helium \\
loop to reduce hot gas \\
leakage
\end{tabular} & $\begin{array}{l}\text { Small } \\
\text { Helium } \\
\text { LOCA, } \\
\text { LBO2 }\end{array}$ & & $1 \mathrm{E}-07 / \mathrm{h}$ & $\begin{array}{l}\text { WSRC-TR- } \\
93-262\end{array}$ & $\begin{array}{l}\text { The PCS controls to } 8 \text { plus or minus } \\
0.3 \mathrm{MPa} \text {. Below } 7.7 \mathrm{MPa} \text { the system } \\
\text { response is not clear. Assume below } \\
\text { that pressure the helium does not } \\
\text { remove adequate heat from the TBM. }\end{array}$ \\
\hline & & $\begin{array}{l}\text { external } \\
\text { rupture }\end{array}$ & $\begin{array}{l}\text { Category } \\
\text { IV }\end{array}$ & $\begin{array}{l}\text { valve body } \\
\text { failure, } \\
\text { attachment weld } \\
\text { failure }\end{array}$ & $\begin{array}{l}\text { Routine } \\
\text { inspection of } \\
\text { valve body and } \\
\text { welds }\end{array}$ & $\begin{array}{l}\text { Leaks large amount of } \\
\text { helium to the room, } \\
\text { may release some } \\
\text { tritium and other } \\
\text { gases }\end{array}$ & \begin{tabular}{|l|} 
Quickly depressurize \\
helium loop to reduce \\
hot gas leakage
\end{tabular} & $\begin{array}{l}\text { Helium } \\
\text { LOCA, } \\
\text { LBO1 }\end{array}$ & & $5 \mathrm{E}-09 / \mathrm{h}$ & $\begin{array}{l}\text { WSRC-TR- } \\
93-262\end{array}$ & $\begin{array}{l}\text { The effects of a large release of }>300 \\
\text { C helium gas into the port cell have } \\
\text { not been evaluated. }\end{array}$ \\
\hline & & $\begin{array}{l}\text { spurious or } \\
\text { premature } \\
\text { opening }\end{array}$ & Category II & $\begin{array}{l}\text { spring fracture, } \\
\text { improper spring } \\
\text { setting }\end{array}$ & $\begin{array}{l}\text { Routine } \\
\text { inspection of } \\
\text { springs }\end{array}$ & $\begin{array}{l}\text { Leaks large amount of } \\
\text { helium to the pressure } \\
\text { control system storage } \\
\text { tanks }\end{array}$ & \begin{tabular}{|l|} 
Assume the helium \\
system cannot \\
continue to remove \\
heat from the TBM \\
unless operator \\
intervention occurs to \\
isolate the PCS tanks.
\end{tabular} & $\begin{array}{l}\text { Helium } \\
\text { LOCA, } \\
\text { LBO1 }\end{array}$ & $\begin{array}{l}\text { Helium is not lost from the } \\
\text { pipework. Helium pressure } \\
\text { will fluctuate, but should } \\
\text { stabilize at a new lower } \\
\text { level. Helium may not be } \\
\text { able to adequately remove } \\
\text { heat from the TBM module } \\
\text { after a let down to the } \\
\text { storage tank. }\end{array}$ & $1 \mathrm{E}-05 / \mathrm{h}$ & GA-A14839 & \\
\hline \multirow[t]{4}{*}{ System piping } & NO & $\begin{array}{l}\text { external } \\
\text { leakage }\end{array}$ & $\begin{array}{l}\text { Category } \\
\text { III }\end{array}$ & $\begin{array}{l}\text { weld fault, pipe } \\
\text { wall flaw, pipe } \\
\text { vibration induced } \\
\text { crack, } \\
\text { construction fault }\end{array}$ & $\begin{array}{l}\text { Materials } \\
\text { selection in } \\
\text { design, pre- } \\
\text { service } \\
\text { inspection, low } \\
\text { flow-induced } \\
\text { vibration, NDT } \\
\end{array}$ & $\begin{array}{l}\text { Leaks small amount } \\
\text { of helium to room, } \\
\text { slowly depletes } \\
\text { makeup helium, may } \\
\text { release some tritium } \\
\text { and other gases to } \\
\text { room }\end{array}$ & $\begin{array}{l}\text { Isolate leak if } \\
\text { possible, depressurize } \\
\text { system, shut down } \\
\text { ITER }\end{array}$ & $\begin{array}{l}\text { Small } \\
\text { Helium } \\
\text { LOCA, } \\
\text { LBP2 }\end{array}$ & $\begin{array}{l}\text { About } 10 \% \text { of piping is in } \\
\text { the Port Cell (LBP2) and } \\
90 \% \text { of the piping is either } \\
\text { in the pipe chase (that } \\
\text { empties into the TWCS } \\
\text { room) or the TWCS room } \\
\text { (LBO2). }\end{array}$ & $\begin{array}{l}9.8 \mathrm{E}-08 / \mathrm{h}- \\
\mathrm{m}\end{array}$ & $\begin{array}{l}\text { WSRC-TR- } \\
93-262\end{array}$ & $\begin{array}{l}\text { Assumed } 195 \mathrm{~m} \text { piping in the flow } \\
\text { loop. } 10 \% \text { is } \approx 20 \mathrm{~m}\end{array}$ \\
\hline & & $\begin{array}{l}\text { external } \\
\text { leakage }\end{array}$ & Category II & $\begin{array}{l}\text { weld fault, pipe } \\
\text { wall flaw, pipe } \\
\text { vibration induced } \\
\text { crack, } \\
\text { construction fault }\end{array}$ & $\begin{array}{l}\text { Materials } \\
\text { selection in } \\
\text { design, pre- } \\
\text { service } \\
\text { inspection, low } \\
\text { flow-induced } \\
\text { vibration, NDT } \\
\end{array}$ & $\begin{array}{l}\text { Leaks small amount } \\
\text { of helium to room, } \\
\text { slowly depletes } \\
\text { makeup helium, may } \\
\text { release some tritium } \\
\text { and other gases to } \\
\text { room }\end{array}$ & $\begin{array}{l}\text { Isolate leak if } \\
\text { possible, depressurize } \\
\text { system, shut down } \\
\text { ITER }\end{array}$ & $\begin{array}{l}\text { Small } \\
\text { Helium } \\
\text { LOCA, } \\
\text { LBO2 }\end{array}$ & $\begin{array}{l}\text { About } 10 \% \text { of piping is in } \\
\text { the Port Cell (LBP2) and } \\
90 \% \text { of the piping is either } \\
\text { in the pipe chase (that } \\
\text { empties into the TWCS } \\
\text { room) or the TWCS room } \\
\text { (LBO2). }\end{array}$ & $\begin{array}{l}9.8 \mathrm{E}-08 / \mathrm{h}- \\
\mathrm{m}\end{array}$ & $\begin{array}{l}\text { WSRC-TR- } \\
93-262\end{array}$ & $\begin{array}{l}\text { Assumed } 195 \mathrm{~m} \text { piping in the flow } \\
\text { loop. } 90 \% \text { is } \approx 180 \mathrm{~m}\end{array}$ \\
\hline & & $\begin{array}{l}\text { external } \\
\text { rupture }\end{array}$ & $\begin{array}{l}\text { Category } \\
\text { III }\end{array}$ & $\begin{array}{l}\text { weld fracture, } \\
\text { piping failure, } \\
\text { flow induced } \\
\text { vibration }\end{array}$ & $\begin{array}{l}\text { Materials } \\
\text { selection in } \\
\text { design, pre- } \\
\text { service } \\
\text { inspection, low } \\
\text { flow-induced } \\
\text { vibration, NDT }\end{array}$ & $\begin{array}{l}\text { Leaks large amount of } \\
\text { helium to the room }\end{array}$ & \begin{tabular}{|l|} 
Isolate leak if \\
possible, depressurize \\
system, shut down \\
ITER
\end{tabular} & $\begin{array}{l}\text { Helium } \\
\text { LOCA, } \\
\text { LBP1 }\end{array}$ & $\begin{array}{l}\text { About } 10 \% \text { of piping is in } \\
\text { the Port Cell (LBP1) and } \\
90 \% \text { of the piping is either } \\
\text { in the pipe chase (that } \\
\text { empties into the TWCS } \\
\text { room) or the TWCS room } \\
\text { (LBO1). }\end{array}$ & $\begin{array}{l}3.3 \mathrm{E}-09 / \mathrm{h}- \\
\mathrm{m}\end{array}$ & $\begin{array}{l}\text { WSRC-TR- } \\
93-262\end{array}$ & $\begin{array}{l}\text { Assumed } 195 \mathrm{~m} \text { piping in the flow } \\
\text { loop. } 10 \% \text { is } \approx 20 \mathrm{~m}\end{array}$ \\
\hline & & $\begin{array}{l}\text { external } \\
\text { rupture }\end{array}$ & $\begin{array}{l}\text { Category } \\
\text { III }\end{array}$ & $\begin{array}{l}\text { weld fracture, } \\
\text { piping failure, } \\
\text { flow induced } \\
\text { vibration }\end{array}$ & $\begin{array}{l}\text { Materials } \\
\text { selection in } \\
\text { design, pre- } \\
\text { service } \\
\text { inspection, low } \\
\text { flow-induced } \\
\text { vibration, NDT } \\
\end{array}$ & $\begin{array}{l}\text { Leaks large amount of } \\
\text { helium to the room }\end{array}$ & \begin{tabular}{|l|} 
Isolate leak if \\
possible, depressurize \\
system, shut down \\
ITER
\end{tabular} & $\begin{array}{l}\text { Helium } \\
\text { LOCA, } \\
\text { LBO1 }\end{array}$ & $\begin{array}{l}\text { About } 10 \% \text { of piping is in } \\
\text { the Port Cell (LBP1) and } \\
90 \% \text { of the piping is either } \\
\text { in the pipe chase (that } \\
\text { empties into the TWCS } \\
\text { room) or the TWCS room } \\
\text { (LBO1). }\end{array}$ & $\begin{array}{l}3.3 \mathrm{E}-09 / \mathrm{h}- \\
\mathrm{m}\end{array}$ & $\begin{array}{l}\text { WSRC-TR- } \\
93-262\end{array}$ & $\begin{array}{l}\text { Assumed } 195 \mathrm{~m} \text { piping in the flow } \\
\text { loop. } 90 \% \text { is } \approx 180 \mathrm{~m}\end{array}$ \\
\hline
\end{tabular}




\begin{tabular}{|c|c|c|c|c|c|c|c|c|c|c|c|c|}
\hline Component & $\begin{array}{c}\text { Operational } \\
\text { State }\end{array}$ & $\begin{array}{c}\text { Failure } \\
\text { Mode }\end{array}$ & $\begin{array}{c}\text { Frequency } \\
\text { Category }\end{array}$ & Possible Causes & $\begin{array}{c}\text { Preventive } \\
\text { Action on } \\
\text { Possible Causes }\end{array}$ & Consequences & $\begin{array}{c}\text { Corrective or } \\
\text { Preventive Actions } \\
\text { on Consequences }\end{array}$ & $\begin{array}{c}\text { ITER } \\
\text { Postulated } \\
\text { Initiating } \\
\text { Events } \\
\end{array}$ & Comments & Frequency & $\begin{array}{l}\text { Comment on } \\
\text { frequency } \\
\text { calculation }\end{array}$ & Design comments \\
\hline \multirow[t]{4}{*}{$\begin{array}{l}\text { Pressure Control } \\
\text { System }\end{array}$} & NO & $\begin{array}{l}\text { external } \\
\text { leakage }\end{array}$ & $\begin{array}{l}\text { Category } \\
\text { III }\end{array}$ & $\begin{array}{l}\text { weld fault, pipe } \\
\text { wall flaw, pipe } \\
\text { vibration induced } \\
\text { crack, } \\
\text { construction fault }\end{array}$ & $\begin{array}{l}\text { Materials } \\
\text { selection in } \\
\text { design, pre- } \\
\text { service } \\
\text { inspection, low } \\
\text { flow-induced } \\
\text { vibration, NDT }\end{array}$ & $\begin{array}{l}\text { Leaks small amount } \\
\text { of helium to room, } \\
\text { slowly depletes } \\
\text { makeup helium, may } \\
\text { release some tritium } \\
\text { and other gases to } \\
\text { room }\end{array}$ & $\begin{array}{l}\text { Isolate and } \\
\text { depressurize the PCS } \\
\text { if possible to reduce } \\
\text { gas leakage. Shut } \\
\text { down the TBM, shut } \\
\text { down ITER pulsing. }\end{array}$ & $\begin{array}{l}\text { Small } \\
\text { Helium } \\
\text { LOCA, } \\
\text { LBO2 }\end{array}$ & $\begin{array}{l}\text { This system has several } \\
\text { tanks and valves but is not } \\
\text { sufficiently designed to } \\
\text { model individual } \\
\text { components at this time. }\end{array}$ & $\begin{array}{l}9.8 \mathrm{E}-08 / \mathrm{h}- \\
\mathrm{m}\end{array}$ & $\begin{array}{l}\text { WSRC-TR- } \\
93-262\end{array}$ & $\begin{array}{l}\text { Assumed } 20 \mathrm{~m} \text { piping in the PCS in } \\
\text { the TCWS room as an initial estimate. } \\
\text { Overestimate to account for valves, } \\
\text { tanks, etc., that are not designed at } \\
\text { present. }\end{array}$ \\
\hline & & $\begin{array}{l}\text { external } \\
\text { rupture }\end{array}$ & $\begin{array}{l}\text { Category } \\
\text { III }\end{array}$ & $\begin{array}{l}\text { weld fracture, } \\
\text { piping failure, } \\
\text { flow induced } \\
\text { vibration }\end{array}$ & $\begin{array}{l}\text { Materials } \\
\text { selection in } \\
\text { design, pre- } \\
\text { service } \\
\text { inspection, low } \\
\text { flow-induced } \\
\text { vibration, NDT }\end{array}$ & $\begin{array}{l}\text { Leaks large amount of } \\
\text { helium to the room }\end{array}$ & $\begin{array}{l}\text { Isolate and } \\
\text { depressurize the PCS } \\
\text { if possible to reduce } \\
\text { gas leakage. Shut } \\
\text { down the TBM, shut } \\
\text { down ITER pulsing. }\end{array}$ & $\begin{array}{l}\text { Helium } \\
\text { LOCA, } \\
\text { LBO1 }\end{array}$ & & $\begin{array}{l}3.3 \mathrm{E}-09 / \mathrm{h}- \\
\mathrm{m}\end{array}$ & $\begin{array}{l}\text { WSRC-TR- } \\
93-262\end{array}$ & $\begin{array}{l}\text { Assumed } 20 \mathrm{~m} \text { piping in the PCS as an } \\
\text { initial estimate }\end{array}$ \\
\hline & & plugs & $\begin{array}{l}\text { Category } \\
\text { III }\end{array}$ & $\begin{array}{l}\text { foreign material } \\
\text { buildup, oil from } \\
\text { compressors, dust } \\
\text { in system }\end{array}$ & $\begin{array}{l}\text { Routine } \\
\text { inspection and } \\
\text { testing }\end{array}$ & $\begin{array}{l}\text { Fails to maintain } \\
\text { helium pressure at } 8 \\
\text { MPa in the helium } \\
\text { loop, lose adequate } \\
\text { cooling of TBM }\end{array}$ & $\begin{array}{l}\text { Shut down the } \\
\text { TBM, shut down } \\
\text { ITER pulsing. }\end{array}$ & $\begin{array}{l}\text { Loss of Heat } \\
\text { Sink, HB1 }\end{array}$ & & $3 \mathrm{E}-09 / \mathrm{h}-\mathrm{m}$ & $\begin{array}{l}\text { WSRC-TR- } \\
93-262\end{array}$ & $\begin{array}{l}\text { Assumed } 20 \mathrm{~m} \text { piping in the PCS as an } \\
\text { initial estimate }\end{array}$ \\
\hline & & $\begin{array}{l}\text { fail to } \\
\text { operate }\end{array}$ & Category II & $\begin{array}{l}\text { Bad control } \\
\text { signals, loss of } \\
\text { helium supply, } \\
\text { loss of power }\end{array}$ & $\begin{array}{l}\text { Routine } \\
\text { inspection and } \\
\text { testing }\end{array}$ & $\begin{array}{l}\text { Fails to maintain } \\
\text { helium pressure at } 8 \\
\text { MPa in the helium } \\
\text { loop, lose adequate } \\
\text { cooling of TBM }\end{array}$ & $\begin{array}{l}\text { Shut down the TBM, } \\
\text { shut down ITER } \\
\text { pulsing. }\end{array}$ & $\begin{array}{l}\text { Loss of Heat } \\
\text { Sink, HB1 }\end{array}$ & $\begin{array}{l}\text { If PCS fails before ITER } \\
\text { startup, then suspend ITER } \\
\text { operations until it can be } \\
\text { repaired. If the PCS fails } \\
\text { during ITER operation, shut } \\
\text { down ITER. }\end{array}$ & $1 \mathrm{E}-02 / \mathrm{yr}$ & $\begin{array}{l}\text { NUREG/CR- } \\
6928, \operatorname{ch} 8\end{array}$ & $\begin{array}{l}\text { Inferred failure rate from PWR Total } \\
\text { Loss of Instrument Air System failure } \\
\text { rate in NUREG, chapter } 8 .\end{array}$ \\
\hline \multirow{3}{*}{$\begin{array}{l}\text { Flowmeter, } 2 \\
\text { units - one is } \\
\text { ahead of } \\
\text { electrical heater } \\
\text { and the other is } \\
\text { ahead of helium- } \\
\text { to-water heat } \\
\text { exchanger }\end{array}$} & NO & $\begin{array}{l}\text { fail to } \\
\text { operate }\end{array}$ & Category II & $\begin{array}{l}\text { fouling, short } \\
\text { circuit, noise }\end{array}$ & $\begin{array}{l}\text { Routine } \\
\text { inspection and } \\
\text { testing }\end{array}$ & $\begin{array}{l}\text { Fail to indicate flow } \\
\text { in helium loop }\end{array}$ & $\begin{array}{l}\text { No immediate actions } \\
\text { needed }\end{array}$ & $\begin{array}{l}\text { Not an IE, } \\
\text { N/S }\end{array}$ & $\begin{array}{l}\text { Operators can infer flow } \\
\text { rate from circulator speed } \\
\text { and helium properties. }\end{array}$ & $3 \mathrm{E}-06 / \mathrm{h}$ & $\begin{array}{l}\text { WSRC-TR- } \\
93-262\end{array}$ & $\begin{array}{l}\text { Consider adding a redundant flow } \\
\text { sensor in the flow loop. Fouling } \\
\text { should be rare in a helium system. } \\
\text { Foreign materials could be weld beads, } \\
\text { weld slag, SiC dust, dirt or debris from } \\
\text { construction }\end{array}$ \\
\hline & & $\begin{array}{l}\text { spurious } \\
\text { alarm }\end{array}$ & Category II & $\begin{array}{l}\text { electronic noise } \\
\text { from EM or } \\
\text { ionizing } \\
\text { radiation, drift }\end{array}$ & $\begin{array}{l}\text { periodic } \\
\text { recalibration, } \\
\text { selection of } \\
\text { setpoints, } \\
\text { redundant sensor } \\
\text { voting logic, } \\
\text { sensor shielding } \\
\text { from noise } \\
\end{array}$ & $\begin{array}{l}\text { Operator must verify } \\
\text { proper functioning of } \\
\text { the helium cooling } \\
\text { system }\end{array}$ & $\begin{array}{l}\text { Verify helium flow is } \\
\text { adequate with other } \\
\text { flow sensors or other } \\
\text { means, e.g., heat } \\
\text { balance on system. }\end{array}$ & $\begin{array}{l}\text { Not an IE, } \\
\text { N/S }\end{array}$ & $\begin{array}{l}\text { Operators can infer flow } \\
\text { rate from circulator speed } \\
\text { and helium properties. }\end{array}$ & $5 \mathrm{E}-06 / \mathrm{h}$ & $\begin{array}{l}\text { WSRC-TR- } \\
93-262\end{array}$ & $\begin{array}{l}\text { Sensor voting logic or output } \\
\text { comparisons will reduce the number of } \\
\text { false alarms but will increase } \\
\text { maintenance costs }\end{array}$ \\
\hline & & $\begin{array}{l}\text { improper } \\
\text { reading }\end{array}$ & $\begin{array}{l}\text { Category } \\
\text { III }\end{array}$ & $\begin{array}{l}\text { calibration error, } \\
\text { drift, meter } \\
\text { damage, partial } \\
\text { fouling }\end{array}$ & $\begin{array}{l}\text { Periodic } \\
\text { recalibration, } \\
\text { routine inspection } \\
\text { and testing }\end{array}$ & $\begin{array}{l}\text { Loss of proper } \\
\text { reading regarding gas } \\
\text { flow may mean that } \\
\text { there is insufficient } \\
\text { cooling of the TBM. }\end{array}$ & $\begin{array}{l}\text { No immediate actions } \\
\text { needed, run to next } \\
\text { shutdown period if } \\
\text { other gas sensors can } \\
\text { provide adequate } \\
\text { information to } \\
\text { operate the TBM } \\
\text { safely. }\end{array}$ & $\begin{array}{l}\text { Not an IE, } \\
\text { N/S }\end{array}$ & $\begin{array}{l}\text { Recalibration activity could } \\
\text { result in a significant } \\
\text { personnel radiation } \\
\text { exposure }\end{array}$ & $1 \mathrm{E}-06 / \mathrm{h}$ & INEL-96/0295 & $\begin{array}{l}\text { Use sensors that can be remotely } \\
\text { recalibrated whenever possible to } \\
\text { reduce personnel exposure }\end{array}$ \\
\hline
\end{tabular}




\begin{tabular}{|c|c|c|c|c|c|c|c|c|c|c|c|c|}
\hline Component & $\begin{array}{c}\text { Operational } \\
\text { State }\end{array}$ & $\begin{array}{c}\text { Failure } \\
\text { Mode }\end{array}$ & $\begin{array}{c}\text { Frequency } \\
\text { Category }\end{array}$ & Possible Causes & $\begin{array}{c}\text { Preventive } \\
\text { Action on } \\
\text { Possible Causes } \\
\end{array}$ & Consequences & $\begin{array}{c}\text { Corrective or } \\
\text { Preventive Actions } \\
\text { on Consequences }\end{array}$ & $\begin{array}{c}\text { ITER } \\
\text { Postulated } \\
\text { Initiating } \\
\text { Events } \\
\end{array}$ & Comments & Frequency & $\begin{array}{c}\text { Comment on } \\
\text { frequency } \\
\text { calculation }\end{array}$ & Design comments \\
\hline & & $\begin{array}{l}\text { external } \\
\text { leakage }\end{array}$ & $\begin{array}{l}\text { Category } \\
\text { IV }\end{array}$ & $\begin{array}{l}\text { instrument pipe } \\
\text { tap crack, } \\
\text { instrument line } \\
\text { crack, weld crack }\end{array}$ & $\begin{array}{l}\text { Materials } \\
\text { selection in } \\
\text { design, pre- } \\
\text { service } \\
\text { inspection, low } \\
\text { flow-induced } \\
\text { vibration in } \\
\text { design }\end{array}$ & $\begin{array}{l}\text { Leaks hot helium to } \\
\text { the } 30 \mathrm{C} \text { air } \\
\text { atmosphere in the } \\
\text { equatorial test port, } \\
\text { lose helium pressure } \\
\text { and TBM cooling is } \\
\text { inadequate. }\end{array}$ & $\begin{array}{l}\text { Isolate leak if } \\
\text { possible, assume that } \\
\text { TBM cannot be } \\
\text { adequately cooled, } \\
\text { shut down TIER and } \\
\text { shut down TBM to } \\
\text { repair the leak. }\end{array}$ & $\begin{array}{l}\text { Small } \\
\text { Helium } \\
\text { LOCA, } \\
\text { LBO2 }\end{array}$ & $\begin{array}{l}\text { Helium makeup capabilities } \\
\text { are not known at this time, } \\
\text { assume leak cannot be } \\
\text { adequately made up in short } \\
\text { time frame and it is a small } \\
\text { LOCA }\end{array}$ & $\begin{array}{l}1 \mathrm{E}-09 / \mathrm{h} \\
\text { assuming } \\
<1 \mathrm{~m} \text { of } \\
\text { tubing }\end{array}$ & $\begin{array}{l}\text { WSRC-TR- } \\
\text { 93-262 }\end{array}$ & $\begin{array}{l}\text { Instrument leaks should be very low } \\
\text { flow rates, such as through cracks, } \\
\text { assume } 1 \% \text { of the coolant flow rate, } \\
\text { i.e., cc's per minute. An important } \\
\text { issue is potential release of any tritium } \\
\text { gas that migrated into the helium } \\
\text { coolant. Tritium concentration should } \\
\text { be small. }\end{array}$ \\
\hline & & $\begin{array}{l}\text { external } \\
\text { rupture }\end{array}$ & $<$ Cat IV & $\begin{array}{l}\text { instrument tap } \\
\text { material failure, } \\
\text { instrument line } \\
\text { material failure, } \\
\text { weld failure }\end{array}$ & $\begin{array}{l}\text { Materials } \\
\text { selection in } \\
\text { design, pre- } \\
\text { service } \\
\text { inspection, low } \\
\text { flow-induced } \\
\text { vibration in } \\
\text { design }\end{array}$ & $\begin{array}{l}\text { Leaks moderate to } \\
\text { large amount of } \\
\text { helium to the } \\
\text { equatorial test port, } \\
\text { TBM cooling is } \\
\text { inadequate }\end{array}$ & $\begin{array}{l}\text { Isolate and } \\
\text { depressurize the } \\
\text { system if possible to } \\
\text { reduce gas leakage. } \\
\text { Shut down the TBM, } \\
\text { shut down ITER } \\
\text { pulsing. }\end{array}$ & $\begin{array}{l}\text { Helium } \\
\text { LOCA, } \\
\text { LBO1 }\end{array}$ & $\begin{array}{l}\text { Helium makeup capabilities } \\
\text { are not known at this time, } \\
\text { assume that the large leak } \\
\text { cannot be made up and it is } \\
\text { a LOCA }\end{array}$ & $\begin{array}{l}3 \mathrm{E}-11 / \mathrm{h}, \\
\text { assuming } \\
<1 \mathrm{~m} \text { of } \\
\text { tubing }\end{array}$ & $\begin{array}{l}\text { WSRC-TR- } \\
\text { 93-262 }\end{array}$ & $\begin{array}{l}\text { A helium break size to leak rate } \\
\text { correlation was not available, but it is } \\
\text { believed to be less sensitive than } \\
\text { water. }\end{array}$ \\
\hline \multirow[t]{6}{*}{$\begin{array}{l}\text { Control valve to } \\
\text { the operating heat } \\
\text { exchanger }\end{array}$} & NO & fails open & Category II & $\begin{array}{l}\text { control element } \\
\text { seized, valve disk } \\
\text { stuck, control } \\
\text { fault }\end{array}$ & $\begin{array}{l}\text { Routine testing } \\
\text { and inspection }\end{array}$ & $\begin{array}{l}\text { Overheat TBM due to } \\
\text { low coolant pressure }\end{array}$ & $\begin{array}{l}\text { Shut down ITER and } \\
\text { TBM }\end{array}$ & $\begin{array}{l}\text { Loss of Heat } \\
\text { Sink, HB1 }\end{array}$ & $\begin{array}{l}\text { This is a depressurization } \\
\text { accident }\end{array}$ & $3 \mathrm{E}-06 / \mathrm{h}$ & $\begin{array}{l}\text { WSRC-TR- } \\
\text { 93-262 }\end{array}$ & \\
\hline & & fails closed & Category II & $\begin{array}{l}\text { control fault, } \\
\text { valve controller } \\
\text { failure }\end{array}$ & $\begin{array}{l}\text { Routine testing } \\
\text { and inspection }\end{array}$ & $\begin{array}{l}\text { Overheat TBM due to } \\
\text { loss of flow }\end{array}$ & $\begin{array}{l}\text { Shut down ITER and } \\
\text { TBM }\end{array}$ & $\begin{array}{l}\text { Helium } \\
\text { LOFA, FB1 }\end{array}$ & & $3 \mathrm{E}-06 / \mathrm{h}$ & $\begin{array}{l}\text { WSRC-TR- } \\
93-262\end{array}$ & $\begin{array}{l}\text { Some flow control valves have a stop } \\
\text { block built in so that some flow can } \\
\text { occur with the valve fully closed, if the } \\
\text { helium design could operate in this } \\
\text { way it would mitigate effects of this } \\
\text { LOF event }\end{array}$ \\
\hline & & $\begin{array}{l}\text { fails to } \\
\text { respond }\end{array}$ & Category II & $\begin{array}{l}\text { controller fault, } \\
\text { loss of power }\end{array}$ & $\begin{array}{l}\text { Routine testing } \\
\text { and inspection }\end{array}$ & $\begin{array}{l}\text { Slow overheat of } \\
\text { TBM due to } \\
\text { decreasing coolant } \\
\text { pressure }\end{array}$ & $\begin{array}{l}\text { Helium makeup } \\
\text { system should } \\
\text { respond to keep } \\
\text { helium pressure up, } \\
\text { so no immediate } \\
\text { actions needed. }\end{array}$ & Not an IE & $\begin{array}{l}\text { Helium makeup system } \\
\text { should maintain helium } \\
\text { pressure despite valve fault, } \\
\text { repair valve during the next } \\
\text { evening outage }\end{array}$ & $3 \mathrm{E}-06 / \mathrm{h}$ & $\begin{array}{l}\text { WSRC-TR- } \\
93-262\end{array}$ & \\
\hline & & plugs & $\begin{array}{l}\text { Category } \\
\text { III }\end{array}$ & $\begin{array}{l}\text { foreign material } \\
\text { intrusion }\end{array}$ & $\begin{array}{l}\text { Coolant } \\
\text { purification to } \\
\text { remove } \\
\text { impurities }\end{array}$ & $\begin{array}{l}\text { Overheat TBM due to } \\
\text { loss of flow }\end{array}$ & $\begin{array}{l}\text { Shut down ITER and } \\
\text { TBM }\end{array}$ & $\begin{array}{l}\text { Helium } \\
\text { LOFA, FB1 }\end{array}$ & & $5 \mathrm{E}-07 / \mathrm{h}$ & $\begin{array}{l}\text { WSRC-TR- } \\
93-262\end{array}$ & \\
\hline & & $\begin{array}{l}\text { external } \\
\text { leakage }\end{array}$ & $\begin{array}{l}\text { Category } \\
\text { III }\end{array}$ & $\begin{array}{l}\text { weld fault, valve } \\
\text { wall flaw, } \\
\text { vibration induced } \\
\text { crack, } \\
\text { construction fault }\end{array}$ & $\begin{array}{l}\text { Materials } \\
\text { selection in } \\
\text { design, pre- } \\
\text { service } \\
\text { inspection, low } \\
\text { flow-induced } \\
\text { vibration in } \\
\text { design }\end{array}$ & $\begin{array}{l}\text { Leaks hot helium to } \\
\text { the } 30 \mathrm{C} \text { air } \\
\text { atmosphere in the } \\
\text { equatorial test port. }\end{array}$ & $\begin{array}{l}\text { Assume that a small } \\
\text { leak cannot be } \\
\text { tolerated until the end } \\
\text { of the campaign, shut } \\
\text { down ITER and TBM } \\
\text { to repair the leak. }\end{array}$ & $\begin{array}{l}\text { Small } \\
\text { Helium } \\
\text { LOCA, } \\
\text { LBO2 }\end{array}$ & $\begin{array}{l}\text { Helium makeup capabilities } \\
\text { are not known at this time, } \\
\text { assume leak cannot be } \\
\text { made up and it is a small } \\
\text { LOCA }\end{array}$ & $1 \mathrm{E}-07 / \mathrm{h}$ & $\begin{array}{l}\text { WSRC-TR- } \\
\text { 93-262 }\end{array}$ & \\
\hline & & $\begin{array}{l}\text { external } \\
\text { rupture }\end{array}$ & $\begin{array}{l}\text { Category } \\
\text { IV }\end{array}$ & $\begin{array}{l}\text { weld fracture, } \\
\text { valve wall failure, } \\
\text { flow induced } \\
\text { vibration }\end{array}$ & $\begin{array}{l}\text { Materials } \\
\text { selection in } \\
\text { design, pre- } \\
\text { service } \\
\text { inspection, low } \\
\text { flow-induced } \\
\text { vibration in } \\
\text { design }\end{array}$ & $\begin{array}{l}\text { Leaks moderate to } \\
\text { large amount of } \\
\text { helium to the } \\
\text { equatorial test port }\end{array}$ & $\begin{array}{l}\text { Isolate and } \\
\text { depressurize the } \\
\text { system if possible to } \\
\text { reduce gas leakage. } \\
\text { Shut down the TBM, } \\
\text { shut down ITER } \\
\text { pulsing. }\end{array}$ & $\begin{array}{l}\text { Helium } \\
\text { LOCA, } \\
\text { LBO1 }\end{array}$ & $\begin{array}{l}\text { Helium makeup capabilities } \\
\text { are not known at this time, } \\
\text { assume that the large leak } \\
\text { cannot be made up and it is } \\
\text { a LOCA }\end{array}$ & $5 \mathrm{E}-09 / \mathrm{h}$ & $\begin{array}{l}\text { WSRC-TR- } \\
\text { 93-262 }\end{array}$ & \\
\hline
\end{tabular}




\begin{tabular}{|c|c|c|c|c|c|c|c|c|c|c|c|c|}
\hline Component & $\begin{array}{c}\text { Operational } \\
\text { State }\end{array}$ & $\begin{array}{l}\text { Failure } \\
\text { Mode }\end{array}$ & $\begin{array}{l}\text { Frequency } \\
\text { Category }\end{array}$ & Possible Causes & $\begin{array}{c}\text { Preventive } \\
\text { Action on } \\
\text { Possible Causes }\end{array}$ & Consequences & $\begin{array}{c}\text { Corrective or } \\
\text { Preventive Actions } \\
\text { on Consequences }\end{array}$ & $\begin{array}{l}\text { ITER } \\
\text { Postulated } \\
\text { Initiating } \\
\text { Events }\end{array}$ & Comments & Frequency & $\begin{array}{l}\text { Comment on } \\
\text { frequency } \\
\text { calculation }\end{array}$ & Design comments \\
\hline \multirow[t]{6}{*}{$\begin{array}{l}\text { Helium-to-water } \\
\text { heat exchanger }\end{array}$} & NO & $\begin{array}{l}\text { fouling heat } \\
\text { transfer } \\
\text { surfaces }\end{array}$ & Category II & $\begin{array}{l}\text { foreign material } \\
\text { intrusion, } \\
\text { chemical } \\
\text { reactions, poor } \\
\text { water quality } \\
\text { control }\end{array}$ & $\begin{array}{l}\text { Keep water } \\
\text { cleanliness high, } \\
\text { do not allow } \\
\text { water to boil in } \\
\text { HX }\end{array}$ & $\begin{array}{l}\text { Fouling degrades heat } \\
\text { transfer from helium } \\
\text { to water }\end{array}$ & $\begin{array}{l}\text { Shut down TBM and } \\
\text { shut down ITER }\end{array}$ & $\begin{array}{l}\text { Loss of Heat } \\
\text { Sink, HB1 }\end{array}$ & & $1 \mathrm{E}-05 / \mathrm{h}$ & $\begin{array}{l}\text { WSRC-TR- } \\
\text { 93-262 }\end{array}$ & \\
\hline & & $\begin{array}{l}\text { plugging } \\
\text { tubes }\end{array}$ & Category II & $\begin{array}{l}\text { foreign material } \\
\text { accumulation in } \\
\text { helium system }\end{array}$ & $\begin{array}{l}\text { design for low } \\
\text { tube bundle } \\
\text { vibration }\end{array}$ & $\begin{array}{l}\text { Plugged tubes will } \\
\text { degrade heat transfer } \\
\text { from helium to water }\end{array}$ & $\begin{array}{l}\text { Shut down TBM and } \\
\text { shut down ITER }\end{array}$ & $\begin{array}{l}\text { Loss of Heat } \\
\text { Sink, HB1 }\end{array}$ & $\begin{array}{l}\text { Assume helium in the tubes } \\
\text { is cleaner than other heat } \\
\text { transfer applications, so } \\
\text { reduce failure rate by a } \\
\text { half-order of magnitude for } \\
\text { this event (from } 3 \mathrm{E}-06 \text { to } \\
1 \mathrm{E}-06 / \mathrm{h}) \text {. }\end{array}$ & $1 \mathrm{E}-06 / \mathrm{h}$ & $\begin{array}{l}\text { WSRC-TR- } \\
93-262\end{array}$ & \\
\hline & & $\begin{array}{l}\text { leakage } \\
\text { from tubes }\end{array}$ & Category II & $\begin{array}{l}\text { Tube degradation } \\
\text { by vibration, } \\
\text { thermal cycling, } \\
\text { fluid jetting on } \\
\text { tubes }\end{array}$ & $\begin{array}{l}\text { design for low } \\
\text { tube bundle } \\
\text { vibration }\end{array}$ & $\begin{array}{l}\text { Lose small amount of } \\
\text { helium into HX shell, } \\
\text { lose TBM cooling as } \\
\text { helium pressure } \\
\text { decreases }\end{array}$ & $\begin{array}{l}\text { Shut down TBM and } \\
\text { shut down ITER }\end{array}$ & $\begin{array}{l}\text { helium HX } \\
\text { tube rupture, } \\
\text { LBO3 }\end{array}$ & & $1 \mathrm{E}-05 / \mathrm{h}$ & $\begin{array}{l}\text { WSRC-TR- } \\
93-262\end{array}$ & \\
\hline & & tube rupture & $\begin{array}{l}\text { Category } \\
\text { III }\end{array}$ & $\begin{array}{l}\text { material flaw, } \\
\text { thermal } \\
\text { overstress, } \\
\text { burnout }\end{array}$ & $\begin{array}{l}\text { design for low } \\
\text { tube bundle } \\
\text { vibration }\end{array}$ & $\begin{array}{l}\text { Lose moderate to } \\
\text { large amount of } \\
\text { helium into HX shell, } \\
\text { lose TBM cooling as } \\
\text { helium pressure } \\
\text { decreases }\end{array}$ & $\begin{array}{l}\text { Shut down TBM and } \\
\text { shut down ITER }\end{array}$ & $\begin{array}{l}\text { helium } \mathrm{HX} \\
\text { tube rupture, } \\
\text { LBO3 }\end{array}$ & & $5 \mathrm{E}-07 / \mathrm{h}$ & $\begin{array}{l}\text { WSRC-TR- } \\
93-262\end{array}$ & $\begin{array}{l}\text { A single HX tube might be perhaps } 12 \\
\text { mm diameter or greater, but even that } \\
\text { small double-ended opening can } \\
\text { depressurize the helium loop. Assume } \\
\text { that the helium loop will be } \\
\text { depressurized by a tube rupture. }\end{array}$ \\
\hline & & $\begin{array}{l}\text { leakage } \\
\text { from shell }\end{array}$ & $\begin{array}{l}\text { Category } \\
\text { III }\end{array}$ & $\begin{array}{l}\text { faulty weld, wall } \\
\text { crack }\end{array}$ & $\begin{array}{l}\text { Routine } \\
\text { inspection }\end{array}$ & $\begin{array}{l}\text { Small leak should not } \\
\text { degrade heat transfer } \\
\text { from helium to the } \\
\text { water }\end{array}$ & $\begin{array}{l}\text { Shut down TBM and } \\
\text { shut down ITER }\end{array}$ & Not an IE & $\begin{array}{l}\text { Small leakage should not } \\
\text { affect operations if the } \\
\text { water can be made up }\end{array}$ & $1 \mathrm{E}-06 / \mathrm{h}$ & $\begin{array}{l}\text { WSRC-TR- } \\
93-262\end{array}$ & \\
\hline & & shell rupture & \begin{tabular}{|l|} 
Category \\
III
\end{tabular} & $\begin{array}{l}\text { weld failure, } \\
\text { severe wall crack }\end{array}$ & $\begin{array}{l}\text { Routine } \\
\text { inspection }\end{array}$ & $\begin{array}{l}\text { Loss of heat sink } \\
\text { accident }\end{array}$ & $\begin{array}{l}\text { Shut down TBM and } \\
\text { shut down ITER }\end{array}$ & $\begin{array}{l}\text { Loss of Heat } \\
\text { Sink, HB1 }\end{array}$ & & $5 \mathrm{E}-08 / \mathrm{h}$ & $\begin{array}{l}\text { WSRC-TR- } \\
\text { 93-262 }\end{array}$ & \\
\hline $\begin{array}{l}\text { Secondary } \\
\text { cooling water } \\
\text { system }\end{array}$ & NO & $\begin{array}{l}\text { fails to } \\
\text { operate }\end{array}$ & $\begin{array}{l}\text { Category } \\
\text { III }\end{array}$ & $\begin{array}{l}\text { many reasons, } \\
\text { loca, power loss, } \\
\text { human error }\end{array}$ & $\begin{array}{l}\text { Routine testing } \\
\text { and inspection }\end{array}$ & $\begin{array}{l}\text { Overheat of TBM if } \\
\text { helium is not cooled } \\
\text { in the HX, loss of heat } \\
\text { sink }\end{array}$ & $\begin{array}{l}\text { Shut down TBM and } \\
\text { shut down ITER }\end{array}$ & $\begin{array}{l}\text { Loss of Heat } \\
\text { Sink, HB1 }\end{array}$ & $\begin{array}{l}\text { Water system fails to } \\
\text { provide cooling to } \mathrm{HX}\end{array}$ & $1.2 \mathrm{E}-03 / \mathrm{yr}$ & $\begin{array}{l}\text { NUREG/CR- } \\
6928, \text { ch } 8\end{array}$ & $\begin{array}{l}\text { As a first approximation, use partial } \\
\text { failure of PWR component cooling } \\
\text { water system as the failure rate for this } \\
\text { heat exchanger secondary system }\end{array}$ \\
\hline \multirow[t]{4}{*}{$\begin{array}{l}\text { Flow control } \\
\text { valve to gas } \\
\text { heater, normally } \\
\text { closed during } \\
\text { plasma operation }\end{array}$} & NO & $\begin{array}{l}\text { fails open or } \\
\text { spurious } \\
\text { open }\end{array}$ & Category II & $\begin{array}{l}\text { control fault, } \\
\text { valve controller } \\
\text { failure }\end{array}$ & $\begin{array}{l}\text { Routine testing } \\
\text { and inspection }\end{array}$ & $\begin{array}{l}\text { Overheat TBM due to } \\
\text { partial loss of heat } \\
\text { sink }\end{array}$ & $\begin{array}{l}\text { Shut down ITER and } \\
\text { TBM }\end{array}$ & $\begin{array}{l}\text { Loss of Heat } \\
\text { Sink, HB1 }\end{array}$ & $\begin{array}{l}\text { There is no quick repair } \\
\text { intervention for this event. }\end{array}$ & $3 \mathrm{E}-06 / \mathrm{h}$ & $\begin{array}{l}\text { WSRC-TR- } \\
93-262\end{array}$ & $\begin{array}{l}\text { This flow control valve should remain } \\
\text { closed during Normal Operation since } \\
\text { the heater is not needed during normal } \\
\text { ops. Opening means helium will } \\
\text { bypass the heat exchanger in a partial } \\
\text { loss of heat sink. }\end{array}$ \\
\hline & & plugs & $\begin{array}{l}\text { Category } \\
\text { III }\end{array}$ & $\begin{array}{l}\text { foreign material } \\
\text { intrusion }\end{array}$ & $\begin{array}{l}\text { Coolant } \\
\text { purification }\end{array}$ & No immediate effects & $\begin{array}{l}\text { No actions to take } \\
\text { until shutdown }\end{array}$ & Not an IE & & $5 \mathrm{E}-07 / \mathrm{h}$ & $\begin{array}{l}\text { WSRC-TR- } \\
\text { 93-262 }\end{array}$ & \\
\hline & & $\begin{array}{l}\text { internal } \\
\text { leakage }\end{array}$ & Category II & $\begin{array}{l}\text { Valve seat wear, } \\
\text { valve disk fault }\end{array}$ & $\begin{array}{l}\text { Routine test and } \\
\text { inspection }\end{array}$ & $\begin{array}{l}\text { Small flow of helium } \\
\text { bypasses the TBM, } \\
\text { overheat the TBM }\end{array}$ & $\begin{array}{l}\text { Attempt to reseat } \\
\text { valve fully closed. If } \\
\text { unsuccessful, shut } \\
\text { down ITER }\end{array}$ & $\begin{array}{l}\text { Loss of Heat } \\
\text { Sink, HB1 }\end{array}$ & & $1 \mathrm{E}-05 / \mathrm{h}$ & $\begin{array}{l}\text { WSRC-TR- } \\
93-262\end{array}$ & \\
\hline & & $\begin{array}{l}\text { internal } \\
\text { rupture }\end{array}$ & $\begin{array}{l}\text { Category } \\
\text { III }\end{array}$ & Valve disk failure & $\begin{array}{l}\text { Routine test and } \\
\text { inspection }\end{array}$ & $\begin{array}{l}\text { Large flow of helium } \\
\text { bypasses the TBM, } \\
\text { overheats the TBM }\end{array}$ & \begin{tabular}{|l|} 
Shut down ITER \\
\end{tabular} & $\begin{array}{l}\text { Loss of Heat } \\
\text { Sink, HB1 }\end{array}$ & & $5 \mathrm{E}-07 / \mathrm{h}$ & $\begin{array}{l}\text { WSRC-TR- } \\
93-262\end{array}$ & \\
\hline
\end{tabular}




\begin{tabular}{|c|c|c|c|c|c|c|c|c|c|c|c|c|}
\hline Component & $\begin{array}{c}\text { Operational } \\
\text { State }\end{array}$ & $\begin{array}{c}\text { Failure } \\
\text { Mode }\end{array}$ & $\begin{array}{c}\text { Frequency } \\
\text { Category }\end{array}$ & Possible Causes & $\begin{array}{c}\text { Preventive } \\
\text { Action on } \\
\text { Possible Causes } \\
\end{array}$ & Consequences & $\begin{array}{c}\text { Corrective or } \\
\text { Preventive Actions } \\
\text { on Consequences }\end{array}$ & $\begin{array}{c}\text { ITER } \\
\text { Postulated } \\
\text { Initiating } \\
\text { Events } \\
\end{array}$ & Comments & Frequency & $\begin{array}{c}\text { Comment on } \\
\text { frequency } \\
\text { calculation }\end{array}$ & Design comments \\
\hline & & $\begin{array}{l}\text { external } \\
\text { leakage }\end{array}$ & $\begin{array}{l}\text { Category } \\
\text { III }\end{array}$ & $\begin{array}{l}\text { weld fault, valve } \\
\text { wall flaw, } \\
\text { vibration induced } \\
\text { crack, } \\
\text { construction fault }\end{array}$ & $\begin{array}{l}\text { Materials } \\
\text { selection in } \\
\text { design, pre- } \\
\text { service } \\
\text { inspection, low } \\
\text { flow-induced } \\
\text { vibration in } \\
\text { design }\end{array}$ & $\begin{array}{l}\text { Leaks hot helium to } \\
\text { the } 30 \mathrm{C} \text { air } \\
\text { atmosphere in the } \\
\text { equatorial test port. }\end{array}$ & $\begin{array}{l}\text { Assume that a small } \\
\text { leak cannot be } \\
\text { tolerated until the end } \\
\text { of the campaign, shut } \\
\text { down ITER and TBM } \\
\text { to repair the leak. }\end{array}$ & $\begin{array}{l}\text { Small } \\
\text { Helium } \\
\text { LOCA, } \\
\text { LBO2 }\end{array}$ & $\begin{array}{l}\text { Helium makeup capabilities } \\
\text { are not known at this time, } \\
\text { assume leak cannot be } \\
\text { made up and it is a small } \\
\text { LOCA }\end{array}$ & $1 \mathrm{E}-07 / \mathrm{h}$ & $\begin{array}{l}\text { WSRC-TR- } \\
93-262\end{array}$ & \\
\hline & & $\begin{array}{l}\text { external } \\
\text { rupture }\end{array}$ & $\begin{array}{l}\text { Category } \\
\text { IV }\end{array}$ & $\begin{array}{l}\text { weld fracture, } \\
\text { valve wall failure, } \\
\text { flow induced } \\
\text { vibration }\end{array}$ & $\begin{array}{l}\text { Materials } \\
\text { selection in } \\
\text { design, pre- } \\
\text { service } \\
\text { inspection, low } \\
\text { flow-induced } \\
\text { vibration in } \\
\text { design }\end{array}$ & $\begin{array}{l}\text { Leaks moderate to } \\
\text { large amount of } \\
\text { helium to the } \\
\text { equatorial test port }\end{array}$ & $\begin{array}{l}\text { Isolate the leak if } \\
\text { possible, shut down } \\
\text { ITER and TBM to } \\
\text { repair the leak. }\end{array}$ & $\begin{array}{l}\text { Helium } \\
\text { LOCA, } \\
\text { LBO1 }\end{array}$ & $\begin{array}{l}\text { Helium makeup capabilities } \\
\text { are not known at this time, } \\
\text { assume that the large leak } \\
\text { cannot be made up and it is } \\
\text { a LOCA }\end{array}$ & $5 \mathrm{E}-09 / \mathrm{h}$ & $\begin{array}{l}\text { WSRC-TR- } \\
93-262\end{array}$ & \\
\hline \multirow[t]{5}{*}{$\begin{array}{l}\text { Gas heater, } \\
\text { normally inlet } \\
\text { isolated and de- } \\
\text { energized during } \\
\text { plasma operation }\end{array}$} & NO & $\begin{array}{l}\text { spurious } \\
\text { actuation }\end{array}$ & $\begin{array}{l}\text { Category } \\
\text { III }\end{array}$ & $\begin{array}{l}\text { command fault, } \\
\text { human error }\end{array}$ & $\begin{array}{l}\text { Monitoring } \\
\text { status, and } \\
\text { procedures }\end{array}$ & $\begin{array}{l}\text { Adds heat to helium } \\
\text { gas downstream of } \\
\text { HX, same as a loss of } \\
\text { heat sink event }\end{array}$ & $\begin{array}{l}\text { Depower heater if } \\
\text { possible }\end{array}$ & $\begin{array}{l}\text { Loss of Heat } \\
\text { Sink, HB1 }\end{array}$ & $\begin{array}{l}\text { For this failure, assume at } \\
\text { present it is equal to circuit } \\
\text { breaker spurious closure }\end{array}$ & $3 \mathrm{E}-07 / \mathrm{h}$ & $\begin{array}{l}\text { WSRC-TR- } \\
\text { 93-262 }\end{array}$ & $\begin{array}{l}\text { Heater can add } 170 \mathrm{~kW} \text { to the helium } \\
\text { gas, which will begin to flow from the } \\
\text { heater tank exit line. With the control } \\
\text { valve remaining in the closed position } \\
\text { (as it should be), the tank will begin to } \\
\text { overheat as the heated helium leaves } \\
\text { the tank. Good monitoring of the } \\
\text { system components is needed to bring } \\
\text { this fault to the attention of operators. }\end{array}$ \\
\hline & & fails to heat & $\begin{array}{l}\text { Category } \\
\text { III }\end{array}$ & $\begin{array}{l}\text { power loss, } \\
\text { command fault, } \\
\text { human error }\end{array}$ & $\begin{array}{l}\text { Monitoring } \\
\text { status, and } \\
\text { procedures }\end{array}$ & $\begin{array}{l}\text { Not a failure mode } \\
\text { during NO }\end{array}$ & No actions to take. & Not an IE & & $1 \mathrm{E}-06 / \mathrm{h}$ & $\begin{array}{l}\text { WSRC-TR- } \\
\text { 93-262 }\end{array}$ & $\begin{array}{l}\text { This failure mode is only an issue } \\
\text { during startup operations, not normal } \\
\text { plasma operations }\end{array}$ \\
\hline & & overheating & $\begin{array}{l}\text { Category } \\
\text { III }\end{array}$ & $\begin{array}{l}\text { controller fault, } \\
\text { command fault }\end{array}$ & $\begin{array}{l}\text { Routine testing } \\
\text { and inspection }\end{array}$ & $\begin{array}{l}\text { Not a failure mode } \\
\text { during NO }\end{array}$ & No actions to take. & Not an IE & & $3 \mathrm{E}-07 / \mathrm{h}$ & $\begin{array}{l}\text { WSRC-TR- } \\
\text { 93-262 }\end{array}$ & $\begin{array}{l}\text { This failure mode is only an issue } \\
\text { during startup operations, not normal } \\
\text { plasma operations }\end{array}$ \\
\hline & & $\begin{array}{l}\text { external } \\
\text { leakage }\end{array}$ & $\begin{array}{l}\text { Category } \\
\text { III }\end{array}$ & $\begin{array}{l}\text { weld fault, wall } \\
\text { flaw, vibration } \\
\text { induced crack, } \\
\text { thermal stress, } \\
\text { construction fault }\end{array}$ & $\begin{array}{l}\text { Materials } \\
\text { selection in } \\
\text { design, pre- } \\
\text { service } \\
\text { inspection, low } \\
\text { flow-induced } \\
\text { vibration in } \\
\text { design, NDT }\end{array}$ & $\begin{array}{l}\text { Leaks hot helium to } \\
\text { the } 30 \mathrm{C} \text { air } \\
\text { atmosphere in the } \\
\text { equatorial test port. }\end{array}$ & $\begin{array}{l}\text { Assume that a small } \\
\text { leak cannot be } \\
\text { tolerated until the end } \\
\text { of the campaign, shut } \\
\text { down ITER and TBM } \\
\text { to repair the leak. }\end{array}$ & $\begin{array}{l}\text { Small } \\
\text { Helium } \\
\text { LOCA, } \\
\text { LBO2 }\end{array}$ & $\begin{array}{l}\text { This tank is stagnant during } \\
\text { Normal Operation, but a } \\
\text { breach will decrease tank } \\
\text { pressure and then helium } \\
\text { loop pressure. }\end{array}$ & $1 \mathrm{E}-07 / \mathrm{h}$ & $\begin{array}{l}\text { WSRC-TR- } \\
93-262\end{array}$ & \\
\hline & & $\begin{array}{l}\text { external } \\
\text { rupture }\end{array}$ & $\begin{array}{l}\text { Category } \\
\text { IV }\end{array}$ & $\begin{array}{l}\text { weld fracture, } \\
\text { wall failure, flow } \\
\text { induced } \\
\text { vibration, thermal } \\
\text { stresses }\end{array}$ & $\begin{array}{l}\text { Materials } \\
\text { selection in } \\
\text { design, pre- } \\
\text { service } \\
\text { inspection, low } \\
\text { flow-induced } \\
\text { vibration in } \\
\text { design, NDT }\end{array}$ & $\begin{array}{l}\text { Leaks moderate to } \\
\text { large amount of } \\
\text { helium to the } \\
\text { equatorial test port }\end{array}$ & $\begin{array}{l}\text { Isolate the leak if } \\
\text { possible, shut down } \\
\text { ITER and TBM to } \\
\text { repair the leak. }\end{array}$ & $\begin{array}{l}\text { Helium } \\
\text { LOCA, } \\
\text { LBO1 }\end{array}$ & & $5 \mathrm{E}-09 / \mathrm{h}$ & $\begin{array}{l}\text { WSRC-TR- } \\
\text { 93-262 }\end{array}$ & \\
\hline Gas circulator & NO & fail to start & Category II & $\begin{array}{l}\text { command fault, } \\
\text { human error, } \\
\text { bearing or shaft } \\
\text { seized, shaft } \\
\text { shear, power loss }\end{array}$ & $\begin{array}{l}\text { periodic system } \\
\text { testing, software } \\
\text { QA }\end{array}$ & $\begin{array}{l}\text { No helium flow to } \\
\text { startup TBM, cannot } \\
\text { start up ITER }\end{array}$ & $\begin{array}{l}\text { Continue the ITER } \\
\text { shutdown to repair } \\
\text { gas circulator }\end{array}$ & Not an IE & & $5 \mathrm{E}-03 / \mathrm{d}$ & $\begin{array}{l}\text { WSRC-TR- } \\
\text { 93-262 }\end{array}$ & $\begin{array}{l}\text { Circulator must start before ITER can } \\
\text { operate. Assume } 4 \text { starts per year, at } \\
\text { the beginning of each campaign. }\end{array}$ \\
\hline
\end{tabular}




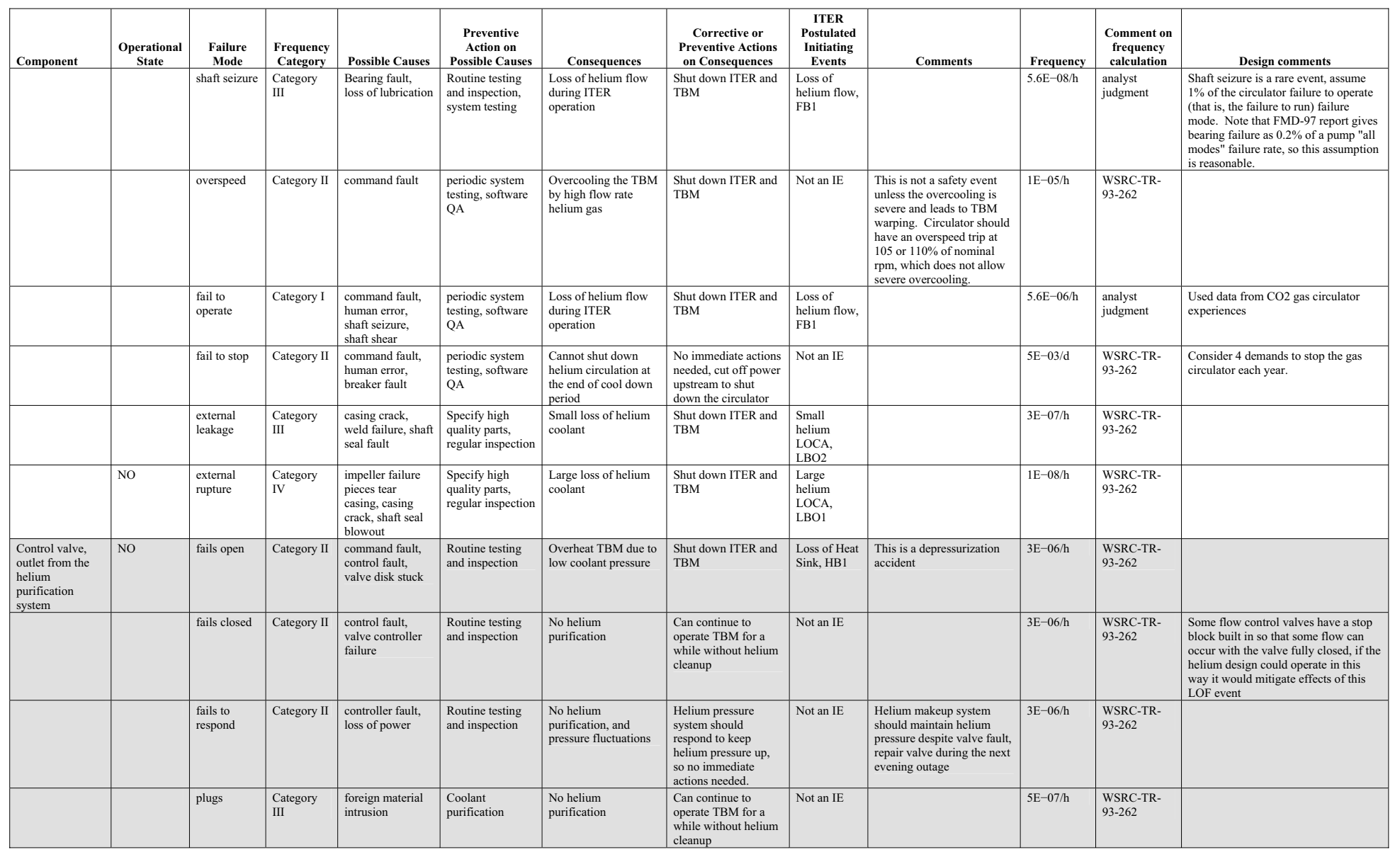




\begin{tabular}{|c|c|c|c|c|c|c|c|c|c|c|c|c|}
\hline Component & $\begin{array}{c}\text { Operational } \\
\text { State }\end{array}$ & $\begin{array}{c}\text { Failure } \\
\text { Mode }\end{array}$ & $\begin{array}{l}\text { Frequency } \\
\text { Category }\end{array}$ & Possible Causes & $\begin{array}{c}\text { Preventive } \\
\text { Action on } \\
\text { Possible Causes }\end{array}$ & Consequences & $\begin{array}{c}\text { Corrective or } \\
\text { Preventive Actions } \\
\text { on Consequences }\end{array}$ & $\begin{array}{c}\text { ITER } \\
\text { Postulated } \\
\text { Initiating } \\
\text { Events } \\
\end{array}$ & Comments & Frequency & $\begin{array}{c}\text { Comment on } \\
\text { frequency } \\
\text { calculation }\end{array}$ & Design comments \\
\hline & & $\begin{array}{l}\text { external } \\
\text { leakage }\end{array}$ & $\begin{array}{l}\text { Category } \\
\text { III }\end{array}$ & $\begin{array}{l}\text { weld fault, valve } \\
\text { wall flaw, } \\
\text { vibration induced } \\
\text { crack, } \\
\text { construction fault }\end{array}$ & $\begin{array}{l}\text { Materials } \\
\text { selection in } \\
\text { design, pre- } \\
\text { service } \\
\text { inspection, low } \\
\text { flow-induced } \\
\text { vibration in } \\
\text { design }\end{array}$ & $\begin{array}{l}\text { Leaks hot helium to } \\
\text { the } 30 \mathrm{C} \text { air } \\
\text { atmosphere in the } \\
\text { equatorial test port. }\end{array}$ & $\begin{array}{l}\text { Assume that a small } \\
\text { leak cannot be } \\
\text { tolerated until the end } \\
\text { of the campaign, shut } \\
\text { down ITER and TBM } \\
\text { to repair the leak. }\end{array}$ & $\begin{array}{l}\text { Small } \\
\text { Helium } \\
\text { LOCA, } \\
\text { LBO2 }\end{array}$ & $\begin{array}{l}\text { Helium makeup capabilities } \\
\text { are not known at this time, } \\
\text { assume leak cannot be } \\
\text { made up and it is a small } \\
\text { LOCA }\end{array}$ & $1 \mathrm{E}-07 / \mathrm{h}$ & $\begin{array}{l}\text { WSRC-TR- } \\
93-262\end{array}$ & \\
\hline & & $\begin{array}{l}\text { external } \\
\text { rupture }\end{array}$ & $\begin{array}{l}\text { Category } \\
\text { IV }\end{array}$ & $\begin{array}{l}\text { weld fracture, } \\
\text { valve wall failure, } \\
\text { flow induced } \\
\text { vibration }\end{array}$ & $\begin{array}{l}\text { Materials } \\
\text { selection in } \\
\text { design, pre- } \\
\text { service } \\
\text { inspection, low } \\
\text { flow-induced } \\
\text { vibration in } \\
\text { design }\end{array}$ & $\begin{array}{l}\text { Leaks moderate to } \\
\text { large amount of } \\
\text { helium to the } \\
\text { equatorial test port }\end{array}$ & $\begin{array}{l}\text { Isolate the leak if } \\
\text { possible, shut down } \\
\text { ITER and TBM to } \\
\text { repair the leak. }\end{array}$ & $\begin{array}{l}\text { Helium } \\
\text { LOCA, } \\
\text { LBO1 }\end{array}$ & $\begin{array}{l}\text { Helium makeup capabilities } \\
\text { are not known at this time, } \\
\text { assume that the large leak } \\
\text { cannot be made up and it is } \\
\text { a LOCA }\end{array}$ & $5 \mathrm{E}-09 / \mathrm{h}$ & $\begin{array}{l}\text { WSRC-TR- } \\
93-262\end{array}$ & \\
\hline \multirow{6}{*}{$\begin{array}{l}\text { Control valve, } \\
\text { inlet to the } \\
\text { helium } \\
\text { purification } \\
\text { system }\end{array}$} & NO & fails open & Category II & $\begin{array}{l}\text { command fault, } \\
\text { controller fault }\end{array}$ & $\begin{array}{l}\text { Routine testing } \\
\text { and inspection }\end{array}$ & $\begin{array}{l}\text { Overheat TBM due to } \\
\text { low coolant pressure }\end{array}$ & $\begin{array}{l}\text { Shut down ITER and } \\
\text { TBM }\end{array}$ & $\begin{array}{l}\text { Loss of Heat } \\
\text { Sink, HB1 }\end{array}$ & $\begin{array}{l}\text { This is a depressurization } \\
\text { accident }\end{array}$ & $3 \mathrm{E}-06 / \mathrm{h}$ & $\begin{array}{l}\text { WSRC-TR- } \\
\text { 93-262 }\end{array}$ & \\
\hline & & fails closed & Category II & $\begin{array}{l}\text { control fault, } \\
\text { valve controller } \\
\text { failure }\end{array}$ & $\begin{array}{l}\text { Routine testing } \\
\text { and inspection }\end{array}$ & $\begin{array}{l}\text { No helium } \\
\text { purification }\end{array}$ & $\begin{array}{l}\text { Can continue to } \\
\text { operate TBM for a } \\
\text { while without helium } \\
\text { cleanup }\end{array}$ & Not an IE & & $3 \mathrm{E}-06 / \mathrm{h}$ & $\begin{array}{l}\text { WSRC-TR- } \\
93-262\end{array}$ & $\begin{array}{l}\text { Some flow control valves have a stop } \\
\text { block built in so that some flow can } \\
\text { occur with the valve fully closed, if the } \\
\text { helium design could operate in this } \\
\text { way it would mitigate effects of this } \\
\text { LOF event }\end{array}$ \\
\hline & & $\begin{array}{l}\text { fails to } \\
\text { respond }\end{array}$ & Category II & $\begin{array}{l}\text { controller fault, } \\
\text { loss of power }\end{array}$ & $\begin{array}{l}\text { Routine testing } \\
\text { and inspection }\end{array}$ & $\begin{array}{l}\text { No helium } \\
\text { purification, and } \\
\text { pressure fluctuations }\end{array}$ & $\begin{array}{l}\text { Helium pressure } \\
\text { system should } \\
\text { respond to keep } \\
\text { helium pressure up, } \\
\text { so no immediate } \\
\text { actions needed. }\end{array}$ & Not an IE & $\begin{array}{l}\text { Helium makeup system } \\
\text { should maintain helium } \\
\text { pressure despite valve fault, } \\
\text { repair valve during the next } \\
\text { evening outage }\end{array}$ & $3 \mathrm{E}-06 / \mathrm{h}$ & $\begin{array}{l}\text { WSRC-TR- } \\
\text { 93-262 }\end{array}$ & \\
\hline & & plugs & $\begin{array}{l}\text { Category } \\
\text { III }\end{array}$ & $\begin{array}{l}\text { foreign material } \\
\text { intrusion }\end{array}$ & $\begin{array}{l}\text { Coolant } \\
\text { purification }\end{array}$ & $\begin{array}{l}\text { No helium } \\
\text { purification }\end{array}$ & $\begin{array}{l}\text { Can continue to } \\
\text { operate TBM for a } \\
\text { while without helium } \\
\text { cleanup }\end{array}$ & Not an IE & & $5 \mathrm{E}-07 / \mathrm{h}$ & $\begin{array}{l}\text { WSRC-TR- } \\
93-262\end{array}$ & \\
\hline & & $\begin{array}{l}\text { external } \\
\text { leakage }\end{array}$ & $\begin{array}{l}\text { Category } \\
\text { III }\end{array}$ & $\begin{array}{l}\text { weld fault, valve } \\
\text { wall flaw, } \\
\text { vibration induced } \\
\text { crack, } \\
\text { construction fault }\end{array}$ & $\begin{array}{l}\text { Materials } \\
\text { selection in } \\
\text { design, pre- } \\
\text { service } \\
\text { inspection, low } \\
\text { flow-induced } \\
\text { vibration in } \\
\text { design }\end{array}$ & $\begin{array}{l}\text { Leaks hot helium to } \\
\text { the } 30 \mathrm{C} \text { air } \\
\text { atmosphere in the } \\
\text { equatorial test port. }\end{array}$ & $\begin{array}{l}\text { Assume that a small } \\
\text { leak cannot be } \\
\text { tolerated until the end } \\
\text { of the campaign, shut } \\
\text { down ITER and TBM } \\
\text { to repair the leak. }\end{array}$ & $\begin{array}{l}\text { Small } \\
\text { Helium } \\
\text { LOCA, } \\
\text { LBO2 }\end{array}$ & $\begin{array}{l}\text { Helium makeup capabilities } \\
\text { are not known at this time, } \\
\text { assume leak cannot be } \\
\text { made up and it is a small } \\
\text { LOCA }\end{array}$ & $1 \mathrm{E}-07 / \mathrm{h}$ & $\begin{array}{l}\text { WSRC-TR- } \\
93-262\end{array}$ & \\
\hline & & $\begin{array}{l}\text { external } \\
\text { rupture }\end{array}$ & $\begin{array}{l}\text { Category } \\
\text { IV }\end{array}$ & $\begin{array}{l}\text { weld fracture, } \\
\text { valve wall failure, } \\
\text { flow induced } \\
\text { vibration }\end{array}$ & $\begin{array}{l}\text { Materials } \\
\text { selection in } \\
\text { design, pre- } \\
\text { service } \\
\text { inspection, low } \\
\text { flow-induced } \\
\text { vibration in } \\
\text { design }\end{array}$ & $\begin{array}{l}\text { Leaks moderate to } \\
\text { large amount of } \\
\text { helium to the } \\
\text { equatorial test port }\end{array}$ & $\begin{array}{l}\text { Isolate the leak if } \\
\text { possible, shut down } \\
\text { ITER and TBM to } \\
\text { repair the leak. }\end{array}$ & $\begin{array}{l}\text { Helium } \\
\text { LOCA, } \\
\text { LBO1 }\end{array}$ & $\begin{array}{l}\text { Helium makeup capabilities } \\
\text { are not known at this time, } \\
\text { assume that the large leak } \\
\text { cannot be made up and it is } \\
\text { a LOCA }\end{array}$ & $5 \mathrm{E}-09 / \mathrm{h}$ & $\begin{array}{l}\text { WSRC-TR- } \\
\text { 93-262 }\end{array}$ & \\
\hline
\end{tabular}




\begin{tabular}{|c|c|c|c|c|c|c|c|c|c|c|c|c|}
\hline Component & $\begin{array}{c}\text { Operational } \\
\text { State }\end{array}$ & $\begin{array}{c}\text { Failure } \\
\text { Mode }\end{array}$ & $\begin{array}{c}\text { Frequency } \\
\text { Category }\end{array}$ & Possible Causes & $\begin{array}{c}\text { Preventive } \\
\text { Action on } \\
\text { Possible Causes }\end{array}$ & Consequences & $\begin{array}{c}\text { Corrective or } \\
\text { Preventive Actions } \\
\text { on Consequences }\end{array}$ & $\begin{array}{c}\text { ITER } \\
\text { Postulated } \\
\text { Initiating } \\
\text { Events }\end{array}$ & Comments & Frequency & $\begin{array}{l}\text { Comment on } \\
\text { frequency } \\
\text { calculation }\end{array}$ & Design comments \\
\hline \multirow[t]{4}{*}{$\begin{array}{l}\text { Helium } \\
\text { Purification } \\
\text { System }\end{array}$} & NO & $\begin{array}{l}\text { external } \\
\text { leakage }\end{array}$ & $\begin{array}{l}\text { Category } \\
\text { III }\end{array}$ & $\begin{array}{l}\text { weld fault, pipe } \\
\text { wall flaw, pipe } \\
\text { vibration induced } \\
\text { crack, } \\
\text { construction fault }\end{array}$ & $\begin{array}{l}\text { Materials } \\
\text { selection in } \\
\text { design, pre- } \\
\text { service } \\
\text { inspection, low } \\
\text { flow-induced } \\
\text { vibration, NDT }\end{array}$ & $\begin{array}{l}\text { Leaks small amount } \\
\text { of helium to room, } \\
\text { slowly depletes } \\
\text { makeup helium, may } \\
\text { release some tritium } \\
\text { and other gases to } \\
\text { room }\end{array}$ & $\begin{array}{l}\text { Isolate and } \\
\text { depressurize the PCS } \\
\text { if possible to reduce } \\
\text { gas leakage. Shut } \\
\text { down the TBM, shut } \\
\text { down ITER pulsing. }\end{array}$ & $\begin{array}{l}\text { Small } \\
\text { Helium } \\
\text { LOCA, } \\
\text { LBO2 }\end{array}$ & & $\begin{array}{l}9.8 \mathrm{E}-08 / \mathrm{h}- \\
\mathrm{m}\end{array}$ & $\begin{array}{l}\text { WSRC-TR- } \\
\text { 93-262 }\end{array}$ & $\begin{array}{l}\text { Assumed } 20 \mathrm{~m} \text { piping in the HPS as an } \\
\text { initial estimate for all piping in the } \\
\text { TCWS room. The system valves, } \\
\text { tanks, etc., that are not designed at } \\
\text { present. }\end{array}$ \\
\hline & & $\begin{array}{l}\text { external } \\
\text { rupture }\end{array}$ & $\begin{array}{l}\text { Category } \\
\text { III }\end{array}$ & $\begin{array}{l}\text { weld fracture, } \\
\text { piping failure, } \\
\text { flow induced } \\
\text { vibration }\end{array}$ & $\begin{array}{l}\text { Materials } \\
\text { selection in } \\
\text { design, pre- } \\
\text { service } \\
\text { inspection, low } \\
\text { flow-induced } \\
\text { vibration, NDT }\end{array}$ & $\begin{array}{l}\text { Leaks large amount of } \\
\text { helium to the room }\end{array}$ & $\begin{array}{l}\text { Isolate and } \\
\text { depressurize the PCS } \\
\text { if possible to reduce } \\
\text { gas leakage. Shut } \\
\text { down the TBM, shut } \\
\text { down ITER pulsing. }\end{array}$ & $\begin{array}{l}\text { Helium } \\
\text { LOCA, } \\
\text { LBO1 }\end{array}$ & & $\begin{array}{l}3.3 \mathrm{E}-09 / \mathrm{h}- \\
\mathrm{m}\end{array}$ & $\begin{array}{l}\text { WSRC-TR- } \\
\text { 93-262 }\end{array}$ & $\begin{array}{l}\text { Assumed } 20 \mathrm{~m} \text { piping in the HPS as an } \\
\text { initial estimate }\end{array}$ \\
\hline & & plugs & $\begin{array}{l}\text { Category } \\
\text { III }\end{array}$ & $\begin{array}{l}\text { foreign material } \\
\text { buildup, oil from } \\
\text { machinery, dust }\end{array}$ & $\begin{array}{l}\text { Routine } \\
\text { inspection and } \\
\text { testing }\end{array}$ & $\begin{array}{l}\text { No immediate effect } \\
\text { upon loss of } \\
\text { purification system }\end{array}$ & $\begin{array}{l}\text { No immediate effects, } \\
\text { no actions to take } \\
\text { until a scheduled } \\
\text { shutdown }\end{array}$ & Not an IE & & $3 \mathrm{E}-09 / \mathrm{h}-\mathrm{m}$ & $\begin{array}{l}\text { WSRC-TR- } \\
93-262\end{array}$ & $\begin{array}{l}\text { Assumed } 20 \mathrm{~m} \text { piping in the HPS as an } \\
\text { initial estimate }\end{array}$ \\
\hline & & $\begin{array}{l}\text { fail to } \\
\text { operate }\end{array}$ & Category II & $\begin{array}{l}\text { Bad control } \\
\text { signals, loss of } \\
\text { helium supply, } \\
\text { loss of power }\end{array}$ & $\begin{array}{l}\text { Routine } \\
\text { inspection and } \\
\text { testing }\end{array}$ & $\begin{array}{l}\text { Fails to clean the } \\
\text { helium to desired } \\
\text { purity, on immediate } \\
\text { effect on helium } \\
\text { cooling loop }\end{array}$ & $\begin{array}{l}\text { No immediate effects, } \\
\text { no actions to take } \\
\text { until a scheduled } \\
\text { shutdown }\end{array}$ & Not an IE & & $1 \mathrm{E}-02 / \mathrm{yr}$ & $\begin{array}{l}\text { NUREG/CR- } \\
6928, \text { ch } 8\end{array}$ & $\begin{array}{l}\text { Inferred failure rate from PWR Total } \\
\text { Loss of Instrument Air System failure } \\
\text { rate in NUREG, chapter } 8 \text {. }\end{array}$ \\
\hline
\end{tabular}

\begin{tabular}{|c|c|c|c|c|c|c|c|c|c|c|c|}
\hline $\begin{array}{l}\text { THE SECONDA } \\
\text { Gas circulator or } \\
\text { compressor }\end{array}$ & $\begin{array}{l}\text { SY HE } \\
\text { NO }\end{array}$ & $\begin{array}{l}\text { OLANT SY } \\
\text { fail to start }\end{array}$ & $\begin{array}{l}\text { TEM to the } \\
\text { Category II }\end{array}$ & $\begin{array}{l}\text { 'b-17Li HEAT EXC } \\
\text { command fault, } \\
\text { human error, } \\
\text { shaft seizure, } \\
\text { shaft shear } \\
\end{array}$ & $\begin{array}{l}\text { HANGER } \\
\text { periodic system } \\
\text { testing, software } \\
\text { QA }\end{array}$ & $\begin{array}{l}\text { No helium flow to } \\
\text { startup TBM, cannot } \\
\text { start up ITER }\end{array}$ & $\begin{array}{l}\text { Continue shutdown to } \\
\text { repair gas mover }\end{array}$ & Not an IE & $5 \mathrm{E}-03 / \mathrm{d}$ & $\begin{array}{l}\text { WSRC-TR- } \\
93-262\end{array}$ & $\begin{array}{l}\text { Circulator must start before ITER can } \\
\text { operate. Assume } 4 \text { starts per year, at } \\
\text { the beginning of each campaign. }\end{array}$ \\
\hline & & $\begin{array}{l}\text { fail to } \\
\text { operate }\end{array}$ & Category II & $\begin{array}{l}\text { command fault, } \\
\text { human error, } \\
\text { shaft seizure, } \\
\text { shaft shear }\end{array}$ & $\begin{array}{l}\text { periodic system } \\
\text { testing, software } \\
\text { QA }\end{array}$ & $\begin{array}{l}\text { Loss of helium flow } \\
\text { during ITER } \\
\text { operation, cannot cool } \\
\text { the Pb-17Li, loss of } \\
\text { heat sink accident }\end{array}$ & $\begin{array}{l}\text { Shut down ITER and } \\
\text { TBM }\end{array}$ & \begin{tabular}{|l|} 
Secondary \\
system \\
LOHS event \\
on Pb-17Li, \\
HB1 \\
\end{tabular} & $5 \mathrm{E}-05 / \mathrm{h}$ & $\begin{array}{l}\text { WSRC-TR- } \\
\text { 93-262 }\end{array}$ & Motor-driven compressor/circulator \\
\hline & & fail to stop & Category II & $\begin{array}{l}\text { command fault, } \\
\text { human error, } \\
\text { breaker fault }\end{array}$ & $\begin{array}{l}\text { periodic system } \\
\text { testing, software } \\
\text { QA }\end{array}$ & $\begin{array}{l}\text { Cannot shut down } \\
\text { helium circulation at } \\
\text { the end of cool down } \\
\text { period }\end{array}$ & $\begin{array}{l}\text { No immediate actions } \\
\text { needed, cut off power } \\
\text { upstream to shut } \\
\text { down the circulator }\end{array}$ & Not an IE & $5 \mathrm{E}-03 / \mathrm{d}$ & $\begin{array}{l}\text { WSRC-TR- } \\
\text { 93-262 }\end{array}$ & \\
\hline & & $\begin{array}{l}\text { external } \\
\text { leak }\end{array}$ & $\begin{array}{l}\text { Category } \\
\text { III }\end{array}$ & $\begin{array}{l}\text { casing crack, } \\
\text { weld failure, shaft } \\
\text { seal fault }\end{array}$ & $\begin{array}{l}\text { Specify high } \\
\text { quality parts, } \\
\text { regular inspection }\end{array}$ & $\begin{array}{l}\text { Small loss of helium } \\
\text { coolant, reduced } \\
\text { cooling capability }\end{array}$ & $\begin{array}{l}\text { Shut down ITER and } \\
\text { TBM }\end{array}$ & \begin{tabular}{|l|} 
Secondary \\
system \\
LOHS event \\
on Pb-17Li, \\
HB1 \\
\end{tabular} & $3 \mathrm{E}-07 / \mathrm{h}$ & $\begin{array}{l}\text { WSRC-TR- } \\
93-262\end{array}$ & \\
\hline & NO & $\begin{array}{l}\text { external } \\
\text { rupture }\end{array}$ & $\begin{array}{l}\text { Category } \\
\text { IV }\end{array}$ & $\begin{array}{l}\text { impeller failure } \\
\text { pieces tear } \\
\text { casing, casing } \\
\text { crack, shaft seal } \\
\text { blowout }\end{array}$ & $\begin{array}{l}\text { Specify high } \\
\text { quality parts, } \\
\text { regular inspection }\end{array}$ & $\begin{array}{l}\text { Large loss of helium } \\
\text { coolant, loss of Pb- } \\
17 \mathrm{Li} \text { cooling } \\
\text { capability }\end{array}$ & $\begin{array}{l}\text { Shut down ITER and } \\
\text { TBM }\end{array}$ & \begin{tabular}{|l|} 
Secondary \\
system \\
LOHS event \\
on Pb-17Li, \\
HB1 \\
\end{tabular} & $1 \mathrm{E}-08 / \mathrm{h}$ & $\begin{array}{l}\text { WSRC-TR- } \\
93-262\end{array}$ & \\
\hline
\end{tabular}




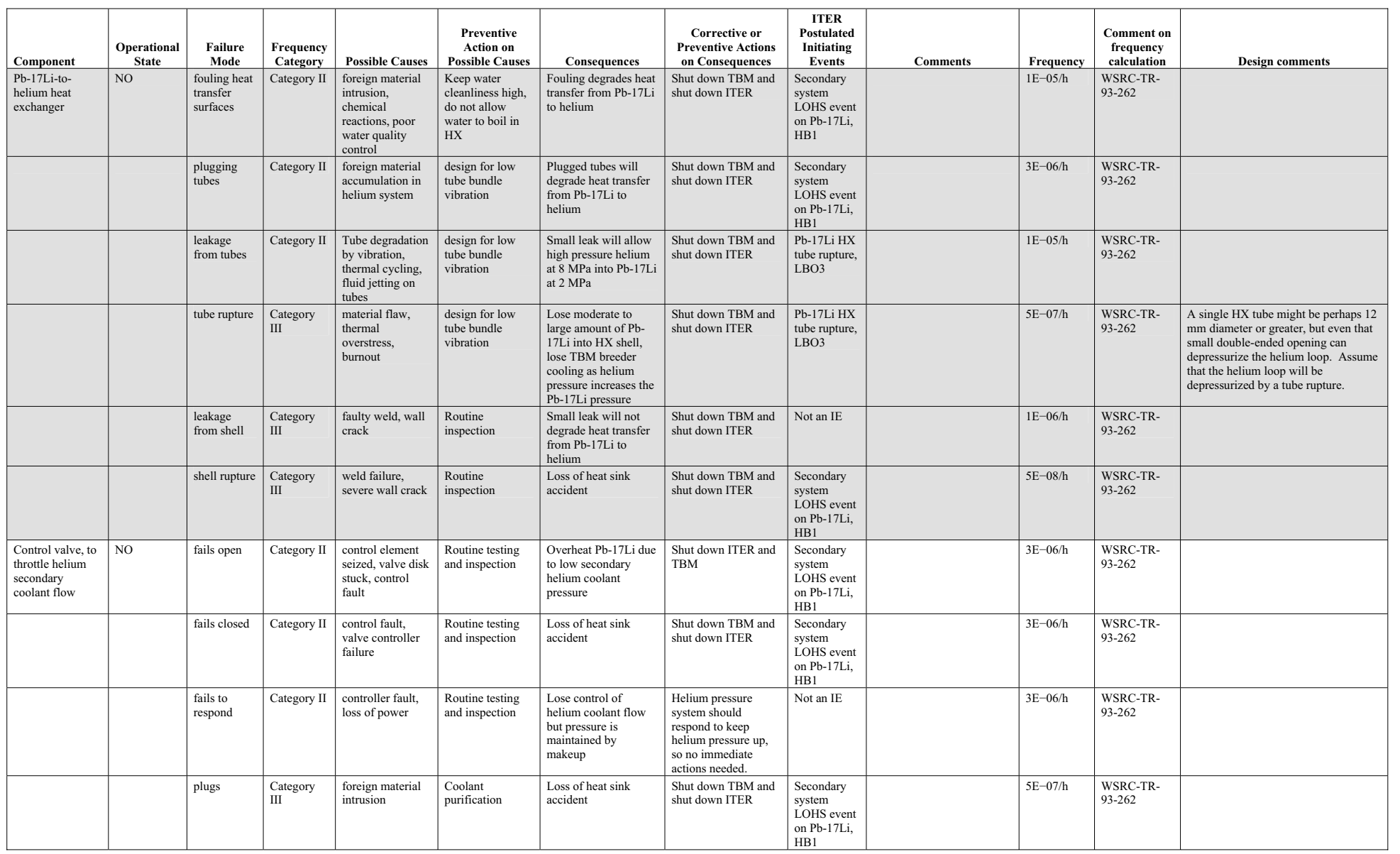

109 


\begin{tabular}{|c|c|c|c|c|c|c|c|c|c|c|c|c|}
\hline Component & $\begin{array}{c}\text { Operational } \\
\text { State }\end{array}$ & $\begin{array}{c}\text { Failure } \\
\text { Mode }\end{array}$ & $\begin{array}{c}\text { Frequency } \\
\text { Category }\end{array}$ & Possible Causes & $\begin{array}{c}\text { Preventive } \\
\text { Action on } \\
\text { Possible Causes }\end{array}$ & Consequences & $\begin{array}{c}\text { Corrective or } \\
\text { Preventive Actions } \\
\text { on Consequences }\end{array}$ & $\begin{array}{c}\text { ITER } \\
\text { Postulated } \\
\text { Initiating } \\
\text { Events } \\
\end{array}$ & Comments & Frequency & $\begin{array}{c}\text { Comment on } \\
\text { frequency } \\
\text { calculation }\end{array}$ & Design comments \\
\hline & & $\begin{array}{l}\text { external } \\
\text { leakage }\end{array}$ & $\begin{array}{l}\text { Category } \\
\text { III }\end{array}$ & $\begin{array}{l}\text { weld fault, valve } \\
\text { wall flaw, } \\
\text { vibration induced } \\
\text { crack, } \\
\text { construction fault }\end{array}$ & $\begin{array}{l}\text { Materials } \\
\text { selection in } \\
\text { design, pre- } \\
\text { service } \\
\text { inspection, low } \\
\text { flow-induced } \\
\text { vibration in } \\
\text { design }\end{array}$ & $\begin{array}{l}\text { Loss of heat sink } \\
\text { accident }\end{array}$ & $\begin{array}{l}\text { Shut down TBM and } \\
\text { shut down ITER }\end{array}$ & $\begin{array}{l}\text { Secondary } \\
\text { system } \\
\text { LOHS event } \\
\text { on Pb-17Li, } \\
\text { HB1 }\end{array}$ & & $1 \mathrm{E}-07 / \mathrm{h}$ & $\begin{array}{l}\text { WSRC-TR- } \\
\text { 93-262 }\end{array}$ & \\
\hline & & $\begin{array}{l}\text { external } \\
\text { rupture }\end{array}$ & $\begin{array}{l}\text { Category } \\
\text { IV }\end{array}$ & $\begin{array}{l}\text { weld fracture, } \\
\text { valve wall failure, } \\
\text { flow induced } \\
\text { vibration }\end{array}$ & $\begin{array}{l}\text { Materials } \\
\text { selection in } \\
\text { design, pre- } \\
\text { service } \\
\text { inspection, low } \\
\text { flow-induced } \\
\text { vibration in } \\
\text { design }\end{array}$ & $\begin{array}{l}\text { Loss of heat sink } \\
\text { accident }\end{array}$ & $\begin{array}{l}\text { Shut down TBM and } \\
\text { shut down ITER }\end{array}$ & $\begin{array}{l}\text { Secondary } \\
\text { system } \\
\text { LOHS event } \\
\text { on Pb-17Li, } \\
\text { HB1 }\end{array}$ & & $5 \mathrm{E}-09 / \mathrm{h}$ & $\begin{array}{l}\text { WSRC-TR- } \\
93-262\end{array}$ & \\
\hline $\begin{array}{l}\text { System helium } \\
\text { piping }\end{array}$ & NO & $\begin{array}{l}\text { external } \\
\text { leakage }\end{array}$ & Category II & $\begin{array}{l}\text { weld fault, pipe } \\
\text { wall flaw, pipe } \\
\text { vibration induced } \\
\text { crack, } \\
\text { construction fault }\end{array}$ & $\begin{array}{l}\text { Materials } \\
\text { selection in } \\
\text { design, pre- } \\
\text { service } \\
\text { inspection, low } \\
\text { flow-induced } \\
\text { vibration, NDT }\end{array}$ & $\begin{array}{l}\text { Leaks small amount } \\
\text { of helium to room, } \\
\text { then the } \mathrm{Pb}-17 \mathrm{Li} \\
\text { begins slowly heating } \\
\text { up. }\end{array}$ & $\begin{array}{l}\text { TBM can tolerate the } \\
\mathrm{Pb}-17 \mathrm{Li} \text { heat } \\
\text { increase. Some heat } \\
\text { will be transferred to } \\
\text { the primary helium } \\
\text { coolant in the TBM. }\end{array}$ & Not an IE & & $\begin{array}{l}9.8 \mathrm{E}-08 / \mathrm{h}- \\
\mathrm{m}\end{array}$ & $\begin{array}{l}\text { WSRC-TR- } \\
93-262\end{array}$ & $\begin{array}{l}\text { Assumed } 140 \mathrm{~m} \text { piping in the flow } \\
\text { loop. }\end{array}$ \\
\hline
\end{tabular}




\section{Appendix C}

Preliminary Failure Modes and Effects Analysis

for the TBM Module Box 


\begin{tabular}{|c|c|c|c|c|c|c|c|c|c|c|c|c|}
\hline Component & $\begin{array}{c}\begin{array}{c}\text { Operational } \\
\text { State }\end{array} \\
\end{array}$ & Failure Mode & $\begin{array}{c}\text { Frequency } \\
\text { Category }\end{array}$ & Possible Causes & $\begin{array}{c}\text { Preventive } \\
\text { Action on } \\
\text { Possible Causes } \\
\end{array}$ & Consequences & $\begin{array}{c}\text { Corrective or } \\
\text { Preventive } \\
\text { Actions on } \\
\text { Consequences } \\
\end{array}$ & $\begin{array}{l}\text { ITER Postulated } \\
\text { Initiating Events }\end{array}$ & Comments & Frequency & $\begin{array}{c}\text { Comment on } \\
\text { frequency } \\
\text { calculation }\end{array}$ & $\begin{array}{c}\begin{array}{c}\text { Design } \\
\text { comments }\end{array} \\
\end{array}$ \\
\hline \multirow[t]{3}{*}{$\begin{array}{l}\text { First wall } \\
\text { assembly (tubes) }\end{array}$} & NO & $\begin{array}{l}\text { small external } \\
\text { leakage to VV }\end{array}$ & Category IV & $\begin{array}{l}\text { material flaw or } \\
\text { defect (thru-wall } \\
\text { crack), thermal or } \\
\text { vibration fatigue }\end{array}$ & $\begin{array}{l}\text { NDT, pre-service } \\
\text { pressure test }\end{array}$ & $\begin{array}{l}\text { Small helium leak } \\
\text { into vacuum } \\
\text { vessel. Does not } \\
\text { cause a plasma } \\
\text { disruption. }\end{array}$ & $\begin{array}{l}\text { Can continue to } \\
\text { operate ITER but } \\
\text { leak should be } \\
\text { repaired in the } \\
\text { next long outage. }\end{array}$ & LBV3 & $\begin{array}{l}\text { Use } 105.7 \mathrm{~m} \text { of } \\
\text { tubing in the FW. } \\
\text { Use } 4032 \\
\text { operating hours } \\
\text { per year. Use } \\
25 \% \text { factor toward } \\
\text { the VV. }\end{array}$ & $2 \mathrm{E}-10 / \mathrm{h}-\mathrm{m}$ & analyst judgment & $\begin{array}{l}\text { Assume a small } \\
\text { leak is } 10 x \text { the } \\
\text { frequency of a } \\
\text { large leak and } \\
100 x \text { the } \\
\text { frequency of a } \\
\text { rupture (Buende, } \\
1991 \text { ). }\end{array}$ \\
\hline & & $\begin{array}{l}\text { external leakage } \\
\text { to VV }\end{array}$ & Category IV & $\begin{array}{l}\text { material flaw or } \\
\text { defect (thru-wall } \\
\text { crack), thermal or } \\
\text { vibration fatigue }\end{array}$ & $\begin{array}{l}\text { NDT, pre-service } \\
\text { pressure test }\end{array}$ & $\begin{array}{l}\text { Helium leak into } \\
\text { vacuum vessel. } \\
\text { Causes a plasma } \\
\text { disruption. }\end{array}$ & $\begin{array}{l}\text { Depressurize, } \\
\text { isolate TBM } \\
\text { helium coolant } \\
\text { line after } \\
\text { disruption has } \\
\text { occurred to reduce } \\
\text { leakage into VV. }\end{array}$ & LBV2 & $\begin{array}{l}\text { Use } 105.7 \mathrm{~m} \text { of } \\
\text { tubing in the FW. } \\
\text { Use } 4032 \\
\text { operating hours } \\
\text { per year. Use } \\
25 \% \text { factor of wall } \\
\text { face toward the } \\
\text { VV. }\end{array}$ & $2 \mathrm{E}-11 / \mathrm{h}-\mathrm{m}$ & see text & $\begin{array}{l}\text { The total helium } \\
\text { flow is } 1.76 \mathrm{~kg} / \mathrm{s} \text {, } \\
\text { divided in plate- } \\
\text { type headers. } \\
\text { Large leaks (up } \\
\text { to } 5 \% \text { of helium } \\
\text { flow) will cause } \\
\text { a plasma } \\
\text { dissuption before } \\
\text { the plasma can } \\
\text { be shut down. }\end{array}$ \\
\hline & & $\begin{array}{l}\text { external rupture to } \\
\text { VV }\end{array}$ & $<$ Cat. IV & $\begin{array}{l}\text { tube wall } \\
\text { longitudinal crack, } \\
\text { wall failure }\end{array}$ & $\begin{array}{l}\text { NDT, pre-service } \\
\text { pressure test }\end{array}$ & $\begin{array}{l}\text { Large helium leak } \\
\text { into vacuum } \\
\text { vessel. Causes } \\
\text { intense plasma } \\
\text { disruption. }\end{array}$ & $\begin{array}{l}\text { Maintain Pb-17Li } \\
\text { coolant flow to } \\
\text { TBM to remove } \\
\text { heat. Isolate } \\
\text { helium makeup } \\
\text { system to reduce } \\
\text { flow into VV. }\end{array}$ & LBV1 & $\begin{array}{l}\text { Use } 105.7 \mathrm{~m} \text { of } \\
\text { tubing in the FW. } \\
\text { Use } 4032 \\
\text { operating hours } \\
\text { per year. Use } \\
25 \% \text { factor of wall } \\
\text { face toward the } \\
\text { VV. }\end{array}$ & $1 \mathrm{E}-12 / \mathrm{h}-\mathrm{m}$ & see text & $\begin{array}{l}\text { Rupture flow is } \\
\text { the entire rated } \\
\text { helium flow or } \\
\text { greater } \\
\text { (depressurization } \\
\text { flow from a large } \\
\text { opening). } \\
\text { Helium speed of } \\
\text { sound is high, so } \\
\text { flow will be high } \\
\text { into the vacuum. } \\
\text { Designers might } \\
\text { consider placing } \\
\text { limits on } \\
\text { allowable } \\
\text { makeup mass, let } \\
\text { plant operators } \\
\text { override limits if } \\
\text { the situation is } \\
\text { not a large } \\
\text { LOCA. }\end{array}$ \\
\hline
\end{tabular}




\begin{tabular}{|c|c|c|c|c|c|c|c|c|c|c|c|c|}
\hline Component & $\begin{array}{c}\text { Operational } \\
\text { State }\end{array}$ & Failure Mode & $\begin{array}{c}\text { Frequency } \\
\text { Category }\end{array}$ & Possible Causes & $\begin{array}{c}\text { Preventive } \\
\text { Action on } \\
\text { Possible Causes } \\
\end{array}$ & Consequences & $\begin{array}{c}\text { Corrective or } \\
\text { Preventive } \\
\text { Actions on } \\
\text { Consequences } \\
\end{array}$ & $\begin{array}{l}\text { ITER Postulated } \\
\text { Initiating Events }\end{array}$ & Comments & Frequency & $\begin{array}{c}\begin{array}{c}\text { Comment on } \\
\text { frequency } \\
\text { calculation }\end{array} \\
\end{array}$ & $\begin{array}{c}\begin{array}{c}\text { Design } \\
\text { comments }\end{array} \\
\end{array}$ \\
\hline & & $\begin{array}{l}\text { small leakage into } \\
\text { TBM }\end{array}$ & Category III & $\begin{array}{l}\text { material flaw or } \\
\text { defect (e.g., } \\
\text { pinhole leak), } \\
\text { thermal or } \\
\text { vibration fatigue }\end{array}$ & $\begin{array}{l}\text { NDT, pre-service } \\
\text { pressure test }\end{array}$ & $\begin{array}{l}\text { Very small helium } \\
\text { leak into Pb-17Li, } \\
\text { slightly } \\
\text { pressurizes the } \\
\text { liquid metal. } \\
\text { Helium should } \\
\text { evolve out of } \\
\text { liquid metal in } \\
\text { pump or } \\
\text { expansion tank. }\end{array}$ & $\begin{array}{l}\text { Continue to } \\
\text { operate TBM, } \\
\text { plan to repair leak } \\
\text { during next long } \\
\text { outage. }\end{array}$ & LBB3 & $\begin{array}{l}\text { Use } 105.7 \mathrm{~m} \text { of } \\
\text { tubing in the FW. } \\
\text { Use } 4032 \\
\text { operating hours } \\
\text { per year. Use } \\
25 \% \text { factor of wall } \\
\text { face toward the } \\
\text { TBM. }\end{array}$ & $2 \mathrm{E}-10 / \mathrm{h}-\mathrm{m}$ & analyst judgment & $\begin{array}{l}\text { Very small } \\
\text { helium leaks are } \\
\text { difficult to sense } \\
\text { with the usual } \\
\text { sensors (T, } \mathrm{P}, \\
\text { flow). The } \mathrm{Pb}- \\
\text { 17Li pressure } \\
\text { will increase with } \\
\text { helium inflow. } \\
\text { The Pb-17Li } \\
\text { operates at } 2 \\
\text { MPa and the } \\
\text { rupture disk to } \\
\text { the drain tank } \\
\text { opens at } 3.5 \\
\text { MPa. Assume } \\
\text { small inleakage } \\
\text { does not elevate } \\
\text { Pb-17Li pressure } \\
\text { to any value } \\
\text { close to the } \\
\text { rupture disk } \\
\text { actuation point. } \\
\end{array}$ \\
\hline & & leakage into TBM & Category III & $\begin{array}{l}\text { material flaw or } \\
\text { defect (e.g., } \\
\text { pinhole leak), } \\
\text { thermal or } \\
\text { vibration fatigue }\end{array}$ & $\begin{array}{l}\text { NDT, pre-service } \\
\text { pressure test }\end{array}$ & $\begin{array}{l}\text { Large helium leak } \\
\text { into } \mathrm{Pb}-17 \mathrm{Li} \text {, } \\
\text { pressurizes the } \\
\text { liquid metal. }\end{array}$ & $\begin{array}{l}\text { Must begin an } \\
\text { orderly shut down } \\
\text { of ITER when } \\
\text { helium leak is } \\
\text { noted by Pb-17Li } \\
\text { pressure increase. }\end{array}$ & LBB2 & $\begin{array}{l}\text { Use } 105.7 \mathrm{~m} \text { of } \\
\text { tubing in the FW. } \\
\text { Use } 4032 \\
\text { operating hours } \\
\text { per year. Use } \\
25 \% \text { factor of wall } \\
\text { face toward the } \\
\text { TBM. } \\
\end{array}$ & $2 \mathrm{E}-11 / \mathrm{h}-\mathrm{m}$ & see text & \\
\hline & & rupture into TBM & $<$ Cat. IV & $\begin{array}{l}\text { tube wall } \\
\text { longitudinal crack, } \\
\text { wall failure }\end{array}$ & $\begin{array}{l}\text { NDT, pre-service } \\
\text { pressure test }\end{array}$ & $\begin{array}{l}\text { Large helium leak } \\
\text { into Pb-17Li. The } \\
\text { rupture disk to the } \\
\text { drain tank opens } \\
\text { rapidly. }\end{array}$ & $\begin{array}{l}\text { Must shut down } \\
\text { ITER as soon as } \\
\text { possible, the TBM } \\
\text { is losing all } \\
\text { cooling and could } \\
\text { overheat. }\end{array}$ & LBB1 & $\begin{array}{l}\text { Use } 105.7 \mathrm{~m} \text { of } \\
\text { tubing in the FW. } \\
\text { Use } 4032 \\
\text { operating hours } \\
\text { per year. Use } \\
25 \% \text { factor of wall } \\
\text { face toward the } \\
\text { TBM. }\end{array}$ & $1 \mathrm{E}-12 / \mathrm{h}-\mathrm{m}$ & see text & $\begin{array}{l}\text { Large helium } \\
\text { leak into } \mathrm{Pb}-17 \mathrm{Li} \\
\text { will } \\
\text { overpressurize it } \\
\text { and open the } \\
\text { rupture disk at } \\
3.5 \mathrm{MPa} \text {, } \\
\text { draining the } \mathrm{Pb}- \\
17 \mathrm{Li} \text { as the } \\
\text { helium } \\
\text { depressurizes. }\end{array}$ \\
\hline & & fouling & Category IV & $\begin{array}{l}\text { foreign material } \\
\text { intrusion and } \\
\text { buildup on tube } \\
\text { walls, moisture in } \\
\text { helium gas }\end{array}$ & $\begin{array}{l}\text { Helium purity } \\
\text { control, gas drying }\end{array}$ & $\begin{array}{l}\text { Gradual } \\
\text { degradation of } \\
\text { heat transfer to the } \\
\text { helium coolant }\end{array}$ & $\begin{array}{l}\text { Gradual heatup of } \\
\text { the TBM. Begin } \\
\text { an orderly } \\
\text { shutdown of ITER } \\
\text { when coolant } \\
\text { temperatures } \\
\text { increase. }\end{array}$ & FB2 & & $1 \mathrm{E}-04 / \mathrm{yr}$ & analyst judgment & $\begin{array}{l}\text { Helium systems } \\
\text { are reputed to be } \\
\text { very clean. } \\
\text { HTGRs have } \\
\text { only had graphite } \\
\text { dust and moisture } \\
\text { concerns. } \\
\text { Assume this is a } \\
\text { category IV } \\
\text { event. }\end{array}$ \\
\hline
\end{tabular}




\begin{tabular}{|c|c|c|c|c|c|c|c|c|c|c|c|c|}
\hline Component & $\begin{array}{l}\text { Operational } \\
\text { State }\end{array}$ & Failure Mode & $\begin{array}{l}\text { Frequency } \\
\text { Category }\end{array}$ & Possible Causes & $\begin{array}{c}\text { Preventive } \\
\text { Action on } \\
\text { Possible Causes }\end{array}$ & Consequences & $\begin{array}{c}\text { Corrective or } \\
\text { Preventive } \\
\text { Actions on } \\
\text { Consequences }\end{array}$ & $\begin{array}{l}\text { ITER Postulated } \\
\text { Initiating Events }\end{array}$ & Comments & Frequency & $\begin{array}{c}\text { Comment on } \\
\text { frequency } \\
\text { calculation }\end{array}$ & $\begin{array}{c}\begin{array}{c}\text { Design } \\
\text { comments }\end{array} \\
\end{array}$ \\
\hline & & flow blockage & Category IV & $\begin{array}{l}\text { construction or } \\
\text { maintenance } \\
\text { debris blocks flow }\end{array}$ & $\begin{array}{l}\text { Comprehensive } \\
\text { system } \\
\text { commissioning, } \\
\text { flow test before } \\
\text { each operating } \\
\text { period. }\end{array}$ & $\begin{array}{l}\text { Localized loss of } \\
\text { helium flow in } \\
\text { TBM. This may } \\
\text { not be sensed by } \\
\text { instrumentation. }\end{array}$ & $\begin{array}{l}\text { Must begin an } \\
\text { orderly shut down } \\
\text { of ITER when } \\
\text { TBM temperature } \\
\text { begins to increase. }\end{array}$ & FB2 & & $9 \mathrm{E}-05 / \mathrm{yr}$ & $\begin{array}{l}\text { Analyst judgment } \\
\text { based on HFIR } \\
\text { PRA analyses }\end{array}$ & $\begin{array}{l}\text { Water cooled } \\
\text { systems have had } \\
\text { screws, bolts, } \\
\text { bearings, gasket } \\
\text { pieces, weld slag, } \\
\text { rust particles, } \\
\text { etc., in the piping } \\
\text { system. } \\
\text { Personnel have } \\
\text { left pencils, rags, } \\
\text { tools, and other } \\
\text { debris. High } \\
\text { Flux Isotope } \\
\text { Reactor PRA, } \\
\text { PLG-0604, } 1988 \text {. }\end{array}$ \\
\hline & & $\begin{array}{l}\text { external rupture } \\
\text { from missile }\end{array}$ & Category IV & $\begin{array}{l}\text { Loose ferro- } \\
\text { magnetic objects } \\
\text { in ITER, I.e., } \\
\text { bolts, antenna } \\
\text { pieces, diagnostic } \\
\text { pieces }\end{array}$ & $\begin{array}{l}\text { Routine camera } \\
\text { inspection of VV } \\
\text { interior, and good } \\
\text { house-keeping }\end{array}$ & $\begin{array}{l}\text { Impact tears open } \\
\text { TBM first wall } \\
\text { tube, large helium } \\
\text { leak into vacuum } \\
\text { vessel. If object } \\
\text { does not cause } \\
\text { plasma disuption, } \\
\text { helium will. }\end{array}$ & $\begin{array}{l}\text { Maintain Pb-17Li } \\
\text { coolant flow to } \\
\text { TBM to remove } \\
\text { heat. Isolate } \\
\text { helium makeup } \\
\text { system to reduce } \\
\text { flow into VV. }\end{array}$ & LBV1 & $\begin{array}{l}\text { Any in-vessel } \\
\text { ferromagnetic } \\
\text { object propelled } \\
\text { by tokamak } \\
\text { magnetic fields } \\
\text { would likely } \\
\text { travel toward the } \\
\text { inboard wall, not } \\
\text { the outboard wall } \\
\text { where the TBM is } \\
\text { located }\end{array}$ & $<0.0001$ per year & analyst judgment & $\begin{array}{l}\text { Ferromagnetic } \\
\text { objects are } \\
\text { always } \\
\text { accelerated } \\
\text { toward higher } \\
\text { magnetic fields, } \\
\text { and moving } \\
\text { inboard on a } \\
\text { tokamak is } \\
\text { certainly the } \\
\text { higher field. The } \\
\text { toroidal field is } \\
\text { stronger than the } \\
\text { poloidal field and } \\
\text { is proportional to } \\
1 / \mathrm{r} \text { in the interior } \\
\text { of the vacuum } \\
\text { vessel. Analyst } \\
\text { jugment is } \\
\text { highly unlikely } \\
\text { event, Category } \\
\text { IV }\end{array}$ \\
\hline & & $\begin{array}{l}\text { external rupture } \\
\text { from plasma } \\
\text { effects }\end{array}$ & Category II & $\begin{array}{l}\text { Plasma disruption } \\
\text { impinges on TBM } \\
\text { face, localized } \\
\text { overheating by } \\
\text { runaway } \\
\text { electrons, arc from } \\
\text { halo current, } \\
\text { MARFE, type I } \\
\text { ELM, etc. }\end{array}$ & $\begin{array}{l}\text { Good planning of } \\
\text { plasma operations, } \\
\text { good control of } \\
\text { plasma, disruption } \\
\text { avoidance }\end{array}$ & $\begin{array}{l}\text { Overheat leads to } \\
\text { overstress and } \\
\text { surface melting } \\
\text { opens TBM first } \\
\text { wall tube, large } \\
\text { helium leak into } \\
\text { vacuum vessel. }\end{array}$ & $\begin{array}{l}\text { Maintain } \mathrm{Pb}-17 \mathrm{Li} \\
\text { coolant flow to } \\
\text { TBM to remove } \\
\text { heat. Isolate } \\
\text { helium makeup } \\
\text { system to reduce } \\
\text { flow into VV. }\end{array}$ & LBV1 & & $1.2 \mathrm{E}-02 / \mathrm{yr}$ & $\begin{array}{l}\text { analyst judgment, } \\
\text { see text for } \\
\text { description }\end{array}$ & \begin{tabular}{|l|} 
This is a highly \\
tentative \\
assumption of the \\
plasma \\
disruption effects \\
from a very \\
intense \\
disruption event.
\end{tabular} \\
\hline
\end{tabular}




\begin{tabular}{|c|c|c|c|c|c|c|c|c|c|c|c|c|}
\hline Component & $\begin{array}{c}\text { Operational } \\
\text { State }\end{array}$ & Failure Mode & $\begin{array}{c}\text { Frequency } \\
\text { Category }\end{array}$ & Possible Causes & $\begin{array}{c}\text { Preventive } \\
\text { Action on } \\
\text { Possible Causes }\end{array}$ & Consequences & $\begin{array}{l}\text { Corrective or } \\
\text { Preventive } \\
\text { Actions on } \\
\text { Consequences } \\
\end{array}$ & $\begin{array}{l}\text { ITER Postulated } \\
\text { Initiating Events }\end{array}$ & Comments & Frequency & $\begin{array}{c}\text { Comment on } \\
\text { frequency } \\
\text { calculation }\end{array}$ & $\begin{array}{c}\begin{array}{c}\text { Design } \\
\text { comments }\end{array} \\
\end{array}$ \\
\hline $\begin{array}{l}\text { Beryllium coating } \\
\text { on first wall } \\
\text { assembly (tube } \\
\text { faces) }\end{array}$ & NO & debonding & Category I & $\begin{array}{l}\text { Bond failure, } \\
\text { overheating from } \\
\text { plasma causes } \\
\text { melting }\end{array}$ & $\begin{array}{l}\text { Good bonding } \\
\text { practices, cautious } \\
\text { approach to } \\
\text { plasma operations }\end{array}$ & $\begin{array}{l}\text { Assume that Be } \\
\text { poison in plasma } \\
\text { results in a plasma } \\
\text { dissuption. } \\
\text { Disruption } \\
\text { severity is not } \\
\text { known. Over } 30 \mathrm{~g} \\
\text { into plasma can } \\
\text { result in a strong } \\
\text { disruption. }\end{array}$ & $\begin{array}{l}\text { Maintain flows to } \\
\text { TBM. Beryllium } \\
\text { may need to be } \\
\text { replaced or } \\
\text { repaired if tubes } \\
\text { are exposed. }\end{array}$ & Not an IE & $\begin{array}{l}\text { While the TBM } \\
\text { design assumes } \\
\text { loss of Be results } \\
\text { in a disruption, } \\
\text { evidence from } \\
\text { JET-droplets of } \\
\text { Be entering the } \\
\text { plasma has not } \\
\text { resulted in } \\
\text { disruptions } \\
\text { (Loarte 2005). }\end{array}$ & $\begin{array}{l}5.8 \mathrm{E}-05 / \mathrm{ITER} \\
\text { pulse }\end{array}$ & $\begin{array}{l}\text { Value based on e- } \\
\text { beam testing }\end{array}$ & $\begin{array}{l}\text { Castro's work on } \\
\text { plasma sprayed } \\
\text { Be has shown } \\
\text { good bond } \\
\text { reliability until } \\
\text { the heat flux } \\
\text { increases } \\
\text { substantially ( } 3 \mathrm{x} \\
\text { to } 5 \mathrm{x} \text { greater than } \\
\text { planned). Castro } \\
\text { work has given a } \\
\text { failure rate of } \\
5.8 \mathrm{E}-05 \\
\text { debondings per } \\
\text { pulse at } \\
\text { conditions } \\
\text { greater than the } \\
\text { planned TBM } \\
\text { conditions. } \\
\text { Using this value } \\
\text { with } 3000 \text { pulses } \\
\text { per year is } 0.17 \text {, a } \\
\text { Category } \mathrm{I} \text { event. }\end{array}$ \\
\hline $\begin{array}{l}\text { Top plate } \\
\text { assembly, same } \\
\text { entries for bottom } \\
\text { plate assembly }\end{array}$ & NO & deformation & Category IV & $\begin{array}{l}\text { thermal } \\
\text { overstress, } \\
\text { warping }\end{array}$ & $\begin{array}{l}\text { Good design } \\
\text { practices, verify } \\
\text { proper flow at } \\
\text { temperature }\end{array}$ & $\begin{array}{l}\text { Top plate } \\
\text { deformation is } \\
\text { assumed to greatly } \\
\text { constrict helium } \\
\text { flow within top } \\
\text { plate. Dual } \\
\text { deformation (rare } \\
\text { event) into flow } \\
\text { area results in } \\
\text { decreased Pb-17Li } \\
\text { flow by } \\
\text { constriction and } \\
\text { potential cracking } \\
\text { of SiC FCI's that } \\
\text { leads to flow } \\
\text { stagnation by } \\
\text { MHD forces. }\end{array}$ & $\begin{array}{l}\text { Maintain helium } \\
\text { coolant flow to } \\
\text { TBM as well as } \\
\text { possible to } \\
\text { remove heat. Shut } \\
\text { down ITER to } \\
\text { replace the } \\
\text { module box. }\end{array}$ & FB2 & $\begin{array}{l}\text { Deformation } \\
\text { could include } \\
\text { irradiation- } \\
\text { induced swelling, } \\
\text { creep, or bowing. } \\
\text { Typically, ferritic } \\
\text { steels have low } \\
\text { swelling and low } \\
\text { creep. TBMs } \\
\text { have a 10,000 } \\
\text { operating hour } \\
\text { lifetime (Wong } \\
\text { 2005), so these } \\
\text { long term } \\
\text { processes should } \\
\text { not be a } \\
\text { significant factor. }\end{array}$ & $1 \mathrm{E}-09$ /hour & analyst judgment & $\begin{array}{l}\text { Based on Carter, } \\
\text { "Mechanical } \\
\text { Reliability", } \\
\text { second edition, } \\
\text { John Wiley, New } \\
\text { York 1986, page } \\
177 \text {, mechanical } \\
\text { components can } \\
\text { achieve an } \\
\text { overall failure } \\
\text { rate of } \\
1 \mathrm{E}-08 \text { hour, and } \\
\text { a plate is a } \\
\text { simple } \\
\text { component. Use } \\
0.1 * 1 \mathrm{E}-08 / \mathrm{h} \text { for } \\
\text { dual plate failure. } \\
\text { Assume } 50 \% \text { of } \\
\text { failure rate is for } \\
\text { mechanical stress } \\
\text { failures, } 50 \% \text { is } \\
\text { for cracks or } \\
\text { other } \\
\text { metallurgical } \\
\text { failures. }\end{array}$ \\
\hline
\end{tabular}




\begin{tabular}{|c|c|c|c|c|c|c|c|c|c|c|c|c|}
\hline Component & $\begin{array}{c}\text { Operational } \\
\text { State }\end{array}$ & Failure Mode & $\begin{array}{c}\text { Frequency } \\
\text { Category }\end{array}$ & Possible Causes & $\begin{array}{c}\text { Preventive } \\
\text { Action on } \\
\text { Possible Causes }\end{array}$ & Consequences & $\begin{array}{l}\text { Corrective or } \\
\text { Preventive } \\
\text { Actions on } \\
\text { Consequences }\end{array}$ & $\begin{array}{l}\text { ITER Postulated } \\
\text { Initiating Events }\end{array}$ & Comments & Frequency & $\begin{array}{l}\text { Comment on } \\
\text { frequency } \\
\text { calculation }\end{array}$ & $\begin{array}{c}\text { Design } \\
\text { comments }\end{array}$ \\
\hline & & external leakage & Category III & $\begin{array}{l}\text { material flaw, } \\
\text { crack, bond fault, } \\
\text { erosive wear }\end{array}$ & $\begin{array}{l}\text { NDT, good design } \\
\text { and construction } \\
\text { practices }\end{array}$ & $\begin{array}{l}\text { Leak helium at } 8 \\
\text { MPa into VV. }\end{array}$ & $\begin{array}{l}\text { Can continue to } \\
\text { operate ITER and } \\
\text { TBM if helium } \\
\text { spill is small and } \\
\text { not contaminating } \\
\text { the plasma. } \\
\text { Larger leaks (such } \\
\text { as } 1 \% \text { of helium } \\
\text { flow rate) will } \\
\text { cause a disruption } \\
\text { or otherwise } \\
\text { require ITER } \\
\text { shutdown. }\end{array}$ & LBV2 & & $8.7 \mathrm{E}-04 / \mathrm{yr}$ & analyst judgment & $\begin{array}{l}\text { Top plate bond } \\
\text { and plate cracks } \\
\text { will result in } \\
\text { leakage failures. } \\
\text { Plate cracks are } \\
50 \% \text { of } 1 \mathrm{E}-08 / \mathrm{h} \\
\text { or } 2 \mathrm{E}-05 / \mathrm{yr} \text {. } \\
\text { Bond failure is } \\
\text { along the edge of } \\
\text { the plate, } 2(0.645 \\
\mathrm{m}+0.413 \mathrm{~m})= \\
2.12 \mathrm{~m} \text { bond } \\
\text { distance, } 4032 \\
\mathrm{~h} / \mathrm{yr} \text {, at } \\
1 \mathrm{E}-07 / \mathrm{m}-\mathrm{h} \text { gives } \\
8.5 \mathrm{E}-04 / \mathrm{yr}\end{array}$ \\
\hline & & external rupture & Category IV & $\begin{array}{l}\text { material failure, } \\
\text { large crack, bond } \\
\text { failure }\end{array}$ & $\begin{array}{l}\text { NDT, good design } \\
\text { and construction } \\
\text { practices }\end{array}$ & $\begin{array}{l}\text { Large leak helium } \\
\text { at } 8 \mathrm{MPa} \text { into VV. }\end{array}$ & $\begin{array}{l}\text { Helium ingress } \\
\text { will cause plasma } \\
\text { disruption. Shut } \\
\text { down ITER to } \\
\text { remove heat from } \\
\text { TBM FW. }\end{array}$ & LBV1 & $\begin{array}{l}\text { Following Buende } \\
\text { (1991) } \\
\text { recommendation, } \\
\text { a bond rupture is } \\
0.1 \mathrm{x} \text { of a leak. } \\
\text { Assume that plate } \\
\text { large crack or } \\
\text { catastrophic } \\
\text { failure is } 0.1 \text { xplate } \\
\text { failure rate. }\end{array}$ & $8.7 \mathrm{E}-05 / \mathrm{yr}$ & analyst judgment & \\
\hline & & flow blockage & Category IV & $\begin{array}{l}\text { construction or } \\
\text { maintenance } \\
\text { debris blocks flow }\end{array}$ & $\begin{array}{l}\text { Comprehensive } \\
\text { system } \\
\text { commissioning, } \\
\text { flow test before } \\
\text { each operating } \\
\text { period. }\end{array}$ & $\begin{array}{l}\text { Localized loss of } \\
\text { helium flow in } \\
\text { TBM. This may } \\
\text { not be sensed by } \\
\text { instrumentation. }\end{array}$ & $\begin{array}{l}\text { Must begin an } \\
\text { orderly shut down } \\
\text { of ITER when } \\
\text { TBM temperature } \\
\text { begins to increase. }\end{array}$ & FB2 & $\begin{array}{l}\text { Helium flow in } \\
\text { the plate may } \\
\text { redistribute } \\
\text { around a flow } \\
\text { blockage. }\end{array}$ & $9 \mathrm{E}-05 / \mathrm{yr}$ & $\begin{array}{l}\text { Analyst judgment } \\
\text { based on HFIR } \\
\text { PRA analyses }\end{array}$ & $\begin{array}{l}\text { Water cooled } \\
\text { systems have had } \\
\text { screws, bolts, } \\
\text { bearings, gasket } \\
\text { pieces, weld slag, } \\
\text { rust particles, } \\
\text { etc., in the piping } \\
\text { system. } \\
\text { Personnel have } \\
\text { left pencils, rags, } \\
\text { tools, and other } \\
\text { debris. High } \\
\text { Flux Isotope } \\
\text { Reactor PRA, } \\
\text { PLG-0604, } 1988 .\end{array}$ \\
\hline & & fouling & Category IV & $\begin{array}{l}\text { foreign material } \\
\text { intrusion and } \\
\text { buildup on tube } \\
\text { walls, moisture in } \\
\text { helium gas }\end{array}$ & $\begin{array}{l}\text { Helium purity } \\
\text { control, gas drying }\end{array}$ & $\begin{array}{l}\text { Gradual } \\
\text { degradation of } \\
\text { heat transfer to the } \\
\text { helium coolant }\end{array}$ & $\begin{array}{l}\text { Gradual heatup of } \\
\text { the TBM. Begin } \\
\text { an orderly } \\
\text { shutdown of ITER } \\
\text { when coolant } \\
\text { temperatures } \\
\text { increase. }\end{array}$ & FB2 & & $1 \mathrm{E}-04 / \mathrm{yr}$ & analyst judgment & $\begin{array}{l}\text { Helium systems } \\
\text { are reputed to be } \\
\text { very clean. } \\
\text { HTGRs have } \\
\text { only had graphite } \\
\text { dust and moisture } \\
\text { concerns. } \\
\text { Assume this is a } \\
\text { category IV } \\
\text { event. }\end{array}$ \\
\hline
\end{tabular}




\begin{tabular}{|c|c|c|c|c|c|c|c|c|c|c|c|c|}
\hline Component & $\begin{array}{c}\text { Operational } \\
\text { State }\end{array}$ & Failure Mode & $\begin{array}{c}\text { Frequency } \\
\text { Category }\end{array}$ & Possible Causes & $\begin{array}{c}\text { Preventive } \\
\text { Action on } \\
\text { Possible Causes } \\
\end{array}$ & Consequences & \begin{tabular}{|c} 
Corrective or \\
Preventive \\
Actions on \\
Consequences \\
\end{tabular} & $\begin{array}{l}\text { ITER Postulated } \\
\text { Initiating Events }\end{array}$ & Comments & Frequency & $\begin{array}{c}\begin{array}{c}\text { Comment on } \\
\text { frequency } \\
\text { calculation }\end{array} \\
\end{array}$ & $\begin{array}{c}\text { Design } \\
\text { comments }\end{array}$ \\
\hline & & $\begin{array}{l}\text { internal leakage } \\
\text { into TBM box }\end{array}$ & Category III & $\begin{array}{l}\text { material flaw or } \\
\text { defect (e.g., } \\
\text { pinhole leak), } \\
\text { plate thermal or } \\
\text { vibration fatigue }\end{array}$ & \begin{tabular}{|l}
$\begin{array}{l}\text { NDT, pre-service } \\
\text { pressure test }\end{array}$ \\
\end{tabular} & $\begin{array}{l}\text { Helium leak into } \\
\mathrm{Pb}-17 \mathrm{Li} \text {, } \\
\text { pressurizes the } \\
\text { liquid metal. }\end{array}$ & $\begin{array}{l}\text { Must begin an } \\
\text { orderly shut down } \\
\text { of ITER when } \\
\text { helium leak is } \\
\text { noted by Pb-17Li } \\
\text { pressure increase. }\end{array}$ & LBB2 & & $9 \mathrm{E}-04 / \mathrm{yr}$ & analyst judgment & $\begin{array}{l}\text { Top plate bond } \\
\text { and plate cracks } \\
\text { will result in } \\
\text { leakage failures. } \\
\text { Plate cracks are } \\
5 \mathrm{E}-09 / \mathrm{h} \text {. Bond } \\
\text { failure is along } \\
\text { the edge of the } \\
\text { plate, } 2(0.645 \mathrm{~m} \\
+0.413 \mathrm{~m})=2.12 \\
\mathrm{~m} \text { bond distance, } \\
4032 \mathrm{~h} / \mathrm{yr} \text {, at } \\
1 \mathrm{E}-07 / \mathrm{m}-\mathrm{h} \text { gives } \\
8.5 \mathrm{E}-04 / \mathrm{yr}\end{array}$ \\
\hline & & $\begin{array}{l}\text { internal rupture } \\
\text { into TBM box }\end{array}$ & Category IV & $\begin{array}{l}\text { metal flaw, } \\
\text { cracking, } \\
\text { overstress failure }\end{array}$ & $\begin{array}{l}\text { NDT, pre-service } \\
\text { pressure test }\end{array}$ & $\begin{array}{l}\text { Large helium leak } \\
\text { into Pb-17Li. The } \\
\text { rupture disk to the } \\
\text { drain tank opens } \\
\text { rapidly. }\end{array}$ & $\begin{array}{l}\text { Must shut down } \\
\text { ITER as soon as } \\
\text { possible, the TBM } \\
\text { is losing all } \\
\text { cooling and could } \\
\text { overheat. }\end{array}$ & LBB1 & $\begin{array}{l}\text { Following Buende } \\
\text { recommendation, } \\
\text { a bond rupture } \\
\text { rate is } 10 \% \text { of a } \\
\text { leak rate. Also } \\
\text { assume that a } \\
\text { plate catastrophic } \\
\text { mechanical failure } \\
\text { is } 10 \% \text { of the plate } \\
\text { failure rate. }\end{array}$ & $9 \mathrm{E}-05 / \mathrm{yr}$ & analyst judgment & $\begin{array}{l}\text { Top plate bond } \\
\text { and plate cracks } \\
\text { will result in } \\
\text { leakage failures. } \\
\text { Plate ruptures are } \\
\text { taken to be } \\
5 \mathrm{E}-10 / \mathrm{h} \text {. Bond } \\
\text { failure is along } \\
\text { the edge of the } \\
\text { plate, } 2(0.645 \mathrm{~m} \\
+0.413 \mathrm{~m})=2.12 \\
\mathrm{~m} \text { bond distance, } \\
4032 \mathrm{~h} / \mathrm{yr} \text {, at } \\
1 \mathrm{E}-08 / \mathrm{m}-\mathrm{h} \text { gives } \\
8.5 \mathrm{E}-05 / \mathrm{yr}\end{array}$ \\
\hline
\end{tabular}




\begin{tabular}{|c|c|c|c|c|c|c|c|c|c|c|c|c|}
\hline Component & $\begin{array}{c}\text { Operational } \\
\text { State }\end{array}$ & Failure Mode & $\begin{array}{c}\text { Frequency } \\
\text { Category }\end{array}$ & Possible Causes & $\begin{array}{c}\text { Preventive } \\
\text { Action on } \\
\text { Possible Causes }\end{array}$ & Consequences & $\begin{array}{c}\text { Corrective or } \\
\text { Preventive } \\
\text { Actions on } \\
\text { Consequences }\end{array}$ & $\begin{array}{l}\text { ITER Postulated } \\
\text { Initiating Events }\end{array}$ & Comments & Frequency & $\begin{array}{c}\text { Comment on } \\
\text { frequency } \\
\text { calculation }\end{array}$ & $\begin{array}{c}\text { Design } \\
\text { comments }\end{array}$ \\
\hline & & $\begin{array}{l}\text { internal leakage } \\
\text { within plate } \\
\text { assembly }\end{array}$ & Category III & $\begin{array}{l}\text { material flaw or } \\
\text { defect (e.g., } \\
\text { pinhole leak), } \\
\text { plate fin thermal } \\
\text { or vibration } \\
\text { fatigue }\end{array}$ & \begin{tabular}{|l|}
$\begin{array}{l}\text { NDT, pre-service } \\
\text { pressure test }\end{array}$ \\
\end{tabular} & $\begin{array}{l}\text { Helium lateral } \\
\text { leakage within } \\
\text { plate must still } \\
\text { enter one of the } \\
\text { two grid plates to } \\
\text { leave the top } \\
\text { plate. Some } \\
\text { cooling might be } \\
\text { reduced in some } \\
\text { parts of the plate. }\end{array}$ & $\begin{array}{l}\text { Effects are judged } \\
\text { to be minor, not a } \\
\text { problem to } \\
\text { operate the TBM }\end{array}$ & \begin{tabular}{|l|} 
Not an IE \\
\end{tabular} & $\begin{array}{l}\text { Helium will } \\
\text { continue to flow } \\
\text { through the plate } \\
\text { assembly, and } \\
\text { judgment is } \\
\text { mostly adequate } \\
\text { cooling to avoid } \\
\text { plate deformation. }\end{array}$ & $1 \mathrm{E}-07 / \mathrm{h}$ & analyst judgment & $\begin{array}{l}\text { Twenty one fins, } \\
\text { each } \approx 0.4 \mathrm{~m} \\
\text { long. A steam } \\
\text { turbine has stator } \\
\text { blades to direct } \\
\text { steam. For a } \\
\text { high pressure } \\
\text { superheated } \\
\text { steam turbine, } \\
\text { there could be } 48 \\
\text { blades per row } \\
\text { and } 15 \text { rows. } \\
\text { EPRI-AP-2071 } \\
\text { gave a steam } \\
\text { turbine failure } \\
\text { rate of } \\
1.83 \mathrm{E}-04 / \mathrm{h} \text {, and } \\
1.81 \% \text { of faults } \\
\text { involve blades, } \\
\text { or a failure rate } \\
\text { of } 3.3 \mathrm{E}-06 / \mathrm{h} \text { for } \\
\text { blades. } \\
\text { Representative } \\
\text { high pressure } \\
\text { turbine is } 48 \\
\text { blades } / \text { row } x 15 \\
\text { rows is } 720 \\
\text { blades, or } \\
4.6 \mathrm{E}-09 / \text { /alde- } \\
\text { hour. For } 21 \\
\text { fins, that would } \\
\text { be } 1 \mathrm{E}-07 / \text { fin- } \\
\text { hour. }\end{array}$ \\
\hline & & $\begin{array}{l}\text { internal rupture } \\
\text { within plate } \\
\text { assembly }\end{array}$ & Category III & $\begin{array}{l}\text { metal flaw, } \\
\text { cracking, } \\
\text { overstress failure }\end{array}$ & $\begin{array}{l}\text { NDT, pre-service } \\
\text { pressure test }\end{array}$ & $\begin{array}{l}\text { Helium lateral } \\
\text { flow in the plate } \\
\text { must still enter } \\
\text { one of the two } \\
\text { grid plates to } \\
\text { leave the top or } \\
\text { bottom plate. }\end{array}$ & \begin{tabular}{|l|} 
Effects could \\
result in thermal \\
overstress, \\
warping and \\
deformation of the \\
plate.
\end{tabular} & FB2 & & $1 \mathrm{E}-08 / \mathrm{h}$ & analyst judgment & $\begin{array}{l}\text { Assume rupture } \\
\text { is } 0.1 \mathrm{x} \text { of leakage }\end{array}$ \\
\hline
\end{tabular}




\begin{tabular}{|c|c|c|c|c|c|c|c|c|c|c|c|c|}
\hline Component & $\begin{array}{c}\text { Operational } \\
\text { State }\end{array}$ & Failure Mode & $\begin{array}{l}\text { Frequency } \\
\text { Category }\end{array}$ & Possible Causes & $\begin{array}{c}\text { Preventive } \\
\text { Action on } \\
\text { Possible Causes }\end{array}$ & Consequences & $\begin{array}{l}\text { Corrective or } \\
\text { Preventive } \\
\text { Actions on } \\
\text { Consequences }\end{array}$ & $\begin{array}{l}\text { ITER Postulated } \\
\text { Initiating Events }\end{array}$ & Comments & Frequency & $\begin{array}{l}\text { Comment on } \\
\text { frequency } \\
\text { calculation }\end{array}$ & $\begin{array}{c}\text { Design } \\
\text { comments }\end{array}$ \\
\hline \multirow[t]{3}{*}{$\begin{array}{l}\text { Center divider } \\
\text { "cross" and "end" } \\
\text { grid plate } \\
\text { assemblies that } \\
\text { support FCIs }\end{array}$} & NO & deformation & Category IV & $\begin{array}{l}\text { thermal } \\
\text { overstress, } \\
\text { warping }\end{array}$ & $\begin{array}{l}\text { Good design } \\
\text { practices, verify } \\
\text { proper flow at } \\
\text { temperature }\end{array}$ & $\begin{array}{l}\text { Constrict or block } \\
\mathrm{Pb}-17 \mathrm{Li} \text { flow } \\
\text { channel in TBM, } \\
\text { stress from } \\
\text { deformed plate is } \\
\text { assumed to fail the } \\
\text { flow channel } \\
\text { insert so } \mathrm{Pb}-17 \mathrm{Li} \\
\text { flow is retarded by } \\
\text { MHD forces. }\end{array}$ & $\begin{array}{l}\text { Drain Pb-17Li to } \\
\text { drain tank. Can } \\
\text { continue to } \\
\text { operate TBM if } \\
\text { helium coolant is } \\
\text { available. }\end{array}$ & Not an IE & $\begin{array}{l}\text { Since the grid } \\
\text { plates are helium } \\
\text { cooled, use the } \\
\text { helium operating } \\
\text { hours for this } \\
\text { component, } 4,032 \\
\text { h/yr }\end{array}$ & $1 \mathrm{E}-09 / \mathrm{h}$ & analyst judgment & $\begin{array}{l}\text { Rather than } \\
\text { assuming } \\
\text { independent } \\
\text { walls of the grid } \\
\text { plate must both } \\
\text { fail (i.e., plate } 1 \\
\text { failure } \\
\text { probability x } \\
\text { plate } 2 \text { failure } \\
\text { probability), it is } \\
\text { assumed here } \\
\text { that similar } \\
\text { failure } \\
\text { mechanisms or } \\
\text { stresses would } \\
\text { attack or act } \\
\text { upon both plates, } \\
\text { so a common } \\
\text { mode failure rate } \\
\text { multiplier of } \\
0.1 \text { (plate } 1 \\
\text { failure rate of } \\
1 \mathrm{E}-08 / \mathrm{h} \text { ) is used } \\
\text { for deformation } \\
\text { of both walls of } \\
\text { the grid plate. }\end{array}$ \\
\hline & & $\begin{array}{l}\text { internal leakage } \\
\text { past fins }\end{array}$ & Category III & $\begin{array}{l}\text { material flaw, } \\
\text { crack, bond failure }\end{array}$ & $\begin{array}{l}\text { NDT, good design } \\
\text { and construction } \\
\text { practices }\end{array}$ & $\begin{array}{l}\text { Helium could leak } \\
\text { within the grid } \\
\text { plate and not } \\
\text { remove heat } \\
\text { uniformly. } \\
\text { Differential } \\
\text { thermal expansion } \\
\text { of the grid plate. }\end{array}$ & $\begin{array}{l}\text { Prudent to drain } \\
\text { Pb-17Li to the } \\
\text { drain tank. Can } \\
\text { operate TBM with } \\
\text { helium coolant } \\
\text { available. }\end{array}$ & Not an IE & $\begin{array}{l}\text { Internal leak is } \\
\text { still routed } \\
\text { through the grid } \\
\text { plate, toward } \\
\text { lower pressure, so } \\
\text { the reduction in } \\
\text { cooling is } \\
\text { believed to be } \\
\text { minor. }\end{array}$ & $1 \mathrm{E}-07 / \mathrm{h}$ & analyst judgment & $\begin{array}{l}\text { Judgment based } \\
\text { on top plate } \\
\text { information } \\
\text { above. }\end{array}$ \\
\hline & & $\begin{array}{l}\text { internal rupture of } \\
\text { fins }\end{array}$ & Category III & $\begin{array}{l}\text { material failure, } \\
\text { large crack, bond } \\
\text { failure }\end{array}$ & $\begin{array}{l}\text { NDT, good design } \\
\text { and construction } \\
\text { practices }\end{array}$ & $\begin{array}{l}\text { Helium flows } \\
\text { throughout the } \\
\text { grid plate without } \\
\text { channeling. } \\
\text { Assume this leads } \\
\text { to hot spot } \\
\text { formation on grid } \\
\text { plate walls, } \\
\text { overstressing the } \\
\text { grid plate. }\end{array}$ & $\begin{array}{l}\text { Prudent to drain } \\
\text { Pb-17Li to drain } \\
\text { tank. Can operate } \\
\text { TBM with helium } \\
\text { coolant available. }\end{array}$ & Not an IE & & $1 \mathrm{E}-08 / \mathrm{h}$ & analyst judgment & $\begin{array}{l}\text { Assume rupture } \\
\text { is } 10 \% \text { of the } \\
\text { leakage failure } \\
\text { rate. }\end{array}$ \\
\hline
\end{tabular}




\begin{tabular}{|c|c|c|c|c|c|c|c|c|c|c|c|c|}
\hline Component & $\begin{array}{c}\text { Operational } \\
\text { State }\end{array}$ & Failure Mode & $\begin{array}{c}\text { Frequency } \\
\text { Category }\end{array}$ & Possible Causes & $\begin{array}{c}\text { Preventive } \\
\text { Action on } \\
\text { Possible Causes } \\
\end{array}$ & Consequences & $\begin{array}{c}\text { Corrective or } \\
\text { Preventive } \\
\text { Actions on } \\
\text { Consequences }\end{array}$ & $\begin{array}{l}\text { ITER Postulated } \\
\text { Initiating Events }\end{array}$ & Comments & Frequency & $\begin{array}{c}\text { Comment on } \\
\text { frequency } \\
\text { calculation }\end{array}$ & $\begin{array}{c}\text { Design } \\
\text { comments }\end{array}$ \\
\hline & & external leakage & Category IV & $\begin{array}{l}\text { material flaw, } \\
\text { crack, bond failure }\end{array}$ & $\begin{array}{l}\text { NDT, good design } \\
\text { and construction } \\
\text { practices }\end{array}$ & $\begin{array}{l}\text { Helium leak into } \\
\text { module box. FCIs } \\
\text { could be hotter } \\
(650 \mathrm{C}) \text { than } \\
\text { helium }(460 \mathrm{C}), \\
\text { and slow helium } \\
\text { leak could warm } \\
\text { and build pressure } \\
\text { to fail the FCIs. }\end{array}$ & $\begin{array}{l}\text { Slowly pressurize } \\
\text { the TBM module } \\
\text { box. }\end{array}$ & LBB2 & $\begin{array}{l}\text { Losing small } \\
\text { amounts of helium } \\
\text { is not a cooling } \\
\text { concern, but } \\
\text { helium gas } \\
\text { buildup in the } \\
\text { TBM module box } \\
\text { could lead to } \\
\text { deformation of } \\
\text { plates in the box, } \\
\text { FCI failure, etc. } \\
\end{array}$ & $1 \mathrm{E}-08 / \mathrm{h}$ & analyst judgment & \\
\hline & & external rupture & Category IV & $\begin{array}{l}\text { material failure, } \\
\text { large crack, bond } \\
\text { failure }\end{array}$ & $\begin{array}{l}\text { NDT, good design } \\
\text { and construction } \\
\text { practices }\end{array}$ & $\begin{array}{l}\text { Helium large leak } \\
\text { into module box. } \\
\text { Helium pressure } \\
\text { release and grid } \\
\text { plate failure } \\
\text { energy are } \\
\text { expected to fail } \\
\text { FCIs, retarding } \\
\text { Pb-17Li flow. }\end{array}$ & $\begin{array}{l}\text { Losing both } \\
\text { helium and Pb- } \\
\text { 17Li cooling. } \\
\text { Must immediately } \\
\text { shut down TBM } \\
\text { and ITER. }\end{array}$ & LBB1 & $\begin{array}{l}\text { Losing a large } \\
\text { amount of helium } \\
\text { at } 8 \text { MPa into the } \\
\text { module box } \\
\text { reduces helium } \\
\text { cooling and } \\
\text { overstresses plates } \\
\text { in the box. }\end{array}$ & $1 \mathrm{E}-09 / \mathrm{h}$ & analyst judgment & $\begin{array}{l}\text { Assume a } \\
\text { catastrophic plate } \\
\text { failure rate is } \\
0.1 x \text { of a plate } \\
\text { crack failure rate }\end{array}$ \\
\hline & & fouling & Category IV & $\begin{array}{l}\text { foreign material } \\
\text { intrusion and } \\
\text { buildup on tube } \\
\text { walls, moisture in } \\
\text { helium gas }\end{array}$ & $\begin{array}{l}\text { Helium purity } \\
\text { control, gas drying }\end{array}$ & \begin{tabular}{|l|} 
Gradual \\
degradation of \\
heat transfer to the \\
helium coolant
\end{tabular} & $\begin{array}{l}\text { Gradual heatup of } \\
\text { the TBM. Begin } \\
\text { an orderly } \\
\text { shutdown of ITER } \\
\text { when coolant } \\
\text { temperatures } \\
\text { increase. }\end{array}$ & FB2 & & $1 \mathrm{E}-04 / \mathrm{yr}$ & analyst judgment & $\begin{array}{l}\text { Helium systems } \\
\text { are reputed to be } \\
\text { very clean. } \\
\text { HTGRs have } \\
\text { only had graphite } \\
\text { dust and moisture } \\
\text { concerns. } \\
\text { Assume this is a } \\
\text { category IV } \\
\text { event. }\end{array}$ \\
\hline & & flow blockage & Category IV & $\begin{array}{l}\text { construction or } \\
\text { maintenance } \\
\text { debris blocks flow }\end{array}$ & $\begin{array}{l}\text { Comprehensive } \\
\text { system } \\
\text { commissioning, } \\
\text { flow test before } \\
\text { each operating } \\
\text { period. }\end{array}$ & $\begin{array}{l}\text { Localized loss of } \\
\text { helium flow in } \\
\text { TBM. This may } \\
\text { not be sensed by } \\
\text { instrumentation. }\end{array}$ & $\begin{array}{l}\text { Must begin an } \\
\text { orderly shut down } \\
\text { of ITER when } \\
\text { TBM temperature } \\
\text { begins to increase. }\end{array}$ & FB2 & & $9 \mathrm{E}-05 / \mathrm{yr}$ & $\begin{array}{l}\text { Analyst judgment } \\
\text { based on HFIR } \\
\text { PRA analyses }\end{array}$ & $\begin{array}{l}\text { Water cooled } \\
\text { systems have had } \\
\text { screws, bolts, } \\
\text { bearings, gasket } \\
\text { pieces, weld slag } \\
\text { rust particles, } \\
\text { etc., in the piping } \\
\text { system. } \\
\text { Personnel have } \\
\text { left pencils, rags, } \\
\text { tools, and other } \\
\text { debris. High } \\
\text { Flux Isotope } \\
\text { Reactor PRA, } \\
\text { PLG-0604, 1988 }\end{array}$ \\
\hline
\end{tabular}




\begin{tabular}{|c|c|c|c|c|c|c|c|c|c|c|c|c|}
\hline Component & $\begin{array}{c}\begin{array}{c}\text { Operational } \\
\text { State }\end{array} \\
\end{array}$ & Failure Mode & $\begin{array}{c}\text { Frequency } \\
\text { Category }\end{array}$ & Possible Causes & $\begin{array}{c}\text { Preventive } \\
\text { Action on } \\
\text { Possible Causes } \\
\end{array}$ & Consequences & $\begin{array}{l}\text { Corrective or } \\
\text { Preventive } \\
\text { Actions on } \\
\text { Consequences } \\
\end{array}$ & $\begin{array}{l}\text { ITER Postulated } \\
\text { Initiating Events }\end{array}$ & Comments & Frequency & $\begin{array}{c}\text { Comment on } \\
\text { frequency } \\
\text { calculation }\end{array}$ & $\begin{array}{c}\begin{array}{c}\text { Design } \\
\text { comments }\end{array} \\
\end{array}$ \\
\hline $\begin{array}{l}\text { Silicon carbide } \\
\text { flow channel } \\
\text { inserts (FCIs), } \\
\text { three U-duct units }\end{array}$ & NO & loss of integrity & Category IV & $\begin{array}{l}\text { vibration induced } \\
\text { cracking, inherent } \\
\text { flaw induced } \\
\text { cracking, surface } \\
\text { wear flaw induced } \\
\text { cracking, fretting } \\
\text { cracking }\end{array}$ & $\begin{array}{l}\text { good material } \\
\text { selection, good } \\
\text { fabrication and } \\
\text { construction } \\
\text { practices }\end{array}$ & $\begin{array}{l}\mathrm{Pb}-17 \mathrm{Li} \text { exposed } \\
\text { to } \mathrm{MHD} \text { forces } \\
\text { that retard coolant } \\
\text { flow, } \mathrm{SiC} \text { pieces } \\
\text { intruding into } \mathrm{Pb}- \\
\text { 17Li cooling } \\
\text { system. }\end{array}$ & $\begin{array}{l}\text { Maintain helium } \\
\text { coolant flow to } \\
\text { TBM to remove } \\
\text { heat. Can } \\
\text { continue to } \\
\text { operate TBM with } \\
\text { helium cooling. }\end{array}$ & Not an IE & $\begin{array}{l}\text { If pieces of } \mathrm{SiC} \\
\text { spall or break off } \\
\text { of the } \mathrm{FCI} \text {, they } \\
\text { will travel around } \\
\text { the } \mathrm{Pb}-17 \mathrm{Li} \text { flow } \\
\text { loop, traversing } \\
\text { the tritium } \\
\text { permeator, heat } \\
\text { exchanger, and } \\
\text { pump. This } \\
\text { foreign material } \\
\text { could lead to } \\
\text { damage in these } \\
\text { components, } \\
\text { including wear } \\
\text { and scoring. }\end{array}$ & $1 \mathrm{E}-08 / \mathrm{h}$ & $\begin{array}{l}\text { analyst judgment, } \\
\text { see text }\end{array}$ & $\begin{array}{l}\text { Assume no } \\
\text { bending of brittle } \\
\text { ceramic material, } \\
\text { so no } \\
\text { deformation } \\
\text { failure mode is } \\
\text { attributable to the } \\
\text { SiC FCIs (other } \\
\text { parts can } \\
\text { overstress the } \\
\text { FCIs). Assume } \\
\text { no FCI } \\
\text { detachment from } \\
\text { walls unless the } \\
\text { material cracks. } \\
\text { After cracking, if } \\
\text { Pb-17Li flow is } \\
\text { retarded, the } \\
\text { liquid metal can } \\
\text { withstand high } \\
\text { heat until the } \\
\text { next plasma } \\
\text { downtime when } \\
\text { the Pb-17Li can } \\
\text { be drained to the } \\
\text { drain tank. Then } \\
\text { ITER operators } \\
\text { can continue to } \\
\text { run the TBM } \\
\text { without liquid } \\
\text { metal coolant. } \\
\end{array}$ \\
\hline $\begin{array}{l}\text { Support key, two } \\
\text { units }\end{array}$ & NO & deformation & & $\begin{array}{l}\text { thermal } \\
\text { overstress, } \\
\text { mechanical stress, } \\
\text { weld fault }\end{array}$ & $\begin{array}{l}\text { good design } \\
\text { practices }\end{array}$ & $\begin{array}{l}\text { TBM can slip, } \\
\text { possibly sag } \\
\text { against water } \\
\text { cooling frame. } \\
\text { Increased } \\
\text { vibration wear, } \\
\text { vibration on } \\
\text { structure reduces } \\
\text { lifetime. }\end{array}$ & $\begin{array}{l}\text { Can continue to } \\
\text { operate TBM until } \\
\text { repairs can be } \\
\text { made. }\end{array}$ & Not an IE & $\begin{array}{l}\text { TBM slightly } \\
\text { receding toward } \\
\text { VV wall will } \\
\text { present a frame } \\
\text { leading edge to } \\
\text { the plasma, but it } \\
\text { is not clear if this } \\
\text { small movement } \\
\text { is significant } \\
\text { enough to cause } \\
\text { damage. } \\
\end{array}$ & $1.5 \mathrm{E}-08 / \mathrm{h}$ & $\begin{array}{l}\text { analyst judgment, } \\
\text { based on metal } \\
\text { part fail rates }\end{array}$ & $\begin{array}{l}\text { Use an assumed } \\
3 \mathrm{E}-08 / \mathrm{h} \text { failure } \\
\text { rate with } 50 \% \\
\text { contribution of } \\
\text { deformation and } \\
50 \% \text { crack } \\
\text { failure. }\end{array}$ \\
\hline
\end{tabular}




\begin{tabular}{|c|c|c|c|c|c|c|c|c|c|c|c|c|}
\hline Component & $\begin{array}{c}\text { Operational } \\
\text { State }\end{array}$ & Failure Mode & $\begin{array}{c}\text { Frequency } \\
\text { Category }\end{array}$ & Possible Causes & $\begin{array}{c}\text { Preventive } \\
\text { Action on } \\
\text { Possible Causes }\end{array}$ & Consequences & \begin{tabular}{|c} 
Corrective or \\
Preventive \\
Actions on \\
Consequences \\
\end{tabular} & $\begin{array}{l}\text { ITER Postulated } \\
\text { Initiating Events }\end{array}$ & Comments & Frequency & $\begin{array}{c}\text { Comment on } \\
\text { frequency } \\
\text { calculation }\end{array}$ & $\begin{array}{c}\text { Design } \\
\text { comments }\end{array}$ \\
\hline & & fracture & & $\begin{array}{l}\text { material failure } \\
\text { (e.g., inclusions), } \\
\text { large crack }\end{array}$ & $\begin{array}{l}\text { NDT, good design } \\
\text { and construction } \\
\text { practices }\end{array}$ & $\begin{array}{l}\text { TBM moves out } \\
\text { of position, sags } \\
\text { onto water cooled } \\
\text { frame, stresses } \\
\text { pipe connections, } \\
\text { vibration wear. }\end{array}$ & $\begin{array}{l}\text { TBM should be } \\
\text { shut down to } \\
\text { preclude further } \\
\text { damage. }\end{array}$ & Not an IE & $\begin{array}{l}\text { High vibration can } \\
\text { reduce life of } \\
\text { TBM box and } \\
\text { pipe connections } \\
\text { to the box. } \\
\text { Assume that a } \\
\text { disruption after } \\
\text { key failure will } \\
\text { vibrate the module } \\
\text { box, but no } \\
\text { significant } \\
\text { damage. Assume } \\
\text { that a disruption } \\
\text { after support key } \\
\text { failure with } \\
\text { concomitant } \\
\text { support pin failure } \\
\text { will cause the } \\
\text { TBM to tear a } \\
\text { helium cooling } \\
\text { plate (top or } \\
\text { bottom). Piping is } \\
\text { judged to have } \\
\text { enough flexibility } \\
\text { that } 20 \text { mm } \\
\text { movement will } \\
\text { not fail it. }\end{array}$ & $1.5 \mathrm{E}-08 / \mathrm{h}$ & analyst judgment & $\begin{array}{l}\text { Assume that with } \\
\text { a failed support } \\
\text { key and a failed } \\
\text { support pin that } \\
\text { disruption EM } \\
\text { forces on the } \\
\text { TBM module } \\
\text { box will } \\
\text { overstress the } \\
\text { box and the pipe } \\
\text { connections to } \\
\text { the box. } 10 \% \text { of } \\
\text { ITER pulses end } \\
\text { in disruptions of } \\
\text { some kind }(\approx 1 \text { or } \\
2 \text { per pulse day). } \\
\text { Therefore, it is } \\
\text { assumed that if a } \\
\text { support pin and } \\
\text { key fails, the } \\
\text { TBM would fail } \\
\text { by disruption } \\
\text { forces the same } \\
\text { operating day. } \\
\text { Even though a } \\
\text { failure might be } \\
\text { difficult to } \\
\text { detect, a dual } \\
\text { failure of these } \\
\text { low failure rate } \\
\text { parts is a } \\
\text { Category IV } \\
\text { event. }\end{array}$ \\
\hline & & detachment & Category IV & weld failure & $\begin{array}{l}\text { NDT, good weld } \\
\text { practices }\end{array}$ & \begin{tabular}{|l|} 
TBM moves out \\
of position, sags \\
onto water cooled \\
frame, stresses \\
pipe connections, \\
vibration wear.
\end{tabular} & $\begin{array}{l}\text { TBM should be } \\
\text { shut down to } \\
\text { preclude further } \\
\text { damage. }\end{array}$ & Not an IE & \begin{tabular}{|l} 
High vibration can \\
reduce life of \\
TBM box and \\
pipe connections \\
to the box. \\
Assume that the \\
first plasma \\
disruption after \\
support key \\
failure with \\
concomitant \\
support pin failure \\
will cause the \\
TBM to tear a \\
helium cooling \\
plate. See above \\
description.
\end{tabular} & $6 \mathrm{E}-09 / \mathrm{h}$ & analyst judgment & $\begin{array}{l}\text { Use a butt weld } \\
\text { value from } \\
\text { Buende (1991). }\end{array}$ \\
\hline
\end{tabular}




\begin{tabular}{|c|c|c|c|c|c|c|c|c|c|c|c|c|}
\hline Component & $\begin{array}{c}\text { Operational } \\
\text { State }\end{array}$ & Failure Mode & $\begin{array}{c}\text { Frequency } \\
\text { Category }\end{array}$ & Possible Causes & $\begin{array}{c}\text { Preventive } \\
\text { Action on } \\
\text { Possible Causes }\end{array}$ & Consequences & $\begin{array}{l}\text { Corrective or } \\
\text { Preventive } \\
\text { Actions on } \\
\text { Consequences } \\
\end{array}$ & $\begin{array}{l}\text { ITER Postulated } \\
\text { Initiating Events }\end{array}$ & Comments & Frequency & $\begin{array}{l}\text { Comment on } \\
\text { frequency } \\
\text { calculation }\end{array}$ & $\begin{array}{c}\begin{array}{c}\text { Design } \\
\text { comments }\end{array} \\
\end{array}$ \\
\hline \multirow[t]{2}{*}{$\begin{array}{l}\text { Support pin, four } \\
\text { units }\end{array}$} & NO & deformation & Category IV & $\begin{array}{l}\text { thermal } \\
\text { overstress, } \\
\text { mechanical stress }\end{array}$ & $\begin{array}{l}\text { good design } \\
\text { practices }\end{array}$ & $\begin{array}{l}\text { TBM can slip, } \\
\text { possibly sag } \\
\text { against water } \\
\text { cooling frame. } \\
\text { Increased } \\
\text { vibration wear, } \\
\text { vibration on } \\
\text { structure reduces } \\
\text { lifetime. }\end{array}$ & $\begin{array}{l}\text { Can continue to } \\
\text { operate TBM until } \\
\text { repairs can be } \\
\text { made. }\end{array}$ & Not an IE & \begin{tabular}{|l|} 
Assume that one \\
pin and one key \\
must be failed and \\
a daily plasma \\
disruption occurs \\
to cause the TBM \\
box to strike the \\
water cooled \\
frame. The frame \\
is expected to \\
remain intact, but \\
assume that the \\
upper or lower top \\
plate will breach, \\
sending helium \\
into the VV. \\
\end{tabular} & $6.6 \mathrm{E}-10 / \mathrm{h}$ & analyst judgment & $\begin{array}{l}\text { FMD- } 97 \text { gives } \\
78 \% \text { of the } \\
\text { failure rate as } \\
\text { cracks (fracture) } \\
\text { and } 22 \% \text { of the } \\
\text { failure rate as } \\
\text { bending } \\
\text { (deformation). } \\
\text { These failure } \\
\text { mode } \\
\text { distributions are } \\
\text { used on the basic } \\
\text { failure rate of } \\
3 \mathrm{E}-09 / \mathrm{h} \text {. }\end{array}$ \\
\hline & & fracture & Category IV & $\begin{array}{l}\text { material failure } \\
\text { (e.g., inclusions), } \\
\text { large crack }\end{array}$ & $\begin{array}{l}\mathrm{NDT} \text {, good design } \\
\text { and construction } \\
\text { practices }\end{array}$ & $\begin{array}{l}\text { TBM moves out } \\
\text { of position, sags } \\
\text { onto water cooled } \\
\text { frame, stresses } \\
\text { pipe connections, } \\
\text { vibration wear. }\end{array}$ & $\begin{array}{l}\text { TBM should be } \\
\text { shut down to } \\
\text { preclude further } \\
\text { damage. }\end{array}$ & Not an IE & $\begin{array}{l}\text { High vibration can } \\
\text { reduce life of } \\
\text { TBM box and } \\
\text { pipe connections } \\
\text { to the box. } \\
\text { Assume that the } \\
\text { first plasma } \\
\text { disruption after } \\
\text { support key } \\
\text { failure with } \\
\text { concomitant } \\
\text { support pin failure } \\
\text { will cause the } \\
\text { TBM to tear a } \\
\text { helium cooling } \\
\text { plate. See above } \\
\text { description. }\end{array}$ & $2.3 \mathrm{E}-09 / \mathrm{h}$ & analyst judgment & $\begin{array}{l}\text { Assume that with } \\
\text { a failed support } \\
\text { key and a failed } \\
\text { support pin that } \\
\text { disruption EM } \\
\text { forces on the } \\
\text { TBM module } \\
\text { box will } \\
\text { overstress the } \\
\text { box and the pipe } \\
\text { connections to } \\
\text { the box. } 10 \% \text { of } \\
\text { ITER pulses end } \\
\text { in disruptions of } \\
\text { some kind }(\approx 1 \text { or } \\
2 \text { per pulse day). } \\
\text { Therefore, it is } \\
\text { assumed that if a } \\
\text { support pin and } \\
\text { key fails, the } \\
\text { TBM would fail } \\
\text { by disruption } \\
\text { forces the same } \\
\text { operating day. } \\
\text { Even though a } \\
\text { failure might be } \\
\text { difficult to } \\
\text { detect, a dual } \\
\text { failure of these } \\
\text { low failure rate } \\
\text { parts is a }< \\
\text { Category IV } \\
\text { event. }\end{array}$ \\
\hline
\end{tabular}




\begin{tabular}{|c|c|c|c|c|c|c|c|c|c|c|c|c|}
\hline Component & $\begin{array}{c}\text { Operational } \\
\text { State }\end{array}$ & Failure Mode & $\begin{array}{c}\text { Frequency } \\
\text { Category }\end{array}$ & Possible Causes & $\begin{array}{c}\text { Preventive } \\
\text { Action on } \\
\text { Possible Causes }\end{array}$ & Consequences & $\begin{array}{l}\text { Corrective or } \\
\text { Preventive } \\
\text { Actions on } \\
\text { Consequences }\end{array}$ & $\begin{array}{l}\text { ITER Postulated } \\
\text { Initiating Events }\end{array}$ & Comments & Frequency & $\begin{array}{l}\text { Comment on } \\
\text { frequency } \\
\text { calculation }\end{array}$ & $\begin{array}{c}\text { Design } \\
\text { comments }\end{array}$ \\
\hline & & detachment & Category IV & bond failure & $\begin{array}{l}\text { NDT, good weld } \\
\text { practices }\end{array}$ & $\begin{array}{l}\text { TBM moves out } \\
\text { of position, sags } \\
\text { onto water cooled } \\
\text { frame, stresses } \\
\text { pipe connections, } \\
\text { vibration wear. }\end{array}$ & $\begin{array}{l}\text { TBM should be } \\
\text { shut down to } \\
\text { preclude further } \\
\text { damage. }\end{array}$ & Not an IE & $\begin{array}{l}\text { High vibration can } \\
\text { reduce life of } \\
\text { TBM box and } \\
\text { pipe connections } \\
\text { to the box. } \\
\text { Assume that the } \\
\text { first plassa } \\
\text { disruption after } \\
\text { support key } \\
\text { failure with } \\
\text { concomitant } \\
\text { support pin failure } \\
\text { will cause the } \\
\text { TBM to tear a } \\
\text { helium cooling } \\
\text { plate. See above } \\
\text { description. }\end{array}$ & $6 \mathrm{E}-09 / \mathrm{h}$ & analyst judgment & $\begin{array}{l}\text { Use a butt weld } \\
\text { value from } \\
\text { Buende (1991). } \\
\text { See above } \\
\text { description of } \\
\text { failure } \\
\text { consequences. }\end{array}$ \\
\hline \multirow[t]{3}{*}{$\begin{array}{l}\text { Inner back } \\
\text { plate/helium } \\
\text { manifold }\end{array}$} & NO & deformation & Category IV & $\begin{array}{l}\text { thermal } \\
\text { overstress, } \\
\text { warping }\end{array}$ & $\begin{array}{l}\text { Good design } \\
\text { practices, verify } \\
\text { proper flow in } \\
\text { operation }\end{array}$ & $\begin{array}{l}\text { Inner back plate } \\
\text { deformation } \\
\text { causes FCI cracks, } \\
\text { retards } \mathrm{Pb}-17 \mathrm{Li} \\
\text { flow to the point } \\
\text { of stagnation. } \\
\text { Restricts helium } \\
\text { flow, increases } \\
\text { helium friction } \\
\text { pressure drop in } \\
\text { TBM. } \\
\end{array}$ & \begin{tabular}{|l|} 
Maintain helium \\
coolant flow to \\
TBM to remove \\
heat. Can \\
continue to \\
operate TBM with \\
helium cooling \\
unless back plate \\
stresses tear \\
module box open.
\end{tabular} & Not an IE & & $1 \mathrm{E}-09 / \mathrm{h}$ & analyst judgment & $\begin{array}{l}\text { Plate failure rate } \\
\text { assumptions } \\
\text { were described } \\
\text { above. }\end{array}$ \\
\hline & & external leakage & Category IV & $\begin{array}{l}\text { material flaw, } \\
\text { crack, bond fault }\end{array}$ & $\begin{array}{l}\text { NDT, good design } \\
\text { and construction } \\
\text { practices }\end{array}$ & $\begin{array}{l}\text { Leak helium at } 8 \\
\text { MPa into TBM } \\
\text { module box. }\end{array}$ & $\begin{array}{l}\text { Can continue to } \\
\text { operate ITER and } \\
\text { TBM if helium } \\
\text { leak is small and } \\
\text { not } \\
\text { overpressurizing } \\
\text { the Pb-17Li. } \\
\text { Larger leaks (such } \\
\text { as } 1 \% \text { of helium } \\
\text { flow rate) will } \\
\text { cause or will } \\
\text { require ITER } \\
\text { shutdown. }\end{array}$ & LBB2 & $\begin{array}{l}\text { Despite FCI being } \\
\text { present, assume } \\
\text { that helium leak } \\
\text { into that part of } \\
\text { the TBM module } \\
\text { will reach the } \mathrm{Pb}- \\
17 \mathrm{Li} \text { and } \\
\text { pressurize it. }\end{array}$ & $1 \mathrm{E}-08 / \mathrm{h}$ & analyst judgment & \\
\hline & & external rupture & Category IV & $\begin{array}{l}\text { material failure, } \\
\text { large crack, bond } \\
\text { failure }\end{array}$ & $\begin{array}{l}\text { NDT, good design } \\
\text { and construction } \\
\text { practices }\end{array}$ & $\begin{array}{l}\text { Large leak of } \\
\text { helium at } 8 \mathrm{MPa} \\
\text { into TBM module } \\
\text { box. }\end{array}$ & $\begin{array}{l}\text { Drain Pb-17Li to } \\
\text { drain tank to limit } \\
\text { spill into VV. } \\
\text { Spill may cause } \\
\text { plasma disruption, } \\
\text { heavy metal at } \\
\text { plasma edge. } \\
\text { Shut down ITER } \\
\text { to clean up spill. }\end{array}$ & LBB1 & & $1 \mathrm{E}-09 / \mathrm{h}$ & analyst judgment & \\
\hline
\end{tabular}




\begin{tabular}{|c|c|c|c|c|c|c|c|c|c|c|c|c|}
\hline Component & $\begin{array}{c}\text { Operational } \\
\text { State }\end{array}$ & Failure Mode & $\begin{array}{c}\text { Frequency } \\
\text { Category }\end{array}$ & Possible Causes & $\begin{array}{c}\text { Preventive } \\
\text { Action on } \\
\text { Possible Causes }\end{array}$ & Consequences & \begin{tabular}{|c|} 
Corrective or \\
Preventive \\
Actions on \\
Consequences \\
\end{tabular} & $\begin{array}{l}\text { ITER Postulated } \\
\text { Initiating Events }\end{array}$ & Comments & Frequency & $\begin{array}{c}\text { Comment on } \\
\text { frequency } \\
\text { calculation }\end{array}$ & $\begin{array}{c}\text { Design } \\
\text { comments }\end{array}$ \\
\hline & & flow blockage & Category IV & \begin{tabular}{|l|} 
construction or \\
maintenance \\
debris blocks flow
\end{tabular} & $\begin{array}{l}\text { Comprehensive } \\
\text { system } \\
\text { commissioning, } \\
\text { flow test before } \\
\text { each operating } \\
\text { period. }\end{array}$ & $\begin{array}{l}\text { Localized loss of } \\
\text { helium flow in } \\
\text { TBM. This may } \\
\text { not be sensed by } \\
\text { instrumentation. }\end{array}$ & $\begin{array}{l}\begin{array}{l}\text { Must begin an } \\
\text { orderly shut down } \\
\text { of ITER when }\end{array} \\
\text { TBM temperature } \\
\text { begins to increase. }\end{array}$ & FB2 & & $9 \mathrm{E}-05 / \mathrm{yr}$ & $\begin{array}{l}\text { Analyst judgment } \\
\text { based on HFIR } \\
\text { PRA analyses }\end{array}$ & $\begin{array}{l}\text { Water cooled } \\
\text { systems have had } \\
\text { screws, bolts, } \\
\text { bearings, gasket } \\
\text { pieces, weld slag, } \\
\text { rust particles, } \\
\text { etc., in the piping } \\
\text { system. } \\
\text { Personnel have } \\
\text { left pencils, rags, } \\
\text { tools, and other } \\
\text { debris. High } \\
\text { Flux Isotope } \\
\text { Reactor PRA, } \\
\text { PLG-0604, 1988. }\end{array}$ \\
\hline & & fouling & Category IV & $\begin{array}{l}\text { foreign material } \\
\text { intrusion and } \\
\text { buildup on } \\
\text { channel walls, } \\
\text { moisture in } \\
\text { helium gas }\end{array}$ & $\begin{array}{l}\text { Helium purity } \\
\text { control, gas drying }\end{array}$ & \begin{tabular}{|l|} 
Gradual \\
degradation of \\
heat transfer to the \\
helium coolant, \\
gradual flow \\
friction increase.
\end{tabular} & $\begin{array}{l}\text { Gradual heatup of } \\
\text { the TBM. Begin } \\
\text { an orderly } \\
\text { shutdown of ITER } \\
\text { when coolant } \\
\text { temperatures } \\
\text { increase to } \\
\text { technical } \\
\text { specification } \\
\text { limits. }\end{array}$ & FB2 & & $1 \mathrm{E}-04 / \mathrm{yr}$ & analyst judgment & $\begin{array}{l}\text { Helium systems } \\
\text { are reputed to be } \\
\text { very clean. } \\
\text { HTGRs have } \\
\text { only had graphite } \\
\text { dust and moisture } \\
\text { concerns. } \\
\text { Assume this is a } \\
\text { category IV } \\
\text { event. } \\
\end{array}$ \\
\hline
\end{tabular}




\begin{tabular}{|c|c|c|c|c|c|c|c|c|c|c|c|c|}
\hline Component & $\begin{array}{c}\text { Operational } \\
\text { State }\end{array}$ & Failure Mode & $\begin{array}{c}\text { Frequency } \\
\text { Category }\end{array}$ & Possible Causes & $\begin{array}{c}\text { Preventive } \\
\text { Action on } \\
\text { Possible Causes }\end{array}$ & Consequences & $\begin{array}{c}\text { Corrective or } \\
\text { Preventive } \\
\text { Actions on } \\
\text { Consequences }\end{array}$ & $\begin{array}{l}\text { ITER Postulated } \\
\text { Initiating Events }\end{array}$ & Comments & Frequency & $\begin{array}{c}\text { Comment on } \\
\text { frequency } \\
\text { calculation }\end{array}$ & $\begin{array}{c}\text { Design } \\
\text { comments }\end{array}$ \\
\hline & & internal leakage & Category III & $\begin{array}{l}\text { material flaw } \\
\text { (e.g., pinhole), } \\
\text { crack, bond fault }\end{array}$ & $\begin{array}{l}\text { NDT, good design } \\
\text { and construction } \\
\text { practices }\end{array}$ & $\begin{array}{l}\text { Leak helium at } 8 \\
\text { MPa across the } \\
\text { back plate, "short } \\
\text { circuits" the TBM } \\
\text { module. }\end{array}$ & $\begin{array}{l}\text { TBM receives } \\
\text { reduced helium } \\
\text { cooling in the first } \\
\text { wall cooling } \\
\text { tubes, TBM FW } \\
\text { temperature } \\
\text { increases. }\end{array}$ & FB2 & $\begin{array}{l}\text { First wall tubes } \\
\text { will not receive } \\
\text { proper cooling in } \\
\text { half of the square } \\
\text { duct tubes. } \\
\text { Thermal stresses } \\
\text { on tube-to-tube } \\
\text { bonds. }\end{array}$ & $1 \mathrm{E}-07 / \mathrm{h}$ & analyst judgment & $\begin{array}{l}\text { Twenty one fins, } \\
\text { each } \approx 1.8 \mathrm{~m} \\
\text { long. A steam } \\
\text { turbine has stator } \\
\text { blades to direct } \\
\text { steam. For a } \\
\text { high pressure } \\
\text { superheated } \\
\text { steam turbine, } \\
\text { there could be } 48 \\
\text { blades per row } \\
\text { and } 15 \text { rows. } \\
\text { EPRI-AP-2071 } \\
\text { gave a high } \\
\text { pressure steam } \\
\text { turbine failure } \\
\text { rate of } \\
1.83 \mathrm{E}-04 / \mathrm{h} \text {, and } \\
1.81 \% \text { of faults } \\
\text { involve blades, } \\
\text { or a failure rate } \\
\text { of } 3.3 \mathrm{E}-06 / \mathrm{h} \text { for } \\
\text { blades. } 48 \\
\text { blades } x 15 \text { rows } \\
\text { is } 720 \text { blades in a } \\
\text { typical high } \\
\text { pressure turbine, } \\
\text { or } \\
4.6 \mathrm{E}-09 / \mathrm{blade}- \\
\text { hour. For } 21 \\
\text { fins, that would } \\
\text { be } 1 \mathrm{E}-07 / \text { fin- } \\
\text { hour. }\end{array}$ \\
\hline & & internal rupture & \begin{tabular}{|l|} 
Category IV \\
\end{tabular} & $\begin{array}{l}\text { material failure, } \\
\text { large crack, bond } \\
\text { failure }\end{array}$ & $\begin{array}{l}\text { NDT, good design } \\
\text { and construction } \\
\text { practices }\end{array}$ & $\begin{array}{l}\text { Leak helium at } 8 \\
\text { MPa across the } \\
\text { back plate, "short } \\
\text { circuits" the TBM } \\
\text { module. }\end{array}$ & $\begin{array}{l}\text { TBM receives } \\
\text { inadequate helium } \\
\text { cooling in the first } \\
\text { wall cooling } \\
\text { tubes. }\end{array}$ & FB1 & \begin{tabular}{|l|} 
First wall tubes \\
will not receive \\
adequate cooling \\
in half the square \\
duct tubes. \\
Thermal stresses \\
on tube-to-tube \\
bonds.
\end{tabular} & $1 \mathrm{E}-08 / \mathrm{h}$ & analyst judgment & $\begin{array}{l}\text { Assume rupture } \\
\text { is } 10 \% \text { of the } \\
\text { leakage failure } \\
\text { rate. }\end{array}$ \\
\hline $\begin{array}{l}\text { Outer back } \\
\text { plate/helium } \\
\text { manifold }\end{array}$ & NO & deformation & Category IV & $\begin{array}{l}\text { thermal } \\
\text { overstress, } \\
\text { warping }\end{array}$ & \begin{tabular}{|l|} 
Good design \\
practices, verify \\
proper flow in \\
operation
\end{tabular} & $\begin{array}{l}\text { Inner back plate } \\
\text { deformation } \\
\text { causes FCI cracks, } \\
\text { retards Pb-17Li } \\
\text { flow to the point } \\
\text { of stagnation. } \\
\text { Restricts helium } \\
\text { flow, increases } \\
\text { helium friction } \\
\text { pressure drop in } \\
\text { TBM. }\end{array}$ & \begin{tabular}{|l} 
Maintain helium \\
coolant flow to \\
TBM to remove \\
heat. Can \\
continue to \\
operate TBM with \\
helium cooling \\
unless back plate \\
stresses tear \\
module box open.
\end{tabular} & Not an IE & & $1 \mathrm{E}-09 / \mathrm{h}$ & analyst judgment & $\begin{array}{l}\text { Plate failure rate } \\
\text { assumptions } \\
\text { were described } \\
\text { above. }\end{array}$ \\
\hline
\end{tabular}




\begin{tabular}{|c|c|c|c|c|c|c|c|c|c|c|c|c|}
\hline Component & $\begin{array}{c}\text { Operational } \\
\text { State }\end{array}$ & Failure Mode & $\begin{array}{c}\text { Frequency } \\
\text { Category }\end{array}$ & Possible Causes & $\begin{array}{c}\text { Preventive } \\
\text { Action on } \\
\text { Possible Causes }\end{array}$ & Consequences & $\begin{array}{l}\text { Corrective or } \\
\text { Preventive } \\
\text { Actions on } \\
\text { Consequences } \\
\end{array}$ & $\begin{array}{l}\text { ITER Postulated } \\
\text { Initiating Events }\end{array}$ & Comments & Frequency & $\begin{array}{c}\text { Comment on } \\
\text { frequency } \\
\text { calculation }\end{array}$ & $\begin{array}{c}\begin{array}{c}\text { Design } \\
\text { comments }\end{array} \\
\end{array}$ \\
\hline & & $\begin{array}{l}\text { external leakage } \\
\text { into TBM }\end{array}$ & Category IV & $\begin{array}{l}\text { material flaw, } \\
\text { crack, bond fault }\end{array}$ & $\begin{array}{l}\text { NDT, good design } \\
\text { and construction } \\
\text { practices }\end{array}$ & $\begin{array}{l}\text { Leak helium at } 8 \\
\text { MPa into TBM } \\
\text { module box. }\end{array}$ & $\begin{array}{l}\text { Can continue to } \\
\text { operate ITER and } \\
\text { TBM if helium } \\
\text { leak is small and } \\
\text { not } \\
\text { overpressurizing } \\
\text { the Pb-17Li. } \\
\text { Larger leaks (such } \\
\text { as } 1 \% \text { of helium } \\
\text { flow rate) will } \\
\text { cause or will } \\
\text { require ITER } \\
\text { shutdown. }\end{array}$ & LBB2 & $\begin{array}{l}\text { Despite FCI being } \\
\text { present, assume } \\
\text { that helium leak } \\
\text { into that part of } \\
\text { the TBM module } \\
\text { will reach the Pb- } \\
\text { 17Li and } \\
\text { pressurize it. }\end{array}$ & $1 \mathrm{E}-08 / \mathrm{h}$ & analyst judgment & \\
\hline & & $\begin{array}{l}\text { external rupture } \\
\text { into TBM }\end{array}$ & Category IV & $\begin{array}{l}\text { material failure, } \\
\text { large crack, bond } \\
\text { failure }\end{array}$ & $\begin{array}{l}\text { NDT, good design } \\
\text { and construction } \\
\text { practices }\end{array}$ & $\begin{array}{l}\text { Large leak of } \\
\text { helium at } 8 \mathrm{MPa} \\
\text { into TBM module } \\
\text { box. }\end{array}$ & $\begin{array}{l}\text { Drain Pb-17Li to } \\
\text { drain tank to limit } \\
\text { spill into VV. } \\
\text { Spill may cause } \\
\text { plasma disruption, } \\
\text { heavy metal at } \\
\text { plasma edge. } \\
\text { Shut down ITER } \\
\text { to clean up spill. }\end{array}$ & LBB1 & $\begin{array}{l}\text { Helium could } \\
\text { fracture } \mathrm{SiC} \mathrm{FCIs} \\
\text { and will reach Pb- } \\
\text { 17Li. }\end{array}$ & $1 \mathrm{E}-09 / \mathrm{h}$ & analyst judgment & \\
\hline & & $\begin{array}{l}\text { external leakage } \\
\text { to VV }\end{array}$ & Category IV & $\begin{array}{l}\text { material flaw, } \\
\text { crack, bond fault }\end{array}$ & $\begin{array}{l}\text { NDT, good design } \\
\text { and construction } \\
\text { practices }\end{array}$ & $\begin{array}{l}\text { Leak helium at } 8 \\
\text { MPa into vacuum } \\
\text { vessel. }\end{array}$ & $\begin{array}{l}\text { Can continue to } \\
\text { operate ITER and } \\
\text { TBM if helium } \\
\text { leak is small and } \\
\text { not } \\
\text { overpressurizing } \\
\text { the Pb-17Li. } \\
\text { Larger leaks (such } \\
\text { as } 1 \% \text { of helium } \\
\text { flow rate) will } \\
\text { cause or will } \\
\text { require ITER } \\
\text { shutdown. }\end{array}$ & LBV2 & & $1 \mathrm{E}-08 / \mathrm{h}$ & analyst judgment & $\begin{array}{l}\text { Plate failure rate } \\
\text { assumptions } \\
\text { were described } \\
\text { above. }\end{array}$ \\
\hline & & $\begin{array}{l}\text { external rupture to } \\
\text { VV }\end{array}$ & Category IV & $\begin{array}{l}\text { material failure, } \\
\text { large crack, bond } \\
\text { failure }\end{array}$ & $\begin{array}{l}\text { NDT, good design } \\
\text { and construction } \\
\text { practices }\end{array}$ & $\begin{array}{l}\text { Large leak of } \\
\text { helium at } 8 \mathrm{MPa} \\
\text { into vacuum } \\
\text { vessel. Assume } \\
\text { plasma disruption } \\
\text { occurs. }\end{array}$ & $\begin{array}{l}\text { Drain Pb-17Li to } \\
\text { drain tank to limit } \\
\text { spill into VV. } \\
\text { Spill may cause } \\
\text { plasma disruption, } \\
\text { heavy metal at } \\
\text { plasma edge. } \\
\text { Shut down ITER } \\
\text { to clean up spill. }\end{array}$ & LBV1 & & $1 \mathrm{E}-09 / \mathrm{h}$ & analyst judgment & \\
\hline
\end{tabular}




\begin{tabular}{|c|c|c|c|c|c|c|c|c|c|c|c|c|}
\hline Component & $\begin{array}{l}\text { Operational } \\
\text { State }\end{array}$ & Failure Mode & $\begin{array}{l}\text { Frequency } \\
\text { Category }\end{array}$ & Possible Causes & $\begin{array}{c}\text { Preventive } \\
\text { Action on } \\
\text { Possible Causes }\end{array}$ & Consequences & $\begin{array}{l}\text { Corrective or } \\
\text { Preventive } \\
\text { Actions on } \\
\text { Consequences }\end{array}$ & $\begin{array}{l}\text { ITER Postulated } \\
\text { Initiating Events }\end{array}$ & Comments & Frequency & $\begin{array}{l}\text { Comment on } \\
\text { frequency } \\
\text { calculation }\end{array}$ & $\begin{array}{c}\text { Design } \\
\text { comments }\end{array}$ \\
\hline & & flow blockage & Category IV & $\begin{array}{l}\text { construction or } \\
\text { maintenance } \\
\text { debris blocks flow }\end{array}$ & $\begin{array}{l}\text { Comprehensive } \\
\text { system } \\
\text { commissioning, } \\
\text { flow test before } \\
\text { each operating } \\
\text { period. }\end{array}$ & $\begin{array}{l}\text { Localized loss of } \\
\text { helium flow in } \\
\text { TBM. This may } \\
\text { not be sensed by } \\
\text { instrumentation. }\end{array}$ & $\begin{array}{l}\text { Must begin an } \\
\text { orderly shut down } \\
\text { of ITER when } \\
\text { TBM temperature } \\
\text { begins to increase. }\end{array}$ & FB2 & & $9 \mathrm{E}-05 / \mathrm{yr}$ & $\begin{array}{l}\text { Analyst judgment } \\
\text { based on HFIR } \\
\text { PRA analyses }\end{array}$ & $\begin{array}{l}\text { Water cooled } \\
\text { systems have had } \\
\text { screws, bolts, } \\
\text { bearings, gasket } \\
\text { pieces, weld slag, } \\
\text { rust particles, } \\
\text { etc., in the piping } \\
\text { system. } \\
\text { Personnel have } \\
\text { left pencils, rags, } \\
\text { tools, and other } \\
\text { debris. High } \\
\text { Flux Isotope } \\
\text { Reactor PRA, } \\
\text { PLG-0604, } 1988 \text {. }\end{array}$ \\
\hline & & fouling & Category IV & $\begin{array}{l}\text { foreign material } \\
\text { intrusion and } \\
\text { buildup on } \\
\text { channel walls, } \\
\text { moisture in } \\
\text { helium gas }\end{array}$ & $\begin{array}{l}\text { Helium purity } \\
\text { control, gas drying }\end{array}$ & $\begin{array}{l}\text { Gradual } \\
\text { degradation of } \\
\text { heat transfer to the } \\
\text { helium coolant, } \\
\text { gradual flow } \\
\text { friction increase. }\end{array}$ & $\begin{array}{l}\text { Gradual heatup of } \\
\text { the TBM. Begin } \\
\text { an orderly } \\
\text { shutdown of ITER } \\
\text { when coolant } \\
\text { temperatures } \\
\text { increase to } \\
\text { technical } \\
\text { specification } \\
\text { limits. }\end{array}$ & FB2 & & $1 \mathrm{E}-04 / \mathrm{yr}$ & analyst judgment & $\begin{array}{l}\text { Helium systems } \\
\text { are reputed to be } \\
\text { very clean. } \\
\text { HTGRs have } \\
\text { only had graphite } \\
\text { dust and moisture } \\
\text { concerns. } \\
\text { Assume this is a } \\
\text { category IV } \\
\text { event. }\end{array}$ \\
\hline
\end{tabular}




\begin{tabular}{|c|c|c|c|c|c|c|c|c|c|c|c|c|}
\hline Component & $\begin{array}{c}\text { Operational } \\
\text { State }\end{array}$ & Failure Mode & $\begin{array}{r}\begin{array}{r}\text { Frequency } \\
\text { Category }\end{array} \\
\end{array}$ & Possible Causes & $\begin{array}{c}\text { Preventive } \\
\text { Action on } \\
\text { Possible Causes }\end{array}$ & Consequences & \begin{tabular}{|c|} 
Corrective or \\
Preventive \\
Actions on \\
Consequences \\
\end{tabular} & $\begin{array}{l}\text { ITER Postulated } \\
\text { Initiating Events } \\
\end{array}$ & Comments & Frequency & $\begin{array}{c}\text { Comment on } \\
\text { frequency } \\
\text { calculation }\end{array}$ & $\begin{array}{c}\begin{array}{c}\text { Design } \\
\text { comments }\end{array} \\
\end{array}$ \\
\hline & & internal leakage & Category III & $\begin{array}{l}\text { material flaw } \\
\text { (e.g., pinhole), } \\
\text { crack, bond fault }\end{array}$ & $\begin{array}{l}\text { NDT, good design } \\
\text { and construction } \\
\text { practices }\end{array}$ & $\begin{array}{l}\text { Leak helium at } 8 \\
\text { MPa across the } \\
\text { back plate, "short } \\
\text { circuits" the TBM } \\
\text { module. }\end{array}$ & $\begin{array}{l}\text { TBM receives } \\
\text { reduced helium } \\
\text { cooling in the first } \\
\text { wall cooling } \\
\text { tubes, TBM FW } \\
\text { temperature } \\
\text { increases. }\end{array}$ & FB2 & $\begin{array}{l}\text { First wall tubes } \\
\text { will not receive } \\
\text { proper cooling in } \\
\text { half of the square } \\
\text { duct tubes. } \\
\text { Thermal stresses } \\
\text { on tube-to-tube } \\
\text { bonds. }\end{array}$ & $1 \mathrm{E}-07 / \mathrm{h}$ & analyst judgment & $\begin{array}{l}\text { Twenty one fins, } \\
\text { each } \approx 1.8 \mathrm{~m} \\
\text { long. A steam } \\
\text { turbine has stator } \\
\text { blades to direct } \\
\text { steam. For a } \\
\text { high pressure } \\
\text { superheated } \\
\text { steam turbine, } \\
\text { there could be } 48 \\
\text { blades per row } \\
\text { and } 15 \text { rows. } \\
\text { EPRI-AP-2071 } \\
\text { gave a high } \\
\text { pressure steam } \\
\text { turbine failure } \\
\text { rate of } \\
1.83 \mathrm{E}-04 / \mathrm{h} \text {, and } \\
1.81 \% \text { of faults } \\
\text { involve blades, } \\
\text { or a failure rate } \\
\text { of } 3.3 \mathrm{E}-06 / \mathrm{h} \text { for } \\
\text { blades. } 48 \\
\text { blades } \mathrm{x} 15 \text { rows } \\
\text { is } 720 \text { blades in a } \\
\text { typical high } \\
\text { pressure turbine, } \\
\text { or } \\
4.6 \mathrm{E}-09 / \mathrm{blade}- \\
\text { hour. For } 21 \\
\text { fins, that would } \\
\text { be } 1 \mathrm{E}-07 / \text { fin- } \\
\text { hour. }\end{array}$ \\
\hline & & internal rupture & Category IV & $\begin{array}{l}\text { material failure, } \\
\text { large crack, bond } \\
\text { failure }\end{array}$ & $\begin{array}{l}\text { NDT, good design } \\
\text { and construction } \\
\text { practices }\end{array}$ & $\begin{array}{l}\text { Leak helium at } 8 \\
\text { MPa across the } \\
\text { back plate, "short } \\
\text { circuits" the TBM } \\
\text { module. }\end{array}$ & $\begin{array}{l}\text { TBM receives } \\
\text { inadequate helium } \\
\text { cooling in the first } \\
\text { wall cooling } \\
\text { tubes. }\end{array}$ & FB1 & $\begin{array}{l}\text { First wall tubes } \\
\text { will not receive } \\
\text { adequate cooling } \\
\text { in half the square } \\
\text { duct tubes. } \\
\text { Thermal stresses } \\
\text { on tube-to-tube } \\
\text { bonds. }\end{array}$ & $1 \mathrm{E}-08 / \mathrm{h}$ & analyst judgment & $\begin{array}{l}\text { Assume rupture } \\
\text { is } 10 \% \text { of the } \\
\text { leakage failure } \\
\text { rate. }\end{array}$ \\
\hline
\end{tabular}




\begin{tabular}{|c|c|c|c|c|c|c|c|c|c|c|c|c|}
\hline Component & $\begin{array}{c}\text { Operational } \\
\text { State }\end{array}$ & Failure Mode & $\begin{array}{c}\text { Frequency } \\
\text { Category }\end{array}$ & Possible Causes & $\begin{array}{c}\text { Preventive } \\
\text { Action on } \\
\text { Possible Causes }\end{array}$ & Consequences & $\begin{array}{l}\text { Corrective or } \\
\text { Preventive } \\
\text { Actions on } \\
\text { Consequences } \\
\end{array}$ & $\begin{array}{l}\text { ITER Postulated } \\
\text { Initiating Events }\end{array}$ & Comments & Frequency & $\begin{array}{c}\text { Comment on } \\
\text { frequency } \\
\text { calculation }\end{array}$ & $\begin{array}{c}\begin{array}{c}\text { Design } \\
\text { comments }\end{array} \\
\text {. }\end{array}$ \\
\hline \multirow[t]{4}{*}{$\begin{array}{l}\text { Helium } \\
\text { distribution } \\
\text { manifold, two sets } \\
\text { to supply the } \\
\text { upper and lower } \\
\text { end plates }\end{array}$} & NO & external leak & Category III & $\begin{array}{l}\text { weld fault, pipe } \\
\text { wall flaw, pipe } \\
\text { vibration induced } \\
\text { crack, } \\
\text { construction fault }\end{array}$ & \begin{tabular}{|l|} 
Materials \\
selection in \\
design, pre- \\
service inspection, \\
low flow-induced \\
vibration, NDT
\end{tabular} & $\begin{array}{l}\text { Leaks small } \\
\text { amount of helium } \\
\text { to the vacuum } \\
\text { vessel, slowly } \\
\text { depletes makeup } \\
\text { helium, slowly } \\
\text { pressurizes VV }\end{array}$ & $\begin{array}{l}\text { Depressurize } \\
\text { helium system, } \\
\text { orderly ITER shut } \\
\text { down }\end{array}$ & \begin{tabular}{|l|} 
Small Helium \\
LOCA, LBV2
\end{tabular} & $\begin{array}{l}\text { Assume that leak } \\
\text { rate of } 1 \mathrm{~g} / \text { minute } \\
\text { is too high and } \\
\text { leaks could easily } \\
\text { yield that much } \\
\text { leakage. A } \\
\text { helium leak could } \\
\text { result in a plasma } \\
\text { disruption over } \\
\text { the course of one } \\
\text { plasma shot. The } \\
\text { helium system } \\
\text { operates for } 4,032 \\
\text { h per year. }\end{array}$ & $9.8 \mathrm{E}-08 / \mathrm{h}-\mathrm{m}$ & $\begin{array}{l}\text { WSRC-TR-93- } \\
262\end{array}$ & $\begin{array}{l}\text { Assume } 18 \text { welds } \\
\text { for each manifold } \\
\text { and estimate } 1 \mathrm{~m} \\
\text { tubing length. } \\
\text { Assuming tiny } \\
\text { leaks, LBV3, } \\
\text { would not create } \\
\text { an issue behind } \\
\text { the TBM module } \\
\text { box. }\end{array}$ \\
\hline & & external rupture & Category IV & $\begin{array}{l}\text { weld fracture, } \\
\text { piping failure, } \\
\text { flow induced } \\
\text { vibration }\end{array}$ & $\begin{array}{l}\text { Materials } \\
\text { selection in } \\
\text { design, pre- } \\
\text { service inspection, } \\
\text { low flow-induced } \\
\text { vibration, NDT }\end{array}$ & $\begin{array}{l}\text { Leaks large } \\
\text { amount of helium } \\
\text { to the room }\end{array}$ & $\begin{array}{l}\text { Depressurize } \\
\text { helium system, } \\
\text { shut down ITER } \\
\text { for post-disruption } \\
\text { inspection. ITER } \\
\text { cannot run until } \\
\text { TBM is repaired. } \\
\end{array}$ & $\begin{array}{l}\text { Helium LOCA, } \\
\text { LBV1 }\end{array}$ & $\begin{array}{l}\text { Assume a rupture } \\
\text { flow rate gives an } \\
\text { immediate plasma } \\
\text { disruption due to } \\
\text { helium intrusion } \\
\text { at the plasma } \\
\text { edge. } \\
\end{array}$ & $3.3 \mathrm{E}-09 / \mathrm{h}-\mathrm{m}$ & $\begin{array}{l}\text { WSRC-TR-93- } \\
262\end{array}$ & $\begin{array}{l}\text { Estimate } 1 \mathrm{~m} \\
\text { tube length }\end{array}$ \\
\hline & & fouling & Category IV & $\begin{array}{l}\text { foreign material } \\
\text { intrusion and } \\
\text { buildup on tube } \\
\text { walls, moisture in } \\
\text { helium gas }\end{array}$ & $\begin{array}{l}\text { Helium purity } \\
\text { control, gas drying }\end{array}$ & $\begin{array}{l}\text { Gradual } \\
\text { degradation of } \\
\text { heat transfer to the } \\
\text { helium coolant }\end{array}$ & $\begin{array}{l}\text { Gradual heatup of } \\
\text { the TBM. Begin } \\
\text { an orderly } \\
\text { shutdown of ITER } \\
\text { when coolant } \\
\text { temperatures } \\
\text { increase. }\end{array}$ & FB2 & & $1 \mathrm{E}-04 / \mathrm{yr}$ & analyst judgment & $\begin{array}{l}\text { Helium systems } \\
\text { are reputed to be } \\
\text { very clean. } \\
\text { HTGRs have } \\
\text { only had graphite } \\
\text { dust and moisture } \\
\text { concerns. } \\
\text { Assume this is a } \\
\text { category IV } \\
\text { event. }\end{array}$ \\
\hline & & flow blockage & Category IV & $\begin{array}{l}\text { construction or } \\
\text { maintenance } \\
\text { debris blocks flow }\end{array}$ & $\begin{array}{l}\text { Comprehensive } \\
\text { system } \\
\text { commissioning, } \\
\text { flow test before } \\
\text { each operating } \\
\text { period. }\end{array}$ & $\begin{array}{l}\text { Localized loss of } \\
\text { helium flow in } \\
\text { TBM. This may } \\
\text { not be sensed by } \\
\text { instrumentation. }\end{array}$ & $\begin{array}{l}\text { Must begin an } \\
\text { orderly shut down } \\
\text { of ITER when } \\
\text { TBM temperature } \\
\text { begins to increase. }\end{array}$ & FB2 & & $9 \mathrm{E}-05 / \mathrm{yr}$ & $\begin{array}{l}\text { Analyst judgment } \\
\text { based on HFIR } \\
\text { PRA analyses }\end{array}$ & $\begin{array}{l}\text { Water cooled } \\
\text { systems have had } \\
\text { screws, bolts, } \\
\text { bearings, gasket } \\
\text { pieces, weld slag, } \\
\text { rust particles, } \\
\text { ett., in the piping } \\
\text { system. } \\
\text { Personnel have } \\
\text { left pencils, rags, } \\
\text { tools, and other } \\
\text { debris. High } \\
\text { Flux Isotope } \\
\text { Reactor PRA, } \\
\text { PLG-0604, 1988. }\end{array}$ \\
\hline
\end{tabular}




\begin{tabular}{|c|c|c|c|c|c|c|c|c|c|c|c|c|}
\hline Component & $\begin{array}{c}\text { Operational } \\
\text { State }\end{array}$ & Failure Mode & $\begin{array}{c}\text { Frequency } \\
\text { Category }\end{array}$ & Possible Causes & $\begin{array}{c}\text { Preventive } \\
\text { Action on } \\
\text { Possible Causes }\end{array}$ & Consequences & $\begin{array}{l}\text { Corrective or } \\
\text { Preventive } \\
\text { Actions on } \\
\text { Consequences } \\
\end{array}$ & $\begin{array}{l}\text { ITER Postulated } \\
\text { Initiating Events }\end{array}$ & Comments & Frequency & $\begin{array}{c}\text { Comment on } \\
\text { frequency } \\
\text { calculation }\end{array}$ & $\begin{array}{c}\begin{array}{c}\text { Design } \\
\text { comments }\end{array} \\
\end{array}$ \\
\hline \multirow[t]{4}{*}{$\begin{array}{l}\text { Helium supply } \\
\text { line, two sets for } \\
\text { the TBM }\end{array}$} & NO & external leak & Category III & $\begin{array}{l}\text { weld fault, pipe } \\
\text { wall flaw, pipe } \\
\text { vibration induced } \\
\text { crack, } \\
\text { construction fault }\end{array}$ & $\begin{array}{l}\text { Materials } \\
\text { selection in } \\
\text { design, pre- } \\
\text { service inspection, } \\
\text { low flow-induced } \\
\text { vibration, NDT }\end{array}$ & $\begin{array}{l}\text { Leaks small } \\
\text { amount of helium } \\
\text { to the vacuum } \\
\text { vessel, slowly } \\
\text { depletes makeup } \\
\text { helium, slowly } \\
\text { pressurizes VV }\end{array}$ & $\begin{array}{l}\text { Depressurize } \\
\text { helium system, } \\
\text { orderly ITER shut } \\
\text { down }\end{array}$ & $\begin{array}{l}\text { Small Helium } \\
\text { LOCA, LBV2 }\end{array}$ & $\begin{array}{l}\text { Assume that leak } \\
\text { rate of } 1 \mathrm{~g} / \text { minute } \\
\text { is too high and } \\
\text { leaks could easily } \\
\text { yield that much } \\
\text { leakage. A } \\
\text { helium leak could } \\
\text { result in a plasma } \\
\text { disruption over } \\
\text { the course of one } \\
\text { plassma shot. The } \\
\text { helium system } \\
\text { operates for } 4,032 \\
\text { h per year. } \\
\end{array}$ & $9.8 \mathrm{E}-08 / \mathrm{h}-\mathrm{m}$ & $\begin{array}{l}\text { WSRC-TR-93- } \\
262\end{array}$ & $\begin{array}{l}\text { Assume } 8 \text { welds } \\
\text { for each supply } \\
\text { line and } 2 \mathrm{~m} \text { pipe } \\
\text { length. }\end{array}$ \\
\hline & & external rupture & Category IV & $\begin{array}{l}\text { weld fracture, } \\
\text { piping failure, } \\
\text { flow induced } \\
\text { vibration }\end{array}$ & $\begin{array}{l}\text { Materials } \\
\text { selection in } \\
\text { design, pre- } \\
\text { service inspection, } \\
\text { low flow-induced } \\
\text { vibration, NDT }\end{array}$ & $\begin{array}{l}\text { Leaks large } \\
\text { amount of helium } \\
\text { to the room }\end{array}$ & $\begin{array}{l}\text { Depressurize } \\
\text { helium system, } \\
\text { shut down ITER } \\
\text { for post-disruption } \\
\text { inspection. ITER } \\
\text { cannot run until } \\
\text { TBM is repaired. }\end{array}$ & $\begin{array}{l}\text { Helium LOCA, } \\
\text { LBV1 }\end{array}$ & $\begin{array}{l}\text { Assume a rupture } \\
\text { flow rate gives an } \\
\text { immediate plasma } \\
\text { disruption due to } \\
\text { helium intrusion } \\
\text { at the plasma } \\
\text { edge. } \\
\end{array}$ & $3.3 \mathrm{E}-09 / \mathrm{h}-\mathrm{m}$ & $\begin{array}{l}\text { WSRC-TR-93- } \\
262\end{array}$ & \\
\hline & & fouling & Category IV & $\begin{array}{l}\text { foreign material } \\
\text { intrusion and } \\
\text { buildup on tube } \\
\text { walls, moisture in } \\
\text { helium gas }\end{array}$ & $\begin{array}{l}\text { Helium purity } \\
\text { control, gas drying }\end{array}$ & $\begin{array}{l}\text { Gradual } \\
\text { degradation of } \\
\text { heat transfer to the } \\
\text { helium coolant }\end{array}$ & $\begin{array}{l}\text { Gradual heatup of } \\
\text { the TBM. Begin } \\
\text { an orderly } \\
\text { shutdown of ITER } \\
\text { when coolant } \\
\text { temperatures } \\
\text { increase. }\end{array}$ & FB2 & & $1 \mathrm{E}-04 / \mathrm{yr}$ & analyst judgment & $\begin{array}{l}\text { Helium systems } \\
\text { are reputed to be } \\
\text { very clean. } \\
\text { HTGRs have } \\
\text { only had graphite } \\
\text { dust and moisture } \\
\text { conserns. } \\
\text { Assume this is a } \\
\text { category IV } \\
\text { event. }\end{array}$ \\
\hline & & flow blockage & Category IV & $\begin{array}{l}\text { construction or } \\
\text { maintenance } \\
\text { debris blocks flow }\end{array}$ & $\begin{array}{l}\text { Comprehensive } \\
\text { system } \\
\text { commissioning, } \\
\text { flow test before } \\
\text { each operating } \\
\text { period. }\end{array}$ & $\begin{array}{l}\text { Localized loss of } \\
\text { helium flow in } \\
\text { TBM. This may } \\
\text { not be sensed by } \\
\text { instrumentation. }\end{array}$ & $\begin{array}{l}\text { Must begin an } \\
\text { orderly shut down } \\
\text { of ITER when } \\
\text { TBM temperature } \\
\text { begins to increase. }\end{array}$ & FB2 & & $9 \mathrm{E}-05 / \mathrm{yr}$ & $\begin{array}{l}\text { Analyst judgment } \\
\text { based on HFIR } \\
\text { PRA analyses }\end{array}$ & $\begin{array}{l}\text { Water cooled } \\
\text { systems have had } \\
\text { screws, bolts, } \\
\text { bearings, gasket } \\
\text { pieces, weld slag, } \\
\text { rust particles, } \\
\text { etc., in the piping } \\
\text { system. } \\
\text { Personnel have } \\
\text { left pencils, rags, } \\
\text { tools, and other } \\
\text { debris. High } \\
\text { Flux Isotope } \\
\text { Reactor PRA, } \\
\text { PLG-0604, } 1988 .\end{array}$ \\
\hline $\begin{array}{l}\text { Vacuum } \\
\text { penetrations for } \\
\text { helium lines, } 2 \\
\text { penetrations }\end{array}$ & NO & leakage & Category III & $\begin{array}{l}\text { fretting wear, } \\
\text { vibration, material } \\
\text { failure }\end{array}$ & $\begin{array}{l}\text { Materials } \\
\text { selection in } \\
\text { design, periodic } \\
\text { inspection, NDT }\end{array}$ & $\begin{array}{l}\text { Small air } \\
\text { inleakage from } \\
\text { port cell room to } \\
\text { VV }\end{array}$ & $\begin{array}{l}\text { Must begin an } \\
\text { orderly shutdown } \\
\text { of ITER, receiving } \\
\text { Be-air reactions }\end{array}$ & VVA2 & $\begin{array}{l}\text { Assume under } \\
\text { vacuum all year, } \\
8760 \mathrm{~h} \text {. }\end{array}$ & $1 \mathrm{E}-07 / \mathrm{h}$ & analyst judgment & \begin{tabular}{|l|} 
Used \\
NUREG/CR- \\
1730 piping \\
penetration \\
failure to seal as \\
basis. \\
\end{tabular} \\
\hline
\end{tabular}




\begin{tabular}{|c|c|c|c|c|c|c|c|c|c|c|c|c|}
\hline Component & $\begin{array}{c}\text { Operational } \\
\text { State }\end{array}$ & Failure Mode & $\begin{array}{r}\text { Frequency } \\
\text { Category }\end{array}$ & Possible Causes & $\begin{array}{c}\text { Preventive } \\
\text { Action on } \\
\text { Possible Causes }\end{array}$ & Consequences & $\begin{array}{c}\text { Corrective or } \\
\text { Preventive } \\
\text { Actions on } \\
\text { Consequences }\end{array}$ & $\begin{array}{l}\text { ITER Postulated } \\
\text { Initiating Events }\end{array}$ & Comments & Frequency & $\begin{array}{c}\text { Comment on } \\
\text { frequency } \\
\text { calculation }\end{array}$ & $\begin{array}{c}\begin{array}{c}\text { Design } \\
\text { comments }\end{array} \\
\end{array}$ \\
\hline & & rupture & Category III & $\begin{array}{l}\text { fretting wear, } \\
\text { vibration, material } \\
\text { failure }\end{array}$ & \begin{tabular}{|l|} 
Materials \\
selection in \\
design, periodic \\
inspection, NDT
\end{tabular} & $\begin{array}{l}\text { Large air } \\
\text { inleakage from } \\
\text { port cell room to } \\
\text { VV }\end{array}$ & \begin{tabular}{|l} 
Must shut down \\
ITER if air has not \\
already disrupted \\
the plasma. \\
Receiving \\
widespread Be-air \\
reactions.
\end{tabular} & VVA2 & $\begin{array}{l}\text { Assume under } \\
\text { vacuum all year, } \\
8760 \mathrm{~h} \text {. }\end{array}$ & $1 \mathrm{E}-08 / \mathrm{h}$ & \begin{tabular}{|l} 
analyst judgment \\
\end{tabular} & $\begin{array}{l}\text { Assume a rupture } \\
\text { is } 0.1 x \text { the } \\
\text { leakage failure } \\
\text { rate. }\end{array}$ \\
\hline
\end{tabular}


Appendix D

Active Repair Times for TBM

$\mathrm{Pb}-17 \mathrm{Li}$ Components 


\section{Appendix D: Active Repair Times for TBM Pb-17Li Components}

\section{D-1. INTRODUCTION}

To perform a radiological dose assessment of workers occupying radiation zones, the expected residence times are needed. The active repair time is the time that workers are at or near the component in question, performing the necessary tasks. Total repair time is generally referred to as the entire component outage time, and it includes the system shut down and cooldown, time spent "safing" the system for personnel access, time to bring spare parts to the work location, time spent outside the radiation zone preparing for the labor activity, and the post-repair system operability testing to demonstrate that the repair is good and the system can be returned to service. The active repair time is the time sought here to give radiation dose estimates. The helium flow loop is not considered here since it is known that helium does not activate and any radiation around the helium loop will be very small, plus most of the helium loop components are located in a vault room far from the tokamak, where radiation fields are very low. The blanket module box is not treated here since it is recognized that there is no hands-on, in situ repair to the irradiated TBM module box, and replacement of the TBM box will be performed as an all-remote handling activity. An initial estimate for TBM box replacement is 400 hours.

As with the component failure rate data needs in the Failure Modes and Effects Analysis for the Pb-17Li flow loop in the main body of this report, representative data from liquid sodium fission reactors was sought first. Literature searches revealed that there has been little published information on maintenance of US sodium reactors. Two papers gave some overall radiation exposures for two sodium reactors, the Fast Flux Test Facility (FFTF) near Hanford, Washington (Bunch, 1990), and the Experimental Breeder ReactorII near Idaho Falls, Idaho (Olson, 1986). The overall exposure information that has been found is summarized below in Table D-1. The TBM exposures are expected to be much less than these exposures since the TBM is much smaller and much less irradiated (short durations of low flux, no fission products) and is a smaller system than found at sodium-cooled reactors.

Other sodium-cooled and liquid metal reactor experiences were searched as well. Notably, the Dounreay Fast Reactor, a NaK cooled, $50 \mathrm{MW}$-thermal plant, discovered a small leak of 100 liters NaK per day in May 1967 (Matthews, 1968). The plant shut down to find and repair the leak on July 29, 1967. Locating the leak was hampered by high radiation fields and confined spaces in the reactor's containment sphere. Leak checking commenced in August 1967 but the leak could not be found. Ten grams of mildly irradiated Gold was mixed into the $\mathrm{NaK}$ coolant to act as a tracer. Eventually traces of Gold were found in the containment building outside the reactor, indicating that the leak was still flowing. In November 1967, core internals were removed to reduce radiation fields to $1-2$ $\mathrm{rem} /$ hour in containment. A manned entry for leak checking was carried out on November 12, but was inconclusive. The 24 heat exchangers were tested for leaks; finally on December 19 the leak was found in a 4-inch line.

Table D-1. Annual Worker Exposures at the EBR-II and FFTF sodium cooled reactors

\begin{tabular}{|c|c|c|c|}
\hline Calendar Year & $\begin{array}{c}\text { Average dose per } \\
\text { person (mrem) }\end{array}$ & $\begin{array}{l}\text { Highest individual } \\
\text { dose (mrem) }\end{array}$ & $\begin{array}{c}\text { Collective dose } \\
\text { (person-rem) }\end{array}$ \\
\hline \multicolumn{4}{|c|}{ Experimental Breeder Reactor-II } \\
\hline 1970 & 720 & -- & -- \\
\hline 1971 & 1,170 & -- & -- \\
\hline 1972 & 1,000 & -- & -- \\
\hline 1973 & 530 & -- & -- \\
\hline 1974 & 630 & -- & 40 \\
\hline 1975 & 1,350 & -- & 117 \\
\hline 1976 & 1,040 & -- & 103 \\
\hline 1977 & 1,200 & -- & 87 \\
\hline 1978 & 800 & -- & 56 \\
\hline 1979 & 830 & -- & 59 \\
\hline 1980 & 310 & -- & 41 \\
\hline 1981 & 370 & -- & 150 \\
\hline 1982 & 450 & -- & 41 \\
\hline 1983 & 320 & -- & 61 \\
\hline 1984 & 270 & -- & 58 \\
\hline \multicolumn{4}{|c|}{ Fast Flux Test Facility } \\
\hline 1982 & 36 & 200 & 10 \\
\hline 1983 & 22 & 200 & 5 \\
\hline 1984 & 37 & 250 & 13 \\
\hline 1985 & 4 & 110 & 1 \\
\hline 1986 & 20 & 290 & 2 \\
\hline 1987 & 5 & 110 & 1.1 \\
\hline 1988 & 7 & 200 & 1.5 \\
\hline 1989 & 6 & 50 & 1.2 \\
\hline \multicolumn{4}{|c|}{$\begin{array}{l}\text { Note: person-rem data for EBR-II came from the web site } \\
\mathrm{http} / / \text { hss.energy.gov/CSA/Analysis/rems/annual/pri_ann.htm } \\
\text { In each reactor, the maintenance workers accounted for } 75-80 \% \text { of the dose, with the remainder } \\
\text { being divided about evenly between plant operators and instrumentation \& controls (I\&C) } \\
\text { technicians. }\end{array}$} \\
\hline
\end{tabular}


The line was drained, cut with hacksaws, and removed. In the January-February time frame, scaffolds were erected, pipe lagging was removed, new pipework was designed and fabricated, equipment was tested, and an internal pipe welding machine was developed. Detailed work plans were made to reduce exposure time. Repairs proceeded in March 1968. The work went slowly due to each person's exposure limit of $1 \mathrm{rem} / \mathrm{month}$; this dose limit could be realized in as little as 2 hours of labor. Several staff volunteered to receive an allowable overexposure of $10 \mathrm{rem} / \mathrm{month}$. In welding, NaK would melt and contaminate the weld, so sodium metal plugs were fashioned and pushed $\sim 18 \mathrm{~cm}$ into the pipe ends to confine the $\mathrm{NaK}$ away from the weld heat affected zones. Eventually the pipe was welded into place and radiographed, then pressure tested (leaving the plugs inside the pipe ends). The Dounreay plant restarted on June 22, 1968. This was roughly eleven months of outage time for a 100 liter/day leak.

The Phenix sodium-cooled plant had cracks forming in some of the superheater and reheater tubes (Cavagna, 2006). In 2001 a building was constructed to handle the tubes for weld repair. Over nine months in 2002, forty-seven steam generator superheater/reheater modules ( 7 tubes per module) measuring $16.9 \mathrm{~m}$ long were removed, given $>160$ hours of cleaning, and then were welded and radiographed. 1,500 welds were made and inspected using 8,500 gamma radiographs. Personnel exposure totalled $6.1 \mathrm{mSv}$ for the task. In two additional months in 2002, all of the modules were reassembled in the Phenix steam generator. Assuming that just one of these modules is comparable to a TBM heat exchanger, then 11 months or 334 days/47 modules gives roughly 7 days per module. This is a poor average, since the time to uninstall and reinstall the tube module is distributed over all of the modules, but it does give the order of magnitude of a tube repair activity.

This document treats three types of repair times, the active repair for corrective maintenance (e.g., replacing a seal on an existing component), the active maintenance time to perform routine actions (e.g., calibration, inspection, surveillance testing), and the active repair time to replace a component (e.g., replace a pump, tank or valve). Some component repair times for water system components in nuclear and in typical industrial environments have been assembled to apply to the Pb-17Li flow loop. Unfortunately, statistical tabulations of repair time data are sparse in the literature. The best known sources of averaged labor times are for construction labor estimating (Means, 2007) and for automobile mechanical repair (Chilton, 2007). Without fusion or fission liquid metal maintenance time data readily available, water cooling system data are used here. The water system data mainly come from power generation, both fossil and nuclear, and other commercial industries. The TBM is much smaller than the components maintained in the power generation industry, so effort was made to find repair times applicable to small size components. For example, Milivojevic (1989) gave repair times for PWR primary cooling pumps that ranged from 142.9 hours to 500 hours in the first 10,000 hours of operation. The repair time peaked at 2,000 hours and was as low as 100 hours over pump lifetime. The overall Mean Time To Repair (MTTR) was $\sim 1,000$ hours. However, a PWR primary coolant pump is large (7.5 MW, versus $20 \mathrm{~kW}$ for the TBM, and water flows of $\sim 350$ $\mathrm{Mg} /$ minute versus $\mathrm{Pb}-17 \mathrm{Li}$ flow at $72 \mathrm{~kg} /$ minute) and requires different maintenance demands (scaffolds, cranes, etc.) to service the unit. Comparing Milivojevic data on a set of about 500 PWR pumps to collected data on smaller water pump units shows that for smaller centrifugal pumps, the mean time to repair (MTTR) is much smaller: 6.8 hours (pumps flowing less than $3.6 \mathrm{Mg} / \mathrm{minute}$ ), 7.8 hours (pumps with flow rates between 3.6 and $7.3 \mathrm{Mg} /$ minute), and 26.7 hours (pumps with flow rates between 7.3 and 364 $\mathrm{Mg} /$ minute) (Shultz, 982; Cullinane, 1989). Another important source of repair times has been given by Butler (2000) for repairs to shipboard components - these components are much closer to the TBM in size than the large power plant components. When repair times for small size components were not available, the repair times for large-scale components were ratioed down to apply to the TBM. The US TBM is helium and lithium-lead cooled rather than water-cooled, but the power industry data for water system components are the most representative repair times available to apply to the low pressure lithium-lead components of interest, and are presently the most reasonable data to use for the scoping ORE assessment. It is noted from the literature that past fusion ORE estimates have also used fission reactor experiences to give repair times (Sandri, 2000; Sandri, 2002; Sandri, 2004). Efforts are also being made to collect actual operating experiences from existing tokamaks to support ITER ORE estimates (Natalizio, 2005; Natalizio, 2005a); however, these data are of limited use on the TBM since the TBM is a unique piece of equipment that is not presently used in tokamaks.

\section{D-2. ACTIVE REPAIR TIMES}

The main $\mathrm{Pb}-17 \mathrm{Li}$ flow loop components, their failure rates and failure probabilities per year (taken from the TBM preliminary FMEA tables in Appendix A), and the average active repair times; that is, mean time to repair (MTTR) values, are listed in Table D-2.

It is noted in Table 2 that most of the annual probabilities of needing repairs to any given component in a particular component type are small. Therefore, in a given year there may not be any repair activities. However, there will be annual preventive maintenance, surveillance testing, and inspections of the flow loop components. Lofaro (1991) discussed frequencies of testing light water reactor Component Cooling Water System components. MOV stroke time and valve seat leakage, and check valve leakage and flow, were measured each 3 months. Pressure relief valve setpoints were checked each 5 years. Pump vibration and pump head were tested each 3 months, as well as suction pressure, flow rate, bearing temperature, lubricant temperature and level, motor voltage, and performance testing. Pump inspection and maintenance for water system pumps has been discussed by Karassik (1976). Karassik suggested daily inspections (just a few minutes duration) to listen for suspect noises and look for leakage of either process fluid or bearing lube oil. Semi-annual inspections for seal performance and bearing lubricant change were recommended, and annual bearing and shaft packing inspection should be performed. Therefore, it seems that many tests and inspections are carried out several times per year and the entries into radiation areas for these purposes will give higher annual exposure times for personnel than the repair activities. 
Table D-2. Component Failure Rates and Repair Times

\begin{tabular}{|c|c|c|c|c|c|c|}
\hline Component type & $\begin{array}{c}\text { Component } \\
\text { count }\end{array}$ & $\begin{array}{c}\text { Overall "all } \\
\text { modes" failure } \\
\text { rate }\end{array}$ & $\begin{array}{c}\text { Probability of a } \\
\text { component in } \\
\text { this type failing } \\
\text { in a calendar } \\
\text { year }\end{array}$ & $\begin{array}{c}\text { Mean Time } \\
\text { to Repair, MTTR } \\
\text { (hours) }\end{array}$ & $\begin{array}{l}\text { Person-hours } \\
\text { active } \\
\text { repair time } \\
\text { (hours) }\end{array}$ & Reference \\
\hline Motor controller & 1 & $7.6 \mathrm{E}-05 / \mathrm{h}$ & $0.26 \mathrm{c}$ & 2.4 & assume 4.8 & Cullinane, 1989 \\
\hline Circuit breaker & 1 & $3 \mathrm{E}-07 / \mathrm{h}$ & 0.001 & 6.0 & assume 12 & IEEE, 1997 \\
\hline Pump motor & 1 & $\begin{array}{c}5.5 \mathrm{E}-03 / \mathrm{d} \\
\text { (hourly motor faults } \\
\text { were included with } \\
\text { the pump) }\end{array}$ & $0.04 \mathrm{c}$ & 50.2 & assume 100.4 & IEEE, 1997 \\
\hline Pump & 1 & $8.23 \mathrm{E}-05 / \mathrm{h}$ & $0.28 \mathrm{c}$ & 6.8 & assume 13.6 & Cullinane, 1989 \\
\hline Level sensor & 2 & $2.4 \mathrm{E}-06 / \mathrm{h}$ & 0.016 & 6 & assume 12 & Hannaman, 1978 \\
\hline Pressure sensor & 3 & $2 \mathrm{E}-06 / \mathrm{h}$ & 0.021 & 6 & assume 12 & Hannaman, 1978 \\
\hline $\begin{array}{l}\text { Temperature } \\
\text { sensor }\end{array}$ & 3 & $1.92 \mathrm{E}-05 / \mathrm{h}$ & $0.18 \mathrm{c}$ & 6 & assume 12 & Hannaman, 1978 \\
\hline Piping & $200 \mathrm{~m}$ & $1.29 \mathrm{E}-08 / \mathrm{h}-\mathrm{m}$ & 0.006 & 30 per leak & $\begin{array}{l}\text { assume } 60 \\
12.5 \text { per } \mathrm{m}\end{array}$ & $\begin{array}{l}\text { Hannaman, } 1978 \\
\text { Butler, } 2000\end{array}$ \\
\hline Check valve & 3 & $\begin{array}{l}2 \mathrm{E}-04 / \mathrm{d}+ \\
2.5 \mathrm{E}-06 / \mathrm{h}\end{array}$ & 0.024 & 24 & assume 48 & Hannaman, 1978 \\
\hline $\begin{array}{l}\text { Motor operated } \\
\text { valve }\end{array}$ & 12 & $\begin{array}{l}1 \mathrm{E}-03 / \mathrm{d}+ \\
1.65 \mathrm{E}-05 / \mathrm{h}\end{array}$ & $0.11 \mathrm{c}$ & 7.5 & 15 & Butler, 2000 \\
\hline Flow control valve & 2 & $\begin{array}{l}1 \mathrm{E}-03 / \mathrm{d}+ \\
2.4 \mathrm{E}-06 / \mathrm{h}\end{array}$ & 0.022 & 7.5 & 15 & Butler, 2000 \\
\hline $\begin{array}{l}\text { Transition to } \\
\text { concentric pipe }\end{array}$ & 1 & $5.05 \mathrm{E}-08 / \mathrm{h}$ & 0.00017 & 30 per leak & assume 60 & Hannaman, 1978 \\
\hline Concentric pipe & $2 \mathrm{~m}$ & $6.69 \mathrm{E}-08 / \mathrm{h}$ & 0.00022 & 30 per leak & assume 60 & Hannaman, 1978 \\
\hline $\begin{array}{l}\text { Concentric pipe } \\
\text { inlet to TBM }\end{array}$ & 1 & $3.3 \mathrm{E}-05 / \mathrm{h}$ & $0.11 \mathrm{c}$ & Remote handling & -- & \\
\hline
\end{tabular}


Table D-2. Component Failure Rates and Repair Times, continued.

\begin{tabular}{|c|c|c|c|c|c|c|}
\hline Component type & $\begin{array}{l}\text { Component } \\
\text { count }\end{array}$ & $\begin{array}{c}\text { Overall "all } \\
\text { modes" failure } \\
\text { rate }\end{array}$ & $\begin{array}{l}\text { Probability of a } \\
\text { component in } \\
\text { this type failing } \\
\text { in a calendar } \\
\text { year }\end{array}$ & $\begin{array}{l}\text { Mean Time } \\
\text { to Repair } \\
\text { (hours) }\end{array}$ & $\begin{array}{l}\text { Person-hours } \\
\text { active } \\
\text { repair time } \\
\text { (hours) }\end{array}$ & Reference \\
\hline $\begin{array}{l}\text { Concentric pipe } \\
\text { outlet from TBM }\end{array}$ & 1 & $1 \mathrm{E}-04 / \mathrm{y}$ & 0.0001 & Remote handling & -- & \\
\hline Mixing tank & 1 & $1.05 \mathrm{E}-07 / \mathrm{h}$ & 0.00035 & 40 & assume 80 & Hannaman, 1978 \\
\hline $\mathrm{T}$ extraction tank & 1 & $2.4 \mathrm{E}-06 / \mathrm{h}$ & 0.008 & 30 & assume 60 & Hannaman, 1978 \\
\hline $\begin{array}{l}\mathrm{Pb}-\mathrm{Li} \text { to } \mathrm{He} \text { heat } \\
\text { exchanger }\end{array}$ & 1 & $4.11 \mathrm{E}-06 / \mathrm{h}$ & 0.014 & 30 & assume 60 & Hannaman, 1978 \\
\hline $\begin{array}{l}\text { Pump expansion } \\
\text { tank }\end{array}$ & 1 & $2.11 \mathrm{E}-05 / \mathrm{h}$ & $0.07 \mathrm{c}$ & 40 & assume 80 & Hannaman, 1978 \\
\hline Cold trap & 1 & $1.15 \mathrm{E}-05 / \mathrm{h}$ & $0.039 \mathrm{c}$ & 20 & assume 40 & analyst judgment \\
\hline $\begin{array}{l}\text { Cold trap heat } \\
\text { exchanger }\end{array}$ & 1 & $1.1 \mathrm{E}-06 / \mathrm{h}$ & 0.004 & 20 & assume 40 & analyst judgment \\
\hline Drain tank & 1 & $1.1 \mathrm{E}-06 / \mathrm{h}$ & 0.004 & 40 & assume 80 & Hannaman, 1978 \\
\hline Rupture disk & 1 & $\begin{array}{c}1 \mathrm{E}-04 / \mathrm{d}+ \\
1 \mathrm{E}-05 / \mathrm{h}\end{array}$ & $0.034 \mathrm{c}$ & 1 & assume 2 & analyst judgment \\
\hline $\begin{array}{l}\text { Pressure relief } \\
\text { valve }\end{array}$ & 1 & $4.16 \mathrm{E}-06 / \mathrm{h}$ & 0.014 & 7.5 & 15 & $\begin{array}{c}\text { assumed from } \\
\text { Butler, } 2000\end{array}$ \\
\hline $\begin{array}{l}\text { Drain tank electric } \\
\text { heater }\end{array}$ & 1 & $1.56 \mathrm{E}-06 / \mathrm{h}$ & 0.005 & 4 & assume 8 & analyst judgment \\
\hline \multicolumn{7}{|c|}{$\begin{array}{l}\text { Notes: Used 3,360 Pb-17Li loop operating hours/year to obtain annual failure probabilities. Used guidance from Derdiger (1981) to estimate man- } \\
\text { hours needed given the MTTR value. } \\
\text { Probability of complete overhaul or replacement over the } 15 \text {-year lifetime of the TBM project ( } ~ 50,000 \text { hours operating time) is considered to } \\
\text { occur if the (probability/year)( } 15 \text { years) is greater than } 0.5 \text {. If a "c" appears in the probability column then the component is expected to require a } \\
\text { changeout; that is, one major overhaul or replacement during the } 15 \text {-year project life. The motor controller is probably not in the radiation area, it } \\
\text { can be close to the motor control center electrical panel. }\end{array}$} \\
\hline
\end{tabular}




\section{D-3. COMPONENT TESTING, PREVENTIVE MAINTENANCE AND CALIBRATION TIMES}

The largest yearly reason to enter the TBM port cell is for component inspection, surveillance testing, preventive maintenance, and calibration. Typical times for these activities in the fission industry are given in Table D-3. At present, it is not clear if fission-type inspections will be necessary on a yearly basis if the Pb-17Li piping is removed to replace the TBM module box every other year. The box removal will allow detailed inspection of the flow loop components on a biannual basis. Some explanations of the fission-based inspection times are given below.

An issue of importance is weld and piping tests. It is assumed that TBM welds in piping would be radiographed during construction, then the inspections would switch to ultrasonic (volumetric) inspection and dye penetration testing performed annually. At the Advanced Test Reactor (ATR), a fission reactor for materials irradiation at the INL, weld inspection is performed in two parts. The first part is dye penetrant. The technician wipes the pipe surface clean with dry rags, or a cleanser if necessary, then paints red dye on the weld with a brush or spray can, lets the dye penetrate for about 10 minutes, the wipes down excess dye with another rag. Then a cleaner solution or plain water is used to remove residual surface dye and the weld is wiped down with rags again. After the solution or water is dried, a developer solution is sprayed on the pipe. The technician waits for 7-8 minutes and visually inspects for indications of dye in any cracks. If none are found, the white residue from the developer is wiped off to prepare the pipe weld for ultrasonic inspection. The dye process typically takes about 30 minutes for a $10 \mathrm{~cm}-$ diameter pipe. The technician, who usually works alone but has a buddy standing by outside the radiological area, can retreat from the radiation area during drying times, so exposure is only about 10 minutes out of the 30 -minute process.

The second part of weld inspection is ultrasonic testing (UT). UT is performed by hand and requires less than 10 minutes per weld to access the weld in a $5 \mathrm{~cm}$-diameter pipe, start the UT equipment, apply the petroleum jelly on the weld for good contact with the probe, track the probe around the weld circumference, verify that the inspection data was good, wipe the jelly off the pipe, and leave the weld location. For a $10 \mathrm{~cm}$-diameter pipe, the ultrasonic test time would be 10-15 minutes/weld. Small piping under $5 \mathrm{~cm}$-diameter would take perhaps only 5-10 minutes per weld. For small diameter welds, the total technician exposure time is estimated to be 20 minutes per weld during a combined dye and UT inspection.

Assuming a total of $200 \mathrm{~m}$ of piping in the TBM Pb-17Li flow loop, and assuming that a pipe section is typically $3 \mathrm{~m}$, and has on average 1 weld, gives 67 welds to inspect in the loop. Assuming the $20 \%$ inspection per year to give complete flow loop inspection in 5 years of loop lifetime gives 13 welds to inspect per year. At 20 minutes inspection time within the radiation field per weld, this is 4.3 hours per year for the piping welds. 
Table D-3. Testing, Calibration, and Preventive Maintenance Times

\begin{tabular}{|c|c|c|c|c|c|}
\hline $\begin{array}{c}\text { Type of } \\
\text { Component }\end{array}$ & $\begin{array}{c}\text { Number of } \\
\text { components } \\
\text { in } \mathrm{Pb}-17 \mathrm{Li} \\
\text { flow loop }\end{array}$ & $\begin{array}{c}\text { Average } \\
\text { test act } \\
\text { duration } \\
\text { per } \\
\text { component } \\
\text { (h) } \\
\text { \{multiply by 2 for } \\
\text { person-hours\} }\end{array}$ & $\begin{array}{l}\text { Range of } \\
\text { Test act } \\
\text { duration } \\
\text { (h) }\end{array}$ & $\begin{array}{l}\text { Typical test or } \\
\text { calibration activities } \\
\text { and frequency }\end{array}$ & Reference \\
\hline $\begin{array}{l}\text { Centrifugal } \\
\text { pump+motor }\end{array}$ & 1 & $\begin{array}{c}1.4 \\
0.005\end{array}$ & $0.25-4$ & $\begin{array}{l}\text { Leak inspection, } \\
\text { output check, four } \\
\text { times per year } \\
\text { Annual PM }\end{array}$ & $\begin{array}{l}\text { WASH, } \\
1975 \\
\text { Shultz, } \\
1982\end{array}$ \\
\hline $\begin{array}{l}\text { Motor } \\
\text { operated } \\
\text { valve }\end{array}$ & 17 & $\begin{array}{l}0.86 \\
0.01\end{array}$ & $0.25-2$ & $\begin{array}{l}\text { Open/close torque, } \\
\text { leak inspection, four } \\
\text { times per year } \\
\text { Annual PM }\end{array}$ & $\begin{array}{l}\text { WASH, } \\
1975 \\
\\
\text { Shultz, } \\
1982\end{array}$ \\
\hline Check valve & 3 & 0.86 & $0.25-2$ & $\begin{array}{l}\text { Leak inspection, valve } \\
\text { disk proper operation, } \\
\text { four times per year }\end{array}$ & $\begin{array}{l}\text { WASH, } \\
1975\end{array}$ \\
\hline Relief valve & 1 & 0.86 & $0.25-2$ & $\begin{array}{l}\text { Leak inspection, } \\
\text { spring tension, suggest } \\
\text { annual inspection }\end{array}$ & $\begin{array}{l}\text { WASH, } \\
1975\end{array}$ \\
\hline Piping & $\begin{array}{c}\sim 200 \mathrm{~m} \\
(0.16 \mathrm{~m} \\
\text { diameter and } \\
\text { less })\end{array}$ & $\begin{array}{c}2.15 \\
\text { (based on } \\
\text { 20\% test per } \\
\text { year) }\end{array}$ & & $\begin{array}{l}\text { Leak inspection, wall } \\
\text { thinning inspection, } \\
\text { ASME ISI, annual }\end{array}$ & $\begin{array}{l}\text { See text for } \\
\text { NDT } \\
\text { discussion }\end{array}$ \\
\hline $\begin{array}{l}\text { Expansion } \\
\text { tank }\end{array}$ & 1 & 0.125 & & $\begin{array}{l}\text { Leak inspection, wall } \\
\text { thinning inspection, } \\
\text { ASME ISI. Once in } \\
\text { TBM lifetime }\end{array}$ & $\begin{array}{l}\text { Butler, } \\
2000\end{array}$ \\
\hline Mixing tank & 1 & 0.125 & & $\begin{array}{l}\text { Leak inspection, wall } \\
\text { thinning inspection, } \\
\text { ASME ISI. Once in } \\
\text { TBM lifetime }\end{array}$ & $\begin{array}{l}\text { Butler, } \\
2000\end{array}$ \\
\hline
\end{tabular}


Table D-3. Testing, Calibration, and Preventive Maintenance Times, continued.

\begin{tabular}{|c|c|c|c|c|c|}
\hline $\begin{array}{c}\text { Type of } \\
\text { Component }\end{array}$ & $\begin{array}{c}\text { Number of } \\
\text { components } \\
\text { in } \mathrm{Pb}-17 \mathrm{Li} \\
\text { flow loop }\end{array}$ & $\begin{array}{c}\text { Average } \\
\text { test act } \\
\text { duration } \\
\text { per } \\
\text { component } \\
\text { (h) } \\
\text { \{multiply by } 2 \text { for } \\
\text { person-hours\} }\end{array}$ & $\begin{array}{l}\text { Range of } \\
\text { Test act } \\
\text { duration } \\
\text { (h) }\end{array}$ & $\begin{array}{l}\text { Typical test or } \\
\text { calibration activities } \\
\text { and frequency }\end{array}$ & Reference \\
\hline Drain tank & 1 & 0.125 & & $\begin{array}{l}\text { Leak inspection, wall } \\
\text { thinning inspection, } \\
\text { ASME ISI. Once in } \\
\text { TBM lifetime }\end{array}$ & $\begin{array}{l}\text { Butler, } \\
2000\end{array}$ \\
\hline $\begin{array}{l}\text { Drain tank } \\
\text { heater }\end{array}$ & 1 & 0.86 & $0.25-2$ & $\begin{array}{l}\text { Operability test, output } \\
\text { measurement, annual }\end{array}$ & $\begin{array}{l}\text { Assumed } \\
\text { from } \\
\text { WASH- } \\
1400 \\
\text { values }\end{array}$ \\
\hline Cold trap & 1 & 0.125 & & $\begin{array}{l}\text { Leak inspection, wall } \\
\text { thinning inspection, } \\
\text { ASME ISI. Once in } \\
\text { TBM lifetime }\end{array}$ & $\begin{array}{l}\text { Assumed } \\
\text { from Butler } \\
\text { values for } \\
\text { tank test }\end{array}$ \\
\hline $\begin{array}{l}\text { Cold trap heat } \\
\text { exchanger }\end{array}$ & 1 & 0.125 & & $\begin{array}{l}\text { Leak inspection, wall } \\
\text { thinning inspection, } \\
\text { ASME ISI. Once in } \\
\text { TBM lifetime }\end{array}$ & $\begin{array}{l}\text { Assumed } \\
\text { to be a } \\
\text { jacket } \\
\text { around the } \\
\text { cold trap, } \\
\text { so applied } \\
\text { a tank } \\
\text { value. }\end{array}$ \\
\hline $\begin{array}{l}\text { Vacuum } \\
\text { permeator } \\
\text { (like a heat } \\
\text { exchanger) }\end{array}$ & 1 & $\begin{array}{l}8.6 \\
6.0\end{array}$ & & $\begin{array}{l}\text { Eddy current test. } \\
\text { Hydraulic test. } \\
\text { Each once in lifetime }\end{array}$ & $\begin{array}{l}\text { Taken from } \\
\text { heat } \\
\text { exchanger } \\
\text { below }\end{array}$ \\
\hline $\begin{array}{l}\mathrm{Pb}-17 \mathrm{Li} \text { to } \\
\text { Helium Heat } \\
\text { exchanger }\end{array}$ & 1 & $\begin{array}{l}8.6 \\
6.0\end{array}$ & & $\begin{array}{l}\text { Eddy current test. } \\
\text { Hydraulic test. } \\
\text { Each once in lifetime }\end{array}$ & See text \\
\hline
\end{tabular}


Table D-3. Testing, Calibration, and Preventive Maintenance Times, continued.

\begin{tabular}{|l|c|c|c|l|l|}
\hline \multicolumn{1}{c}{$\begin{array}{c}\text { Type of } \\
\text { Component }\end{array}$} & $\begin{array}{c}\text { Average } \\
\text { test act } \\
\text { duration } \\
\text { per } \\
\text { components } \\
\text { in Pb-17Li } \\
\text { flow loop }\end{array}$ & $\begin{array}{c}\text { (omponent } \\
\text { (h) } \\
\text { fmultiply by } 2 \text { for } \\
\text { person-hours }\end{array}$ & $\begin{array}{c}\text { Range of } \\
\text { Test act } \\
\text { duration } \\
\text { (h) }\end{array}$ & $\begin{array}{c}\text { Typical test or } \\
\text { calibration activities } \\
\text { and frequency }\end{array}$ & Reference \\
\hline $\begin{array}{l}\text { Temperature } \\
\text { instrument }\end{array}$ & 3 & 1.4 & $0.25-4$ & $\begin{array}{l}\text { Adjust, calibrate, } \\
\text { biannual }\end{array}$ & $\begin{array}{l}\text { WASH, } \\
1975\end{array}$ \\
\hline $\begin{array}{l}\text { Pressure } \\
\text { instrument }\end{array}$ & 3 & 1.4 & $0.25-4$ & $\begin{array}{l}\text { Adjust, calibrate, } \\
\text { biannual }\end{array}$ & $\begin{array}{l}\text { WASH, } \\
1975\end{array}$ \\
\hline $\begin{array}{l}\text { Level } \\
\text { instrument }\end{array}$ & 2 & 1.4 & $0.25-4$ & $\begin{array}{l}\text { Adjust, calibrate, } \\
\text { biannual }\end{array}$ & $\begin{array}{l}\text { WASH, } \\
1975\end{array}$ \\
\hline
\end{tabular}

Notes: A buddy system of two workers in radiation areas should be assumed, hence the multiplication by 2 for person-hours. Typical surveillance includes component testing, calibration or inspection to assure proper component operation within safety limits and that limiting conditions for operation will be met. Some of this testing would be carried out during, or near the end of, ITER outages when personnel ORE would be minimized.

The piping In Service Inspection is a 120-month interval test of welds as specified in the ASME Section XI. Power plants typically perform $10 \%$ of their piping NDT inspections during outages each year to determine that they are meeting the 120-month schedule. A suggestion is that the TBM inspect $20 \%$ of its piping annually, or at least annually inspect the piping regions of greatest reliability concern.

Eddy current inspection of the heat exchanger tubes must be performed periodically. At the ATR, eddy current inspection is performed every 10 years. A full inspection of all tubes in a heat exchanger (containing about 1,300 tubes that are bent into U-tubes for about 92,000 square feet per heat exchanger) requires about 1.5 weeks, or roughly 60 calendar hours, with a crew of two inspectors, so 120 person-hours per heat exchanger. This figure would be scaled down for a smaller unit by number of tubes or perhaps by square footage. The TBM Pb-17Li-to-helium heat exchanger has 56 tubes and $4.22 \mathrm{~m}^{2}$ tube surface area (Wong, 2005 Table 2.2.2-3), so using a ratio from the ATR experience ( $\sim 10.8$ tubes/person-hour) gives 5.2 person-hours for eddy current testing. Cleaning the heat exchanger to allow eddy current testing is estimated from Butler (2000), where a $5 \mathrm{~m}^{2}$ heat exchanger cleaned by air or water lance required 12 man-hours. Thus, heat exchanger eddy current testing could require 17.2 person-hours or 8.6 hours. For smaller heat exchangers, a hydraulic test can require $\sim 12$ man-hours ( 6 hours) for preparation, testing, and restoration to operational configuration (Butler, 2000).

According to ASME BPVC Section III, Division I, Part NB-6000, pressure tests of equipment, the equipment must undergo the hydrostatic test pressure for a minimum of 10 minutes before the inspector begins a visual inspection for leaks, deformation, out-ofround components, etc. The inspector does not have to remain in a radiation zone while the 10 minutes of 'pressure hold time' are passing, but the inspector does have to enter to examine the tank. Any leaks must be assessed as being within specifications or 
originating from temporary seals installed to perform the test. Considering the test setup time, gradual pressure increase time, hold time, inspection time, and pressure bleed-off time, a rough estimate of 1 hour is needed for pressure tests, but the Inspector and one system engineer do not stay in the radiation zone the entire time. A pressure test is performed before initial operation and after each major refurbishment of the system.

Some instruments can be calibrated remotely, and this capability is worth investigation for the TBMs (Hashemian, 1993). These so-called smart sensors are digital units that can accept remote commands; self-interrogate, self-adjust and even self-calibrate. If these sensors work well in the ITER fringe magnetic field, they would be useful to reduce personnel radiation exposure and also reduce personnel exposure to industrial hazards in the port cell.

\section{D-4 COMPONENT REPLACEMENT TIMES}

The third aspect of repairs is replacement of components. Replacement would only occur as a result of a complete failure that is too extensive to repair locally (e.g., pump impeller binds on pump volute) or too time consuming in a radiation field to repair (e.g., motor winding replacement), or externally-induced damage to a component. Some equipment replacement times from the Advanced Test Reactor (ATR), a fission reactor for materials irradiation at the INL, have been gathered to give some insights on component replacement times.

Major overhauls of equipment, or equipment replacements, tend to be lengthy but rare events, perhaps occurring every 5 to 10 years. Some data on typical repairs and major equipment overhaul times have been taken from INL internal records on the Advanced Test Reactor (ATR; operated 1968-present). ATR is a $250 \mathrm{MW}$-thermal fission reactor for materials irradiation. Several events are discussed below.

On October 10,1992, a small heat exchanger at ATR suffered a tube failure that resulted in tube-side liquid flowing into shell-side liquid. The heat exchanger had only been in service for 8 years. Operators noted what appeared to be a 17 gallon/minute leak from the process fluid to the lower pressure cooling fluid. For this heat exchanger unit neither the process fluid (tube side at $200 \mathrm{psi}$ ) nor the cooling fluid (shell side) were radioactive, but the fluid was important to proper operation of the plant. The reactor was shut down and the affected heat exchanger (one of two side-by-side units) was identified. The heat exchanger was shut down and cooled down, then the stuffing box was accessed. The leaking stainless steel tube was located, plugged, and the three adjacent tubes were also plugged in case the damaged tube had inflicted damage on the neighboring tubes. The tube bundle was not pulled to inspect the failure, that action was deferred to a later time in favor of plant restart. The heat exchanger was scheduled to be inspected during a future scheduled outage. The heat exchanger was pressure tested on both tube and shell sides and upon satisfactory results it was returned to service. Vibration and acoustical monitoring were also installed to allow for increased surveillance in case another tube failed. From plant scram to power ascension, 166 hours of operating time were lost. Accounting for overall plant cooldown, then heatup \& power ascension time, that leaves approximately 150 calendar hours for the tube repair activity. The number of workers is 
not known. It is assumed that there was one mechanic, one testing technician for tube eddy current testing, a radiological controls technician, and one foreman/supervisor. Some other typical repairs have included a 3-inch pipe weld repair on October 24, 1992 the small pipe leak was sensed, the pipe was depressurized and cooled for personnel safety. Repair time took 80 calendar hours to cut out the old pipe section, check the pipe ends, weld in a new pipe piece, and radiograph the work. On February 12, 1995, a very small water pump began to leak at its volute seal, the gasket was "washing out". Replacement of the seal required 92 calendar hours of reactor forced outage for repair and pressure test of the pump to return it to service, so 76 hours of actual repair time. On December 8, 1998, a one-inch pipe tee began to leak about 1 gallon/hour. From plant scram to power ascension, 120 hours of operating time were lost. Repair of the leaking weld required $\sim 104$ calendar hours for access, re-welding, radiography, and pressure test. The number of personnel is not known, but the area is a contamination zone, so as a guess, two welders, a radiation worker for decon, preparation, and area cleanup work, and a health physics technician. The supervisor and fire watch could observe from outside the zone.

Large equipment overhauls at ATR have included the four, 36-inch diameter check valves in the primary coolant system. During a plant outage, these valves were disassembled, decontaminated, inspected, the valve disk pins were surface re-hardened, the dash pot assemblies were cleaned and inspected for corrosion, the valve case was non-destructive test (NDT) inspected, then the valves were reassembled and the casing bolts torqued. The valves were leak checked and functionally tested, then declared operable again. The four valves were isolated at 0243 hours on September 25, 1995, then drained. Once dry, they were disassembled and parts laid down on the floor near the valves. Decontamination was performed, then interior inspection. Clevis units and hinge pins were hard surfaced. The valve case seals were changed and the valves reassembled. The valve bolts were retorqued and the valves were re-flooded for leak testing. This was accomplished for all four valves by 2352 hours on October 3, 1995, for a total of about 213 calendar hours. Thus, the overhaul of one large check valve would have required about 53.5 calendar hours with a crew of four workers (mechanics, fitters, and health physics technicians for survey and decon tasks).

A small, $40 \mathrm{hp}$ electric-motor driven centrifugal pump, 4,700 gpm water flow, at the ATR required shaft seal changeout. The pump shaft is horizontal. During a planned reactor outage on February 9, 1997, the pump was shut down and isolated at 2010 hours. At 1800 hours on February 10 the work began. The mechanic removed the pump top case and wrapped it in plastic to contain contamination left behind from evaporated coolant water. Radiological smear samples in the dry pump casing read $50 \mathrm{mr} / \mathrm{h}$, so work was suspended until a new Radiation Work Permit and ALARA review could be completed. Work stopped at 2249 hours while awaiting new paperwork. Work resumed at 1400 hours on February 13, the new seals were placed and the pump case top rebolting began by 1730 hours. Rebolting the pump casing top was completed and a pressure test took place at 2225 hours. The test failed; another set of new seals were needed. On February 17, from 1455 to 2310 hours, seal replacement tasks were under way. On February 18, work continued between 1120 and 1630 hours, ending with a leak check that showed a 1 
pint/minute leak (too high of a leak rate). Another two hours of labor were needed to correct the new seal leak problem. The total time was $4.75+8.5+8+5+2$ for two seal installations, or $\sim 14$ hours per seal for two mechanics. The companion pump unit seal replacement began at 0800 on February 19 and was completed with testing by 1500 hours, for a total time of 9 calendar hours with a crew of two mechanics. Thus, three pump shaft seal replacements required on average $\sim 12$ hours each, for two workers in each case.

In 1998, several pumps were replaced or given major overhauls at the reactor. A $100 \mathrm{hp}$, 300 gpm pump was overhauled. The impeller rings had bound up, seizing the shaft and halting the impeller. The pump was completely disassembled, new parts installed, and it was returned to service in 3.5 months after labor by an untracked number of workers. This was not a high urgency replacement since the ATR was in a scheduled outage for other reasons and there was a redundant pump available to meet any needs during the outage. Another pump was also replaced. The $30 \mathrm{~kW}$ (40 hp) pump and its motor were replaced over 14 days (336 hours) in October 1998 using an untracked number of workers. This was a major task but was not pursued 24-hours per day, there were some lulls in the task as workers were drawn away to perform other tasks during the plant outage. The task was not urgent since the facility was in a long outage for other reasons. Nonetheless, a time less than 14 days to replace a medium-sized pump and its motor is an initial estimate for a replacement time at a reactor facility.

In 2000, a heat exchanger sprung a shell leak at a weld. The leak was discovered at 1000 hours on March 27. Steps were taken to reduce the water leakage from the shell side. At 1000 hours on March 28, carpenters began erecting scaffolds to access the leak in the 10 to $100 \mathrm{mr} /$ hour radiation field. Any known or surveyed hot spots (e.g., $>1 \mathrm{rem} /$ hour) require sheets of temporary lead shielding to be placed for personnel protection. The ATR approach is to administratively limit that shield placement task exposure to below a safe value, such as $<100$ mrem. Scaffolding was in place by 2330 hours, about 13 hours of work for two carpenters. By March 30 at 0000 hours, the heat exchanger had been completely drained in preparation for weld repair. Repairs began at 1230 hours on March 31 , and the weld was completed, cooled, inspected, and radiographed by 1800 hours that day. This was 7.5 calendar hours for two welders with 0.5 hour for one radiographer to position equipment, shoot the weld, and check the results. The heat exchanger leak repair required 52 person-hours for scaffold setup and takedown, 15 person-hours for welders, and 0.5 person-hours for radiography. Health physics technicians surveyed the area before the work began, 0.5 person-hour, and a fire watch was needed during and after the hot work, 16 person-hours. It is noted that the TBM is horizontal mounted at floor level, so scaffolds are not needed for maintenance work. However, there may be temporary shielding curtain placement for extra protection above that offered by the permanent TBM shielding, and plastic sheets deployed at the parts lay-down area for contamination control. By INL procedure, parts weighing $22 \mathrm{~kg}$ or more require a chain hoist or other mechanical lifting apparatus. If similar rules are in force foe ITER, then lifting equipment must also be staged to support the maintenance replacement activity. 
The Engineering Test Reactor (ETR; operated 1957-1981), a predecessor to the ATR, discovered a primary coolant leak in a 36-inch SS304L pipe on August 28, 1965 (Smith, 1966). The pipe crack was 'weeping' liquid. A pipe crack had formed in a Y pattern around a 1.5-inch tap for a gas probe. The cause of the crack was fatigue due to vibrational flutter of the $\sim 12$ inch long gas probe wand in the primary coolant flow. A 9.5-inch by 6.25 inch pipe section containing the crack was cut out of the pipe and the edges of the pipe hole were beveled, then ultrasonically and dye penetrant tested. A backing strip was arc welded on the inner edge of the opening. A patch was cut to dimension, beveled and rolled to pipe wall curvature, then arc welded into the pipe wall. The initial weld pass on the patch and the completed weld were radiographed and dye penetrant tested. The actual repair work began at 0800 hours on August 29 with cutting out the "window" in the pipe wall to remove the cracked section. A patch was fabricated and welded into place. The patch was completed and ready for pressure testing by 0800 on September 2. After pressure testing was completed, a reinforcing band was placed around the patch. The initial pipe repair task required 96 calendar hours in an 80-100 $\mathrm{mrem} /$ hour radiation field. The documentation did not provide information on the number of workers involved. It is assumed that there were two welders, two NDT testers, and several health physics technicians standing by during work on the patch, but only one person of each craft was in the radiation field at a time, so an estimate of 288 personhours for this repair. Other personnel, such as the fire watch for hot work, machinists who fabricated the patch in the workshop, etc., could perform their work beyond the radiation field. Table D-4 gives the INL repair time experiences. Noting these times compared to a complete, remote changeout of the TBM ( 400 hours), perhaps an early TBM changeout would be less exposure than an in situ repair activity for a failed component.

Butler (2000) gave some values for motor operated gate valves of $150 \mathrm{~mm}$ bore and 20 atmospheres - major overhaul would be 21 man-hours per valve. A rupture disk is stated to be quickly and easily changed out in product literature. An analyst judgment value to open and remake the flange containing the rupture disk is 4 man-hours. Replacing a temperature sensor should take one instrument technician approximately 2.5 hours, one to replace the sensor head and 1.5 hour to calibrate the new sensor head. Small tank replacements require some time to "safe" the system, drain the tank, etc. An analyst judgment value of 48 man-hours is given to small tank replacement tasks.

Hummler (1988) described recirculation pipe replacements at the Muhleberg Boiling Water Reactor. The pipe replaced was: 177 feet of 18 -inch diameter ( 29 welds), 140 feet of 10-inch diameter (18 welds), 23 feet of 8 -inch diameter ( 6 welds), 6 feet of 6 -inch diameter ( 4 welds), 60 feet of 3 -inch diameter ( 13 welds), and 354 feet of 2 -inch diameter (156 welds). The pipe weighed a total of 30 metric tonnes. Project planning was 73,000 man-hours before the on-site work began. Training was given to 58 persons for mechanical cutting, 48 persons for welding, 15 persons for shielding installation and removal, 7 persons for decontamination, 8 persons for radiological survey operations. 
Table D-4. Summary of repair and replacement times from INL operating experiences

\begin{tabular}{|l|l|l|l|l|}
\hline Plant and date & Type of activity & Calendar hours & Man-hours & Comments \\
\hline ATR 1992 & HX tube plug & 150 & 600 & $\begin{array}{l}\text { Non-urgent } \\
\text { repair }\end{array}$ \\
\hline ATR 1992 & $\begin{array}{l}\text { 3-inch pipe weld } \\
\text { repair }\end{array}$ & 80 & 160 & Typical repair \\
\hline ATR 1995 & $\begin{array}{l}\text { Volute seal } \\
\text { replaced on small } \\
\text { pump }\end{array}$ & 76 & 152 & $\begin{array}{l}\text { Semi-urgent } \\
\text { repair }\end{array}$ \\
\hline ATR 1997 & $\begin{array}{l}\text { 40 hp pump shaft } \\
\text { seal replaced }\end{array}$ & 12 & 24 & Typical repair \\
\hline ATR 1998 & $\begin{array}{l}\text { 1-inch pipe weld } \\
\text { repair }\end{array}$ & 104 & 416 & Typical repair \\
\hline ATR 1998 & $\begin{array}{l}\text { 40 hp motor and } \\
\text { pump } \\
\text { replacement }\end{array}$ & 336 & $\begin{array}{l}\text { Non-urgent } \\
\text { repair }\end{array}$ \\
\hline ATR 2000 & $\begin{array}{l}\text { HX shell leak } \\
\text { repair }\end{array}$ & 144 & 84 & $\begin{array}{l}\text { Non-urgent } \\
\text { repair }\end{array}$ \\
\hline ETR 1965 & Pipe crack repair & 96 & $\sim 288$ & Urgent repair \\
\hline Note: urgency of repair concept was taken from IEEE, 1974. & \\
\hline
\end{tabular}

Total radiation exposure was 810 man-rems for the 760 feet of pipe replaced. The work began on November 11, 1986 and required about 12 weeks and 310,000 man-hours. A temporary piping workshop was built adjacent to the reactor containment before plant shutdown. Only one weld of the $29+18$ welds (in the 18- and 10-inch pipes) had to be remade. Welds were performed by machines for the large diameter pipes. Full volumetric ultrasonic testing and weld radiography were performed by machine on all of the piping before the recirculation system was pressure tested.

These maintenance times are point estimates from individual activities at a single nuclear facility. They are not good statistical average times for such activities, and the urgency of repair was not well defined in all cases; it was inferred from the documentation in the INL cases. Nonetheless, these values are indicative of the order of magnitude of time needed to perform major equipment repairs and replacements, e.g., hours to days to weeks.

Methods to work with alkali metal piping can be adapted to the $\mathrm{Pb}-17 \mathrm{Li}$ TBM piping. Figure D-1 shows how welding was performed on piping at the JOYO sodium-cooled reactor during heat exchanger replacement. The heat exchanger replacement activity at JOYO required 10 calendar months. The estimated dose to replace 6 heat exchangers (two intermediate $\mathrm{Na}-\mathrm{Na}$ heat exchangers and four $\mathrm{Na}$-air ultimate heat sink heat exchangers) was 5,235 person-mSv (523.5 person-rems). When the task was completed, the actual dose was 2,156 person-mSv (215.6 person-rems).

Some discussion of design for maintainability is given for military equipment (MIL, 1988) and has been adopted by industrial designers as well. The concepts are design simplification, standardized parts and interchangeable parts, personnel accessibility and 
component accessibility for replacement, modular components, component identification and labeling, and testability and diagnostic capability of the system.

The time estimates presented here should help to support the occupational radiation exposure estimation task for the DCLL TBM.

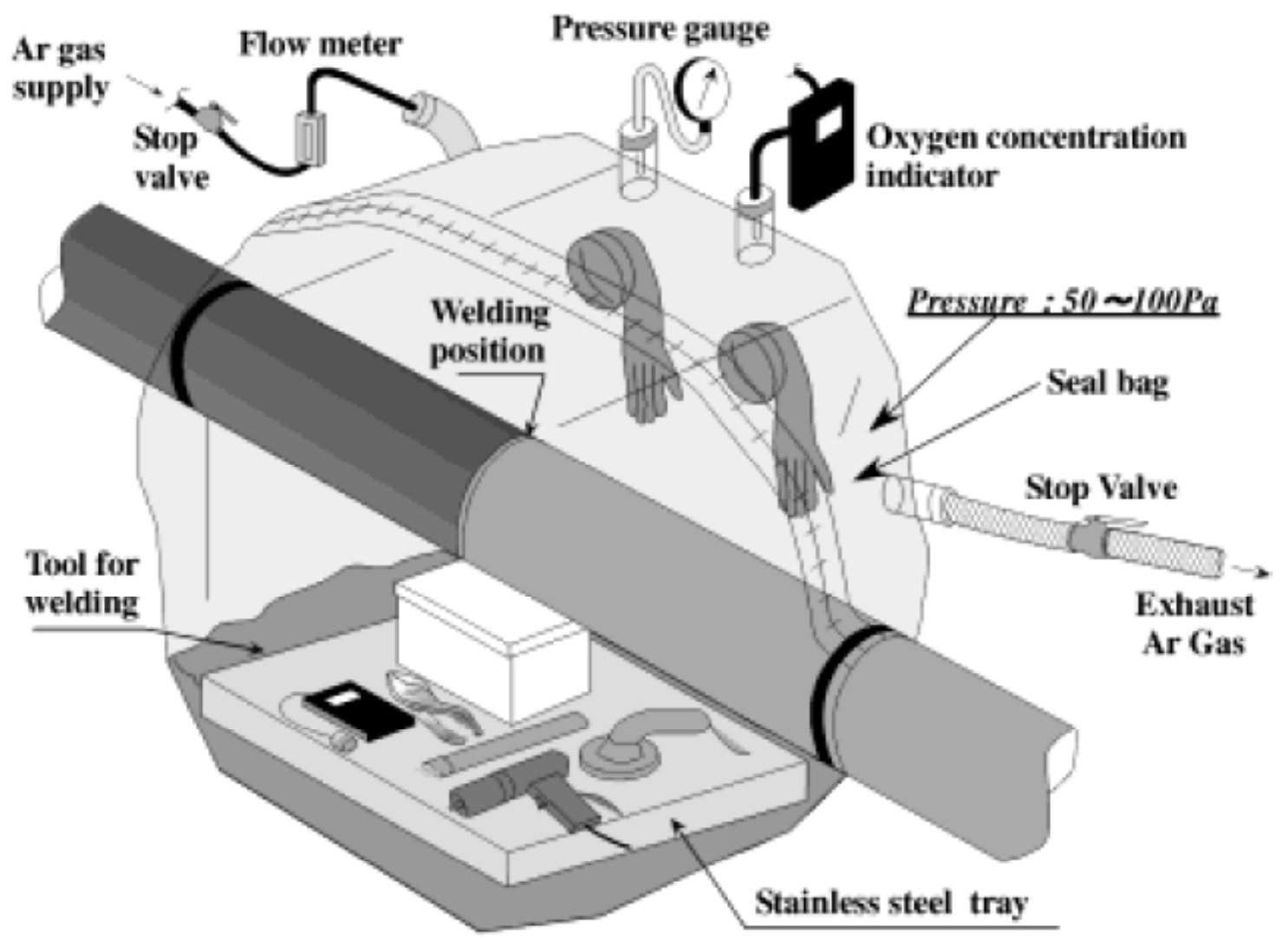

Figure D-1. Depiction of the inert atmosphere seal bag for welding piping. (Isozaki, 2005) 


\section{APPENDIX D REFERENCES}

Butler, 2000. D. Butler, Guide to Ship Repair Estimates (in Man-Hours), Butterworth Heinemann Publishers, Amsterdam, 2000.

Cavagna, 2006. Ch. Cavagna, O. Gastaldi, L. Martin, and V. Grabon, "Phenix Steam Generator Module Repair: Sodium Removal Process, Ultrasonic Controls, and Repair Method," Nuclear Technology, 153 (2006) 274-281.

Chilton, 2007. Chilton Labor Guide Manual, 2007 edition, Thomson Delmar Learning, Clifton Park, NY, 2007.

Cullinane, 1989. M. J. Cullinane, Jr., "Reliability and Maintainability Data for Water Distribution System Components," in L.W. Mays, editor, Reliability Analysis of Water Distribution Systems, American Society of Civil Engineers, New York, 1989, pages 225-246.

Derdiger, 1981. J. A. Derdiger, K. M. Bhatt, and W. E. Siegfriedt, Component Failure and Repair Data for Coal-fired Power Units, EPRI-AP-2071, Electric Power Research Institute, Palo Alto, CA, October 1981.

GA, 1978. G. W. Hannaman, GCR Reliability Data Bank Status Report, GA-A14839, General Atomic Company, San Diego, CA, July 1978.

Hashemian, 1993. H. M. Hashemian, D. W. Mitchell, K. M. Petersen, and C. S. Shell, Validation of Smart Sensor Technologies for Instrument Calibration Reduction in Nuclear Power Plants, NUREG/CR-5903, US Nuclear Regulatory Commission, Washington DC (1993).

Hummler, 1988. A. Hummler and R. Holz, "Recirculation loop replacement at boiling water reactors," Kerntechnik, 52 (1988) 131-135.

IEEE, 1974. IEEE Committee Report, "Report on Reliability Survey of Industrial Plants, Part III: Causes and Types of Failures of Electrical Equipment, the Methods of Repair, and the Urgency of Repair," IEEE Transactions on Industry Applications, 10 (1974) 242-252.

IEEE, 1984. IEEE Guide to the Collection and Presentation of Electrical, Electronic, Sensing Component, and Mechanical Equipment Reliability Data for NuclearPower Generating Stations, IEEE Std 500-1984, Institute of Electrical and Electronics Engineers, New York, December 1983, Page 286.

IEEE, 1997. IEEE Recommended Practice for the Design of Reliable Industrial and Commercial Power Systems, IEEE Std 493-1997, Institute of Electrical and Electronics Engineers, New York, December 1997, Appendices A and H. 
Isozaki, 2005. K. Isozaki, T. Ashida, K. Sumino, and S. Nakai, "Upgrade of Cooling System Heat Removal Capacity of the Experimental Fast Reactor JOYO," Nuclear Technology, 150 (2005) 56-66.

Karassik, 1976. I. J. Karassik, W. C. Krutzsch, W. H. Fraser, and J. P. Messina, Pump Handbook, McGraw-Hill Book Company, New York, 1976, chapter 13.

Lofaro, 1991. R. Lofaro, "Monitoring of LWR Component Cooling Water Systems," Proceedings of the International Meeting on Nuclear Power Plant and Facility Maintenance, Salt Lake City, Utah, April 7-10, 1991, American Nuclear Society, La Grange Park, IL, June 1991, volume 2, pages 597-605.

Matthews, 1968. R. R. Matthews and K. J. Henry, "Location and repair of the DFR leak," Nuclear Engineering, 13 (1968) 840-844.

Means, 2007. Building Construction Cost Data 2007, sixty-fifth edition, RS Means Company, Kingston, MA, 2007.

MIL, 1988. Maintainability Design Techniques, DOD-HDBK-791, US Department of Defense, Washington, DC, March 1988.

Milivojevic, 1989. S. Milivojevic and J. R. Riznic, "The Empirical Failure Rate and Repair Rate of PWR Primary Coolant Pumps," Reliability Engineering and System Safety, 24 (1989) 267-273.

Natalizio, 2005. A. Natalizio, T, Pinna, and J. D. Levine, "TFTR occupational radiation exposure data collection and analysis," Fusion Engineering and Design, 75-79 (2005) 1187-1191.

Natalizio, 2005a. A. Natalizio, M. T. Porfiri, and B. Patel, "Collection and analysis of occupational radiation exposure data from the JET tokamak," Fusion Engineering and Design, 75-79 (2005) 1193-1197.

Olson, 1986. W. H. Olson, "The Impact of Radionuclides on Maintenance of Experimental Breeder Reactor II," Argonne National Laboratory, CONF-8603111, presented at the American Nuclear Society Topical Meeting on Nuclear Power Plant Maintenance, Salt Lake City, Utah, March 23-27, 1986.

Sandri, 2000. S. Sandri and L. Di Pace, "Occupational radiation exposure during the inspection and maintenance of the ITER water cooling system, a comparison between two working strategies," Fusion Engineering and Design, 51-52 (2000) 445-551.

Sandri, 2002. S. Sandri and L. Di Pace, "Collective dose at ITER FEAT," Fusion Engineering and Design, 63-64 (2002) 199-203. 
Sandri, 2004. S. Sandri, A. Coniglio, L. Di Pace, and M. Pillon, "Radiological safety of ITER personnel during normal operation and maintenance of the divertor," Radiation Physics and Chemistry, 71 (2004) 809-810.

Shultz, 1982. D. W. Shultz and V. B. Parr, Evaluation and Documentation of Mechanical Reliability of Conventional Wastewater Treatment Plant Components, EPA-600/2-82-044, accession number PB82227539, US Environmental Protection Agency, Cincinnati, Ohio, March 1982.

Smith, 1966. E. H. Smith, J. L. Liebenthal, H. D. Killian, K. R. Hoopingarner, and R. A. Moen, Crack in the Engineering Test Reactor Primary Cooling System, IDO17158, Phillips Petroleum Company, Atomic Energy Division, Idaho Operations Office, U.S. Atomic Energy Commission, March 1966.

WASH, 1975. Appendix III, "Failure Data," to Reactor Safety Study, an Assessment of Accident Risks in U.S. Nuclear Power Plants, WASH-1400, NUREG-75/014, US Nuclear Regulatory Commission, October 1975. 